\title{
Toddling 'long the river Meuse : integrated assessment and participatory agent-based modelling to support river management
}

Citation for published version (APA):

Valkering, P. (2009). Toddling 'long the river Meuse : integrated assessment and participatory agentbased modelling to support river management. [Doctoral Thesis, Maastricht University]. Universitaire Pers Maastricht. https://doi.org/10.26481/dis.20091211pv

Document status and date:

Published: 01/01/2009

DOI:

$10.26481 /$ dis.20091211pv

Document Version:

Publisher's PDF, also known as Version of record

\section{Please check the document version of this publication:}

- A submitted manuscript is the version of the article upon submission and before peer-review. There can be important differences between the submitted version and the official published version of record. People interested in the research are advised to contact the author for the final version of the publication, or visit the DOI to the publisher's website.

- The final author version and the galley proof are versions of the publication after peer review.

- The final published version features the final layout of the paper including the volume, issue and page numbers.

Link to publication

\footnotetext{
General rights rights.

- You may freely distribute the URL identifying the publication in the public portal. please follow below link for the End User Agreement:

www.umlib.nl/taverne-license

Take down policy

If you believe that this document breaches copyright please contact us at:

repository@maastrichtuniversity.nl

providing details and we will investigate your claim.
}

Copyright and moral rights for the publications made accessible in the public portal are retained by the authors and/or other copyright owners and it is a condition of accessing publications that users recognise and abide by the legal requirements associated with these

- Users may download and print one copy of any publication from the public portal for the purpose of private study or research.

- You may not further distribute the material or use it for any profit-making activity or commercial gain

If the publication is distributed under the terms of Article $25 \mathrm{fa}$ of the Dutch Copyright Act, indicated by the "Taverne" license above, 


\section{Toddling 'long the River Meuse}

Integrated Assessment and participatory Agent-Based Modelling to support River Management

Pieter Valkering 
To toddle is to walk unsteadily, like a young child. Another meaning of the word is 'to take a stroll'. A toddler is a young child who is of the age of learning to walk. During the toddler stage, the child learns a great deal about social roles, develops motor skills, and first starts to use language.

Source: www.wikipedia.org, accessed January 2009.

This PhD research was carried out at the International Centre for Integrated assessment and Sustainable development (ICIS), Maastricht University

(C) Copyright Pieter Valkering, Maastricht 2009 Druk: Datawyse / Universitaire Pers Maastricht Omslag en logo: uitgeverij Diginio naar een idee van Pieter Valkering ISBN: 978-90-5278-897-5 


\title{
Toddling 'long the River Meuse
}

Integrated Assessment and participatory Agent-Based Modelling to support River Management

\author{
PROEFSCHRIFT \\ ter verkrijging van de graad van doctor \\ aan de Universiteit Maastricht \\ op gezag van de Rector Magnificus, \\ Prof. mr. G.P.M.F. Mols \\ volgens het besluit van het College van Decanen, \\ in het openbaar te verdedigen \\ op vrijdag 11 december 2009 om 16:00 uur \\ door
}

Pieter Jeroen Valkering

$\underbrace{1}_{\substack{\text { UNIVERSITAIRE } \\ \text { PERS MAASTRICHT }}}$ 


\section{Promotores}

Prof. dr. P. Martens

Prof. dr. ir. J. Rotmans (Erasmus Universiteit Rotterdam)

\section{Beoordelingscommissie}

Prof. dr. J.H. Stel (voorzitter)

Dr. R.J.M. Cörvers

Prof. dr. A.Y. Hoekstra (Universiteit Twente)

Prof. dr. A. van der Veen (Universiteit Twente)

This PhD research was supported by:

The FIRMA project (Freshwater Integrated Resource Management with Agents) funded by the 5th framework programme of the European Union, contract EVK1-CT199900016.

The MATISSE project (Methods and Tools for Integrated Sustainability Assessment) funded by the 6th framework programme of the European Union, contract 004059 (GOCE) - MATISSE.

The project 'Perspectives in Integrated Water Management' funded by the Dutch Living with Water programme, project P1015. 


\section{Preface and Acknowledgements}

The book Toddling 'long the River Meuse is the product of a challenging interdisciplinary PhD project. It aims to advance the integrated modelling of river management by integrating both its physical aspects ('the river') and its social aspects ('the decision-making process') in a single modelling framework. The ultimate aim is to support river management.

Learning is an important underlying theme of this book, as reflected by the words 'toddling' and 'toddler' prominent on its cover. A 'toddler' is a young child who is of the age of learning to walk. A parallel can be drawn to undertaking a PhD project. Doing research, and writing about it, is a skill not easily acquired. There is plenty of example around you to show you how its done. Still, learning to walk requires perseverance and comes with the unavoidable ups and downs. A parallel can also be drawn to river management. River management is all about learning how to deal with rivers, with climate change, flooding, and drought. Most importantly, it is about learning how to deal with each other, as the different stakeholders of river management governments, interest groups, businesses - are intrinsically linked though their dependency on their common resource: the river.

'Toddling' is to walk unsteadily, like a toddler does. The way the river management project 'Maaswerken' developed over the years - as discussed in this book - bears some resemblance to a toddling walk. At a number of occasions, new insights and emerging interests forced upon the project a reconsideration of previously established river management plans. (Something similar holds for my PhD project, by the way.) Learning to walk, in that context, probably implies being able to hold course, while being flexible at the same time. Another meaning of the word toddling is 'to take a stroll'. It expresses a kind of 'take-it-easy' attitude and aims to moderate somewhat the importance of the issues discussed in this book. River management research is important, however, the problems surrounding the River Meuse are of a different order of magnitude than many other sustainability issues around the world. Also in integrated research, a minimal dose of self-reflection is needed, not to loose oneself in the complexity of trying to understand it all. Last but not least, the word toddler provided a nice acronym for the model developed: Tool to Openup Dialogue and Debate for Long-term Effective River management.

I hope my toddle along the River Meuse has eventually resulted in a book that can be of value to some. Foremost, it is aimed at the research community dealing with complex societal issues and sustainable development. It contains a number of concepts and ideas for better representing stakeholder decision-making in integrated models of complex societal systems. To this end, it makes the approach of participatory Agent-Based modelling applicable within the context of Integrated Assessment. Also, the book may provide a forum for communication between scientists of different disciplines. It may form a bridge between the water and social scientists, the analytical and participatory minded, the 'doers' and the 'thinkers', as elements of different camps are blended in this book. Second, it is aimed at the broader community of policymakers and stakeholders of river management. I hope they can find inspiration in the idea that the uncertainties and value diversity of river management are reason for following a more flexible and reflexive river management approach; an approach in which a modelling tool like Toddler can provide support. In general, they might be intrigued by the way the research community is trying to advance its understanding of what they are doing in practice.

This research project could not have been completed without the support of many. To start, I would like to thank my two promotors. Jan Rotmans offered me the opportunity to start this 
PhD project. His style of doing research, enthusiasm and seemingly inexhaustible energy has inspired me a lot. Pim Martens made sure that a good start led to a good end. I enormously appreciate the way ICIS is maturing under his guidance, with ample of opportunity for initiative 'from the bottom up'. Also, I would like to thank sincerely all the members of the promotion committee for their critical review of my work.

This thesis benefits mainly from three research projects. It started with the EU FIRMA project, already a while ago. I want to thank the members of the FIRMA project for the many stimulating discussions. I thank especially my 'FIRMA brother' Jörg Krywkow for the many adventures in and around the Mediterranean, and for developing together the first concepts and ideas that have eventually found their way in this book. The thesis also draws from the EU project Matisse, finished in April 2008. I want to thank notably the water case study team: David Tàbara from the Autonomous University of Barcelona and the LUCSUS team from Lund University. It was a great collaboration in which we developed the gaming concept of Chapter 7. Finally, it benefits from the Dutch project Perspectives in Integrated Water management. My thanks goes to the entire project team for the stimulating collaboration in which we try to further mould the clutter of gaming, water modelling, and participatory scenario development into reasonable shape.

This work could not have been done without various stakeholders participating in this study. I want to thank all the stakeholder representatives that participated in the interviews, and the Maaswerken experts that supported the model development.

I want to thank all my colleagues and ex-colleagues at ICIS for the pleasant working environment. We are quite busy together! But luckily it stays fun .. A special thanks goes to Astrid Offermans, who is working with me on the Perspectives project, and well underway with here own PhD. I hope we continue to approach things from different perspectives, which - as we now - leads to better solutions.

Where would I be without a little help from my friends? I want to thank especially my friends from the Maastricht Student Alpine Club who made me feel at home the first years of my stay in Maastricht. Of them, Caspar and Carijn, a big, big, big thanks for the many intellectual discussions, challenging sports events, and creative musical gatherings that made life worthwhile. Daan and Caspar will provide the moral support during my defence. I am very happy to have such good friends by my side.

I shouldn't forget a few things. My running shoes and mountain bike took care of the highly needed relaxation-through-exhaustion. The best ideas emerge during a course through the woods. Also my loyal laptop, with which I spent many inspirational hours together, thanks.

I want to thank my parents for all the support and affection I have received over the past years. My father Theo deserves a thanks 'hors catégorie'. Probably, you are the one to whom I've talked most about my thesis, definitely also in terms of content. Especially your help with preparing the journal publication of Chapter 6 (already several years ago) was indispensable.

Last, I want to thank my dear Monika. When we met, I was about half-way through this research. We made it to the end! Thanks for all your patience, for all your support, and just for being there. I am incredibly looking forward to our trip to Africa that we have both well deserved.

A book like this obviously doesn't mark an end, just a beginning. Toddling on ...

Pieter Valkering

Maastricht, October 2009 


\section{Contents}

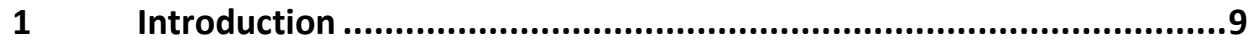

$1.1 \quad$ The social aspects of river management ....................................................... 11

1.2 Research context: Integrated Assessment for Sustainable Development ........ 12

$1.3 \quad$ The case study of the Maaswerken project................................................... 14

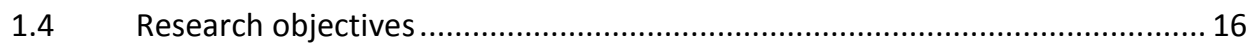

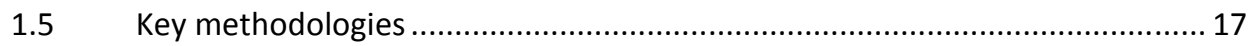

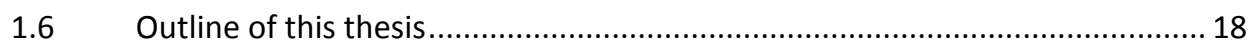

2 Methodology and Conceptualisation .........................................21

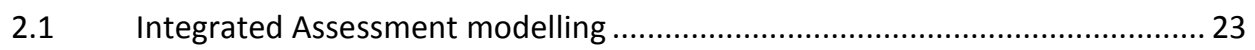

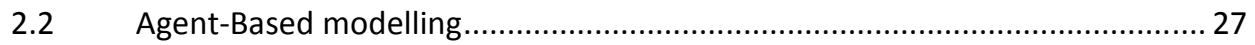

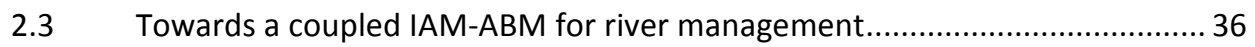

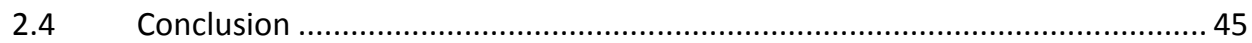

3 The Meuse in Limburg.......................................................47

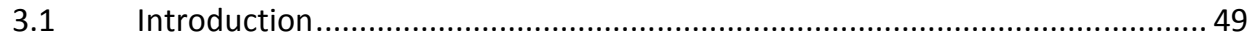

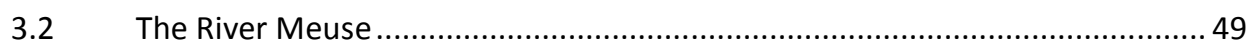

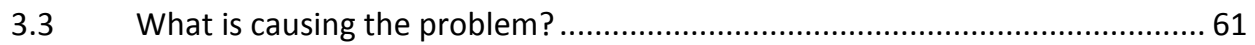

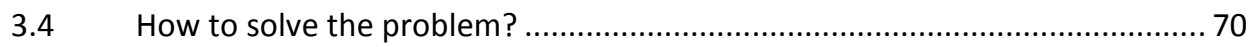

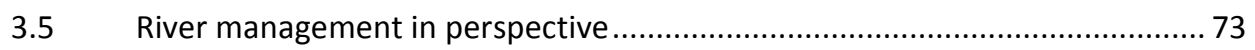

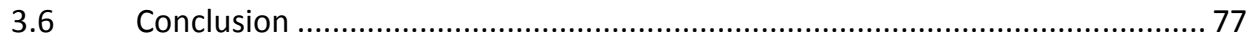

$4 \quad$ The Maaswerken project ................................................... 79

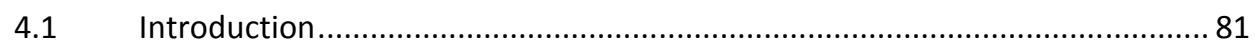

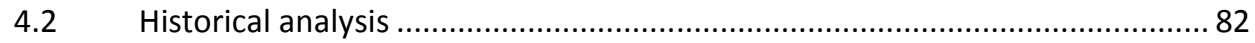

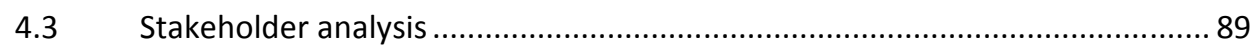

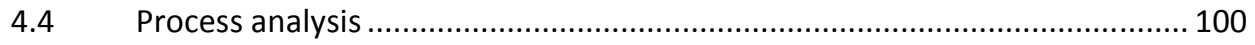

4.5 Beyond the Maaswerken: Some results from the Integral Exploration of the Meuse................................................................................................... 104

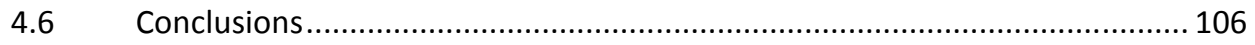

$5 \quad$ An integrated River Model .................................................. 109

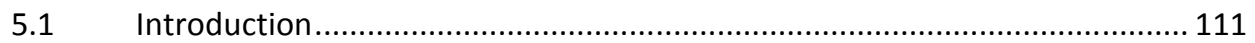

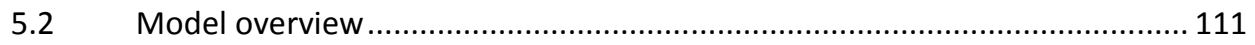

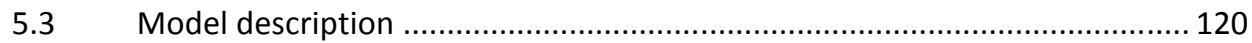

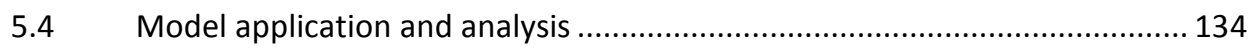

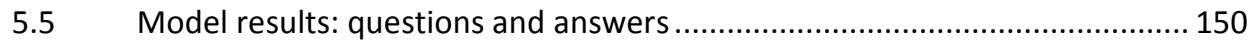

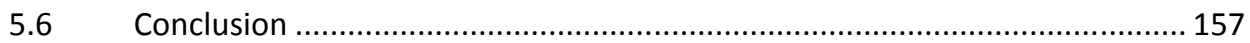


$6 \quad$ Simulating Stakeholder Support in the Maaswerken Planning

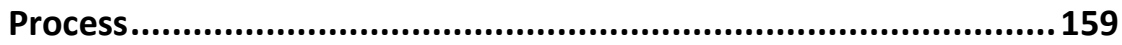

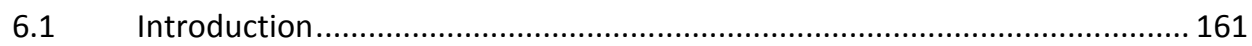

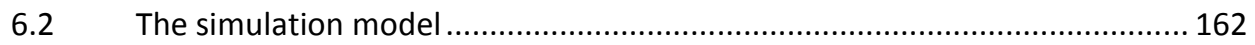

6.3 The Grensmaas project in retrospect ....................................................... 166

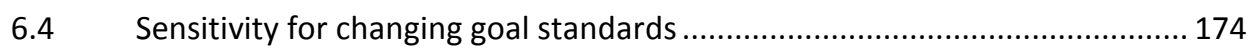

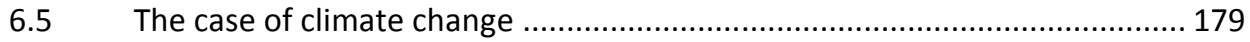

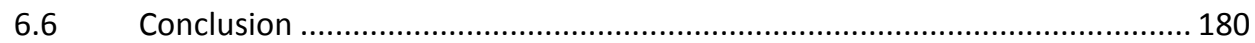

7 Modelling Water Management Policy in the Broader Context of Cultural and Behavioural Change: an Integrated, Agent-Based,

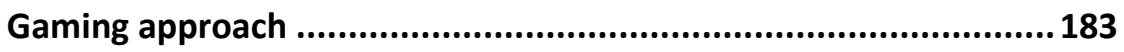

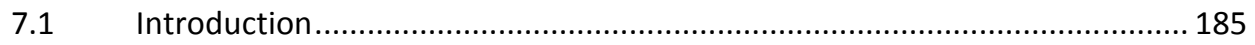

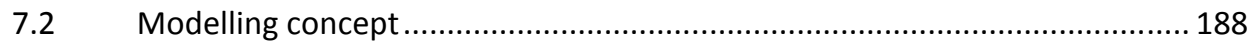

7.3 From concept to implementation: an interactive computer game................ 195

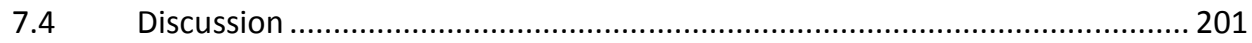

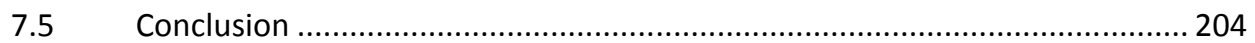

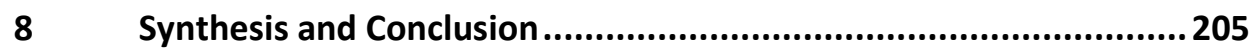

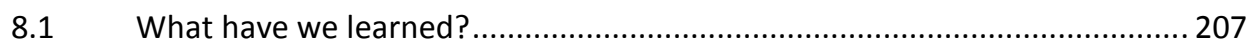

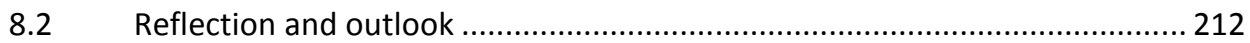

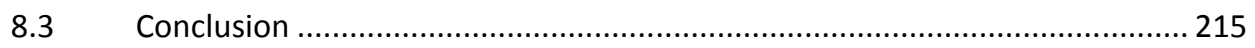

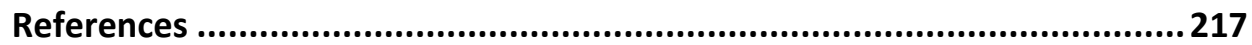

Appendix A: The conditional peak method ...................................................226

Appendix B: Schematisation of the location Borgharen ................................237

Appendix C: The hydraulic effectiveness parameter...................................244

Appendix D: Stakeholder participation .......................................................246

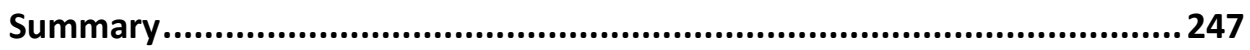

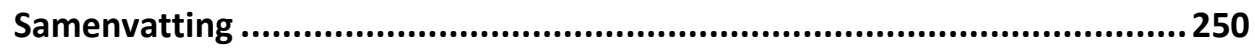

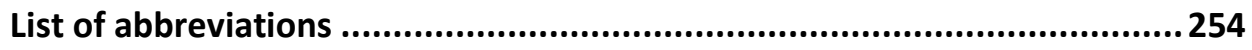

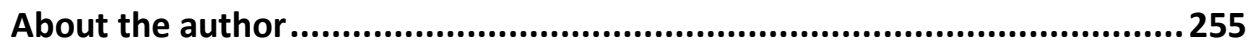


Chapter 1

INTRODUCTION 


\begin{abstract}
To support sustainable river management, a balanced representation of river dynamics and stakeholder decision-making is required for a better understanding of the river system as a whole. To achieve such a representation, participatory Agent-Based modelling within the context of Integrated Assessment modelling is adopted as an innovative core approach. The approach is applied to the case study of the Maaswerken project, which is a typical example of a complex sustainability planning problem characterized by high stakes and salient uncertainties. Representing this case entailed the development of an integrated River Model to calculate the impacts of different river management strategies, coupled to an Agent-Based Model representing stakeholder decision-making. The specific modelling objectives are to better understand the course of the Maaswerken planning process over the medium term, to reflect upon plausible future developments for the management of the Meuse in Limburg on the long term, and to provide a tool to support stakeholder dialogue on sustainable river management.
\end{abstract}




\section{Introduction}

\subsection{THE SOCIAL ASPECTS OF RIVER MANAGEMENT}

Rivers don't have problems. Only people may have problems with rivers. ${ }^{1}$

River management research has traditionally focussed on the understanding of rivers. Hydrology has provided profound insights in the processes of run-off generation. Hydraulic models reflect a detailed understanding of channel flow. Since Darcy uncovered the main laws of groundwater flow in 1856, advanced software packages can calculate groundwater flow in 2 or 3D. Ecology has contributed to an understanding of ecosystem functioning. Various impact models have been developed that can calculate economic damage and agricultural impacts. Moreover, climate science has brought a fairly detailed understanding of possible changes in climate (e.g. precipitation and temperature), and the impacts of climate change on rivers has received much attention. Nonetheless, considering the river system as whole, probably social aspects are most decisive for the river's course. And yet, these social aspects are probably least understood.

The FIRMA project ${ }^{2}$ - Freshwater Integrated Resource Management with Agents - aimed to fill this gap (Warwick \& Gilbert, 2003). This EU project aimed to improve water resource planning by developing and applying Agent-Based modelling to integrate physical, hydrological, social and economic aspects of water resource management. The models aimed to improve on existing integrated assessments by explicitly representing water consumers, water suppliers, governments and other stakeholders, and their interaction at various levels of aggregation, to yield insights in the social processes of water management. The FIRMA project has produced innovative agent-based applications for five case studies in Europe, covering a variety of water management issues (Warwick \& Gilbert, 2003). The work presented here has originated from the case study of the River Meuse in Limburg, dealing specifically with stakeholder behaviour in the process of river management.

There are two main reasons why insight in stakeholder behaviour is crucial for sustainable river management. The first reason is that stakeholders care. Any sustainability problem (of which river management is one) is defined only in relation to the needs and desires of stakeholders involved. On the one hand, it concerns the state of the river and its floodplains (in terms of discharge, water level, land use, and the fulfilment of various socio-economic and ecological river functions), and on the other hand the beliefs, norms and values of stakeholders that determine whether this state is perceived as a problem or not. The second reason is that stakeholders do. Stakeholders influence the river system in various ways, through land use, pollution and water consumption. Moreover, stakeholders have a significant influence on river management. Since the Aarhus Convention of 1998 and the EU Water Framework Directive of 2000 , stakeholder participation is increasingly called for in water management. The traditional approach of government-centred policymaking is increasingly being replaced by processes of multi-actor governance. For sustainable river management, it is thus is as much necessary to

\footnotetext{
${ }^{1} \mathrm{~J}$. David Tàbara at a Matisse project meeting

${ }^{2}$ http://cfpm.org/firma accessed July 2009
} 
understand the dynamics of rivers, as it is to better understand the dynamics of needs, desires, and behaviour of stakeholders of river management.

Let's not forget about the river! The premise of this thesis is that a balanced representation of river dynamics and stakeholder decision-making is needed for a better understanding of the river system as a whole. Its main challenge is to contribute to the development of new approaches and tools to facilitate sustainable river management. After all, rivers don't have problems; only people may have problems with rivers.

\subsection{ReSEARCH CONTEXT: INTEGRATED ASSESSMENT FOR SUSTAINABLE DEVELOPMENT}

The broader context of this research is set by the research field of Integrated Assessment applied to issues of Sustainable Development.

\subsubsection{Sustainable development}

The concept of Sustainable Development (SD) arose in the early eighties of the last century, and has since then become the stated aspiration of governments and societies all over the world (Martens, 2006a). Sustainable development, by definition, refers to the development of a societal system that does not undermine its existence on the longer term. In our world, it has become synonym for providing the needs of humankind without depleting our environmental resources. It is most commonly regarded as a balance between economic growth, social progress, and environmental quality (Grosskurth, 2008).

Sustainable development is a complex notion, which has appeared notoriously hard to define. Out of many possible definitions, the Brundtland definition is the most cited: 'Sustainable development is a development that meets the needs of present generations without compromising the ability of future generations to meet their own needs' (WCED, 1987). In fact, it is easier to point out what SD is not. On the global scale, main unsustainable developments appear in the form of climate change, biodiversity loss, and poverty (MNP, 2008). On the regional level, one can think of the shrinking of the Aral see, desertification in the Mediterranean, and air pollution in industrialized areas. In our daily lives, it might appear in the form of traffic jams, work related stress, and impoverished urban neighbourhoods.

Three main principles stand out across the many definitions of SD (e.g. see Martens, 2006a). First, it is an intergenerational phenomenon. This implies a relevant time scale of at least one generation, hence some 25 to 50 years. Second, it covers multiple scales. Sustainable (or unsustainable) developments can be associated with the local, regional and global levels and developments across levels interrelate. As a consequence, developments in one part of the world can cause unsustainable developments in other parts. Third, it involves multiple domains. Developments within the economic, social, and environmental domains are interrelated, and positive developments in one domain can go to the cost of developments in the other.

Despite its intuitive appeal, the notion of SD is complex and difficult to put into practice (e.g. see Grosskurth, 2008). The concept of SD is subjective (crucially dependent on personal values), ambiguous (it lacks guidance on how trade-offs can be resolved) and normative (since even its main principles can be disputed). Moreover, it relates to the development of complex systems that show inherently unpredictable behaviour. As a consequence, sustainable development problems are particularly difficult. They can be described as wicked problems (Rittel \& Webber, 
1973) (characterized by a disputed problem definition, complex dynamics, ambiguous analysis, and subjective and normative choice), unstructured problems (Hisschemöller \& Hoppe, 1995) (characterized by high uncertainty and low consensus on values), and persistent problems (Rotmans et al., 2001; Rotmans, 2005) (requiring structural societal change).

Given the complexity of the notion of SD, one may wonder: "how to manage something that is subjective and can never be achieved?' (Kemp \& Martens, 2007) or - to use the words of Robinson (2004) - 'how to square the circle?' The solution - which in a way is unsatisfying from any individual perspective - is to reframe sustainable development from a world state to strive for, to a process of dialogue, experimenting and learning. This view is well expressed by Robinson who states that: "The only way out is the recognition that multiple conflicting views on sustainability exist and cannot be reconciled with each other. [..] What is needed, therefore, is a process by which these views can be expressed and evaluated. [..] Sustainability is itself the emergent property of a conversation about what kind of world we collectively want, now and in the future." This view is articulated in various concepts for sustainability assessment and governance, such as social learning (Pahl-Wostl et al., 2007), sustainability learning (Tàbara \& Pahl-Wostl, 2007), transition management (Rotmans et al., 2001), Integrated Sustainability Assessment (Weaver \& Rotmans, 2006), and reflexive governance (Kemp \& Martens, 2007).

\subsubsection{Integrated Assessment}

To support the sustainability dialogue described above, Integrated Assessment can help. Integrated Assessment (IA) (Rotmans, 1998; Valkering et al., 2006) is a research approach that aims to provide coherent analyses of complex societal problems by combining knowledge from a variety of scientific disciplines. Building upon a tradition of systems dynamics (Forrester, 1975), an IA study typically aims to derive a systems view capturing causes and effects, feedback loops, and interactions across multiple domains. Understanding long term developments, treatment of uncertainty, choosing appropriate scale levels for analysis, including stakeholders in the assessment process, and blending qualitative and quantitative knowledge are just some of the common challenges of IA.

IA modelling has traditionally been the most widely used method in IA. However, other methods like scenario development (Van Notten, 2005) and participatory methods (Van Asselt \& RijkensKlomp, 2002) have become equally important in the 'toolbox' of IA. Different tools complement each other, and are ideally combined to arrive at an assessment that is most complete. IA lends itself for application to a variety of sustainability issues. IA has been amply applied for the issue of climate change (Schneider \& Lane, 2005). Recent IA studies deal, e.g., with tourism (Amelung, 2006), global health (Huynen, 2008), and regional development (Grosskurth, 2008).

The philosophy of IA is based upon a new paradigm of policy relevant science that emerged in the early nineties of the last century, referred to as Mode 2 science (Gibbons et al., 1994) or post-normal science (Funtowicz \& Ravetz, 1993). Although both streams show different nuances, they share the basic notion that traditional science (i.e. 'mode 1' or 'normal' science) - striving for certainty and objectivity - is not suited to address the complex problems society faces today. In the face of system complexity, the unavoidable uncertainties should not be treated as an artefact, but be in the forefront of the analysis. Moreover, high decision stakes and value diversity imply that a legitimate analysis of a societal problem should reflect multiple perspectives on the issue at hand, rather then reflecting the viewpoint of the researcher (or its subsidiser) alone. Acknowledging uncertainty and normativity as starting points, one arrives at 
new principles for doing science. This involves a shift from technocratic to participative approaches, from predictive to exploratory analyses, from monodisciplinary to trans- and interdisciplinary research, and from a purely academic to a broader social engagement (e.g. see Martens, 2006a).

Earlier definitions of IA have focussed amongst others on its aim to be relevant for decisionmaking (e.g. see Rotmans, 1998). Over the last decade, the aim has more explicitly become supporting the governance of complex societal problems, involving various actors from state, business, and civil society. In line with this development, the recent concept of Integrated Sustainability Assessment (Weaver \& Rotmans, 2006) has put IA in an explicit process based context. It is also reflected in the current IA definition of TIAS ${ }^{3}$ that stresses societal learning as a central aim. Drawing in particular from the definition of TIAS, we adopt the following modified one:

Integrated assessment can be defined as the scientific 'meta-discipline' that integrates knowledge from various scientific disciplines and other societal sectors about a complex issue, and makes it available for societal learning and decision-making to facilitate action towards sustainable development.

One of the main current challenges in IA is to better represent stakeholder behaviour in Integrated Assessment models. Integrated Assessment models (IAMs) - described in Chapter 2are typically computer models that aim to describe a societal subsystem 'as a whole', covering the environmental, social, economic, and institutional dimensions of a specific issue at hand (Rotmans \& Van Asselt, 2001). While IAMs have been quite successful in covering the environmental and socio-economic dimensions of societal change, they tend to under-represent stakeholder behaviour. To respond to this challenge, several scholars (Rotmans, 1998; Downing et al., 2001; Moss et al., 2001; Van der Veen \& Rotmans, 2001; Pahl-Wostl, 2002; Rotmans, 2006) have proposed to extend the IAM framework with Agent-Based modelling (ABM). There are various reasons why $A B M s$ are considered promising for better representing stakeholder behaviour. First, $A B M s$ might provide a better representation of individual stakeholder cognition, decision-making, and behaviour by incorporating insights from behavioural theory in the ABM design. Second, ABMs are considered suitable to model stakeholder interactions, thereby better representing the complex, emergent, collective behaviour of multi-stakeholder systems. Third, the combination of $A B M$ and participatory processes (participatory $A B M$ ) is considered promising, both to improve the representation of stakeholder behaviour in the models, and to facilitate social learning amongst stakeholders involved.

\subsection{THE CASE STUDY OF THE MAASWERKEN PROJECT}

To gain experience with this innovative approach, this thesis aims to apply participatory ABM within the context of IAM for the case study of the 'Maaswerken' (Meuse Works) project ${ }^{4}$. The Maaswerken - extensively described in Chapter 4 - is a large scale river engineering project,

\footnotetext{
${ }^{3}$ The Integrated Assessment Society is a main forum for the IA research community and is host of The Integrated Assessment Journal. See www.tias.uni-osnabrueck.de accessed July 2009.

${ }^{4}$ www.maaswerken.nl accessed July 2009
} 
carried out along the River Meuse in the Netherlands. Its principle aim is to implement river widening measures over a length of some $150 \mathrm{~km}$, covering the Meuse from Maastricht to Den Bosch. The project is split into three parts: the 'Grensmaas' (Border Meuse) project that covers the most natural $40 \mathrm{~km}$ stretch upstream, the 'Zandmaas' (Sand Meuse) project that covers the remaining stretch, and the 'Maasroute' (Meuse route) project that specifically covers the shipping route. The project's main objectives are to reduce the chance of flooding, to develop new natural areas, to improve the shipping route, and the excavation of gravel and sand. The project is government-led, but explicitly aims for stakeholder participation to achieve broad societal support. Following preparatory studies in the early 1990s, and flood events in 1993 and 1995, the project was officially initiated in 1997. Implementation has started in the Zandmaas in 2005, Maasroute in 2006, and Grensmaas in 2008 and the project is scheduled to be finish around 2018.

The rationale of the Maaswerken project is in line with a new perspective on Dutch water management, emerging in the eighties and gaining momentum over the nineties (Van der Brugge et al., 2005). This new perspective emphasises the importance of the natural resilience of water systems. It is a plea for 'accommodating water' rather then 'fighting the water' as the Dutch traditionally have done. In terms of river management, it advocates river widening and natural river restoration as an alternative to the traditional dike-building approach. The Maaswerken project can be considered the first large-scale implementation of this new river management style in the Netherlands. As such, it poses a relatively experimental case.

The Maaswerken project can be classified as a 'large infrastructure project' (Hertogh et al., 2008). In this thesis, it is referred to as a 'complex sustainability planning problem'. It is a good example of an unstructured problem, involving high uncertainty and a low consensus on interests and values. Apart from the main project objectives listed above, crucial stakes include minimizing loss of farming land, hindrance in the residential area, and the profitability of gravel extracting. Main uncertainties include inaccuracies in the hydraulic calculations, an uncertain effect of vegetation development on river flow, imperfect knowledge on sub-soil composition, limited understanding of morphological dynamics, and risks related to clay pollution and groundwater quality.

In this thesis, the Maaswerken case study is approached from two angles. The first angle is to analyse the Maaswerken project in retrospect. We zoom in on the planning process of the Maaswerken project, covering roughly the time period from 1990 to 2003. As we will see in Chapter 4, the planning processes of both the Grensmaas and Zandmaas/Maasroute projects turned out to be long, dynamic and complex. Both processes were subject to unforeseen events, new insights, and controversial changes of plans. Also the final outcomes of the planning processes were disputed by various stakeholders involved. The Maaswerken project thus poses some interesting questions regarding both the effectiveness of the planning process, and the sustainability of the end-result. In Chapter 6, we explore to what extent these dynamics can be reconstructed through our modelling approach.

The second angle is then - given the obtained insights about the past - to reflect upon the development of river management in the future (e.g. for a time horizon of 50 - $100 \mathrm{yrs}$ ). In Chapter 6, for example, the developed model is used to reflect upon the possible implication of climate change for future river management. Moreover, in Chapter 7 an extended modelling concept is developed to better represent the dynamics of river management in relation to the cultural perspectives underlying the river management debate, which are assumed to be relevant for understanding the dynamics of river management on the longer term. 


\section{$1.4 \quad$ RESEARCH OBJECTIVES}

The main and generic objective of this study is to further IAM methodology by adopting an ABM approach to better represent stakeholder behaviour. The Maaswerken project serves as the main case study for model development and application. This complex sustainability planning problem provides a specific case in which 'stakeholder behaviour' refers to the behaviour of key stakeholders involved in the river management planning process ${ }^{5}$. Representing this process entailed the development of an integrated River Model (iRM) to calculate the impacts of different river management strategies, and an ABM to calculate stakeholder support and to reconstruct plausible river management outcomes. The specific aims of the coupled iRM-ABM were first to represent the Maaswerken planning process in retrospect, second to explore possible developments of river management on the longer term, and third to support stakeholder dialogue surrounding sustainable river management. In light of the latter aim, the coupled iRM-ABM is also referred to as the 'Toddler' model: Tool to Open-up Dialogue and Debate for Long-term Effective River management.

Consequently, the main research question of this thesis is phrased as follows:

- To what extent is it possible to represent the complex dynamics of river management through an Integrated Assessment modelling - Agent-Based modelling approach, and what can be learned from that?

Four sub-questions have been defined:

- How to integrate the IAM and ABM approaches for developing a coupled integrated River Model - Agent Based-Model for the case study under concern?

- To what extent can this model adequately represent the course of the Maaswerken planning process over the medium term (roughly from 1990 to 2005)? To what extent does the model provide policy relevant reflection in retrospect?

- To what extent can this model be used to explore plausible future developments of the management of the River Meuse on the long term (e.g. 50 to 100 years)? To what extent does it provide new and policy relevant insight?

- To what extent is the model suitable to support stakeholder dialogue to facilitate sustainable river management?

\footnotetext{
${ }^{5}$ A very different type of case, for example, is the case of sustainable consumption, where behaviour refers to the buying behaviour of individuals.
} 
This research draws from, and connects, the following key methodologies:

\subsubsection{Integrated Assessment modelling}

Following IAM methodology (e.g. see Rotmans \& de Vries, 1997; Rotmans, 1998), conceptual model development was based on the well-known conceptual model of Pressure-State-ImpactResponse (PSIR). This model concept was originally developed by the OECD (1993), and is currently adopted, for example, by EEA (2003) and UNEP (2007) to support their environmental assessments and outlooks. In this thesis, the PSIR model of Hoekstra (1998) is adopted and further developed by elaborating on the multi-actor dynamics underlying the response. As described in Chapter 2, one thus obtains a system conceptualisation composed of two main interacting parts: a 'river system' - representing the pressures, states, and impacts - and an 'actor response system' representing stakeholder decision-making. This elaborated PSIR system conceptualisation provided the basis underlying the implementation of the iRM-ABM.

The work on river modelling, in particular, followed the IA approach of meta-modelling (e.g. see Rotmans \& de Vries, 1997). Meta-modelling involves the development of simplified, reducedform models of expert models, which are coupled in the IAM. In practice, model development was fed both by expert models (e.g. for calculating discharges, flood damage, and agricultural impacts), textbook knowledge (e.g. for the hydraulics and groundwater calculations), and Maaswerken expert knowledge and project methodology (e.g. for calculating nature diversity and cost-benefit calculations). Model implementation was followed by model analysis, calibration, and validation as described in (Janssen et al., 1990). Besides practical validation (testing model results against the available data), also conceptual validation was performed. This entailed an assessment by the experts of Maaswerken of the validity of the theories and concepts underlying model design.

Finally, the agent conceptualisation and notably the gaming concept developed in Chapter 7 is strongly inspired on the so-called perspective based modelling approach (Rotmans \& de Vries, 1997; Hoekstra, 1998; Hoekstra, 2000; De Vries, 2001; Rotmans \& Van Asselt, 2001; Van Asselt \& Rotmans, 2002). In this approach, different legitimate interpretations of model uncertainty and advocated policy options are coherently structured along the cultural perspectives people may hold.

\subsubsection{Agent-Based modelling}

In this thesis, Agent-Based modelling (ABM) - further described in Chapter 2 - refers to a variety of (similar) agent based approaches in which social actors like individual people, firms, or nation states are represented as computer agents generally located within some social or physical environment (Gilbert \& Troitzsch, 2005). Following ABM methodology, the stakeholders of Maaswerken were represented as so-called cognitive stakeholder agents. The conceptual model of agent behaviour (or 'agent architecture') highlights the goals that the stakeholder agents pursue, and their beliefs about the river system, where the latter corresponds to the way the uncertainties in the river system are interpreted. This agent architecture is inspired on existing agent architectures. It notably draws from a model of Social and Cognitive action (Conte \& Castelfranchi, 1995a), which elegantly represents goal-directed agent behaviour, highlighting the 
motivations underlying the agents' goals, and poses a nuanced view on goal change and agentagent interaction. The architecture also draws from the perspective based modelling approach, mentioned above, by relating possible interpretations of uncertainty to the agent perspective.

\subsubsection{Stakeholder participation}

The models and concepts developed in this thesis are generally aimed at participatory model application. Moreover, stakeholder participation has been crucial in model development. Stakeholder participation was guided by the concepts of participatory modelling (Vennix, 1996; Van Asselt \& Rijkens-Klomp, 2002) and participatory ABM (Barreteau, 2003; Ramanath \& Gilbert, $2004)^{6}$. In this research, the following participatory methods were deployed. In the early stages of this research, a stakeholder analysis was performed. Semi-structured interviews were conducted with a selection of key stakeholders to map out their goals and uncertainty interpretations, the ways they might have changed over the course of the planning process, and the ways in which stakeholders had interacted in the development of the river management plan. Further, a content analysis was performed of the official documentation of stakeholder reactions to a number of river management alternatives proposed over course of the Maaswerken planning process. Moreover, Maaswerken experts were involved in various stages of the iRM development: in the initial stages to provide data and expert knowledge, and in later stages for conceptual model validation. Given the time constraints, more 'advanced' forms of stakeholder participation - such as the participatory validation of the ABMs and the actual participation of stakeholders in the simulation process - have not been carried out. Nonetheless, the concepts and tools described in this thesis are suitable and intended to support such participatory model application in future research.

\subsection{OUTLINE OF THIS THESIS}

The outline of this thesis roughly follows the respective phases of the conducted research:

The methodology and conceptualization - described in Chapter 2 - first involves an inventory of the current state of the art in IAM and ABM. Both fields are highly diverse, and the inventory provides a necessary reference context for positioning the research presented in this thesis. Following, we describe the conceptual framework developed for our specific case. This framework conceptualizes the interaction between the river system and stakeholder agents following the PSIR scheme. Chapter 2 also describes the developed agent architecture and presents our approach towards stakeholder learning, adaptive cognition, and stakeholder interaction.

The case study analysis - described in Chapters 3 and 4 - analyses respectively the river system and the Maaswerken planning process, following the conceptual framework developed in Chapter 2. Chapter 3 provides an integrated analysis of the River Meuse in Limburg. Following the conceptual model of PSIR, it discusses the current system state (e.g. its geography and

\footnotetext{
${ }^{6}$ In the literature, this mode of modelling is mostly referred to as 'participatory Agent-Based Social
} Simulation' or 'Companion Modelling'. In this thesis, the term participatory ABM is adopted for consistency. 
hydrology), main changes that are currently taking place (e.g. climate change, spatial developments, and canalisation), the impacts for the various river functions (e.g. in relation to floods and droughts), and possible response options to take (e.g. river widening, dike-building, natural retention, and river function adaptation). Chapter 4 zooms in on the process of river management, surrounding the implementation of a river widening response, by analysing the Maaswerken project. It contains a historical analysis of the Maaswerken planning process mapping out the different events and developments and their consequences on the planning process over the planning period (roughly from 1990 - 2003) - and describes the results of the stakeholder analysis. Both case study analyses deliver policy relevant insights, but their primary function is to provide a basis for the further modelling work.

Model development and application is described in Chapters 5 and 6. Chapter 5 describes the integrated River Model that is used to assess the impacts of river widening. The iRM implements a main part of the PSIR model of Chapter 3, focussing on the issues of specific relevance to the Maaswerken project. Chapter 6 describes the Agent-Based Model - and its coupling to the iRM for representing the planning process of Maaswerken. Adopting the stakeholder descriptions of Chapter 4, the model is applied to reconstruct the planning process of the Grensmaas project as a model validation. Following, a number of model experiments are performed. Model development draws notably from the stakeholder analysis of Chapter 4 that provided necessary information for implementing the ABM, and set the scope for iRM development by outlining which decision-making criteria and salient uncertainties to include.

Chapter 7 presents a concept for an interactive computer game for modelling water management policy in the broader context of cultural and behavioural change, for a better understanding the development of river management on the long-term. To this end, the chapter aims to further connect the participatory IAM-ABM approach developed so far, with the perspective based modelling approach (Rotmans \& de Vries, 1997; Hoekstra, 1998; Hoekstra, 2000; De Vries, 2001; Rotmans \& Van Asselt, 2001; Van Asselt \& Rotmans, 2002). This chapter was developed as part of the EU project Matisse ${ }^{7}$ and adopts a different case study: water management in the Ebro River basin in Spain. It builds upon the approach developed for the Maaswerken case in two ways. First, it develops a concrete participatory application using similar modelling tools. Second, it extends the PSIR conceptualisation of Chapter 2 to describe the dynamics of water policy within the broader context of societal change. To this end, it draws upon additional theory, like the advocacy coalition framework (Sabatier \& Jenkins-Smith, 1993), social-psychological theory (e.g. see Jackson, 2005), cultural theory (Thompson et al., 1990), structuration theory (Giddens, 1984), and recent work on societal transitions (Rotmans et al., 2001; Rotmans, 2005; Geels \& Schot, 2007; Loorbach, 2007).

The synthesis and conclusion of Chapter 8, finally, addresses the research questions outlined above, highlights the main lessons learned, extracts the main points of discussion, and provides an outlook towards future work.

\footnotetext{
${ }^{7}$ Methods and Tools for Integrated Sustainability Assessment, see www.matisse-project.net accessed July 2009
} 

Chapter 2

METHODOLOGY AND CONCEPTUALISATION 


\begin{abstract}
This chapter describes the methodological building blocks upon which this study is based, and develops a conceptual framework underlying the modelling work. It gives a brief account of the field of Integrated Assessment modelling (IAM), emphasising current methodological challenges, including a better representation of stakeholder behaviour in IAMs. It discusses Agent-Based modelling (ABM) as a promising approach with which this challenge can be addressed. Building upon insights from the IAM and $A B M$ fields, a conceptual framework is developed for representing the complex sustainability planning problem the Maaswerken project presents. The framework considers stakeholder agent decision-making, as part of the well-known PSIR model, on the basis of a simple architecture of goals and beliefs. The river management planning process is interpreted as a process of social learning. In this process, stakeholder agents are assumed to adapt their goals and beliefs in response to perceived changes in the river system and/or the interaction with other stakeholder agents. Compromising, learning about the environment, and learning from agent interaction (including cooperation and the development of social norms) are introduced as key mechanism driving the social learning process. Participatory ABM is highlighted as the most suitable approach for modelling the river management process.
\end{abstract}




\title{
2 Methodology and Conceptualisation
}

\author{
2.1 INTEGRATED ASSESSMENT MODELLING
}

\subsubsection{What is IAM?}

Integrated Assessment Modelling (IAM) is a modelling paradigm suitable for addressing complex, sustainability issues. Various definitions of IAM have been given (Rotmans, 1998; Van der Sluijs, 2002; Lotze-Campen, 2006; Martens, 2006b), see Van der Sluis (1997) for an overview, that highlight the following features. IAMs are typically computer models that aim to describe a societal subsystem 'as a whole', covering the environmental, social, economic, and institutional domains. They aim to describe both the cause-effect relationships within subsystems (vertical integration), and the cross-linkages and interactions between subsystems (horizontal integration). To do so, they integrate knowledge elements from various scientific disciplines.

The tradition of IAM is often said (Rotmans, 1998) to date back to the study Limits to Growth of the club of Rome (Forrester, 1971; Meadows et al., 1972). Using relatively simple sets of equations, their World3 model illustrated how exponential 'run-away' population growth and industrialization may propel back at society in a number of undesired effects, such as resource depletion and pollution. Besides creating profound international awareness about the limits to growth, their study also illustrated for the first time how a complex and large scale system like the 'world' can be meaningfully modelled with a relatively simple system dynamics approach.

In their footsteps, a first generation of IA models emerged in the late 1970s / early 1980s. These models focused on specific environmental issues, like early work on the DICE model of the energy climate system (Nordhaus, 1979) and the RAINS model on acid rain (Alcamo et al., 1990). Towards the nineties, the emerging issue of climate change set the background for a second generation of IA models. Following pioneering work on the IMAGE model (Rotmans, 1990), a suite of integrated models of climate change were developed (see Van der Sluijs, 1997 for an overview). Roughly since the late 1990s, IAMs became geared towards more general sustainable development issues, aiming for a balanced representation of the environmental, economic, and social domains. Some key model examples are MIASMA (Martens, 1998) on climate and health, AQUA (Hoekstra, 1998) on water management, TARGETS (Rotmans \& de Vries, 1997) describing various dimensions of global change, and QUEST (Carmichael et al., 2004) addressing regional development.

\subsubsection{Overview and classification}

Recent overviews of IAMs are presented by Grosskurth (2008) and Lotze-Campen (2008), the latter drawing from the results of the SustA-Test project ${ }^{8}$. Grosskurth describes a number of IAMs classified into three groups: 1) integrated models, like TARGETS and QUEST, that broadly cover the environmental, economic and socio-cultural domains, 2) energy-environment models, like RAINS, that focus on emissions, climate change and resource depletion, and 3) economic-

\footnotetext{
${ }^{8}$ See the SustA-Test webbook www.sustainabilitya-test.net accessed July 2009
} 
environmental models, like $\mathrm{E} \mathrm{ME}^{9}$, that focus on the link between economic development and environmental consequences. Lotze-Campen, notably differently, reviews modelling tools for Integrated Assessment. The classification into three groups is similar: 1) bio-physical models primarily covering natural-scientific phenomena, 2) socio-economic models focussing on human dimensions of sustainability, and 3) integrated models that aim to bridge the gap between the natural and social sciences. In this classification, IAMs are positioned as a specific subcategory of the integrated models group, along other types of integrated models, like land use models, qualitative system models, and scenario planning tools. The SustA-Test overview thus illustrates that an IA model is not necessarily the same as a model for IA. ${ }^{10}$

The reviews show first that IAM is a diverse field. There is potentially much to integrate - i.e. within and across domains - so that modellers have to make a choice what to integrate in their model and what not. As a result, models tend to differ strongly, both in terms of the level of integration, and regarding the specific focus chosen. In particular, the more economically oriented and the more environmentally oriented models can be identified.

A comparison of the reviews also indicates that the label 'IAM' is actually quite ambiguously defined. The SustA-Test definition of IAM is narrower than the definition Grosskurth implicitly adopts, and seems more in line with his subgroup of energy-environment models. Consequently, models like QUEST and E3ME are in the SustA-Test review not considered IAMs, but are referred to as scenario planning tools and socio-economic general economy models respectively ${ }^{11}$.

Furthermore, both IAM overviews neglect various other modelling traditions that follow, at least to some extent, similar modelling principles. Examples are Decision Support Systems (DSSs), like the ones from the projects MedAction (Van Delden et al., 2005) and Mulino (Mysiak et al., 2005), and integrated models developed within the environmental modelling community (Parker et al., 2002). Also, participatory oriented modelling tools and methods, like the Tools to Inform Debates, Dialogues, and Deliberations ${ }^{12}$ (TIDDD) (Pereira et al., 2004), group model building (Vennix, 1996), and Qualitative Systems Analysis (Grosskurth, 2008) are generally not considered as part of IAM, although they reflect many of its key principles.

\footnotetext{
${ }^{9}$ See www.camecon-e3memanual.com accessed April 2009

${ }^{10}$ Indeed, the integration of knowledge within IA need not take place within one overarching model. It can also take place as part of the broader IA process, in which various less integrated models can be used.

${ }^{11}$ In fact, Grosskurth's respective model groups integrated models, energy-environment models, and economic-environmental models correspond roughly to the scenario-planning tools, the Integrated Assessment models, and the socio-economic general economy models of Lotze-Campen. The fact that, in the SustA-Test review, TARGETS is classified as a socio-economic model with a focus on health is considered a typing error.

${ }^{12}$ The TIDDDs have developed from a tradition of DSS at the JRC in line with the changing design criteria: from rather technocratic systems aimed at legitimizing policy decisions, to more open platforms for common ground and dialogue (Pereira \& Quintana, 2002)
} 


\section{Box 2.1: Pressure, State, Impact, Response}

IA models generally adopt some ordering framework to structure cause-effect relationships. A well-known example is the DPSIR concept: Driving Forces-Pressure-States-ImpactsResponses. Originally developed by the OECD as PSR (OECD, 1993), it has been adopted, for example, by EEA (2003) and UNEP (2007) in their environmental assessments and outlooks. Here, we adopt the PSIR version developed for the IA models TARGETS (Rotmans \& de Vries, 1997) and AQUA (Hoekstra, 1998), see the figure below. The pressures represent socioeconomic and environmental changes affecting the state of the water system. The impacts represent the (value laden) effects for the various socio-economic and environmental water functions. The responses represent human interventions in the system. They can generally be sub-divided into (coordinated) policy responses (for example to modify infrastructures or introduce a water tax) or (individual) autonomous responses (for example a change in water demand).

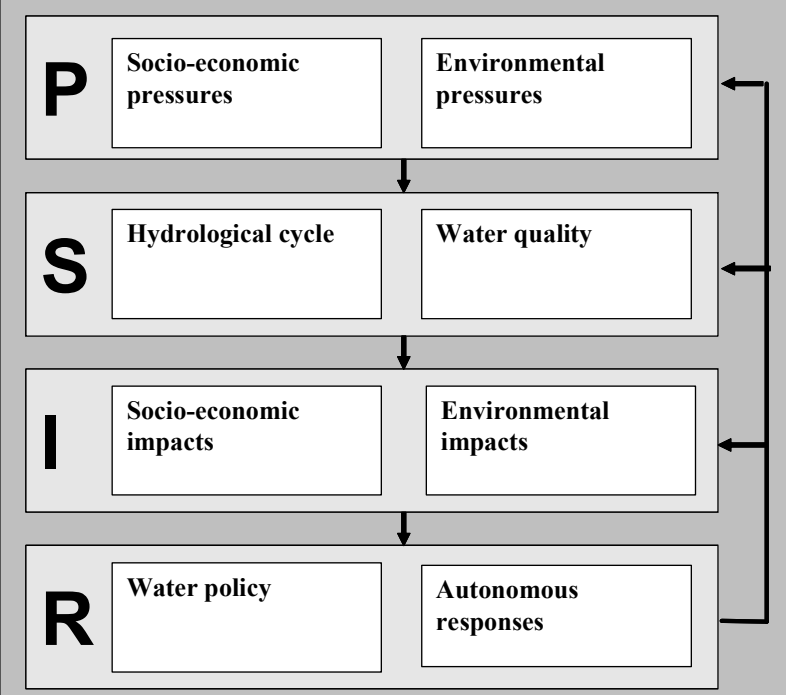

A generic application of the Pressure, State, Impact, Response model to the water domain (Hoekstra, 1998).

Although the PSIR concept has proven useful in many cases, it is not without critique. First, it should be realized that PSIR forms a relative ordering framework. Exactly what constitutes a Pressures, State, Impact or Response depends on the perspective one takes in terms of scale level and problem focus. Second, it fails to address interactions across multiple scales. For example, a PSIR model applied to global developments fails to capture local developments that may, however, significantly influence the dynamics at a higher scale. Third, the model fails to address human agency, societal structure and technology as main system components. In particular, it fails to acknowledge niches - emerging cultural beliefs and innovative practices - as main drivers of system change. As such, the model seems ill suited for understanding sustainability transitions. Nonetheless, the PSIR model remains an effective approach for outlining main cause and effect loops across a number of domains. In this study, we build upon the PSIR concept, elaborating upon the response module with an agent-based approach. 
Trying to avoid a subjective discussion on labels of specific modelling types, we feel that the philosophy of IA modelling clearly stands out. In line with previous descriptions of the IAM field (Rotmans, 1998; Grosskurth, 2008), this philosophy can be summarized as follows:

- A balanced representation of the social, economic, environmental and institutional dimensions of a sustainability issue;

- The integration of knowledge from a variety of scientific disciplines, and expert knowledge from stakeholders and practitioners;

- The explicit consideration of interactions and feedbacks mechanisms within and between subsystems;

- An 'aggregated' or 'meta modelling' approach, since integration within and between subsystems is valued higher than the representation of detail on the sub-system level;

- Accepting uncertainties as a starting point rather than a model artefact, seeking for and explicit representation of the salient uncertainties regarding the issue of concern.

Adopting several or all of the above starting points to more or lesser extents, IA models can come in all 'shapes and sizes'. For example, they may differ in terms of scale (local, regional, global, multi-scale), form (system dynamics, agent based, cellular automata, qualitative analysis, conceptual models, or hybrid models), topic (e.g. water, health, regional development, or climate), and purpose (strategic policymaking, societal learning, scientific exploration).

\subsubsection{Current trends and challenges}

Currently, two contrasting trends can be observed in the IAM field. On the one hand, one might say the IAM field is reaching a level of maturity. Under large accumulated investments in time and money, existing models like IMAGE ${ }^{13}$ and RAINS $^{14}$ have grown into sophisticated modelling tools. They are continuously further developed and expanded, moving towards a broader coverage of issues (see Bouwman et al. (2006) and Klaassen et al. (2004) for recent developments of the respective models). They are increasingly being applied in the policy contexts, such as (for IMAGE) the IPCC Special Report on Emissions Scenarios (SRES) and the UNEP Global Environment Outlook (GEO), and (for RAINS) the conventions on Long Range Transboundary Air Pollution (LRTAP) of the UNECE ${ }^{15}$.

On the other hand, some main and fundamental challenges still exist that require fundamental model innovation. Lotze-Campen (2008), for example, concludes that deep model integration is still in its infancy. Bridging different time and spatial scales, developing interfaces for information exchange between modules, and connecting different modelling paradigms are just some of the main challenges still to be addressed. Rotmans (2006), moreover, points to the limited capacity of IA models to model societal transitions which are considered highly relevant for supporting decision-making in the sustainability domain. Both authors, finally, argue strongly for an increased participation of stakeholders in the modelling processes. Stakeholders should be better involved as advisors (to better include stakeholder knowledge in the models), as users

\footnotetext{
${ }^{13}$ See www.mnp.nl/en/themasites/image/ accessed July 2009

${ }^{14}$ See http://gains.iiasa.ac.at/ accessed July 2009

${ }^{15}$ See www.unece.org/env/Irtap/ accessed July 2009
} 
(to better match the model and the user needs), and as actors (to better incorporate stakeholder behaviour in the model) (Rotmans, 2006).

To address those challenges, Rotmans (2006) proposes a 'two-track' approach: improving existing models in a creative way, and developing new models in parallel. The work described in this thesis falls under the latter category; improving the representation of stakeholder behaviour in IA models, adopting Agent-Based modelling as the methodologically innovative starting point.

\subsection{AGENT-BASED MODELLING}

\subsubsection{What is $A B M$ ?}

In this study, the term Agent-Based modelling ( $A B M)$ is chosen as an umbrella term for various agent-based modelling approaches. These include, amongst others, agent-based modelling, agent-based social simulation, multi-agent simulation, agent-based computational modelling, and Individual Based Modelling (see Hare \& Deadman, 2004) ${ }^{16}$. ABM can be used to model a variety of human and non-human agent based systems (e.g. including animals, insects, and organic cells). Here, we specifically address agents based models of human behaviour. Following Gilbert \& Troitzsch (2005, p. 5), we define ABMs as:

Agent-based models consist of agents that interact within an environment. Agents are either separate computer programs or, more commonly, distinct parts of a program that are used to represent social actors - individual people, organizations such as firms, or bodies such as nation states. They are programmed to react to the computational environment in which they are located, where this environment is a model of the real environment in which the agents operate.

The environment - referred to in this definition - may reflect a geographical space, but also more abstract forms of space (e.g. a 'belief space') or simply reflect the interactions amongst agents, in which case the environment is considered to be the agent-network each agent is in. The computer agents are typically endowed with autonomy (able to control their own actions and internal state), reactivity (the ability to perceive and respond to their environment), social ability (the possibility to communicate with other agents), and proactivity (capable of generating goals and acting rationally to achieve them) (Wooldridge, 1999, p. 32).

ABM is rooted in a variety of adjacent scientific fields encompassing a wide range of applications. ABM can be said to have originated from the field of Artificial Intelligence (AI) and in particular distributed artificial intelligence (DAI) involving the study, design and application of interacting intelligent systems (Weiss, 1999). From the Al perspective, agents have been typically designed to perform relatively complex tasks to substitute for, or support, human action. A main example is the information agent that is able to intelligently collect information from the internet (e.g. see Klusch et al., 2003). In the field of ecological modelling, so-called Individual Based Models (IBM) have been developed to model complex behaviour of animal populations

\footnotetext{
${ }^{16}$ Although Hare \& Deadman propose to adopt the term Agent Based Simulation (ABS) as an overarching label, we believe the notion 'modelling' better reflects the value of (the process of) conceptual model design, whereas the notion 'simulation' suggests that the final computer runs are most important.
} 
(Grimm, 1999). Simulations of the behaviour of bee colonies on their comb (Hogeweg \& Hesper, 1983) and the aggregate motion of flocks, herds, and schools (Reynolds, 1987) (in the context of computer graphics design) are early examples in this field. Also in the field of Artificial Life emerging in the late $80 \mathrm{~s}$ - cellular automata and agent based approaches have come to the fore. AL draws amongst others from complexity theory, physics, chemistry, biology and Al to study and recreate processes of life. Some of the earlier applications in this field - concerning molecular biology, animal intelligence, evolutionary processes and more - are described by Langton (1995). Political scientists, finally, were among the first to apply ABM approaches for modelling human behaviour. Notably the earlier work of Axelrod $(1984,1986)$ on simulated prisoners dilemma games, showed how $A B M s$ can contribute to a better understanding of negotiation processes, the emergence of cooperation, and the evolution of norms.

Since the early nineties, $A B M$ has become a more and more popular tool in the social sciences (Gilbert, 2008). From the social scientific perspective, ABM is applied as a tool to study human behaviour from the individual to the societal level. Agents thus represent different types of social actors like individuals, NGOs, firms, regions, nation states, and so on. Together, they make up a so-called Artificial Society. Some pioneering applications are the ones of Doran et al. (1994) who simulated the emergence of hierarchical social relations for an archaeological case, Epstein \& Axtell (1996) whose Sugarscape model illustrated several dynamical features of human societies 'from the bottom up', and Conte \& Castelfranchi (1995b) whose simulation aimed at a better understanding of the functions of norms in social groups. Around the same time, the first applications to environmental management appeared. Pioneering studies are a model of irrigation systems in Indonesia (Lansing \& Kremer, 1993), and the fisheries model of Bousquet (1994).

Current day, ABM has found its way into various research disciplines. It continuous to be popular in social science, as illustrated by numerous publications in $J A S S S^{17}$. It thrives in environmental modelling, where the ABM tradition already extends some 15 years (see Bousquet \& Page, 2004; Hare \& Deadman, 2004; Matthews et al., 2007 for overviews). ABM has also been adopted in economics, as illustrated by the quite recent handbook on Agent Based computational economics (Tesfatsion \& Judd, 2006). ABM has become particularly popular for modelling socialecological systems, as illustrated by special issues in Ecological Economics (Janssen \& Jager, 2000) and Ecology \& Society (Janssen \& Ostrom, 2006a). Above all, ABM can be considered a highly interdisciplinary field, linking aspects of computer science, social-psychology, sociology, environmental modelling, and complexity theory to name but a few. In that sense, it might be considered already a suitable candidate for enriching the 'toolbox' of IA.

\subsubsection{What can $A B M s$ do?}

ABM can be applied to model a variety of social phenomena. We discuss a number of relevant phenomena that can be tackled with $\mathrm{ABM}$, along some illustrative modelling examples.

\footnotetext{
${ }^{17}$ Journal of Artificial Societies and Social Simulation: http://jasss.soc.surrey.ac.uk/JASSS.html
} 


\section{Modelling emergent phenomena}

ABMs are particularly suitable to model so-called emergent properties of a system. Emergence is said to occur "when interactions among objects at one level give rise to different types of objects at another level" (Gilbert \& Troitzsch, 2005). In other words, the properties of the system cannot be understood directly from the properties its parts, but arises from the interactions between those parts. Nature provides ample examples of emergent properties, such as the stability of a pile of sand grains, the movement of a flock of birds, and an organism that emerges from its cells.

A good example of emergence in a social system is found in the well-known segregation model of Schelling (see Gilbert \& Troitzsch, 2005). Schelling addressed ethnic segregation in the US. He designed a simple simulation model in which 'black' and 'white' agents could move around on a grid. The agents' decision to move or stay depended on the observation of their social environment (e.g. primary black or white) and their so-called 'threshold of tolerance'. For example, for a threshold of $40 \%$, black agents would decide to move if their neighbours were on average more than $40 \%$ white (and vive versa). This simple simulation (performed not even at a computer at the time) demonstrated how strong segregation can occur for unexpectedly low values of the threshold tolerance down to $30 \%$. Methodologically, it shows how the segregation pattern develops as a complex emergent property from simple agent interaction rules.

\section{Modelling negotiation processes}

ABMs have also been successfully used to study issues of negotiation. A simple, but influential example is the famous study 'The Evolution of Cooperation' of Axelrod (1984). This study aimed to assess the conditions under which cooperation emerges out of the interaction between two negotiating partners, similar to real-life cases such as the US - Soviet Union arms race, or the issue of international trade barriers. To this end, Axelrod paired various strategies for playing the iterated prisoners dilemma game in a computer tournament. A 'strategy' refers to the generic decision rule specifying when to cooperate or to defect, depending on the observed behaviour of ones opponent. Experts from various fields (economics, psychology, mathematics, sociology and political science) were invited to design and submit their strategy. Letting all submitted strategies compete against one another - and systematically analysing the results - relevant insights into cooperation came to the fore. The so-called TIT FOR TAT strategy - cooperating on the first move and following the opponent's moves after that - turned out to be robustly victorious. The strength of TIT FOR TAT is that it strikes the balance between being nice (never first to defect), retaliatory (it doesn't let itself be exploited), forgiving (it starts to cooperate as soon as the other does), and clear (it is predictable).

\section{Modelling agent- environment interaction}

The specific class of ABMs that is relevant for sustainable development will generally consist of agents operating within some natural and socio-economic environment. Agent interactions are then 'mediated' by their common environment, which they both influence and are influenced by. One illustrative example of such agent-environment interaction is the Sugarscape model of Epstein \& Axtell (1996). Their model represents ants located on a grid on which a renewable resource (sugar) is distributed. The ants eat the sugar, depending on it for survival, and move around in search of sufficient quantities. The simple model demonstrates various real-life features from society, including emerging inequalities between few 'wealthy' ants able to accumulate large quantities of sugar, and the majority of others that are barely able to survive. 


\section{Modelling world management}

Another, quite different example of modelling agent-environment interaction was provided by Bossel (2000) who modelled world management. Bossel states that the sustainability of systems depends on six 'Basic Orientors' (BOs): existence, effectiveness, freedom of action, security, adaptability, and coexistence. On the basis of these orientors, an experiment was designed to show how the world system could be managed in a sustainable way. To this end, the World2 model of Forrester was coupled to a single, 'intelligent' management agent equipped with orientor representations. Using a mapping between its orientors and specific World 2 indicators, the agent was able to assess the sustainability of the world state. Moreover, the agent was able to design sustainable 10-year policy plans, using a policy search routine optimizing its orientor satisfaction. The agent proved highly successful in managing the world, 'guiding a model world from certain collapse to sustainability' (Bossel, 2000, p. 350). ${ }^{18}$

\section{Modelling the consumption of common pool resources}

Jager (2000) provides an elegant, theoretically grounded model of consumer behaviour regarding an environmental commons dilemma. Consumer agents - or 'consumats' - drawing from a common pool resource are endowed with four possible decision rules: repetition (repeating ones own behaviour), imitation (doing what ones neighbour does), deliberation (optimizing over ones own interests), and social comparison (deliberate choice between repetition and imitation of a consumat reference group). Shifts between decision rules may occur, depending the consumat's need satisfaction (calculated using utility curves for needs) and uncertainty perception (the difference between actual and expected resource consumption). E.g. satisfied agents tend to engage in automated processes (in repetition or imitation), whereas unsatisfied agents tend to engage in reasoned behaviour (deliberation or social comparison).

The simulation experiments address, amongst others, the implications of different behavioural models on consumption patterns. Experiments on lock-in consumption, for example, indicate that global lock-in is likely to occur when consumats tend to deliberate, whereas local lock-in (lock-in within clustered agent groups) is more likely to happen under social comparison mode. Another experiment focussed on the consumption of two interacting resources: fishing and mining in a simple lake model. Here, the results showed that pure deliberation leads to faster resource decline and an uneven transition from fishing to mining, compared to the situation where agents are allowed to choose freely among its four behavioural modes.

\section{Modelling the evolution of institutions}

One particular feature of cognitive agents - like humans - is the ability to perceive (emergent) system properties, and respond to them in a coordinated way. In the absence of a distinctive 'ruler' (e.g. nation state), such coordinated response is referred to as self-governance. Selfgovernance takes shape through the emergence of institutions: loosely defined as implicit or explicit rules - also referred to as norms - that constrain or influence agent behaviour. A key focus within the ABM and Common Pool Resources (CPR) literature is to understand how these institutions emerge and evolve.

\footnotetext{
${ }^{18}$ In fact, this application did not aim to model real-life global management, but rather provided a
} (normative) illustration of how global management could be done better. 
Axelrod (1986) was among the firsts to investigate the emergence of norms with an ABM. To this end, Axelrod extended the standard $n$-person prisoners dilemma game with the possibility to punish observed defectors. The agents' strategies thus specified both their tendency to defect and their tendency to punish defectors. The emergence of a norm was assessed by letting agent strategies evolve (on the basis of evolutionary algorithm) from an initial random distribution of strategy parameters. A stable norm implied an emerging dominant strategy of low defection and high punishment, whereas norm collapse implied the opposite (high defection and low punishment). As it turned out, this game did not lead to stable norms initially: the tendency to punish eventually went down in all simulations, causing defection to rise. One way out was to adopt the mechanism of meta-norms: the norm to punish those that fail to punish defectors. The simulations showed that the meta-norm indeed enforces the norm, in any case when initial tendencies to punish are at least moderate.

Janssen \& Ostrom (2007) provide a more recent example of modelling rule change in a CPR problem. They developed a stylized model of agents, harvesting a renewable resource of biomass, and evolving according their harvesting success. The model features the implementation of a single rule: limiting harvesting for cells with biomass below some threshold. The implementation of this rule depends not only on the agents' perceived necessity (biomass depletion), but also critical on the level of trust among the agent populations. The simulation allowed for reflection upon various empirical findings regarding critical factors for cooperative behaviour. E.g. it supports the notion that group stability enhances chances of cooperation, but contradicts the empirical finding that smaller communal groups have a better chance of cooperative success. Moreover, it shows group heterogeneity does not have to be a bottleneck to cooperative behaviour, as long as other mechanisms for the development of trust are in place.

\subsubsection{State of the art ABM for sustainability assessment}

The current state of the art in ABM in relation to environmental modelling and socio-ecological systems research has been assessed in a number of relatively recent review articles (Bousquet $\&$ Page, 2004; Hare \& Deadman, 2004; Janssen \& Ostrom, 2006b; Matthews et al., 2007). Besides these overviews, a special issue of the FIRMA project (Edmonds \& Möhring, 2005) describes a number of $A B M$ applications on water management.

There are various possibilities for classifying current ABMs. Hare \& Deadman (2004), for example, develop a taxonomy of ABMs in environmental modelling on the basis of specific model characteristics, such as a) the way social and environmental models are coupled (spatial/non-spatial), b) the type of social interactions it includes, and c) the way adaptive behaviour is implemented. Matthews et al. (2007) look into the specific purpose of Agent Based Land Use Models (ABLUMs), concerning a) policy analysis and planning, b) participatory modelling, c) explaining spatial patterns of land use or settlement, d) testing social science concepts and e) explaining land use functions. The paper of Janssen \& Ostrom (2006b), finally, is structured along the methodological challenges ABMs address for governing Socio-Ecological systems: a) social dilemma's, b) dealing with uncertainty and learning, and c) understand the implications of different interaction typologies. Here, we focus on three broad application areas that are of specific relevance for sustainability assessment and IA modelling: environmental modelling, common pool resource problems, and models of societal change. 


\section{Box 2.2: Simple or cognitive agents?}

It appears that for modelling world policy (Bossel, 2000) one needs a different type of agent than for modelling sugar consumption (Epstein \& Axtell, 1996). Indeed, agents can be broadly divided into two groups: simple agents (also called sub-cognitive or reactive) implemented with straightforward behavioural rules, and cognitive agents (also called complex, proactive, deliberative, intelligent, or reasoning) endowed with a (more) elaborate representation of their mental state and cognitive processing rules. The simple agent approach is based on the rationale that system complexity arises from the interactions between agents, rather then from agent reasoning. The cognitive agent approach, on the other hand, is based on the rationale that agent reasoning, usually in combination with agent interaction, is crucial for system behaviour.

So, when do we need cognitive agents for modelling human behaviour in the context of sustainable development? In some cases, a simple agent approach might be adequate. This holds, for example, for cases where human action is based on reflexes rather than on reasoning (e.g. in relation to car driving behaviour), or for cases where automated processes such as imitation and repetition prevail over reasoning (e.g. see the model of Jager (2000) on consumption behaviour). Also, Gilbert (2006) points out that the model aim might simply not be to understand motivations underlying human behaviour, but primarily to show the consequences of that behaviour (e.g. Schelling's model). Nonetheless, in most applications related to sustainable development, a cognitive approach seems more adequate. Sustainability assessment typically requires agent applications that facilitate understanding of 1) proactive, future oriented behaviour, 2) human needs, values, and perceptions underlying (non) sustainable behaviour, and 3) social learning amongst various actors at multiple scale levels and consequent behavioural change. In other words, a nuanced view on both agent cognition and agent interactions is in principle required. A potential pitfall of detailed implementations of cognition and interaction, however, is increased model complexity, going to the cost of transparency. Considering ABMs to be more exploratory than predictive tools, the challenge is thus to strike a balance between a simple, yet cognitive approach.

\section{ABMs in environmental modelling}

In the realm of environmental modelling, there currently exist numerous practical agent-based applications. These models generally include agents to model the implications of local humandecision-making for the development of some larger natural environment, often represented in a spatially explicit way. This application area corresponds roughly to the category c) of Janssen \& Ostrom (2006b), the categories a), c), and e) of Matthews et al. (2007), and most of the models of Hare \& Deadman (2004) and Edmonds \& Möhring (2005).

The reviews report a wealth of examples on various topics, notably on land use development (agriculture, urban sprawl, deforestation/reforestation, historical settlement) and water management (urban water demand, irrigation, hydraulic management), with additional applications on fisheries, recreation, and waste management. The wealth of examples shows that $A B M$ is applicable for a variety of topics to model human decision-making in a meaningful way. Particular strengths of the ABM approach mentioned are the ability to model micro-level decision-making, to assess the consequences of agent heterogeneity, to include agent interactions like imitation behaviour, and to illustrate the implications of social dynamics on resource consumption and/or patterns of spatial development. 
Some of the main challenges appear to be the following. The first challenge is to strive towards improved model quality and credibility (Bousquet \& Page, 2004; Janssen \& Ostrom, 2006b). Methodologies should be developed for model testing, model selection, and model validation. In particular, more effort should be spent on verifying model results with respect to empirical data, and comparing ABMs with other model approaches. A second challenge is to better establish a niche for model use. Matthews et al. (2007) argues that for several reasons ABLUMs are probably not suitable as operational decision-support tools. One suggested way out is translating ABLUM insights into simple 'rules-of-thumb' to be communicated to end-users. However, most authors are careful with attaching predictive value to $A B M$ results, suggesting the main practical value of $A B M$ to be to support learning processes. A third challenge is to move towards more cognitive agent representations. "Despite a myriad of possible cognitive architectures" (Hare \& Deadman, 2004), decision-making models are based on simple sets of heuristic rules, and social interaction tends to be implemented in terms of simple nearestneighbour imitation algorithms. This suggests a limited ability of existing models to address the more value laden issues of sustainable development.

\section{ABMs for common pool resource problems in social-ecological systems}

As a second application area, we consider the study of common pool resource (CPR) problems in social-ecological systems (SESs). Since these models generally contain agents in a natural environment as well, they might be called a subset of the application area already described above. However, the area is distinguishable, and of particular relevance for sustainable development, for its explicit focus on social dilemmas, the evolution of institutions, and complex adaptive systems. This application area corresponds roughly to the category a) of Janssen \& Ostrom (2006b), the category d) of Matthews et al. (2007), and some of the models of Hare \& Deadman (2004).

In CPR research, $A B M$ forms only one part of a triangular methodology combining theory, laboratory experiments, and model applications (Janssen \& Ostrom, 2006b). The field has contributed greatly to insights on human behaviour in social dilemmas, with as a main finding the indication that (under the right conditions) individuals can devise agreed-upon norms for governing a resource that they themselves can monitor and enforce. To support this 'governing of the commons', current ABMs can help: "Fortunately, we now have methods-agent-based models - that facilitate the analysis of complex SESs by stakeholders and officials. No longer do we need to throw up the hands in the air that the system is so complex!" (Janssen \& Ostrom, $2006 b$, p. 1485). Nonetheless, modesty is called for, since ABMs can 'rarely prescribe "the" optimal solution in any complex setting'. Some of the current challenges are to explore the internet for new opportunities to study social-ecological systems from an agent perspective, and to work towards a formal model of the process of rule change and the evolution of institutional rules. Finally, also here quality assessment is addressed, in particular to find a balance between detail and simplicity, and explanatory value of ABMs (Janssen \& Ostrom, 2006b).

\section{ABMs of societal change}

A third application area is modelling societal change. From the research field of socio-technical and societal transitions (Rotmans, 2005; Geels \& Schot, 2007; Loorbach, 2007) it is becoming increasingly clear that behavioural change towards sustainable development cannot be expected to emerge in isolation. It needs to be embedded within broader process of societal innovations, including new institutional rules, cultural paradigm shift, and technological change, all in the context of broader environmental and socio-economic developments. 
Modelling these dynamics poses an obvious challenge, which so far few applications have addressed. A first example worth mentioning is the 'Battle of the Perspectives' model of (Janssen \& de Vries, 1998). Janssen modelled shifts of stereotype cultural perspectives of Cultural Theory (Thompson et al., 1990) in a heterogeneous population of agents coupled to an economy-energy-climate model. The agents were able to observe the model world and reflect on the consistency of their observation vis-à-vis their current world view. This was formally implemented with evolutionary learning algorithm which tested their worldview fitness. After repeated inconsistencies - referred to as 'surprises' (Thompson et al., 1990) - agents became more and more inclined to shift their worldview.

A second example is the recent transition model of (Bergman et al., 2008; Haxeltine et al., 2008; Schilperoord et al., 2008) developed in the Matisse project. In this model, societal change is perceived as an ongoing competition between a currently established regime, and emerging and competing niches, in response to landscape changes. To this end, the model includes both collective agents (regimes and niches) and individual agents ('consumers' attached to either the regime or one of the niches) located on a practice space. In each time step, individual agents decide which collective agent to support, depending on their practice preference, as well as the collective agent's strength. The collective agents, from their side, move around (adapt) in practice space on the basis of specific strategies, and change state (transform, e.g. from 'niche' to 'empowered niche' to 'regime') as their support changes. The dynamics is strongly driven by the so-called landscape signals - representing changes of e.g. worldview, macro-economy, physical infrastructure, natural environment and demographics - that induce an external pressure on individual agents to move in practice space. Various model applications to historical cases of socio-technical transitions (Bergman et al., 2008) have shown a 'proof of concept' for transitions modelling. These models are not (and will never be) predictive tools that can predict the speed or direction of future transitions in the traditional sense. They are considered explorative tools to be used in interactive contexts, and to support creating plausible transition scenarios.

Various challenges exist for this emerging stream. In particular for the transition modelling stream, one can distinguish conceptual challenges (e.g. to allow agent transformation at the individual level) (Schilperoord et al., 2008), and more practical ones (e.g. more empirical grounded case studies) (Bergman et al., 2008). Probably the main challenge, however, is to work towards applications that truly assess the interaction between environmental and socioeconomic developments on the one hand, and the social dynamics of societal change on the other. Janssen focuses more on the environmental and socio-economic drivers ('surprises') with a shallow representation of social dynamics. The transition models, on the other hand, focus on the social dynamics, but externalize environmental and socio-economic changes in the form of landscape signals. The water game described in Chapter 7 of his thesis aims to overcome this challenge by combing elements from perspective based integrated modelling and participatory ABM.

\subsubsection{Participatory $A B M$}

One message from the description above is that - just like IAMs - ABMs are considered to have limited predictive capacity, and are primarily perceived as explorative tools. In line with this observation, there is a great added value of developing and applying ABMs as part of a participatory process with stakeholders. This mode of $A B M$ is referred to as 'companion modelling' (Barreteau, 2003), 'participatory Agent-Based Social Simulation' (Ramanath \& Gilbert, 
2004), and - in this thesis - 'participatory $A B M^{\prime}$. The purpose of participatory ABM is twofold (Barreteau, 2003). On the one hand, it is aimed at the production of knowledge for 'the researcher'. The participatory ABM is then perceived as a social simulation model representing aspects of the complex dynamics of real-life human-natural environments. On the other hand, it is aimed at process support. In that case, the participatory ABM is perceived as a tool to support learning, negotiation, and decision-making regarding the complex management issue at stake.

Although a precise definition of participatory $A B M$ is lacking, it clearly implies the development of ABMs in close cooperation with the stakeholders they represent. This cooperation can take various forms. In the first stage of model development, it may involve stakeholder interviews to elicit their mental models, and the design of role-playing games to assess stakeholder interactions. After preliminary ABM design, stakeholders may again be drawn into the process. They might reflect on the agent representations of themselves and their peers, assess the implications of model results, and actively engage in role-plays e.g. with agent representations of their real-life adversaries. Critically, they are stimulated to reflect upon the nature and implications of their own behaviour portrayed by the ABM. It is this iterative process of model design and stakeholder reflection that is assumed to lead to a better representation of stakeholder behaviour in complex environments.

A typical example of participatory ABM is the SHADOC model (Barreteau \& Bousquet, 2000; Barreteau et al., 2001) representing agricultural irrigation in the Senegal River Valley. In SHADOC, irrigation revolves around the allocation of two main resources: water and credit. The model comprises a scheme representation - representing a water courses, a pumping station, and farming plots - coupled to an agent society representing individual farmers and management (or 'group') agents controlling credit and water flow. The farmer agents operate on the basis of individual rules, e.g. specifying when to start to cultivate their plot, or ask for a loan. The group agents operate on the basis of collective rules, e.g. specifying when to allocate a loan, or which water allocation scheme to use. For both individual and group agents, rule change generally follows from an unsatisfactory evaluation of their current practice, upon which agents tend to imitate successful agents. The SHADOC model was transformed in a simpler format as a role playing game in which Senegal farmers and other stakeholder participated. The gaming sessions allowed the research team to test the validity of the hypothesised individual and collective rules, and general model dynamics. Moreover, the session provided a valuable learning experience for the stakeholders involved, reframing their perception of the irrigation system.

There are ample further examples of participatory $A B M$ applications showing the value of the approach, both in terms of social simulation models and process support. For example, the Zurich water game - developed as part of the EU FIRMA project - was used to improve the communication between stakeholders of urban water management (Pahl-Wostl \& Hare, 2004). Gurung et al. (2006) showed that their companion modelling approach helped to resolve water sharing conflict between farmers in Bhutan. Castella et al. (2005) combined role playing games, $A B M$ and Geographical Information Systems (GIS) for developing land use change scenarios and providing decision-support for local farmers and policymakers in Vietnam. Guyot \& Honiden (2006) and Briot et al. (2007) describe a number of simulation experiments to study issues of 
power and negotiation amongst agents involved in the coffee market (SimCafe), renewable resource management (SimComMod), and biodiversity conservation (SimParc) ${ }^{19}$.

These recent participatory ABM applications generally focussed on local scale case studies, in which a limited set of stakeholders and relatively well defined management issues allowed for a detailed study of specific agent interactions and a relatively straightforward decision-support. A main challenge would be to 'upscale' the methodology to more complex issues, such as the one river management presents. Dray et al. (2005) describe a first example of such an application, aiming to provide process support for groundwater management in a low coral island. Their study indicates, amongst others, that the participatory ABM approach can successfully bring together diverging viewpoints on the water management debate. However, there is a major risk that the outcomes of the participatory process are overruled by powerful players (e.g. governments) that have to deal with constraints that are considered external to the participatory process. Despite these (and probably many other) main challenges, we consider participatory $A B M$ a promising way ahead.

\subsection{TOWARDS A COUPLED IAM-ABM FOR RIVER MANAGEMENT}

So, how to combine the approaches of IAM and ABM into a model for river management? Before moving on, let's first recall the specific characteristics of the river management case. As explained in the introduction, the case study of the Maaswerken project is perceived as a complex sustainability planning problem. It deals with the management of a complex river system involving numerous interrelated developments across multiple domains (environmental, economic, and socio-cultural developments) that play out over the long term. Consequently, it is an unstructured problem, involving high uncertainty and a low consensus on interests and values. The stakeholders involved in the planning process are thus assumed to have very different perspectives on the problem and its solutions, and these different perspectives are confronted with each other, and presumably subject to change, as part of the river management planning process. The question is: how to model that?

\subsubsection{Pressure, State, Impact, Response}

The starting point of this modelling exercise is the PSIR model of Box 2.1. From the perspective of the Maaswerken planning area (see Chapter 3 ), a main environmental pressure $(P)$ is climate change, significantly altering the hydrology of the Meuse. The socio-economic pressure is formed primarily by the increased demand for space, e.g. for agriculture, housing, and other socio-economic functions. The pressures result in state changes (S) referring to a changing discharge pattern, water levels, and land use within the floodplain area. These, in turn, have impacts (I) for river related functions - such as housing, agriculture, nature and shipping - often related to the increased occurrence of floods and drought. The water policy - or in our case 'river policy' - response $(R)$ entails the development and implementation of a river management plan,

\footnotetext{
${ }^{19}$ Guyot's methodology is referred to as 'agent based participatory simulation' and is considered a variation of the companion modelling approach
} 
e.g. a set of measures for river widening, the creation and heightening of embankments and so on $^{20}$. This implementation of the PSIR model is described in more detail in Chapter 3.

The river management policy response is explicitly framed as the outcome of a planning process amongst so-called 'stakeholder agents' representing the real-life stakeholders involved. There are various ways the term 'stakeholder' can be defined. Here, we adopt a broad definition from the HarmoniCOP project (Ridder et al., 2005).

A stakeholder includes all persons, groups and organisations with an interest or 'stake' in the issue, either because they will be affected or because they may have some influence on its outcome. This includes individual citizens and companies, economic and public interest groups, government bodies and experts.

This broad definition, however, is insufficiently precise for modelling purposes. In the conceptual model, we therefore focus further on stakeholders that actually have an interest or responsibility in the river management issue of concern. This excludes, for example, experts, who are considered important mediators and planners, but not decisive in determining the course of the planning process. Second, we adopt the notion of an 'aggregated' or 'collective' stakeholder agent. This implies that we do not focus on individuals, specific organisations, or the public at large, but rather on groups of stakeholders sharing the same role in the planning process. The conceptual model thus includes aggregated stakeholder agents, typically originating from the domains of state, market, and civil society, such as a 'policymaker', 'gravel extractor', and 'citizen'.

One thus obtains a representation of the total PSIR system composed of two main interacting parts: a river system - including pressures, states and impacts - and an actor response system representing the river management policy response ${ }^{21}$. The river system - representing the various environmental and socio-economic dimensions of the system under concern - is modelled with a 'traditional' IA approach in the form of an integrated River Model. The actor response system - representing the decision-making processes of stakeholders operating within some political and institutional context - is described with an agent-based approach, see Figure 2.1.

The interaction between the river and actor response system is framed as a simple actionperception feedback loop. This loop refers to the iterative process of the stakeholder agents perceiving the river system, deciding on the implementation of a river management plan, which

\footnotetext{
${ }^{20}$ Note that the selected case study poses a purely water policy problem. In terms of the PSIR scheme of Box 2.1, this implies that the autonomous responses are excluded from the analysis. In terms of the structure of the $A B M$, it implies a case of purely collective action. In contrast to most ABMs, agents have no autonomous actions for influencing the water system at their disposal, other than influencing the development the river management strategy as part of the planning process.

${ }^{21}$ Note that the distinction proposed here is quite different from separating the 'human' and the 'environment', or the 'social' and 'ecological'. The water system has both a human/social and an environmental/ecological side. The distinction adopted here rather separates the 'world' system on the one hand, and the system of human deliberation and decision-making on the other, so as to better assess the interactions between the two. See also (Janssen, 1996) and (Jager, 2000), who propose similar conceptualisations of the agent decision-making within the broader human-environment system.
} 
changes the river system, triggering and/or influencing further stakeholder action in the future. This feedback mechanism, however, is less straight forward than it seems. Note, for example, that the time scales at which both systems operate are different. The river system represents the development of the river Meuse on the longer term (e.g. 50 - 100 years). It evolves under various 'slow' drivers, like climate change, economic growth, and demographic change, and, once in a while, under the implementation of river management strategy. The actor response system represents river management planning processes that typically last some 5-10 years (depending on process efficiency). These are subject to various 'fast' drivers, like unexpected events (e.g. flood and drought) and new scientific insights (e.g. the latest IPCC report). In other words, the perception of the water system depends on much more than the 'objective' state of water system alone. It should be interpreted as a highly unpredictable and changeable feature of the actor response system, subject not only to river system change, but also to various probabilistic events and external developments. One particular consequence, complicating the planning processes, is that the perception of the river system may change significantly over the course of a planning process (as actions are being considered), and not only as a result of monitoring actions taken.

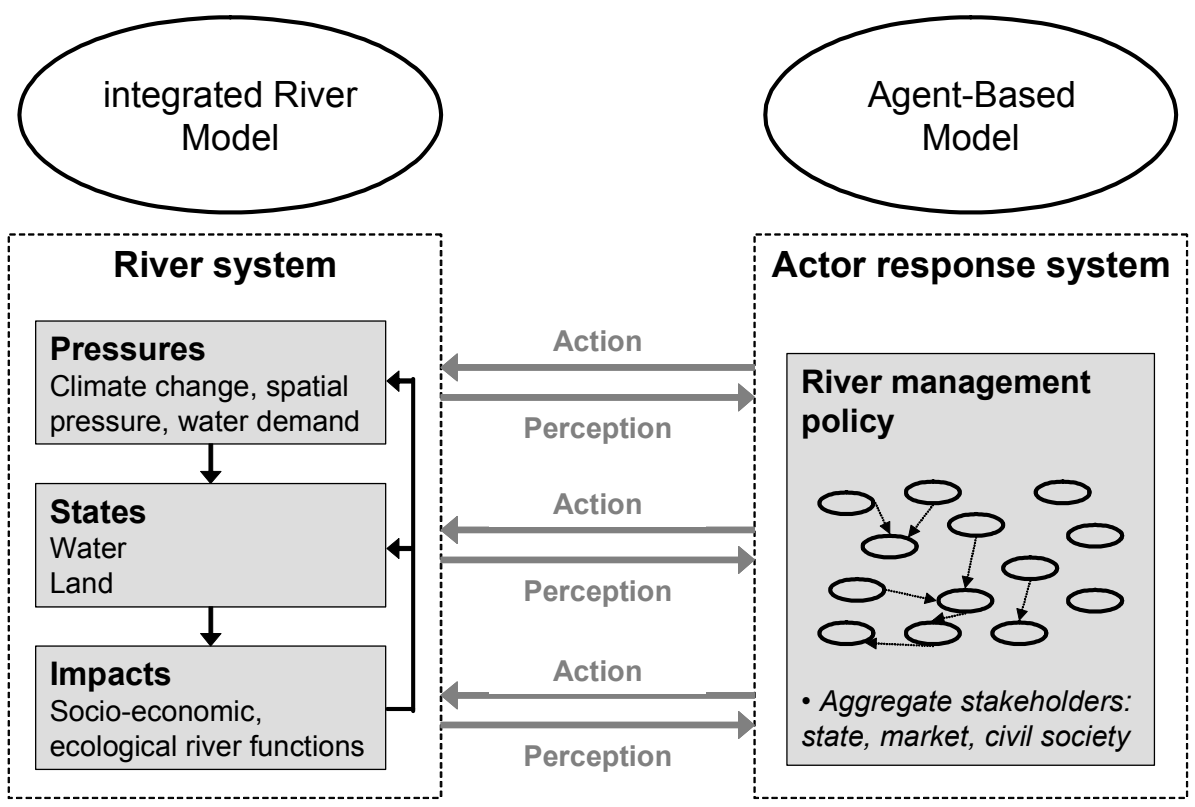

Figure 2.1: The agent-based PSIR model for a river management planning issue.

\subsubsection{The cognitive stakeholder agent}

Having conceptualized the position of stakeholder agents in the total human-environment system, we now look further to the representation (or 'architecture') of the stakeholder agents themselves. A first step in any conceptual agent design is deciding on whether to take a simple or a cognitive approach, see Box 2.2. For our case, the choice for a cognitive approach is obvious. The design of river management strategies is clearly the result of a good amount of reasoning and pro-active behaviour (i.e. anticipating on things that can be achieved through river management), involving an explicit consideration of the state and functioning of the river 
environment, and stakeholder interests related to that. This process can surely not be explained with a purely reactive agent architecture.

From the field of $A B M$, various cognitive architectures exist. A well-known example is the socalled Beliefs Desires Intentions (BDI) model ${ }^{22}$ of Bratman (1987). The BDI model follows from a philosophical tradition of practical reasoning, describing mechanisms of deliberation (deciding what ones intentions are) and means-ends reasoning (deciding how to achieve them) in a very intuitive way. It was adopted in various successful Al applications, for example, for supporting air traffic control (Weiss, 1999). Other architectures exist that are more grounded in the cognitive and social sciences, and portray better representations of both individual cognitive processes and social interactions. These architectures have been particularly suitable for the study of social phenomena, like game playing behaviour, distributed problem solving, and group dynamics (see Sun (2006) for a number of applications). Of specific interest in this tradition, is the model of Cognitive and Social Action of Conte \& Castelfranchi (1995a). Like other agent models, their agents act on the basis of explicit representations of goals. What their model adds, however, is an elegant description of the beliefs underlying different types of goals, as a way to model how goals are adopted and rejected by the agents. It poses a nuanced view on agent-agent interaction (implemented through a mechanism called goal adoption) and the interaction between agency and macro-social structures (implemented through the mechanism of social norms).

The architecture of the stakeholder agent - presented in Figure 2.2 - is inspired on existing architectures, such as the ones described above, albeit following its own rationale. It is a very simple architecture in which the agent's action is (i.e. its preferred river management strategy) is determined from its perspective, representing its goals regarding the water system and the agent's beliefs about the river system (see Box 2.3). The beliefs correspond directly to the agent's interpretation of the uncertainties in the river system. This uncertainty interpretation feeds into a river system model that the agents use to assess the effects of a river management strategy $^{23}$. Consequently, it is assumed that for given goals, a preferred river management strategy will consistently follow as the strategy that optimizes goal fulfilment under the river system model adopted by the agent.

Note that there is an assumed interaction between the beliefs and the goals. This interaction relates, on the one hand, to consistency of goals with respect to the adopted beliefs: goals that are not feasible given the beliefs about the river system are likely to be dropped. On the other hand, it can be assumed that beliefs are, at least to some extent, driven by the goals that are pursued, as a way to 'guarantee' the fulfilment of goals. For example, if one is concerned with flood prevention, one would probably take into account an extreme climate scenario 'just to be sure'.

\footnotetext{
${ }^{22}$ In the BDI model, the beliefs refer to the information the agent has about its current (social and physical) environment, the desires (similar to goals) represent situations that the agent would like to accomplish in principle, and the intentions are the state of affairs it has actually decided to bring about.

${ }^{23}$ The river system model thus includes both an objective part (representing undisputed, certain knowledge, or 'facts') equal for all agents, and a subjective part (representing disputed, uncertain knowledge, or 'beliefs') captured in each agents' individual, legitimate uncertainty interpretation.
} 


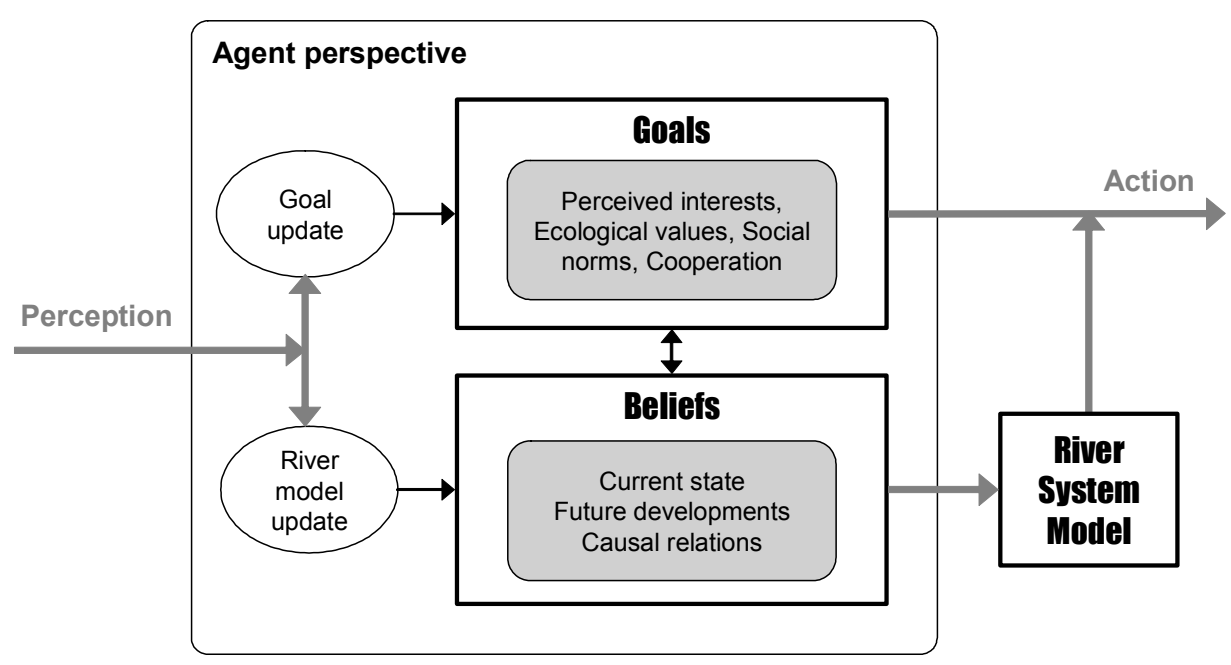

Figure 2.2: A simple stakeholder agent architecture on the basis of goals and beliefs.

Key to understanding changes in river management strategies is then to understand the rules by which goals and beliefs are updated, notably through perceived changes of the river system and/or interaction with other stakeholder agents. To this end, the architecture explicitly includes the so-called 'goal update' and 'river model update' rules as part of the agent's perspectives. The river model update rule may refer to any update to the river system model, such as a new statistical method for calculating peak flow probability, a more advanced hydraulic model, or new insights on climate change. The goal update rule includes any change in the set of goals one aims to pursue, such as a renewed interest in flood prevention, or the emergence of ecological objectives, or changing budgetary constraints. Following the concept of adaptive cognition (Conte \& Castelfranchi, 1995a), the architecture thus highlights both the agent's mental state (goals and beliefs), as well as the rules with which this state is manipulated. In the next section, potential mechanisms of adaptive cognition are further discussed.

\subsubsection{Representing social learning}

In a complex project like Maaswerken, learning appears to be an essential part of the planning process. New knowledge about the river system is continuously created, for example through modelling studies and pilot projects. The perception of the river system may further change through various external developments, like unexpected events (e.g. floods and droughts) and ongoing context developments (e.g. climate change). Finally, a lot is learned about the actor system as stakeholder perspectives are mutually shared in participatory processes, and different modes of interaction (e.g. conflict and cooperation) develop. Key to understanding the planning process is an understanding of these types of learning. 


\section{Box 2.3: Goals and beliefs}

\section{Goals}

The goals portray those states of affairs that the stakeholder agent aims to bring about. In our case, goals are typically related to the impacts of the water system model, for example, reducing flood risk, nature development and gravel extraction. From the literature, one may identify a variety of motivations underlying the selection of goals. Following the rational actor model, for example, goals are typically related to self-interests. Other theories, however, focus also on ecological values, altruism, social norms, cooperation, perceived abilities and many other possible determinants of goals (e.g. see Conte \& Castelfranchi, 1995a; Jackson, 2005). It is outside the scope of this thesis to present a full overview of possible goal motivations. What is important here is that the architecture explicitly requires a list of the stakeholder agent's goals, and, ideally, insight in the reason why these goals are pursued.

\section{Beliefs}

The beliefs reflect the stakeholder agents' knowledge about the river system. This knowledge, however, can be assumed to be incomplete. Given the complexity and our limited understanding of the river system at hand, various more or less fundamental uncertainties exist. These uncertainties may relate to the current state of affairs (e.g. the current probability of peak flows), future developments (e.g. climate change), and various causal relations (e.g. related to the projected effects of river engineering measures). Following the concept of pluralistic uncertainty management (Van Asselt, 2000; Rotmans \& Van Asselt, 2001), it is assumed that each stakeholder agent holds different, legitimate interpretations of these uncertainties as part of its belief system. This implies that the agent can adopt specific settings for uncertain parameters and context developments in the river system model, as described in Chapter 5. Van Asselt (2000) shows how the uncertainty interpretations can be related to underlying cultural beliefs. Here, we assume that uncertainty interpretations can also be related to the goals the stakeholder agent pursues.

Here, we will adopt the concept of 'social learning' as a way to interpret and model the multistakeholder river management planning process. Social learning is a form of collective learning (as opposed to individual learning) in which various social processes play an important role (Liberatore, 1999). The concept is increasingly being used to analyse and support collective decision-making in water resource management, for example in the recent HarmoniCOP project (Pahl-Wostl et al., 2007). In HarmoniCOP, social learning was described as: "a means of developing and sustaining the capacity of different authorities, experts, interest groups, and the general public to manage their river basins effectively. This includes the capacity to deal effectively with differences in perspective, to solve conflicts, to make and implement collective decisions, and to learn from experience" (Pahl-Wostl et al., 2007). This broad interpretation of social learning thus goes beyond the mere assimilation of new information, explicitly placing the capacity for 'learning together to manage together' (Ridder et al., 2005) at the heart of what social learning is about. Consequently, social learning can be said to encompass various types of learning (Craps, 2003). It includes:

- $\quad$ cognitive aspects (regarding both technical and social process knowledge),

- attitudinal aspects (regarding the willingness to accept differences and to collaborate),

- $\quad$ the development of skills (regarding both technical and social-relational skills), 
- $\quad$ and realizing joint actions for managing the river basin.

In this context, it is relevant to distinguish between single-loop (or 'instrumental', 'first-order', 'lower order') learning and double-loop (or 'political', 'second-order', 'higher order') learning (Van de Kerkhof \& Wieczorek, 2005). Single-loop learning can be said to correspond to the cognitive aspects of learning, while double-loop learning corresponds to more fundamental attitudinal aspects of learning. While single loop learning typically leads to a minor shift of strategy within the constraints of given norms, values and beliefs, double loop learning typically leads to a radical change of strategy as a result of changing underlying norms, values and beliefs (Pahl-Wostl et al., 2007).

For modelling social learning, it should be clear that there are currently no ABM approaches 'on the shelf' that capture the breath-and-depth of social learning processes. In the field of ABM, models of agent learning (in general) are considered state-of-the-art (Gilbert, 2008). Two fairly 'established' types of learning models can be distinguished: Reinforcement Learning and Evolutionary Computation. Reinforcement learning, or individual learning through trial-anderror, refers to the process of an agent trying to maximize a reward by testing out different courses of action; the agent's success generally depending on the balance between exploration (trying new courses of action) and exploitation (sticking to more or less successful ones). Evolutionary computation, or population learning, refers not so much to learning of individual agents, but rather to the learning of an agent population through the survival and reproduction of its most successful members. Gilbert et al. (2006), finally, introduce social learning as a mode of learning which is explicitly driven by the communication between agents. Their approach of simulating the development of a language among agents remains, however, fairly experimental and abstract. The most direct link between (participatory) ABM and social learning is probably made in the analysis of the Zurich water game (Pahl-Wostl \& Hare, 2004) mentioned above. However, although the authors show the game supports social learning, it does not provide a detailed conceptualisation of the social learning process suitable as a basis for the model of our case.

In our case, social learning is interpreted as the process of changing goals and beliefs (i.e. adaptive cognition) as part of the (multi-stakeholder agent) process of river management planning, notably through perceived changes of the river system and/or interaction with other stakeholder agents. For modelling these processes, a number of key mechanisms were identified:

\section{Compromising}

The basic principle for modeling the outcome of the multi-agent planning process is compromising ${ }^{24}$. Compromising can be considered a simple, indirect form of agent interaction, which expresses the agents' mutual interference and (in a stronger case) dependency given their common, shared world (Castelfranchi, 1998). In compromising, every stakeholder agent is assumed to be able to express its support for proposed river management strategies, and the final outcome is the strategy that maximizes some total-support function on the basis of the individual stakeholder agents' support. Significant differences in power amongst the various

\footnotetext{
${ }^{24}$ This way of modeling the policy outcome was considered both simple and realistic, and was assumed to fit well with the actual Dutch water management culture.
} 
stakeholders may exist. To this end, each agent can be attributed a power factor (both in terms of a 'veto' and a simple 'weight'), which determines the weight of its support in the totalsupport function. Note, that different variations of the total-support function can be applied in principle. The total-support function may simply add-up all the (weighted) individual agents support, but may also takes into account differences in support, for example attaching a higher value to more equitable solutions. Reasoning from a single stakeholder agent, the preferred strategy is referred to as an 'ideal strategy'. Reasoning from a group of stakeholder agents, this strategy is referred to as a 'compromising strategy' or 'policy outcome'. Compromising - in our interpretation - is not a form of social learning as such, since it does not require adaptive cognition to occur. However, it does provide the basic interaction structure under which social learning may (or may not) take place.

\section{Learning about the environment}

Learning about the environment relates to adaptive cognition initiated through a changing perception of the river system of any individual stakeholder agent as new insights about the river system become available. This form of learning corresponds to Reinforcement Learning (Gilbert, 2008), although it encompasses more then the trial-and-error mechanism adopted in most ABMs. Learning about the environment can be based on observation (e.g. new measurements of water quality) and can also be the result of study (e.g. the results of a new hydraulic model). The perception change can be gradual (increasing water stress, changing landscapes) or manifested in sudden events (a flood, drought, or algae outbreak). Also, the perception change can be said to occur at different levels. Minor perception changes, reflected in an updated river system model alone, will cause the agent to change its preferred river management strategy for achieving its goals (e.g. in response to a drought, sluices are improved to maintain a proper shipping route). However, as the perception changes become more pronounced, more fundamental changes - in the form of an updated set of goals - can be expected as well. Some examples are emerging interests (after a flood, citizens start to realize the importance of flood prevention), triggering environmental values (after observing an ecological disaster, ecological quality is acknowledged as an important objective), and learning from failure (after a series of drought, shipping is abandoned as a main mode of bulk-transport).

\section{Learning from agent interaction}

Learning from agent-agent interaction refers to adaptive cognition that results from direct interaction among the stakeholder agents. Here, we focus on two interaction modes:

The first interaction mode involves cooperation and (stronger) coalition-forming, see Figure 2.3. In the ABM literature, cooperation is said to occur when "agents intentionally achieve a common goal [..] Cooperation is a multi-agent plan that requires more than one agent for it to be accomplished successfully" (Conte \& Castelfranchi, 1995a). Drawing the analogy to river management, cooperation can be said to occur when stakeholder agents recognize the interference of their goals and beliefs with the goals and beliefs of other agents, and are willing to modify their goals and beliefs for the common goal of reaching a broadly supported river management strategy. Cooperation can thus be said to occur when stakeholder agents modify their goals and beliefs to reach a river management strategy with higher stakeholder support. Coalition-forming is interpreted as a stronger form of cooperation. Coalition-forming implies that stakeholder agents merge into a new 'meta-agent' operating in a unanimous way, and advocating a single set of goals and beliefs. Coalition forming is a form of cooperation that occurs within a subset of all stakeholder agents involved. It may actually imply a conflict between the coalition and other (coalitions of) agents. 
The second interaction mode refers to the mechanism of social norms. Conte \& Castelfranchi (1995a) regard social norms as "prescriptions, which control the behaviour of autonomous agents by modifying their beliefs and influencing their goals. [They form] a fundamental connection between the macro (social) and micro (mental)". It is outside the scope of this thesis to present a detailed account of how norms emerge and are sustained. It is sufficient to note that - in our case - we assume that 1) norms can exists, 2) that they can form an important constraint on the policy process by influencing the stakeholder agents' goals, and 3) that the modification of norms is considered a strong form of social learning.
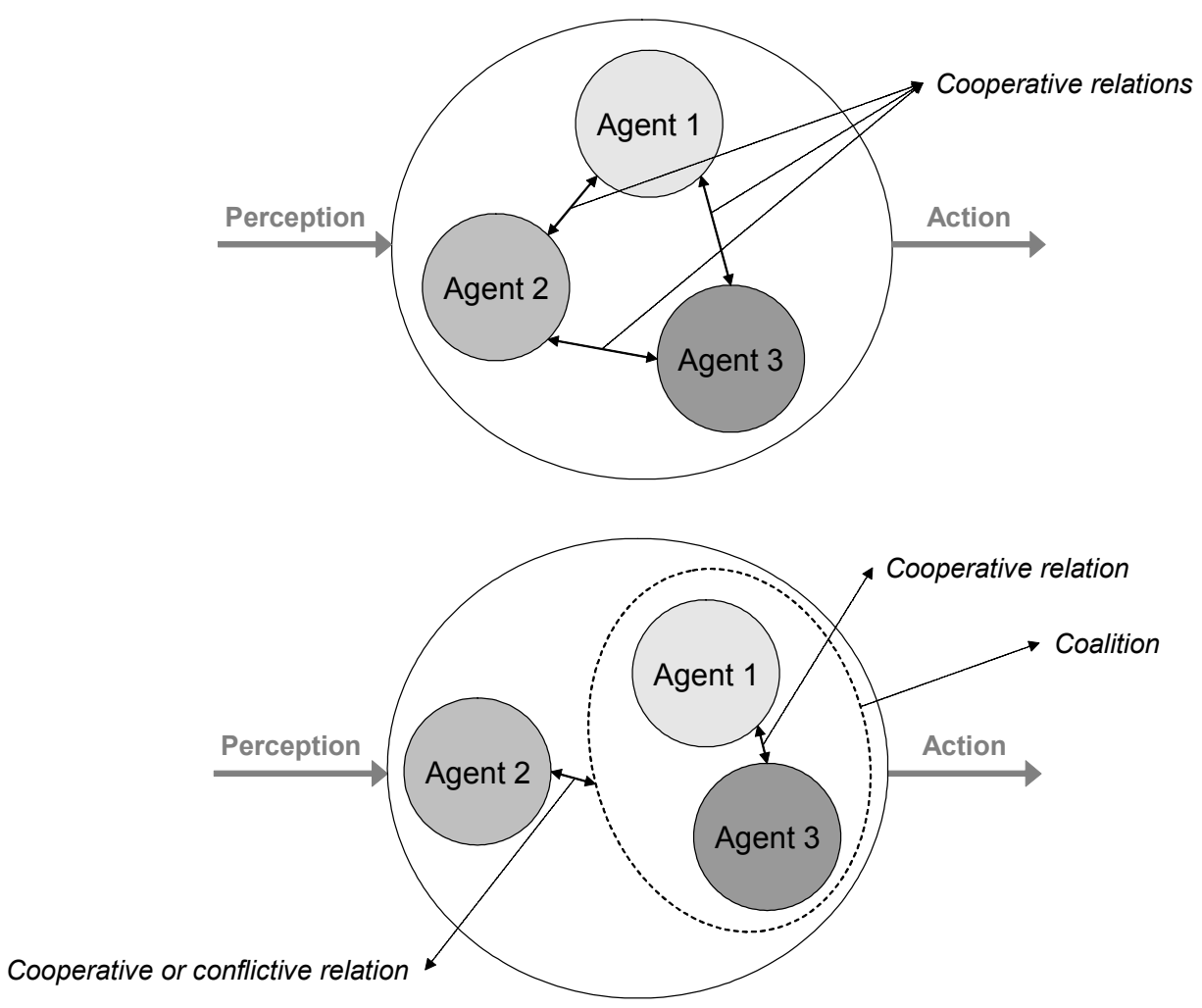

Figure 2.3: The Maaswerken planning process is modelled as a process of social learning among stakeholder agents. Relevant learning mechanisms include learning about the environment - based upon a changed perception of the river system - and learning from agent interaction. The figure illustrates learning through agent interaction among three stakeholder agents involving cooperation (above) and coalition forming (below). 
After a short introduction of IA modelling, this chapter has provided a broad discussion on the field of $A B M$. ABM was portrayed as a highly diverse and interdisciplinary field. We focussed on applications for modelling social actors and zoomed in further on applications of specific relevance to sustainability assessment and IA modelling. In this context, we identified three applications areas: environmental modelling, social-ecological systems and common pool resource problems, and models of societal change. In these application areas, ABMs have proven to be useful tools. Mentioned strengths are: modelling micro-level decision-making, assess the consequences of agent heterogeneity, include agent interactions like imitation behaviour, and illustrating the implications of social dynamics on resource consumption and/or patterns of spatial development. Moreover, ABMs have contributed to insights on human behaviour in social dilemmas and provide an innovative viewpoint for studying fundamental societal change. Among its weak points are: the limited predictive value of $A B M s$, hence their limited suitability as operational decision-support tools, and the fact that practical ABM applications (e.g. in environmental modelling) generally fail to take scientifically grounded cognitive models into account. Consequently, ABMs are generally not intended to be predictive modelling tools. ABMs are rather considered to be heuristic tools, aimed to support reflection on the implication of behavioural processes, and to explore possible scenarios of behavioural change. In this light, participatory ABM was identified as an approach that offers high potential, both for realizing a better representation of stakeholder behaviour in the model, and to support learning processes amongst the stakeholders involved.

Following, we sketched the outline of a coupled integrated River Model - Agent-Based Model (iRM-ABM) for river management. The modelling approach taken can be characterized as one where few cognitive stakeholder agents are engaged in a collective planning process for managing a river system representing long term environmental and socio-economic change. Stakeholder agent cognition has been implemented by explicit representations of stakeholder perspectives, in terms of their goals and beliefs, reflecting the real-life stakes and various possible interpretations of the salient uncertainties in the river system. The river management planning process was interpreted as a process of social learning. Stakeholder agents are in principle engaged in a process of compromising on the basis of their individual goals and beliefs. Social learning, then, is implemented through the 'river model update' and 'goal update' rules that are explicitly included in the agent perspective. Relevant learning mechanisms include learning about the environment - based upon a changed perception of the river system - and learning from agent interaction. The latter was related on the one hand to cooperation and coalition-forming, and on the other hand to the mechanism of social norms.

The framework presented here does not provide us with a blue print for modelling the Maaswerken planning process. However, it does provide us with a framework of analysis and a set of testable hypothesis. For example: Do the stakeholders' preferred river management strategy indeed follow consistently from their goals and beliefs? And: Is the outcome of the planning process indeed well described through the compromising mechanism described above? If so, key to understanding the development of river management will be to understand the rules through which the goals and beliefs are updated, as a result of the perceived changes of the river system and/or interaction with other stakeholder agents. A consistent analysis of those rules - under various circumstances - is a main challenge which is probably best addressed through a participatory ABM approach. 

Chapter 3

\section{THE MEUSE IN LIMBURG}




\begin{abstract}
This chapter presents an integrated analysis of the River Meuse in Limburg, as a basis for the further modelling work. It describes its current state hydrology, its main river functions, and touches upon problems of flooding, drought, and pollution generally associated with river management. Focussing on the issue of flooding, three distinct problem perceptions are discussed, stating that the flood problem can be attributed to a changing discharge pattern, a reduced discharge capacity, or an increasing vulnerability over time. Following, three related river management approaches are described: upstream retention as a way to regulate discharge, river engineering as way to increase the discharge capacity, and river adaptation as a way to reduce vulnerability. For synthesis, the conceptual model of Pressure, State, Impact and Response is applied to gain better insight in the relation between various developments over the longer term, and to further evaluate the river management approaches discussed. Although river widening is an effective way for increasing the discharge capacity during peak flows, the main risk is that it will contribute to spatial scarcity, especially under ongoing climate change. In that respect, river function adaptation was highlighted as an effective approach which is inherently robust towards both climate change and spatial pressure.
\end{abstract}




\section{The Meuse in Limburg}

\subsection{INTRODUCTION}

The River Meuse fulfils an important role for the Province of Limburg. The values and functions of the Meuse are manifold, encompassing all sustainability domains. Its ecological values, for example, originate from the natural river morphology. With its gradual transitions between wet and dry terrain, the river offers a unique habitat for typical river related flora and fauna. Moreover, rivers are important corridors for connecting nature areas and creating ecological networks. The economic value is apparent in its role as a shipping route. The Meuse forms an important connection within the network Rotterdam - Liege - Antwerp - Rotterdam. The Meuse also has been an important location for mining of gravel, sand and clay. The social and cultural values of the Meuse, finally, are related to recreation, landscape and historical value. The importance of the Meuse for the cultural identity of Limburg is illustrated, for example, by second couplet of the Limburg anthem.

Despite the virtues of the Meuse there is also reason for concern. Recent developments have increased in particular the concern for floods. In 1993 (RWS, 1994) and 1995 (RWS, 1995) two major floods caused large damage, and 2002 and 2003 exceptionally high discharges nearly caused floods again. Furthermore, there is a growing recognition that phenomena like climate change and urbanisation are responsible for an increased vulnerability of the river system for floods. Apart from flooding, the concern also applies to the problem of droughts. There is a growing awareness of the increased dependency on water and the possibility for increasing periods of drought notably due to climate change. These issues apply not only to the River Meuse, but are also recognized for water management in The Netherlands as a whole (CWB21, 2000).

In response, notably, to the flood events of 93 and 95 the Dutch government has initiated the river engineering project Maaswerken. The Maaswerken project aims to improve safety, to develop new nature, and to improve the shipping route, through a river widening approach. The question that arises is too which extent this approach is indeed most suitable to address problem at hand. Will it offer a solution that is 'future proof'? To address those questions, this chapter aims to reflect upon the management of the River Meuse from an integrated, long term perspective. Following the conceptual model of Pressure, State, Impact and Response (PSIR), we discuss what really the problem is that the Maaswerken is trying to solve. Furthermore, we reflect upon the pros and cons of various river management approaches, including (but not exclusively) the river widening approach of Maaswerken.

\subsection{THE RIVER MEUSE}

\subsubsection{Geographical characteristics}

\section{The Meuse catchment}

One can find excellent descriptions of the geography of the Meuse catchment in (Berger, 1992; WL, 1994b; Middelkoop \& Van Haselen, 1999; De Wit, 2001; De Wit, 2008). Here, we describe some of its main characteristics. The Meuse (see Figure 3.1) rises about two hundred kilometres north-east of the city of Dijon, some 400 meters above see level. It passes through France, Belgium, and enters The Netherlands practically at its southernmost point some $20 \mathrm{~km}$ south of 
the city of Maastricht. From this point it follows the Dutch-Belgian border for some $40 \mathrm{~km}$, continues through the Province of Limburg, then follows the northern border of the Province of Noord-Brabant and finally reaches the North-Sea near the city of Rotterdam. Its total course is approximately $940 \mathrm{~km}$. Its course through the Netherlands measures about $250 \mathrm{~km}$. With a catchment area of about $36000 \mathrm{~km}^{2}$ (roughly the size of the Netherlands) and an average discharge of some $230 \mathrm{~m}^{3} / \mathrm{s}$ near Maastricht, the Meuse can be considered a medium sized river compared to its European counter parts ${ }^{25}$.

On the basis of hydrological characteristics the Meuse can be divided in three main parts (e.g. see Berger, 1992):

- The Upper reaches or 'Meuse Lorraine'. This section corresponds roughly to the French part of the Meuse. It covers approximately the first $300 \mathrm{~km}$ of its course up to the mouth of the tributary of the Chiers in Northern France. The upper reach is characterized by a moderate gradient, a narrow catchment area, and permeable soils. As a result, the Meuse has a calm course with a relatively stable discharge pattern.

- The Central reaches or 'Meuse Ardennes'. This section corresponds roughly to the Belgian part of the Meuse, running from the Chiers in the south to the Dutch border in the North. Here, the river runs through the Ardennes mountain range where it cuts through rocky, impermeable soils in steep river valleys. With occasionally strong rainfall, this area may greatly contribute to flood waves. The contribution to low flows is generally small.

- The Lower reaches or Dutch Meuse. This section corresponds roughly to the Dutch part of the Meuse, running from the Dutch border near Maastricht to the river's mouth in the North Sea. In this section the river's character turns more and more to that of a delta river characterised by a low gradient, large floodplains, and tidal influence. River flow is strongly regulated through a system of (lower) summer embankments and (higher) winter dikes.

\section{The Maaswerken planning area}

The planning area of the Maaswerken covers the main part of the lower reaches of the Meuse. It extends roughly from Maastricht in the South to the city of Den Bosch in the North, see Figure 3.2. The major part of the planning area is situated within the Dutch province of Limburg. The planning area is divided into three sections: 1) the Grensmaas (Border Meuse) that covers the first $40 \mathrm{~km}$ from Maastricht to the town of Maasbracht (somewhat South of the city of Roermond), 2) the Zandmaas (Sand Meuse) that covers a roughly $100 \mathrm{~km}$ stretch from Maasbracht to Den Bosch, and 3) the Maasroute (Meuse route) referring to the shipping route roughly from Maastricht to the cities of Nijmegen and Den Bosch. Besides the Zandmaas, the latter includes the Meuse through Maastricht, the Juliana canal (from Maastricht to Maasbracht), the Lateral canal (bypassing the so-called Plassenmaas, see below), and the MaasWaal canal (connecting the Zandmaas to the Waal at Nijmegen) (Maaswerken, 1999a, p. 12).

\footnotetext{
${ }^{25}$ E.g. see (Middelkoop \& Van Haselen, 1999, p. 19) and www.eea.europa.eu/themes/water/europeanwaters/rivers accessed January 2009.
} 


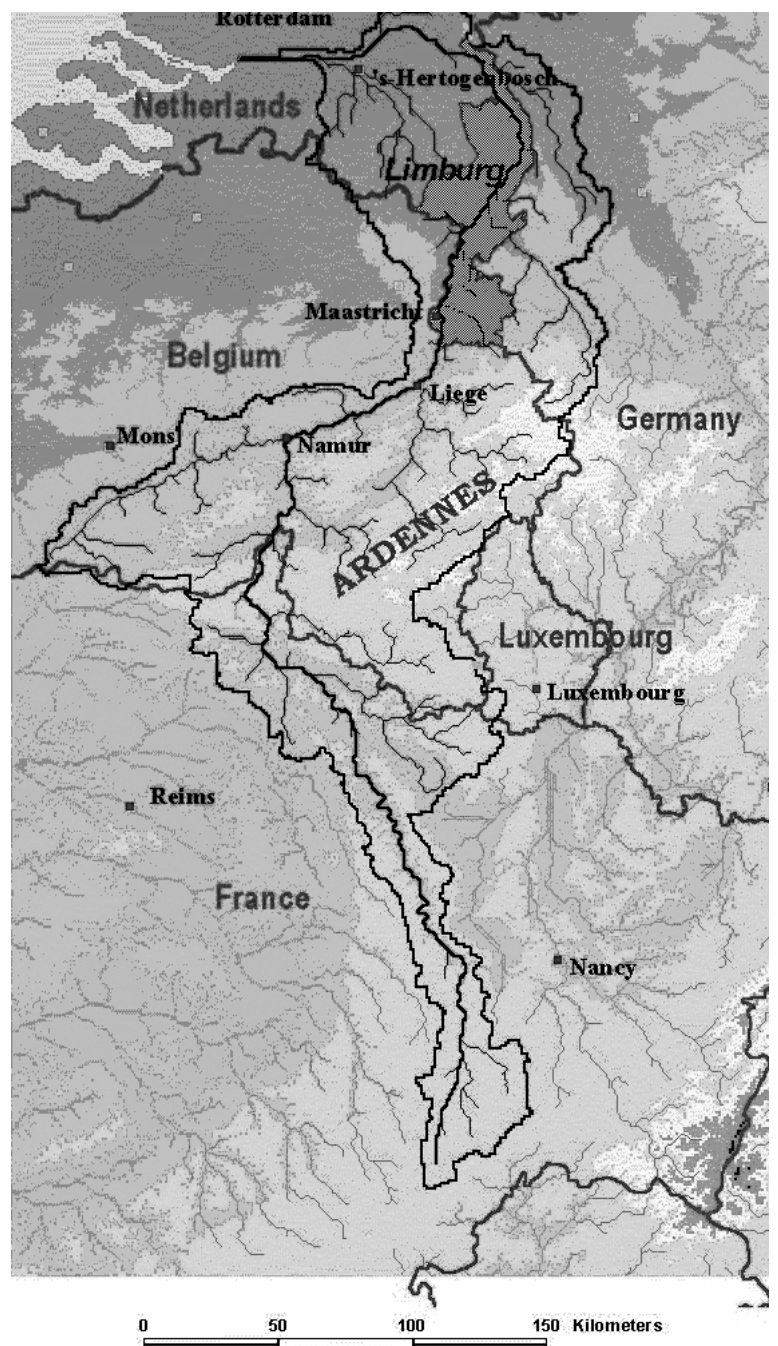

Figure 3.1: The catchment of the River Meuse

The river stretches of Grensmaas and Zandmaas are of quite different character. The Grensmaas can be regarded as transitional stretch between the central and lower reaches of the Meuse. It is a gravel based river with a relatively high gradient, descending from some $40 \mathrm{~m}$ NAP at Maastricht to about $20 \mathrm{~m}$ NAP at Maasbracht. The river meanders through a - for Dutch standards - pronounced river valley with relatively small floodplains. In absence of locks and sluices, the Grensmaas is not navigable: ships pass through the adjacent Juliana canal. Main river dikes - that mark the Dutch river landscape further downstream - do not exist here, although smaller scale embankments ('kades') provide local protection for settlements in the flood prone areas. Land use in the Grensmaas area is primarily devoted to agriculture. Nonetheless, as an unregulated, gravel based river it has potential for ecological quality comparable to that of the Allier in France (Stroming, 1991). 


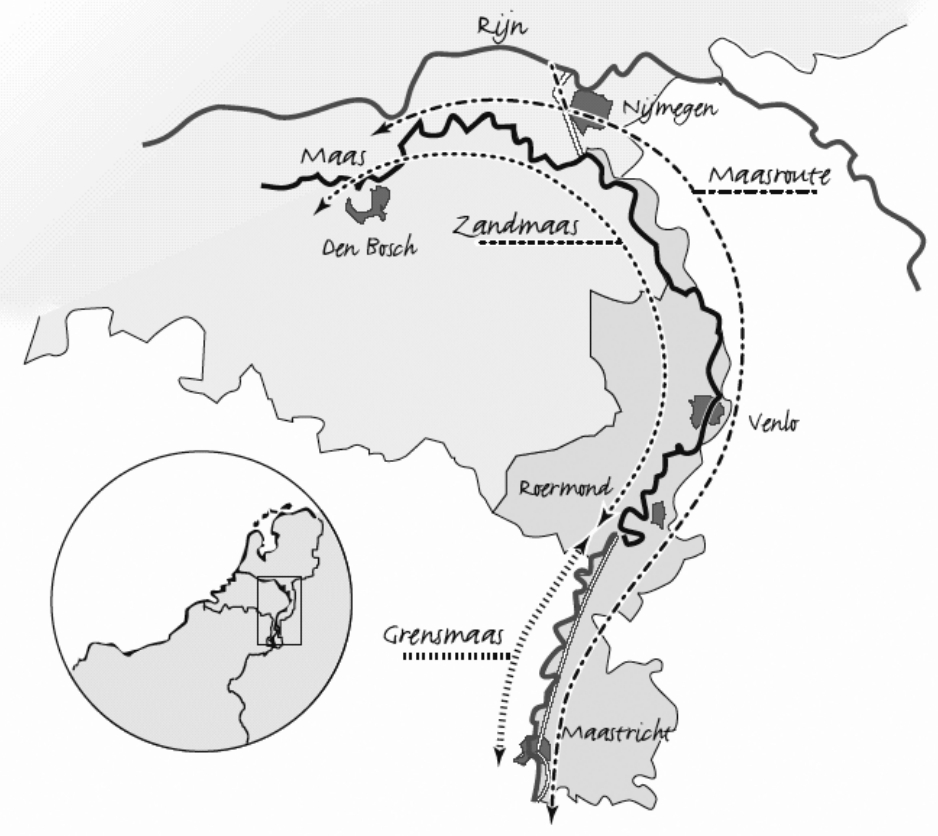

Figure 3.2: The Maaswerken planning area (retrieved January 2009 from www.maaswerken.nl).

The Zandmaas stretch shows more of a delta river character. The slope and flow velocity of the river is smaller than in the Grensmaas and sediments consist mainly of sand. The stretch is navigable, with locks and sluices to control the river water level, and is intensively used for water transport. The Zandmaas area is used for agriculture and recreation, and has a more urbanized character with a number of medium-sized cities (Roermond, Venlo, Nijmegen, Den Bosch) and industrial areas in the vicinity of the river. The first part of the Zandmaas is referred to as 'Plassenmaas'. This short stretch of some $20 \mathrm{~km}$ is characterised by numerous lakes, created through gravel extraction, which are currently used for water recreation. In the following stretches, the Meuse continues its course, without river dikes, through a gradually widening river valley, referred to as 'Peelhorst' and 'Venloslenk' respectively. At the downstream end of the planning area the river flows out into the Dutch delta, with river dikes protecting the adjacent land (river dikes starting at the town of Mook) and tidal influence downstream from the lock at Lith (Middelkoop \& Van Haselen, 1999).

\section{Discharge pattern}

The Meuse is a rain fed river with a relatively variable discharge pattern. No accumulations of snow and ice exist in the catchment area to feed the river with a stable discharge of melting water. Moreover, the geographical characteristics of its main tributary area (the Ardennes) are such that the hydrological response to precipitation is relatively short. The average monthly discharge pattern of the Meuse at Borgharen and Monsin is displayed in Figure 3.3. The station of 'Borgharen' is located at the inlet of our study area, just North of Maastricht. The station of 
'Monsin' is located just North of Liege, some $40 \mathrm{~km}$ upstream from Borgharen. This station is particularly relevant since it represents the 'undivided Meuse'. Between Monsin and Borgharen, three main canals branch of, reducing the discharge at Borgharen with approximately $30 \mathrm{~m}^{3} / \mathrm{s}$ throughout the year. The average discharge in winter $\left(\sim 450 \mathrm{~m}^{3} / \mathrm{s}\right)$ is significantly higher than in summer $\left(\sim 100 \mathrm{~m}^{3} / \mathrm{s}\right)$, mainly due to a difference in evapotranspiration over the year (Middelkoop \& Van Haselen, 1999).

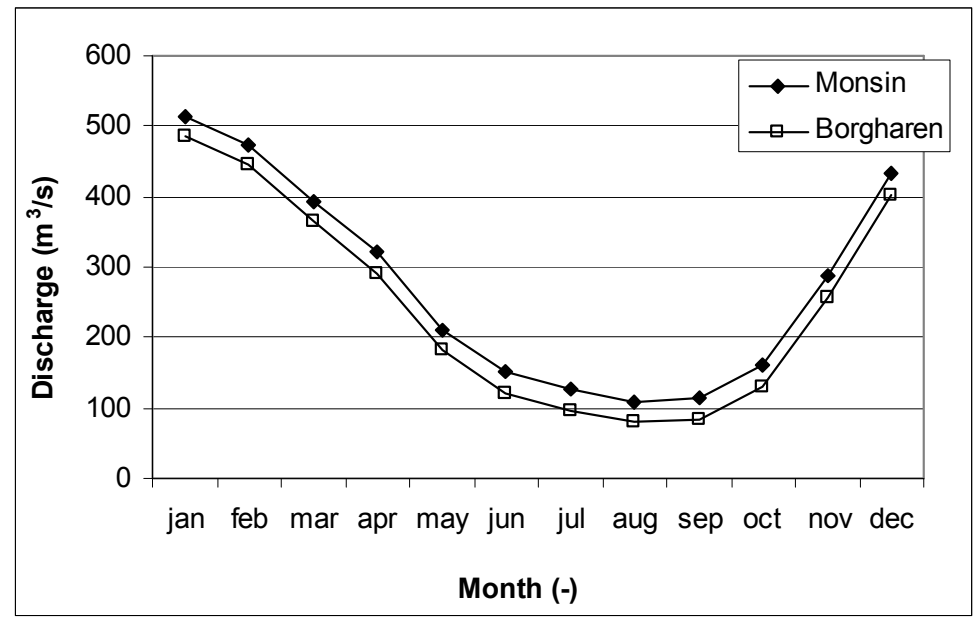

Figure 3.3: Average monthly discharges at Borgharen and Monsin for the period 1911-2000. Based on (RWS, 2003).

\subsubsection{River functions and values along the Limburg Meuse}

The river Meuse and its floodplains in the planning area of Maaswerken serve a variety of functions and values. In this section the most relevant of those functions and values are shortly described.

\section{Housing}

The river's natural floodplains are extensively used for housing. The Grensmaas region is a rural area with some small villages and hamlets. It accommodates some 15.000 inhabitants with a total of 6000 houses (Maaswerken, 2003a, p. 34). The Zandmaas region is stronger urbanized with a number of medium-sized cities, such as Roermond (45.000 inhabitants), Venlo (65.000), Nijmegen (152.000) and Den Bosch (128.000). Housing along the Zandmaas is generally located on the higher parts of the river valley, although is some cases urbanisation has occurred in the floodplain area, for example in the village of Herten near Roermond (Maaswerken, 1998c, p. 15).

\section{Agriculture}

Agriculture is the primary form of land use in the flood plains of the Meuse. In the Grensmaas area some 47 farms are located, their lands covering an area of 2375 ha. These areas comprise mainly grassland (54\%) and arable land (45\%) (Maaswerken, 2003a, p. 81). In the Zandmaas region some $80 \%$ of the area is covered by agriculture with a total number of around 790 farms. The land is divided between grassland (42\%), arable land (35\%), and horticulture $(24 \%)$ (Maaswerken, 1999b, p. 167/169). 


\begin{abstract}
Nature
The present natural value of the Meuse is strongly restricted by its agricultural use and the canalisation of the river bed. Characteristic river ecosystems and natural morphological processes are largely absent. Present natural values in the Grensmaas are found in the river bed, in the steep river banks, in some recent nature development areas, and cultural landscape elements (pastures, hedges, tree orchards) hosting several characteristic types of fish, birds, insects, mammals and plants. (Maaswerken, 2003a, p. 52). In the Zandmaas, some relevant natural values include the Plassenmaas as a winter area for water birds, pastures in the Peelhorst, and characteristic hedges ('Maasheggen') in the Venloslenk (Maaswerken, 1998c, p. $67)$.
\end{abstract}

\title{
Shipping
}

The Meuse route is a main route in the Dutch inland shipping network. Internationally, it is important as a link in the triangle Rotterdam-Liege-Antwerp-Rotterdam and part of the TransEuropean transport network (TEN) (Maaswerken, 1998c, p. 12). Presently, the Meuse route is used to transport some 24 million tons bulk (of which 60\% gravel and sand) and some 60.000 containers on a yearly basis (Maaswerken, 1998c, p. 61). However, the Meuse route is not considered yet to provide a sufficient alternative for road transport. To fulfil the ambition of shifting the modal-split in long distance transport, the Maaswerken aims to improve the shipping route to allow for larger and faster ships (Maaswerken, 1998c, p. 83).

\section{Tourism and recreation}

In the Meuse region there is room for outdoor activities like hiking, biking, sport fishing, pleasure cruising and swimming. Especially in the Zandmaas region, the recreational sector is well developed. With a total turnover of some 1 billion $€$ it exceeds agriculture in economic importance. The Plassenmaas area is particularly popular for water recreation, accounting for some $30 \%$ of recreation related expenditure (Maaswerken, 1998c, p. 70). In the Grensmaas region, the recreational sector is lesser developed. It is particularly popular for extensive forms of recreation, such as hiking, biking, and fishing.

\section{Mining}

During the past decades, significant gravel and sand extraction has taken place at a number of locations along the Meuse. Several gravel pits remain, in particular in Maasplassen region. Further downstream, mining focuses more on sand and clay, with several old brick factories in the vicinity of clay extraction sites near the Meuse. There has been an increasing societal resistance against large scale gravel and sand extractions, because of their negative impacts on landscape and nature. Accordingly, future mining is intended to be 'secondary': only for the benefit of other goals, such as nature development, recreation or flood protection (Maaswerken, 1998c, p. 69).

\section{Landscape and cultural values}

The landscape along the Limburg Meuse is unique in the Netherlands. The hilly and open river landscape is highly appreciated by tourists, recreants, and the inhabitants along the river Meuse. Of geo-morphological value are the so-called river terraces - plateaus of different elevations formed a long time ago by the meandering Meuse - notably along the Grensmaas and Peelhorst. Archaeological values include finding sites from the Middle-Palaeolithic $(270.000 \mathrm{BC})$ until the early Middle Ages (650 AC), and a number of locations with remains of dikes and city defences. See (Maaswerken, 2003a, p. 56) and (Maaswerken, 1999a, p. 297). 


\section{Drinking water supply}

The current drinking water supply in the Province of Limburg - some 90 million $\mathrm{m}^{3} /$ year or 2.8 $\mathrm{m}^{3} / \mathrm{s}$ - is met primarily through the use of groundwater resources. However, the Province of Limburg aims to achieve a drinking water supply where groundwater and surface water resources are 'in balance', where surface water covers some $30 \%$ of the drinking water supply (Limburg, 2001, p. 149). This is done to as part of an overall policy to achieve resilient water systems and to prevent droughts. To this end, the capacity of water extraction sites along the Meuse will be enlarged, while some groundwater extractions will be closed.

\section{Power generation}

The Meuse is also used to facilitate the generation of electricity. Three power plants are located in the Zandmaas area in Maasbracht (gas and biomass), Linne (hydroelectric) and Cuijk (biomass). The power plants depend on Meuse water for cooling and - in Linne - electricity generation. Negative environmental impacts include warming of the river water and fish mortality at the hydroelectric power station (Maaswerken, 1998c, p. 67).

\section{Industry (excluding mining)}

A number of industrial areas are located along the Meuse route. These areas comprise some 150 factories and shipyards. Most of these industries are located there for logistical reasons and benefit from the transport facility of the Meuse. Some of these industries take up water and/or drain wastewater into the Meuse (Maaswerken, 1998a, p. 61).

\subsubsection{Problems of flooding, drought, and pollution}

Most river functions benefit from a stable discharge of clean water. River management problems are often associated with floods (too much water), drought (too little water), and pollution (a poor quality of water).

\section{Floods}

The concern for flooding has been strongly triggered by two relatively recent flood events in 1993 and 1995. In December 1993, the Meuse was forced to accommodate a peak discharge of $3120 \mathrm{~m}^{3} / \mathrm{s}$ at Borgharen; the highest discharge ever recorded. An area of 18.000 ha overflowed, causing some $115 \mathrm{M} €$ of monetary damage, and the evacuation of some 8.000 people (WL, 1994a). Only one year later - in January/February 1995 - the water levels again rose to extreme levels. With a somewhat smaller peak discharge, but a longer duration of the flood wave, the water level and inundated area were comparable to the figures of 1993. Due to a better flood preparedness, monetary damage was somewhat smaller, but substantial nonetheless (Nierop, 1997). Sectors that are particularly vulnerable to flooding include housing (some $32 \%$ of the total damage of the '93 and '95 floods concerned private property), agriculture ( $11 \%)$, and mining and other industry ( $34 \%)$. A major portion of the flood damage was also inflicted on governmental property and river infrastructure ( $24 \%)$. Also non-monetary damages, such as evacuation and emotional damage, are considered among the main impacts of floods.

At the same time the Meuse flooded in 1995, there was also a high water in the River Rhine. Due to the significant threat of dike-breach in various low-lying polder areas in the Provinces of Brabant, Gelderland and Utrecht, some 200.000 people and half a million head of cattle were evacuated. According to a journalist report (Volkskrant, 1995) "the largest logistical operation the Netherlands since the Second World War". Although the dikes held out, the perception of a 'real' threat, and a sense of urgency for flood protection remained. 


\begin{tabular}{|l|l|l|l|l|}
\hline & $\begin{array}{l}\text { Peak } \\
\text { discharge } \\
\left(\mathrm{m}^{3} / \mathrm{s}\right)\end{array}$ & $\begin{array}{l}\text { Water level } \\
\text { (m NAP) }\end{array}$ & $\begin{array}{l}\text { Inundated area } \\
(* 1000 \mathrm{ha})\end{array}$ & $\begin{array}{l}\text { Monetary } \\
\text { damage (M€) }\end{array}$ \\
\hline December 1993 & 3120 & 45.90 & 17.0 & 115 \\
\hline February 1995 & 2870 & 45.71 & 15.5 & 74 \\
\hline
\end{tabular}

Table 3.1: Some key figures for the floods of 1993 and 1995. Discharge and water level apply to the measuring station at Borgharen. Inundation and damage occurred largely in the Province of Limburg. After (RWS, 1994; WL, 1994a; RWS, 1995; Nierop, 1997).

The probability of flooding is directly related to the recurrence times of peak discharges. For current flood policy, these recurrence times are statistically estimated from a time series of observed peak discharges starting in 1911. The time series is periodically updated to include the most recent peak discharge data. The recurrence time curve (state 2001) (RIZA, 2001) is shown in Figure $3.4^{26}$. The figure shows, for example, that the village of Borgharen - which inundates roughly at a discharge of $2700 \mathrm{~m}^{3} / \mathrm{s}$ - can expect flooding to occur roughly every 50 years. Also, the figure indicates that, for a flood protection norm of 1:250 years to be met, a discharge of some $3300 \mathrm{~m}^{3} / \mathrm{s}$ (the 'design discharge') must be accommodated through the river channel.

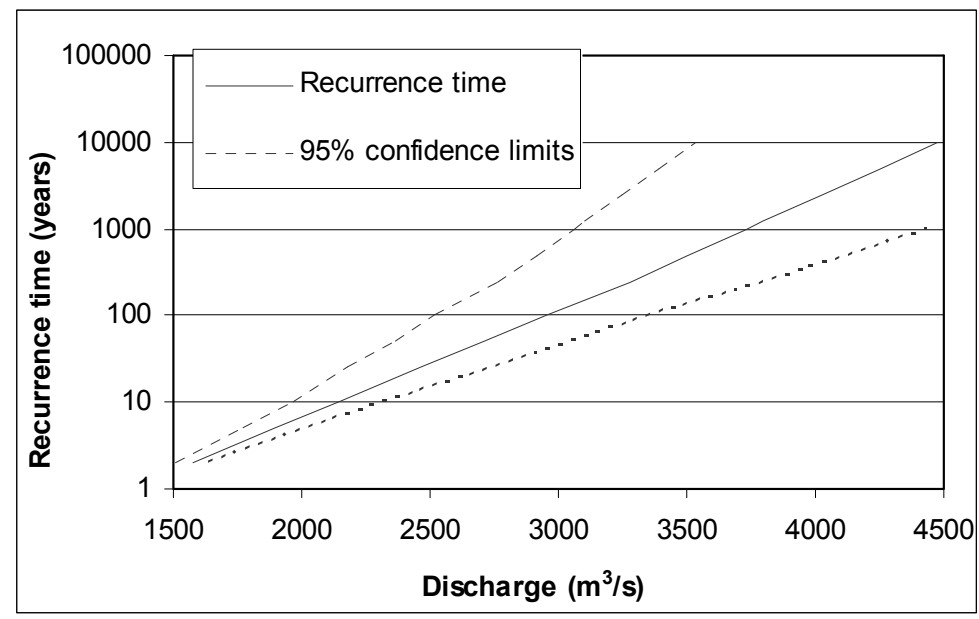

Figure 3.4: Estimated recurrence times of peak flows at Borgharen (RIZA, 2001).

These figures, however, must be interpreted with care. Due to ongoing developments - like climate and land use change - it is unclear to which extent the historical discharge series on which the recurrence times estimates are based is representative for the current situation. The

\footnotetext{
${ }^{26}$ This curve is derived from the historical daily discharge data from 1911 - 2000 using a combination of different extreme value distributions such as Gumble and Pearson III.
} 
last two decades have shown a significant number of extreme peak discharges flowing through the Meuse. Table 3.2 shows that within 20 years, four peak discharges have been observed, each with an estimated recurrence time larger than 50 years. The probability of such a sequence of events to happen (roughly $20 / 50$ to the power four) is of the order of $1 \%$. There are two ways of explaining the occurrence of such a sequence of events. On the one hand, one may argue that it is simply a matter of chance. In that case, the historical peak discharge series is considered representative for the current state, but we had 'bad luck'. On the other hand, one may argue that the events indicate a structural change of the discharge pattern of the Meuse. In that case, the historical peak discharge series is considered not representative for the current situation, implying that the recurrence time estimates of Table 3.2 are simply wrong. In any case, the uncertainty in current peak discharge probability is an important factor to take into account, see also Section 3.3.1.

\begin{tabular}{|l|l|l|l|l|}
\hline & 1993 & 1995 & 2002 & 2003 \\
\hline Discharge $\mathrm{m}^{3} / \mathrm{s}$ & 3120 & 2870 & 2488 & 2730 \\
\hline Recurrence times (years) & $\sim 160$ & $\sim 79$ & $\sim 27$ & $\sim 53$ \\
\hline
\end{tabular}

Table 3.2: Peak discharges at Borgharen over the past two decades (RWS, 2003). The corresponding recurrence times follow directly from Figure 3.4.

\section{Drought}

The most important drought period in the Meuse over the last century took place in 1976. For a long summer period, the discharge of the Meuse at Borgharen dropped below $10 \mathrm{~m}^{3} / \mathrm{s}$ for 5 months in a row. The more recent summers of 2002 and 2003 were dry as well, although significantly less severe than the one in 1976, see Figure 3.5. According to De Wit (2008), the 2003 drought revealed the vulnerability of various river functions to drought, even when the drought period could not even be considered that extreme. The question remains to what extent water management would be prepared for another drought of the order of the one in 1976.

Shortage of river water or groundwater can cause significant damage for several river functions (see e.g. RIZA, 2005). Water shortage is potentially harmful for agriculture, due to an insufficient amount of water in the soil and insufficient water availability for irrigation. Damage to shipping may occur due to a decrease of the navigation depth (decreasing the ship's freight capacity) and increased waiting times at sluices and locks. The power generation sector can be hampered because of shortage of cooling water and limited hydropower capacity. Damage to nature may occur due to desiccation of vegetation, and as a result of botulism and algae growth. The financial risks associated with water shortage have not yet been assessed in detail. It is clear, however, that in extreme cases like the one in 1976, total damage for shipping, agriculture, and power generation may add up to some dozens $\mathrm{M} €$, and that also during less severe droughts, significant damage may occur (De Wit, 2008). Moreover, natural damage, although difficult to express in monetary terms, forms an obvious concern. 


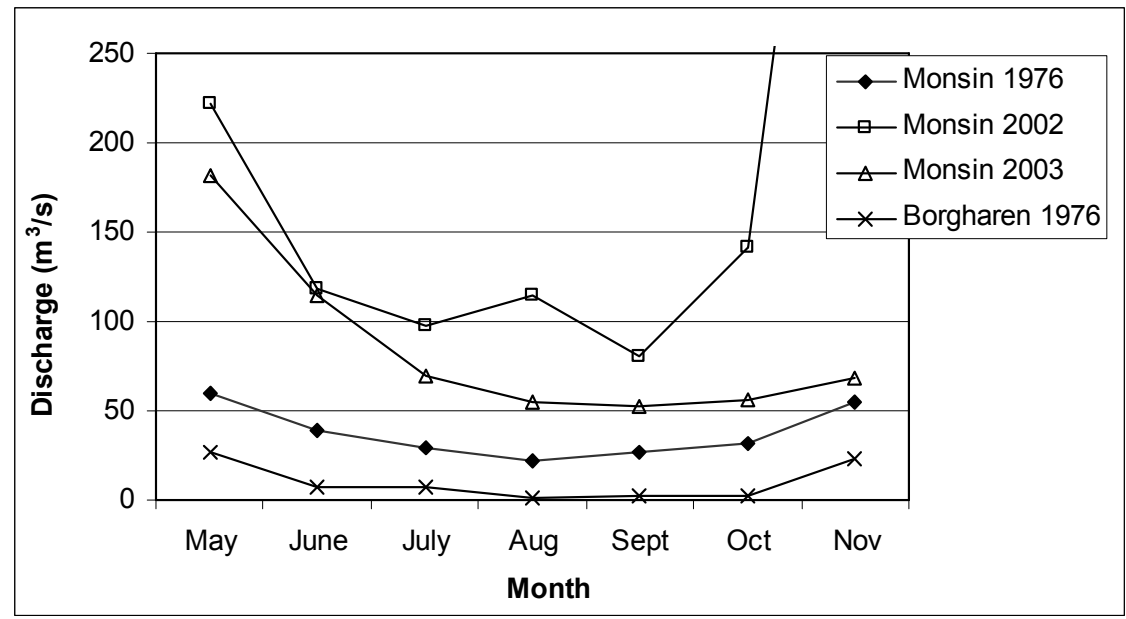

Figure 3.5: Drought along the Meuse: Average monthly discharges in 1976, 2002, and 2003 at Monsin and Borgharen (1976 only). After (RWS, 2003).

The probability of droughts can be expressed through the flow duration curve of Figure 3.6. The flow duration curve specifies the average number of days per year the discharge falls below a critical value. A discharge below $100 \mathrm{~m}^{3} / \mathrm{s}$ at Monsin, for example, occurs $\sim 90$ days/year. At this discharge, a water distribution treaty between the Dutch and Belgian government comes into effect, reducing allowed water use in the Dutch and Belgium canals to $25 \mathrm{~m}^{3} / \mathrm{s}$ (RWS, 1999b). Concretely, this implies that pumping is required to compensate for the water loss of lock operation. As discharge reduces below $60 \mathrm{~m}^{3} / \mathrm{s}$ ( 33 days/year), an 'alarm phase' comes into affect, and a 'crisis phase' starts for discharges below $30 \mathrm{~m}^{3} / \mathrm{s}$ ( 3 days/year). During the various phases, water use for the various river functions is restricted, following a prioritisation scheme. Of lowest priority (3) are cooling water supply for power stations, agricultural water use, and maintaining navigation depths. Higher priority functions (2) are drinking water supply, water use for horticulture, and industrial extractions. Of highest priority (1), finally, is maintaining the stability of weirs and dams, and avoiding irreversible natural drought damage, for which a minimal discharge of $10 \mathrm{~m}^{3} / \mathrm{s}$ through the Grensmaas is required.

\section{Pollution}

A number of water quality aspects can be considered (Maaswerken, 2003a, p. 75) and (Maaswerken, 1998a, p. 73):

- Oxygen balance: Due to the presence of oxygen binding chemicals the oxygen level falls often below the norm ${ }^{27}$ of $5 \mathrm{mg} / \mathrm{l}$.

\footnotetext{
${ }^{27}$ This concerns the so called MTR value (Maximaal Toelaatbaar Risico or 'Maximum Allowed Risk') for water quality, prescribed in (V\&W, 1998).
} 


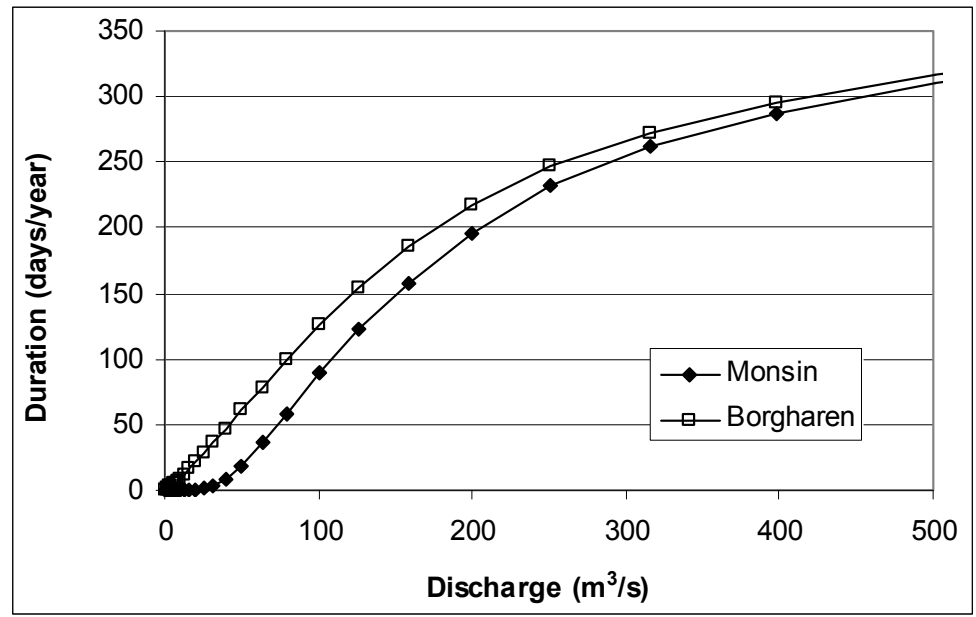

Figure 3.6: Flow duration curves for discharges at Monsin and Borgharen. The curves specify the yearly average duration river flow falls below specified discharge values. The curves are derived from daily discharge data for the time period 1911-2000 (RWS, 2003).

- Nutrients: Nutrients typically enter the water system through the fertilisation of agricultural grounds. The current levels of phosphate and nitrogen are 2 to 3 times higher than the norms of $0.15 \mathrm{mg} \mathrm{P} / \mathrm{I}$ and $2.2 \mathrm{mg} \mathrm{N} / \mathrm{I}$ respectively.

- Toxic waste: Concentrations of heavy metals, PAH's (Polycyclic Aromatic Hydrocarbons) and PCB's (Polychloorbifenylen) regularly exceed standard norms.

- Bacterial waste: There is a high concentration of pathogenic bacteria, in particular due to un-purified household sewage originating from Belgium.

- Algae growth: High concentrations of nutrients, high water temperature, strong light incidence, and low flow velocities may increase algae growth, although in the current situation algae growth falls below the accepted norm.

- Blue algae and botulism: Specific attention is given to the so-called 'blue algae' and botulism bacteria's that secrete toxic substances. During warm and dry periods these may endanger the water quality of ponds and lakes connected to the Meuse.

- Litter: During a high water, a large amount of litter is transport through the Meuse, which remains on the riverbanks. This causes both a visual problem, and endangers the quality of nature along the river.

Strongly related to the water quality problem is the problem of polluted sediments. Years of deposition of polluted silt have resulted in a strong pollution of the floodplains' top clay layer. The main pollutants are heavy metals and PAH's (Polycyclic Aromatic Hydrocarbons). These originate from a variety of sources and activities over the past century, including mining, the metal industry, and sewage from households and factories (Maaswerken, 1998a, p. 79; Maaswerken, 2003a, p. 62). According to Dutch standards, the situation is severe. The Dutch 'Law on Soil protection' classifies the pollution in the winter bed as 'inadmissible', and points to the 'necessity' and 'urgency' of decontamination. However, given the magnitude of the pollution problem, such a decontamination process is not likely to take place in the near future (Maaswerken, 1998a, p. 68). 
Poor water and sediment quality may cause damage to a number of user functions. Regarding nature, the poor quality of soil and surface water has a clear negative effect on the quality of vegetation and animal life in the Meuse. In a significant fraction of the Grensmaas area ( $14 \%)$ at least one species of flora and fauna is considered to suffer a large toxicological risk, while $\sim 67 \%$ of the area is still considered to pose a medium risk (Maaswerken, 1998a, p. 60). For the drinking water supply, water and sediment pollution requires additional cleaning efforts. Although this may be technically possible ${ }^{28}$, it may require significant additional costs. When it comes to agriculture, the soil quality is below the Dutch norm for agricultural soils in significant parts ( $56-93 \%$ ) of the floodplain area (Maaswerken, 2003a, p. 64). For recreation, finally, poor water quality and algae growth may decrease the attractiveness of the Meuse for water recreation such as swimming, canoeing, and fishing.

Since the early nineties, an important effort has been developing to improve the water quality of the Meuse. The International Meuse Commission ${ }^{29}$ was established to co-ordinate the so-called 'Meuse Action Programme'. This programme is a collaborative effort amongst the countries within the Meuse catchment to reduce emissions and improve the quality of the Meuse water. Too this end, a common monitoring system was set up to prepare for setting common goals and further actions in the period $2003-2010$ (IMC, 2003). The European Water Framework directive (EU WFD) of the year 2000 further enforces these initiatives, calling for a river basin management and a 'good ecological status' of water bodies. Due to these initiatives, water quality in the Meuse has significantly improved over the past decades (De Wit, 2008). Under de EU WFD, one can expect further improvements of water quality to occur. Unfortunately, this does not hold for sediment quality. Since the residence time of sediments is much longer than that of water, sediment pollution must be considered a longer-term problem.

\section{Summary}

In summary, the problems floods, droughts, and pollution can be associated to the various river functions described before, see Table 3.3. The problem of floods is mainly associated with impacts for housing, agriculture and industry (including mining) that are subject to the highest flood damage. The flood issue is currently high on the Dutch water management agenda, due to the recent floods of '93 / '95 and the increasing awareness of climate change. The main drought problems occur in the sectors of nature, agriculture, shipping, and power generation. Although currently at a relatively low priority, the drought problem receives increasingly more attention and may become a high priority issue in the future. Pollution, finally, may impact functions on nature, drinking water, agriculture, and recreation. Water quality has significantly improved over the past decades and further improvements are expected. Polluted sediments, however, will remain in the river for a longer term.

\footnotetext{
${ }^{28}$ For example through indirect water extraction through riverbank infiltration or infiltration reservoirs

${ }^{29}$ This organization was founded in 1994 under the name International Commission for Protection of the Meuse (CIPM-ICBM) and changed names in 2002. See http://www.cipm-icbm.be/ accessed July 2009.
} 


\begin{tabular}{|l|l|l|l|}
\hline & Floods & Droughts & Pollution \\
\hline Housing & $*$ & & \\
\hline Agriculture & $*$ & $*$ & $*$ \\
\hline Nature & & $*$ & $*$ \\
\hline Shipping & & $*$ & \\
\hline Tourism and recreation & & & $*$ \\
\hline Mining & $*$ & & \\
\hline Landscape and cultural values & & & \\
\hline Drinking water supply & & & $*$ \\
\hline Power generation & & $*$ & \\
\hline Industry (excl. mining) & $*$ & & \\
\hline
\end{tabular}

Table 3.3: Most vulnerable river functions in relation to floods, drought, and pollution

\subsection{WHAT IS CAUSING THE PROBLEM?}

From the previous section it is clear that various river functions benefit from the Meuse, but that there are also problems of flooding, drought, and pollution. In this section, we discuss further the underlying causes of these problems, focussing on the issue of flooding. To this end, we reflect upon three possible ways of explaining the flood problem. First, one may argue that the problem is caused by a changing discharge pattern. The peak flow probability, one would say, is on the rise, for example due to climate change, land use change, and canalisation. Second, one may argue that the discharge capacity along the Meuse is too small. Ongoing spatial pressure, one would say, has constrained the river channel to such an extent that it is no longer able to accommodate peak discharges that naturally occur. Third, one may argue that the vulnerability for flooding has increased. Flooding, one would say, is a natural phenomenon; the problem is the inflicted damage due to the careless development of socio-economic functions in the river's floodplain. In the following, each problem perception is further discussed and evaluated.

\subsubsection{A changing discharge}

There is ample scientific argument to support the view that the discharge pattern has been structurally changing over the past century and that the probability of peak flows has increased. These changes may be attributed to climate change, land use change, and canalization, as described later on. There are, however, two problems in underpinning this view. The first problem is the uncertainty in the relation between the discharge pattern on the one hand, and (notably) climate and land use change on the other. Although the insight that global climate is changing is well established, its impacts on regional weather patterns are poorly understood. Also, while land use in the Meuse catchment has significantly changed over the past century, it precise impact on peak discharge and drought is highly unclear. The second problem is that peak flow probability is practically immeasurable. Measuring peak flow probability typically requires long time series to be able to distinguish peak discharge trends from natural variability. As a result, various studies that have aimed to assess changes in peak flow probability over the past 
century (WL, 1994b; De Wit, 2001; Tu et al., 2004) have not reached conclusive evidence. Although a small increasing trend of yearly peak flows is observed, it can not (yet) be statistically relayed to underlying climate and / or land use change. Given these uncertainties, it is a priori difficult to assess whether the flood problem can be related to a changing discharge pattern. In the following, therefore, the relations between climate change, land use change, canalization, and the discharge pattern of the Meuse are further discussed.

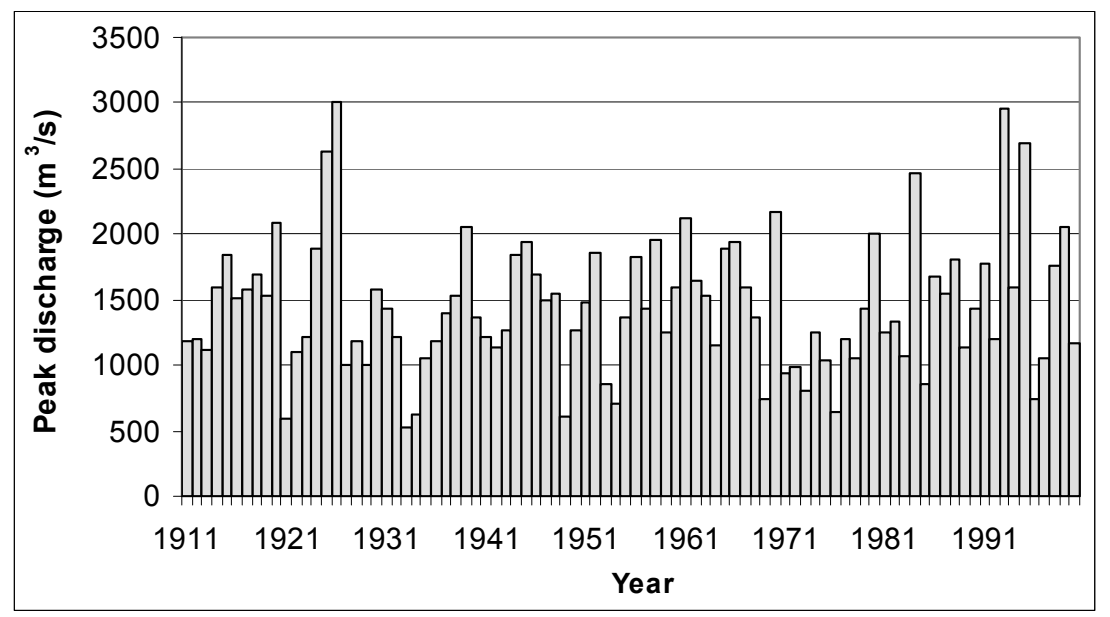

Figure 3.7: Yearly peak discharges (daily average values) for the Meuse at Borgharen from the year 1911 to 2000 (RWS, 2003).

\section{Climate change}

Climate change may strongly affect the discharge pattern of the Meuse. Most obvious is the direct effect of precipitation change, for example the potential increase of flood probability through an increasing precipitation volume and variability. Also important is the indirect effect of temperature changes, for example the potential decrease of summer discharge through an increase of evapotranspiration.

The current 'state of the art' scientific knowledge on climate change is reflected in the IPCC's fourth assessment report (IPCC, 2007) and the recent climate assessment of the Royal Netherlands Meteorological Institute (KNMI, 2006). Among the common findings are that global average surface temperature has increased since the year 1900 with some $0.8^{\circ} \mathrm{C}$ (see Figure 3.8) and that warming is largely anthropogenic. Projections for future temperature increase range between 1 and $6^{\circ} \mathrm{C}$ over the period 1990 to 2100 . Although the trend of global warming is uncertain, its implication for regional climates even more so. Local climates depend on atmospheric circulation patterns which, as a result of global warming, are likely to change. To assess climate change in The Netherlands, four scenarios (the so-called G, W, G+, W+ scenarios) have therefore been developed, based upon two different assumptions for global temperature change, and two different assumptions for the circulation response. These four scenarios provide different projections for temperature and precipitation change, with the common denominator that warming will continue in summer and winter, that the winters will be wetter both in terms of average and extreme precipitation, and that extreme precipitation in summer will increase while the number of precipitation days will fall (KNMI, 2006). 


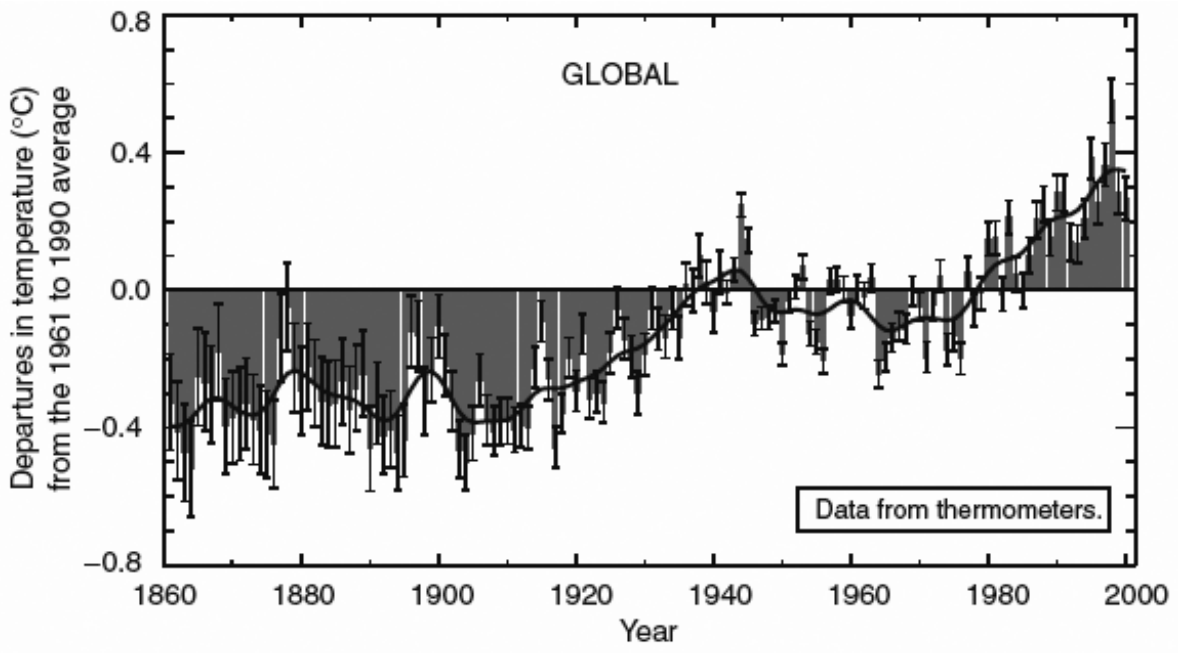

Figure 3.8: Variations of the earth's global surface temperature for the past 140 years. Reprinted from (IPCC, 2001).

The impact of climate change on the discharge pattern of the Meuse has been studied with the rainfall-runoff model Meuseflow (Van Deursen, 1999, 2000). Recent assessments of the G, W, G+ and W+ scenarios (Van Deursen, 2006, 2007) indicate that (in the W scenario) winter discharge may increase up to $10 \%$ by 2050 , and that (in the $W+$ scenario) summer discharge might drop with some $25 \%$, see Figure 3.9. The analysis presented in Appendix A, consequently, indicates that peak discharges may increase with $9 \%$, and that the number of days the discharge at Borgharen falls below $50 \mathrm{~m}^{3} / \mathrm{s}$ may increases with some $30 \%$ in 2050 .

In a different approach, Booij (2002) focuses on precipitation variability to investigate the impact of climate change on flood probability. Booij uses a broad set of daily precipitation data derived from of a suite of regional and global climate models, which simulate climate for present day climate (for the current $\mathrm{CO}_{2}$ concentration), and changed climate conditions (assuming a doubled $\mathrm{CO}_{2}$ concentration, roughly to be expected by the year 2070). These data indicate that the projected changes in average yearly precipitation are not significant at all. The precipitation variability, however, increases, with an increase in standard deviation of some $10 \%$ and an increase in extreme precipitation of some $15-20 \%$. Further hydrological analysis shows that these changes in precipitation translate to a small decrease of the average discharge ( $5 \%)$ and a small increase in the discharge variability and extremes. The 100 year discharge, for example, may increase with some $15 \%$ (see Booij, 2002, figure 6.32, p. 169).

It is thus clear that climate change may cause a significant change of discharge regime over the coming decades. The direction of change (wet - dry) and the extent to which it will occur remains highly uncertain. It is particularly uncertain to what extent climate change is already affecting the discharge pattern of the Meuse. Weighing the evidence, given the steady rise of global temperatures since the 1980s and the increased occurrence of extreme discharges over the past two decades, our stance is that the influence of climate change on the discharge pattern is most probably already felt. 


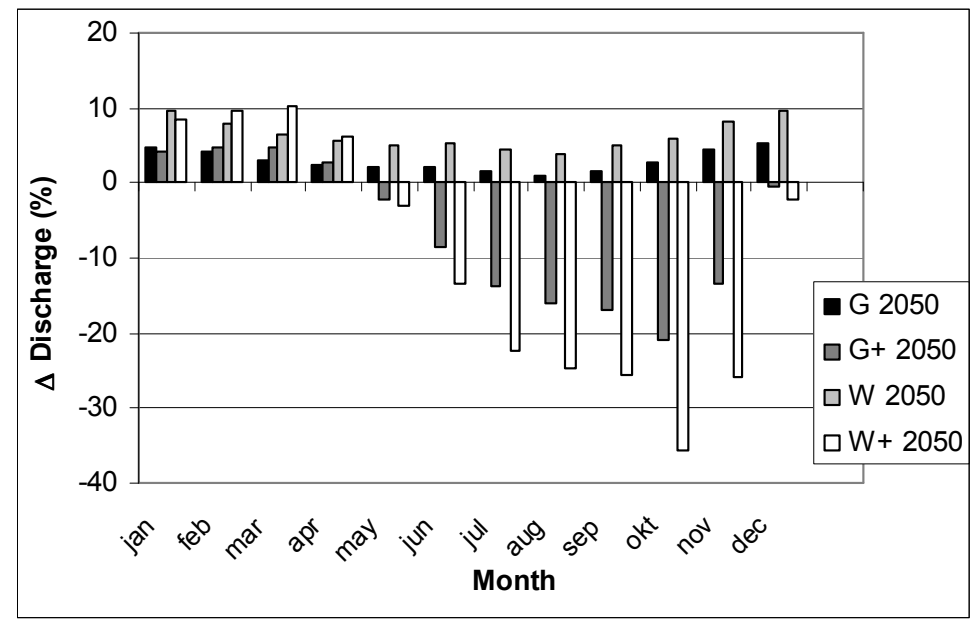

Figure 3.9: Changes in average monthly discharges (\%) for the $G, G+, W$, and $W+$ scenarios (2050) of (KNMI, 2006) calculated with the Meuseflow model (Van Deursen, 2006).

\section{Land use change}

The hydrology of a river catchment is strongly affected by land use type (e.g. urban, forested, agricultural area) and drainage. These factors influence relevant hydrological properties, such as the rate of rainwater infiltration, the rate of surface and subsurface runoff, and the rate of evapotranspiration. These properties, in turn, influence the relation between rainfall and runoff, notably concerning the built-up of peak discharges, and the availability of water flow during period of drought. In paved urban areas, for example, rainwater is often not able to infiltrate in the soil. Precipitation thus quickly runs off, which contributes to the build up of floods. This also holds for drained agricultural and forested area, where artificial drainage systems stimulate rapid run-off. Natural (forested) areas, on the other hand, generally allow for a high infiltration of rainwater into the soil. These areas are said to retain incoming precipitation, thereby mitigating floods. In these areas, however, the evapotranspiration can be relatively high, which can increase the problem of low flows.

Land use is the Meuse catchment has strongly changed over the past century. One of the main trends is an increase in urbanized area throughout the Meuse catchment. Notably since the 1960s, a rapid increase of urban area is observed, especially in the valley of the Meuse (WL, 1994b). Changes in forested area differ strongly among different regions. Although in the main industrial catchment areas (e.g. Sambre, Meuse) forestation decreased, the rural catchment areas (e.g. Ourthe, Lesse, Semois, Chiers) show a compensating increase, with some $8 \%$ increase of forested area in the Belgian Meuse catchment overall (WL, 1994b). Agricultural area, finally, has remained rather stable. Here, the intensification of agricultural practices over the past decades is the most relevant factor in relation to a potential impact on the discharge of the river Meuse (Tu et al., 2004).

The correlation between the historical land use changes and the discharge regime of the Meuse, however, is unclear. Recent hydrological studies have not revealed reasons to believe that peak discharges have been aggravated by land use change (Tu et al., 2004), or that the rainfall-runoff relation in general has changed over the past century (De Wit, 2008). A first reported reason is 
the stability of forested area over the past century, due to which evapotranspiration and hydrological properties have not significantly changed. A second reason is that local effects (which in themselves might be significant) level out on the catchment scale (De Wit, 2008).

A particularly interesting debate is whether further land use changes in the Meuse catchment can in principle significantly affect the occurrence of flooding along the Meuse. On the one hand, hydrological model studies (Middelkoop et al., 2004) indicate that even radical land use change has only a minor effect on the occurrence of peak discharges in the Meuse. The argument goes that extreme discharges in the Meuse floods are generated by a long periods (in the order of weeks) of extreme rainfall. Under these conditions, soils become completely saturated and the retention capacity effectively zero. Land use type or drainage then does not matter anymore (Van Deursen et al., 2002). Landscape ecologists (Stroming, 2004), on the other hand, argue that the potential of natural retention in the Ardennes region is underestimated. In their view, land use change through increasing natural retention will give a significant reduction of peak flows, and also increase the stability of discharge in summer ${ }^{30}$. The belief one holds in this respect will strongly affect the attitude one takes towards natural retention as en effective river management approach, see also Section 3.4.1.

\section{Canalisation}

Finally, the discharge pattern is affected by canalisation. Canalisation typically increases the velocity of river flow and hence may increase peak flows. During the last two centuries many water works have been carried out to canalise the Belgian Meuse and its side rivers to improve navigation and reduce floods (Berger, 1992; WL, 1994b). During high flow periods, canalisation typically increases the speed of water flow, leading to more pronounced flood waves ${ }^{31}$. On the basis of hydraulic modelling it was estimated that river engineering works over the past century have increased peak discharges with roughly $6 \%$ and have advanced the peak occurrence with around 10 hours (WL, 1994b).

\section{Conclusion}

So, can the flood problem be legitimately related to a changing discharge pattern? The analysis shows that, indeed, there are several drivers that may have been responsible for a changing discharge pattern (see Table 3.4). However, none of those drivers can be conclusively held 'responsible' for an increasing occurrence of peak discharge in the Meuse. The potential impact of climate change is undisputed; however it is uncertain to which extent climate change is already having an effect. Land use change over the past century is a fact; but the relation between land use change and the discharge pattern remains unclear. Canalisation, finally, is least debated; canalisation has most probably led to an increase of the peak discharges in the Meuse, but this increase is only moderate. Weighing the evidence, it seems likely that the peak flow probability has indeed moderately increased over the past decades - as the combined result of climate change, urbanisation, and canalisation - and that this increase is likely to continue

\footnotetext{
${ }^{30}$ Their argument is supported by a contradictory observation made in (WL, 1994b, p. 7-18). They observe that, approximately since 1960, peak discharges have increased for given precipitation volumes. Unexpectedly, this observation holds only for peak discharges $>1500 \mathrm{~m} 3 / \mathrm{s}$ and not for peak discharges smaller than that. This observation contradicts the general argument that urbanisation would primarily affect only the smaller peak discharges. Such uncertainties typically form a legitimisation of the ecologists' view.

${ }^{31}$ During periods of low flows, on the contrary, canalization may delay water flow, because of the operation of sluices and locks.
} 
over the years ahead. However, given the uncertainties involved, the real-question is probably not weather the discharge pattern is changing, but how one should deal with the fact that peak discharge probability - even in the current situation - is highly uncertain and unknown.

\begin{tabular}{|c|c|}
\hline $\begin{array}{l}\text { Climate } \\
\text { change }\end{array}$ & $\begin{array}{l}\text { - Global warming confirmed beyond reasonable doubt. Current warming } \\
\sim 0.8^{\circ} \mathrm{C} \text { over the past century. Future projections range between } 1 \text { and } \\
6^{\circ} \mathrm{C} \text { for the coming century. } \\
\text { - The effect of global climate change on regional climates is highly } \\
\text { uncertain. For the Meuse Basin, projections given by the } \mathrm{G}, \mathrm{W}, \mathrm{G}+\mathrm{W}+ \\
\text { scenarios (KNMI, 2006) indicate an increase in temperature, average } \\
\text { precipitation, and precipitation variability. } \\
\text { Possible impacts on the discharge of the River Meuse include a } \\
\text { significant increase in peak discharge ( } \sim 10 \% \text { by } 2050) \text { as well as } \\
\text { increasing occurrence of low flows. } \\
\text { The current discharge pattern is probably already affected by climate } \\
\text { change }\end{array}$ \\
\hline $\begin{array}{l}\text { Land use } \\
\text { change }\end{array}$ & $\begin{array}{l}\text { - Over the past century, land use changes in the Meuse catchment } \\
\text { include strong urbanisation, a (small) overall increase in forested area, } \\
\text { and intensification of agricultural area. } \\
\text { - The influence of historical land use change on the discharge pattern of } \\
\text { the Meuse has not been demonstrated. } \\
\text { - The possible impact of land use change on extreme peak discharges } \\
\text { (e.g. }>2500 \mathrm{~m}^{3} / \mathrm{s} \text { at Borgharen) is disputed. Landscape ecologists argue } \\
\text { that increasing natural retention will significantly reduce peak flows, } \\
\text { but hydrological model studies indicate this effect is much smaller than } \\
\text { the possible effect of climate change. }\end{array}$ \\
\hline Canalisation & Canalisation of the Meuse has led to a small increase in peak discharges \\
\hline
\end{tabular}

Table 3.4: The impact of climate change, land use change and canalisation on the discharge pattern of the River Meuse. A summary of current insights.

\subsubsection{A changing discharge capacity}

A second way to approach the problem of flood is to argue that the discharge capacity along the Meuse in Limburg is too small to accommodate peak discharges that naturally occur. The argument goes that the space required for human development in the floodplain area, and the creation of embankments to protect human property, has eventually constrained river flow to the extent that the room for the river no longer suffices. Figure 3.10 gives an impression of the human influence on the river channel along the Grensmaas. Roughly up till 1800, the Meuse River was in a relatively natural state, with a shallow and meandering river bed. In the $19^{\text {th }}$ century, so-called 'river improvements' were carried out, to create a more straight, smooth, and stable river bed. Over the $20^{\text {th }}$ century, ongoing main channel deepening, main channel erosion, and floodplain sedimentation have created the riverbed of today. These developments have clearly modified the discharge capacity along the Limburg Meuse. To better understand this relation, we here discuss the human interventions in the river bed (here referred to as 'river engineering') that have taken place over the past century, the natural morphological response that followed, and the overall impact on the discharge capacity of the Meuse in Limburg. 

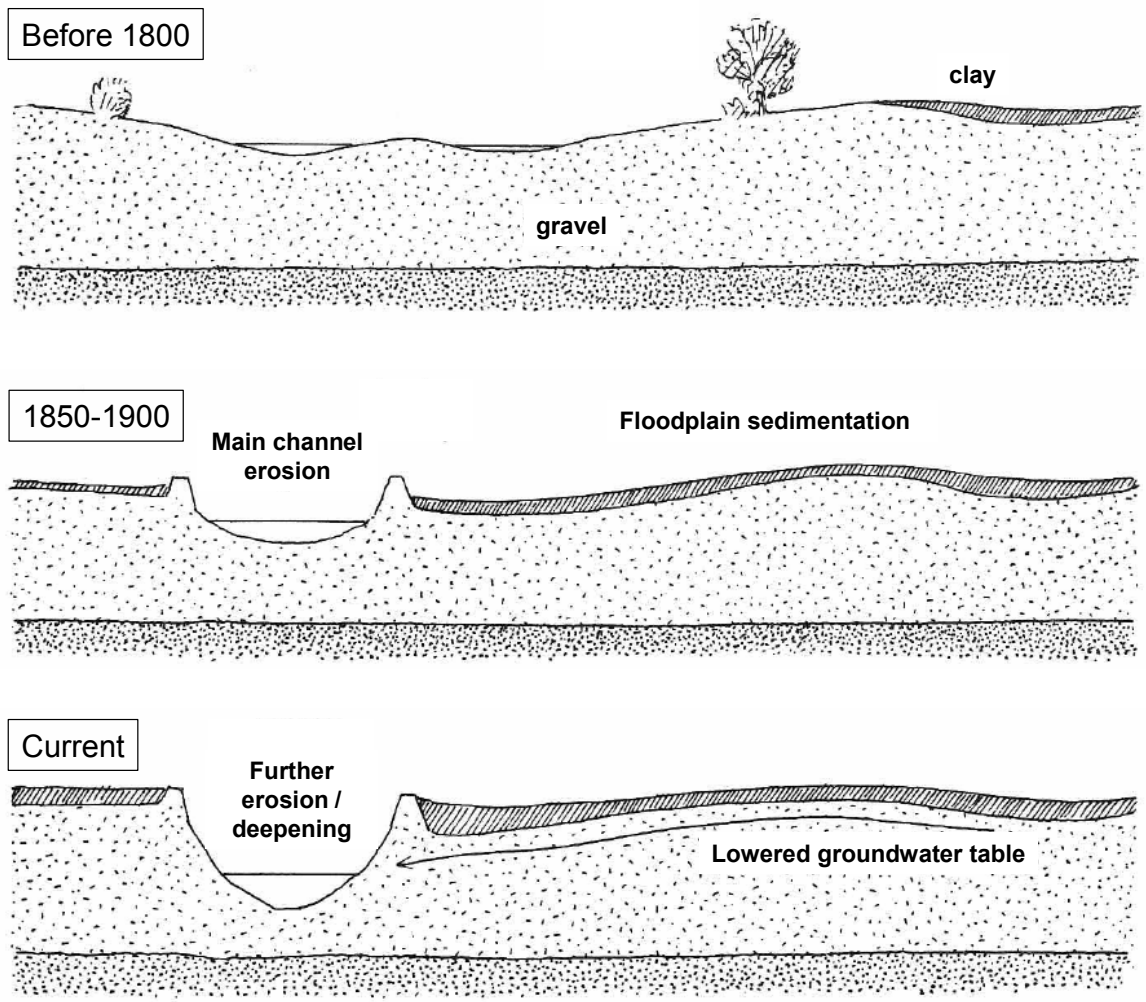

Figure 3.10: An impression of the human influence on the river channel along the Grensmaas from 1800 up till the current state. Reprinted from (Stroming, 1991).

\section{River engineering}

Along the Limburg Meuse, human interventions in the riverbed date back to at least the Roman times. Typical measures taken - like the construction of embankments and groins - were of a much smaller scale than the typical measures carried out today. Nonetheless, it is likely that the human interventions in the $17^{\text {th }}$ and $18^{\text {th }}$ century, have already been largely responsible for fixing the river's course to its current main channel bed (Maaswerken, 1998b).

Roughly since the $19^{\text {th }}$ century, the scale at which river engineering could be carried out reached a higher level. Ongoing industrialisation, technological development, and the centralisation of government allowed for an unprecedented capacity to control river flow. Major normalisation works were carried out for the benefit of shipping, flood prevention, and for the reclamation (or to avoid the loss) of land (Weyden, 1997). These so-called 'river improvements' were primarily directed at creating a straight and smooth river bed. Also, riverbank defences were created to avoid river bank erosion and to stabilize the river's course. Already in the late $19^{\text {th }}$ century, the river bed was probably significantly deepened as a result of local dredging (Maaswerken, 1998b, p. 190). 
Towards the $20^{\text {th }}$ century, river engineering was primarily directed towards improving the shipping route. Especially in the period 1918 - 1926 a number of plans are designed for the canalisation of the Meuse (Weyden, 1997). After the floods of 1926, also flood protection became a leading goal. A coordinated river widening program was set up, including main channel deepening and broadening to increase the discharge capacity of the Meuse. Just like today, these flood protections measures were combined with the construction of sluices for the benefit of shipping and to compensate for the drop in water level. Between 1920 and 1940, six sluices were built between Maasbracht and Nijmegen. Also the Juliana canal was constructed in this period (Weyden, 1997, p. 52). The most recent development is the construction of embankments after the ' 93 and ' 95 floods. A total of $140 \mathrm{~km}$ of embankments were built to protect several villages and cities along the Meuse (VROM \& V\&W, 1997).

\section{Morphological response}

Human interventions in the riverbed generally disturb its morphological equilibrium. The interventions are thus followed by a natural morphological response. In the Meuse, this response included both erosion (of the main channel) and sedimentation (of the floodplain areas). The erosion, on the one hand, can be contributed to an increase in flow velocity due to the canalisation works. While the river banks were protected, the river bottom was free to erode and did so to a significant extent. Sedimentation, on the other hand, occurs when, during high water, the river inundates the floodplain. While the flow velocity in the main channel is high, the flow velocity across the floodplain area is sufficiently low for fine sediments to remain. This effect is responsible for some $30-50 \mathrm{~cm}$ increase of the floodplain level, since the beginning of the $20^{\text {th }}$ century (Maaswerken, 1998b, p. 191).

\section{Effect on the discharge capacity}

It is beyond the scope of this study to present a detailed quantitative assessment of the effects of the above developments on the discharge capacity and water level of the Meuse. However, some general observations can be made. A number of developments (river normalisation, river widening, gravel extraction, and natural erosion) have contributed to an increase of the discharge capacity of the river's main channel. Other developments (sedimentation, the construction of buildings and embankments), however, have constrained the discharge capacity over the rivers floodplain. As a result, one expects that during low flows (when water flow is constrained to the main channel) the water level has overall decreased. During high flows (when water flows through both the main channel and floodplain) the positive and negative effect on the discharge capacity will too some extent compensate each other.

This effect is illustrated in Figure 3.11, which give an indication of the stage-discharge relations at Borgharen and Grevenbicht ( $25 \mathrm{~km}$ downstream) for the beginning and end of the $20^{\text {th }}$ century. The stage-relations are derived by correlating water level data from the respective locations, with the discharge data at Monsin. This is done for a number of years in the beginning and towards the end of the 20th centuries, with peak discharges in the high discharge range. The curves show that for low flows (e.g. $<500 \mathrm{~m}^{3} / \mathrm{s}$ ), the water level has indeed considerably dropped in the order of $2 \sim 3 \mathrm{~m}$. For higher discharges (e.g. $>2000 \mathrm{~m}^{3} / \mathrm{s}$ ), the positive and negative effect appear to level out, as no significant difference in water level can be observed from the graphs.

\section{Conclusion}

So, can the flood problem be legitimately related to a changing discharge capacity? On the basis of this analysis, the answer is clearly 'no'. Human interventions over the past centuries, and the natural morphological response that followed, have modified the discharge capacity. However, 
while the discharge capacity over the floodplains has decreased, the discharge capacity through the main channel has increased. For high discharges (e.g. $>2000 \mathrm{~m}^{3} / \mathrm{s}$ ), the positive and negative effect appear to roughly level out.

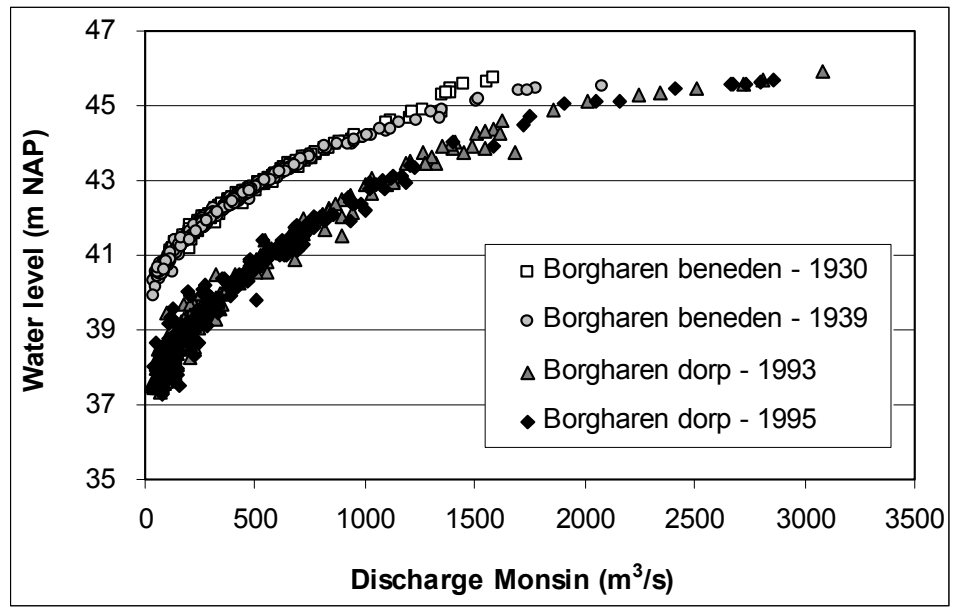

a)

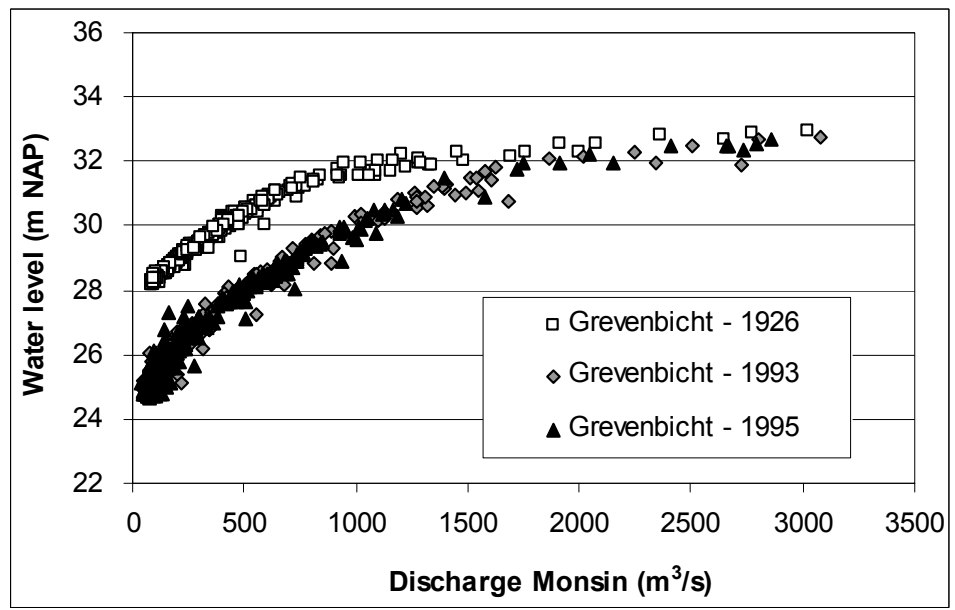

b)

Figure 3.11: Indication of the stage discharge relation at the Grensmaas locations a) Borg-haren and b) Grevenbicht at the beginning and end of $20^{\text {th }}$ century. The relations are derived by correlating the original water level data from the respective locations with the discharge data at Monsin. After (RWS, 2003).

\subsubsection{An increased vulnerability}

A third way to approach the flood problem is to stress that the vulnerability for flooding has increased. In this line of reasoning, flooding is considered a natural phenomenon, which can only partly be controlled. The real problem is the presence of socio-economic capital in the river's floodplain, adding to the potential damage inflicted in the case of flooding. 
Indeed, the damage potential has clearly increased over the past century. Especially since the 1970s, the Meuse valley has become increasingly densely populated (Van de Ven, 1996). Cities and villages have expanded, whereby also in the lower floodplain areas houses have been built. Significant investments were made in agricultural equipment and farms, the construction of several greenhouse complexes, the development of industries, and land and river based infrastructure. It appears that flood risk has been largely ignored in deciding on these investments. In the investigation that followed the 1993 flood (WL, 1994a), it was argued that the aspect of flood risk had been largely neglected in spatial planning regulations, and that the damage of the 1993 flood could have been significantly reduced when the aspect of flood risk would have been better taken into account in spatial planning.

However, although the damage potential has been clearly on the rise, this does not necessarily mean that vulnerability has increased. In their account of the historical floods along the Meuse, (Trompetter \& Kuijper, 1995) give an impression of the impact of the 1926 flood. At that time, families spent hours in fear on the roofs of their houses before being rescued. 14.000 people were evacuated and cattle occasionally drowned. Trains were disrupted, gas and electricity was shut down, and phone lines were blocked. There was no guarantee that flood damage could be reclaimed with the government (such as in '93 and '95); one depended on charity for compensation. It thus appears that the overall societal disruption and non-monetary costs were probably larger than they would be today.

So, can the flood problem be legitimately attributed to an increased vulnerability? The answer is 'yes' and 'no'. On the one hand, economic and private property has increased along the Meuse, leading to higher monetary damage in case of floods. On the other hand, improved flood warning, better emergency management, better insurance, and the overall richness of people today are reasons for a reduced vulnerability towards floods. Given this ambiguity, the question whether vulnerability has increased is of lesser relevance. The more important question is which level of acceptance one would hold towards flooding, and to what extent one can be prepared for a flood if it occurs.

\subsection{HOW TO SOLVE THE PROBLEM?}

In line with the three problem perceptions described above, one can distinguish three different types of river management approaches: retention measures upstream (as a way to regulate discharge), river engineering (as a way to increase discharge capacity), and river adaptation (as a way to reduce vulnerability). In the following, each approach is further described.

\subsubsection{Upstream retention}

As a first management approach, we discuss retention measures that may be applied in the upstream part of the river catchment in order to decrease the variability of the discharge pattern. A retention measure typically slows the water flow down somewhere along the hydrological chain between rain-fall and river runoff. From a technical point of view, these measures may be aimed at increasing the infiltration of water in the soil, increasing the use of storage capacity in the soil, and retention of water flow in the drainage system. 
There are a large number of potential measures for upstream water retention. Without aiming to be comprehensive, possible measures are:

- Land use change: For example, an increase in natural forests to the cost of agricultural or urban land may be pursued to increase the water retention capacity of the catchment area $^{32}$ (De Wit, 2001).

- $\quad$ Reducing drainage: Reducing drainage for agriculture and forestry may lead to a significant increase in summer discharge and a decrease in winter discharge (De Wit, 2001). A further way to reduce is drainage is to decouple sewage systems of cities from precipitation (WHM, 2002).

- $\quad$ Constructing artificial water reservoirs: These may range from small-scale rainwater buffers (WHM, 2002) to large-scale lakes in de Ardennes.

Natural restoration forms a special class of measures aimed at increasing natural retention. A number of measures can be proposed (Stroming, 2004), including the conversion of farmland and drained pine forest into foliage forest, restoring natural wetland areas on the high plateaux of the Ardennes, and the natural restoration of streams, small rivers and river floodplains from the upper to the lower river valleys. As described before (Section 3.3.1), the effect of these measures on the discharge pattern of the Meuse remains to a large extent unclear. On the one hand, landscape ecologists (Stroming, 2004) argue that more natural retention in the Ardennes contributes to a reduction of drought, and especially flood problems. By a rough investigation of water flows through the catchment area during the build up of peak flows, the maximum reduction of peak discharges is estimated at some $500 \mathrm{~m}^{3} / \mathrm{s}$ for a typical peak discharge of 3000 $\mathrm{m}^{3} / \mathrm{s}$. On the other hand, hydrologists like Van Deursen et al. (2002) do not support this view on the basis of their model results, and stress the limited effect of land use change on the discharge regimes.

\subsubsection{River engineering}

As a second river management approach, we look into river engineering measures along the Limburg Meuse. River engineering is aimed at increasing the discharge capacity to reduce flooding, and regulating the water depth for the benefit of shipping or groundwater. Typical river engineering measures are river widening to reduce the water level during peak discharges, dike-building to protect flood prone areas, constructing sluices and dams to regulate the water level, and appointing retention areas along the river to reduce the peak flow of a passing flood wave.

\section{River widening}

River widening basically implies changing the geometry of the riverbed in order to increase its discharge capacity. We distinguish a number of different ways for doing say, each with its own characteristics and effects (see e.g. Maaswerken, 1999a, p. 55):

\footnotetext{
${ }^{32}$ Although this may equally lead to an increase in drought, as a result of increased evapotranspiration.
} 
- Main channel deepening: This is the most efficient measure to lower the water level: a specific water level decrease is obtained with minimal excavation. Since the extracted material is largely marketable this option is also relatively profitable. A disadvantage of main channel deepening is a reduction in water level during low flows, with a negative effect on the groundwater level. Furthermore, main channel deepening may uncover fine sediments that will easily erode, causing negative and uncontrollable morphological effects.

- Main channel broadening: This measure is less efficient than deepening: excavation is roughly $35 \%$ higher to achieve the same water level decrease. Broadening is also less profitable, since it involves the extraction of a top layer of not marketable and is partly polluted clay. Finally, broadening requires land, which generally is generally in agricultural use. The broadened river sections do have a potential for nature development and form an essential part of natural river restoration.

- Floodplain measures: Floodplain measures include a variety of excavation measures in the river's floodplain, such as floodplain lowering, high water channels, side channels, eroding river banks, and natural river banks, as described in (Maaswerken, 1999a, p. 72). The efficiency and profitability of these measures for water level decrease is generally lower compared to main channel deepening and broadening. Moreover, floodplain measures require relatively much land. The great benefit of floodplain measures lies in its potential for nature development and natural river restoration.

- Clay storage: Clay storage is not a river widening measure as such, but may form an important part of a river widening strategy along the Meuse. Extracted clay from main channel broadening or floodplain measures is stored in so-called 'clay shields' in the floodplain area. The benefits of clay storage are threefold: firstly it is a cheap solution for handling the large volume of strongly polluted river clay, secondly it allows more and efficient gravel extraction, and finally a clay shield restrains water drainage and thereby mitigates a potential drop in groundwater table.

\section{Dike-building}

Dike-building is a very effective way to protect areas from inundation. Dikes can be constructed as high dikes along the main river channel to protect all low lying areas of the Meuse valley, or as local embankments (in Dutch: 'kades') to protect only the most valuable regions. Although dikes can provide effective flood protection, a number of negative effects must be taken into account. Embankments are relatively cheap (compared to river widening), but do not allow for additional profits to weigh against the costs. In particular the higher and heavier embankments can compromise the openness of the landscape. In many cases additional measures have to be taken to prevent seepage through the sand /gravel subsoil. Paradoxically, the construction of embankments can lead to a lower safety level: the probability of inundation of the embanked area is small, but when the river water level rises above the height of the embankment, the area may inundate quickly and damages may be high.

\section{Sluices and dams}

The river water level can be controlled through the construction of sluices and dams. This measure is typically taken to increase navigation depth. Also, this measure is often taken to mitigate water level lowering effect of river widening to avoiding a structural decrease of the groundwater level in the areas alongside the river. 


\section{Retention areas}

A retention area is an area that may be used to temporarily store water during high water flow, which serves to reduce the peak discharge downstream. The effectiveness of the retention areas along the Maas in Limburg is moderate. The planned retention areas near the municipalities of Heel and Haelen, for example, will reduce the water level by approximately $10 \mathrm{~cm}$ over a given river stretch ${ }^{33}$. Furthermore, the effectiveness depends on the right timing of water inflow. When water is let in too soon or too late, the main peak discharge will remain unaffected. Given the limited certainty in precipitation and flood forecasting, effective use of the retention capacity can thus not be guaranteed. Nonetheless, the retention area may just provide the difference between flooding or no flooding.

\subsubsection{River adaptation}

A third river management approach is referred to as 'river adaptation'. River adaptation basically refers to a modification of the human use of the river and its floodplains in order to reduce the vulnerability for floods. One can distinguish two categories of adaptation measures:

\section{Restricting human activity}

Restricting human activity in the floodplain area is an obvious way to reduce flood damage potential. Policy may be aimed at restricting further expansion of housing and businesses in the floodplain area. Going one step further, one may consider the relocation of valuable capital from the floodplain to higher areas. This is typically relevant for economically valuable functions, such as glasshouse horticulture, but may also apply to housing. Although in the Netherlands largescale relocation is currently not considered as a serious option, some small-scale examples of the relocation of glasshouse horticulture along the Meuse can be found (De Wit, 2008).

\section{Adaptation of river functions}

A different approach is to adapt human activity (i.e. the river functions) in the flood plain areas, so that they become less vulnerable to floods. Regarding housing, one can think of choosing proper building materials, or by moving valuable assets to a high floor level. Furthermore, the option of floating houses is currently investigated. Regarding agriculture, one can think of choosing different crops. Also emergency preparedness, for example by ensuring proper evacuation routes and establishing good flood warning system, is a way to become less vulnerable to floods.

\subsection{RIVER MANAGEMENT IN PERSPECTIVE}

In the previous sections, possible problem perceptions and river management approaches were discussed. For synthesis, the conceptual model of Pressure, State, Impact and Response is applied to gain better insight in the relation between various developments over the longer term, and to further evaluate the various river management approaches.

\footnotetext{
${ }^{33}$ see www.maaswerken.nl (Encyclopedie) accessed July 2009
} 


\subsubsection{Pressure, State, Impact, and Response}

The conceptual model of Figure 3.12 frames and summarizes the most relevant issues and developments in relation to the management of the river Meuse in Limburg, as previously discussed. It is structured along the well-known concept of Pressure - State - Impact - Response described in Chapter 2. This model implementation explicitly relates to the local perspective of the Limburg Meuse within the wider context of its catchment area.

The pressures on the river system are twofold. On the one hand, there are the environmental pressures. These include developments like climate change, land use change, canalization, and pollution that affect the discharge pattern and water quality along the Limburg Meuse. From the perspective of the Limburg Meuse, these pressures are considered 'external'. Although discharge and water quality are influenced from within the Limburg area as well, its main determinants lie outside the area on the river basin scale. On the other hand, we distinguish socio-economic pressures. These refer basically to the increased usage of the Limburg Meuse for housing, agriculture, shipping, tourism, industry and other functions. All uses add up to an increasing spatial pressure and water demand. For the latter, we distinguish between consumptive demands - e.g. for drinking water and irrigation - and in-stream demands - e.g. for nature and shipping. From the perspective of the Limburg Meuse, the socio-economic pressures are considered 'internal'.

The state describes the main environmental stocks of the river system: water and land. The water state includes various aspects. It includes the quantity of river water - in terms of its discharge pattern, associated water levels, and flow velocities - as well as its quality. Also, it includes quantity and quality of groundwater in the river's sphere of influence. The land state broadly refers to the state of the river channel and floodplain area. First, it is characterized by the channel geometry ${ }^{34}$ and the floodplain elevation, which are main determinants of the river's hydraulic characteristics. Second, it involves its land use that primarily defines its socio-economic value and potential damage, and influences the hydraulic characteristics as well. Finally, it involves the composition of soil, where - in our specific case - the presence of profitable gravel and polluted clay are important variables.

The impacts generally refer to the extent to which the various river functions are satisfactorily fulfilled. As a first aspect, we consider the extent to which floods, droughts and pollution cause damages for the river function of concern. This might involve, for example, damage to housing as a result of flooding, damage to the shipping sector as a result of prolonged period of drought, or damage to nature as a result of pollution. A second aspect considered is the scarcity of space. Space is obviously a bounded resource; clear trade-offs exist between the use of space for one purpose (e.g. housing) or another (e.g. agriculture), or for the common good (e.g. space for water). Scarcity of space then refers to a mismatch between a spatial demand for a giver river function, and the actual allocation of space for that function. As a third aspect we consider what might be referred to as 'landscape design'. This includes, for example, landscape openness and various cultural, geological and historical values along the Limburg Meuse. These aspects constitute important values which may be directly affected by river management.

\footnotetext{
${ }^{34}$ Also existing river infrastructure likes sluices and dikes that are used to direct river flow are considered to be part of the channel geometry.
} 


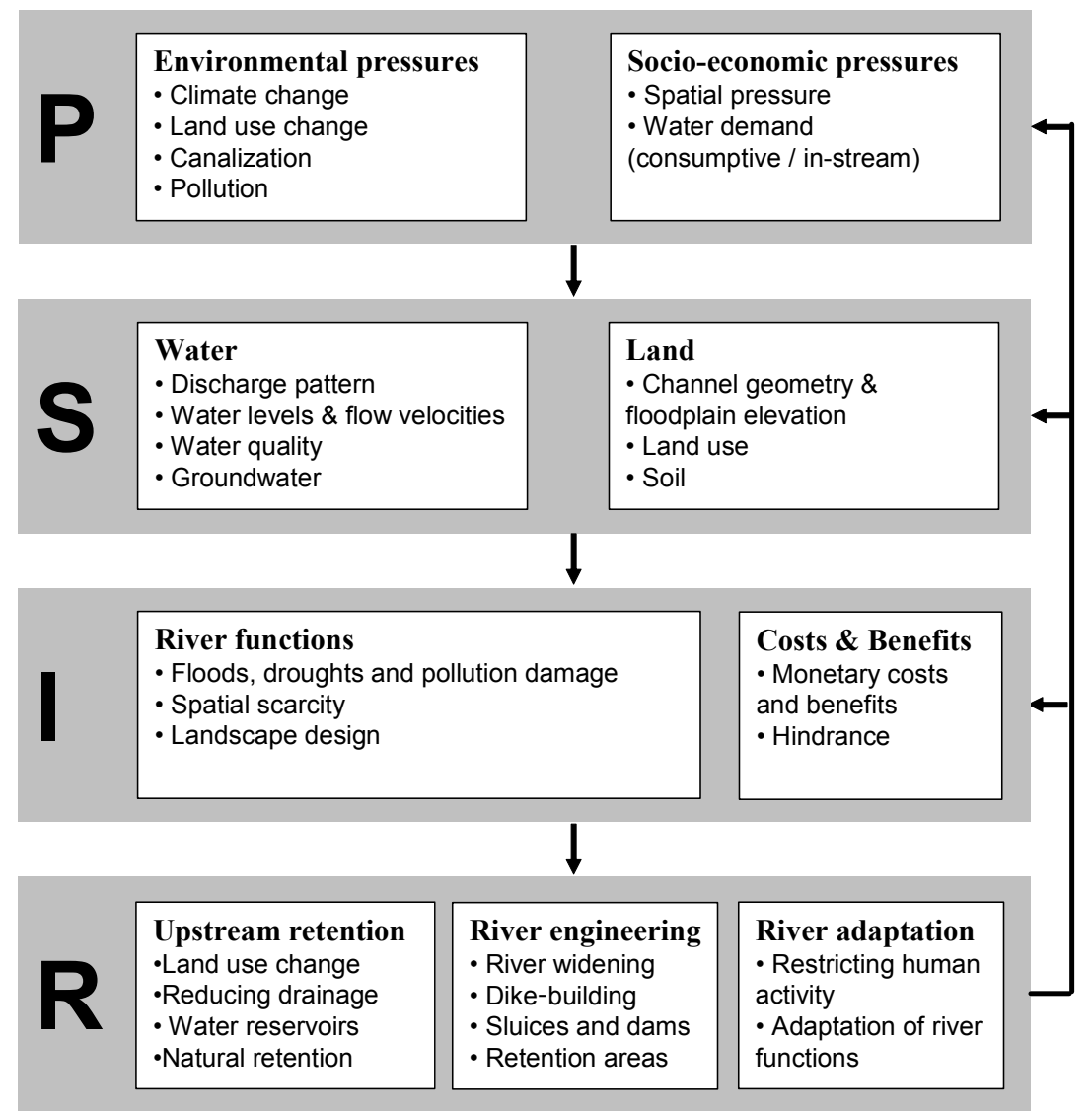

Figure 3.12: A Pressure-State-Impact-Response (PSIR) conceptual model for the Meuse in Limburg. Adapted from (Hoekstra, 1998).

The response box, finally, includes the three river management approaches described in Section 3.4: We distinguish upstream retention (including natural retention and water reservoirs), river engineering (including river widening, dike-building, sluices and dams, and retention areas) and river adaptation (including restricting human activity and river function adaptation). Note that the PSIR model explicitly represents the costs and benefits of the various response options as part of the impacts. The cost and benefits refer to any temporary effect, positively evaluated (benefit) or negatively evaluated (cost), in monetary (e.g. gravel benefits) or non-monetary (e.g. hindrance) terms.

\subsubsection{Problem perceptions revisited}

The PSIR model can be used to illustrate the various problem perceptions described in Section 3.3. The changing discharge pattern, for example, is interpreted as a direct influence of the environmental pressures on the water state. Developments like climate change, land use 
change, and canalisation may have modified the discharge pattern, which in turn relates to all other variables considered in the water state. We have concluded that it is likely that the peak flow probability has moderately increased over the past decades, as the combined result of climate change, urbanisation, and canalisation. Moreover, it is likely that - notably under influence of climate change - the discharge pattern will change further in the years to come. The direction of change, however, remains uncertain. In particular, it is unclear to which extent climate change will cause extreme situations of both drought and floods.

The changing discharge capacity is due to various developments that originate from the socioeconomic pressures. Notably, the spatial development of the floodplain area and the development of shipping (pressure) have led to the normalisation and canalization of the Meuse (response), which caused drastic changes of channel geometry (land state) and consequently strongly modified the stage-discharge relation (water state). Changes in water levels and flow velocities (water state) caused a natural morphological response, which -through floodplain sedimentation and main channel erosion - further modified the river bed (land state). Also, the increased human activity in the floodplain area (land state) - and the consequent construction of buildings and other objects - has obstructed water flow over the floodplain area (water state). The various developments have had opposite effects on the stage-discharge relation. The discharge capacity of the main channel has increased, while the discharge capacity over the floodplain area decreased. Consequently, the water level under conditions of low flow has strongly decreased, but during high flows the effects appear to roughly level out.

Changes in vulnerability, finally, are driven by the socio-economic pressures as well. Notably the increasing spatial pressure, through growing economic and private property in the floodplain area (state), has increased the damage potential in case of floods (impact). It was concluded that - in terms of monetary damage - vulnerability has clearly increased over the past century. However, considering non-monetary damages and overall societal disruption, it was argued that the vulnerability is currently much lower than a century ago.

\subsubsection{River management in perspective}

The PSIR model is useful tool to reflect further on the river management approaches previously discussed in Section 3.4. Here, we discuss their effectiveness and robustness. Effectiveness refers to the extent to which the approach in principle can effectively reduce flood risk. Robustness refers to the extent to which this reduction will be maintained under the ongoing development of the environmental and socio-economic pressures discussed.

The first approach, retention measures upstream, is primarily directed towards mitigating or reversing the environmental pressure of land use change. Being directed towards those pressures implies that the approach is inherently robust. It aims to the address the root of problem and its influence on the Limburg Meuse can be positive both in terms of floods and droughts. Regarding the flood problem, however, the effectiveness of such measures is debated. Hydrological studies have pointed out that even radical land use changes will only have a limited effect on peak flow probability. The potential effect of creating upstream retention is thus probably not sufficient to mitigate the effect of climate change on the discharge pattern of the Meuse.

The second approach, 'river engineering' is directed towards changing the land state. It notable includes river widening and dike-building as a way to reduce flood risk. Both approaches can be 
considered effective and can lead to significant reductions of flood probability. In terms of robustness, however, both approaches seem flawed, since they do not take ongoing pressures into account. The dike-building strategy is particularly vulnerable to climate change. If indeed peak flow levels increases, dike-building might turn out insufficient to protect against flooding, leading to enhanced risk of severe flood damage, due to the inundation of embanked areas and dike breach. The approach of river widening is less vulnerable to climate change. Also when peak discharges turn out higher than anticipated, the obtained water level reduction remains a positive effect (no-regret). However, in the face of climate change, currently pursued flood norms might no longer be fulfilled, and further widening might be required. Moreover, river widening seems particularly vulnerable to ongoing spatial pressure, as it contributes to the pressure on the already scarce amount of space. Particularly in the face of climate change, an increasing tension between space for water and space for socio-economic development might arise.

The third option, river adaptation, is directed towards the spatial pressure as part of the socioeconomic pressures. It considers the two sub-approaches 'restricting human activity' and 'river function adaptation'. Both sub-approaches are potentially effective for reducing flood risk by strongly reducing the damage potential in the floodplain area. Restricting human activity, however, seems less robust. Socio-economic pressure are not easily controlled, and increasing spatial pressure combined with policy for restricting human use in the floodplain area might lead to unacceptable scarcity of space on the longer term. River function adaptation is the only approach that scores well on both effectiveness and robustness. It is robust for a changing discharge by explicitly adapting to different possible discharge regimes. It is also robust for increasing socio-economic demands by aiming to incorporate spatial demands in the floodplain area in innovative ways.

\begin{tabular}{|l|l|l|}
\hline & Effectiveness & Robustness \\
\hline Upstream measures & Low & High \\
\hline River widening & Medium & Medium \\
\hline Dike-building & Medium & Low \\
\hline Restricting human activity & High & Low \\
\hline River function adaptation & High & High \\
\hline
\end{tabular}

Table 3.5: A qualitative assessment of the effectiveness and robustness of different river management approaches

\subsection{CONCLUSION}

In the introduction, the question was raised to what extent the river widening approach is indeed most suitable to address the problem at hand. To answer this question, this chapter evaluated a number of possible perceptions underlying the problem of floods (that it is a problem of discharge, discharge capacity, or vulnerability) and related river management approaches.

The problem perception of discharge can be considered partly valid. It seems likely that the peak flow probability has moderately increased over the past decades, and this increase is likely to 
continue over the years ahead. At the same time, the natural variability of the discharge pattern is so large that the uncertainty in the flood occurrence as such is probably of bigger concern than a possibly changing flood probability. The problem perception of discharge capacity was rejected. Over the past centuries, the modifications made to the riverbed have strongly changed the discharge capacity. However, a decreasing discharge capacity over the floodplains is compensated with an increasing discharge capacity through the main channel, which - for high discharges - roughly levels out. The problem perception of vulnerability was also considered partly valid. Economic and private property has increased along the Meuse, leading to higher monetary damage in case of floods. However, improved flood warning, better emergency management, better insurance, and the overall richness of people today are reasons for a reduced vulnerability towards floods. Given that none of the problem perceptions are fully valid, the real problem is probably best described as a decreasing flood acceptance, in combination with a likely increase of peak flow probability, and growing economic and private damage potential.

This problem perception allowed for further reflection on the suitability of the river widening approach. The river widening approach is an effective way for increasing the discharge capacity during peak flows, while maintaining the current discharge capacity for low flows. It is striking, however, that - apparently - it is not directed at the core of the problem, since the problem perception of discharge capacity was rejected. This implies that the river widening approach remains to some extent vulnerable towards ongoing pressures of climate change and socioeconomic development. Considering that river widening requires a considerable amount of space, the main risk would be that under a combination of climate change and ongoing spatial pressure, river widening would turn out to be a main competitor for space, contributing to problems of spatial scarcity. In that respect, the approach river function adaptation was highlighted as an effective approach which is inherently robust towards both climate change and spatial pressure. Therefore, river function adaptation is considered a promising approach, which deserves further attention.

Considering the general aims of this thesis, the analysis presented in this chapter poses some interesting questions. For example, what will be the impact of the currently pursued river widening approach under ongoing climate change and spatial pressure? And to what extent might possible negative impacts drive a transition towards one of the other river management approaches? To which extent might other problems (e.g. drought) become dominant concerns over time? These questions are guiding for the modelling work ahead. 
Chapter 4

THE MAASWERKEN PROJECT 


\begin{abstract}
This chapter zooms in on the planning process of the Maaswerken project, to gain a better understanding of stakeholder decision-making in river management. A historical analysis is presented of both the Grensmaas and Zandmaas/Maasroute projects, which - as it turns out - were strongly driven by unexpected events, changing insights, increasing stakeholder involvement, and financial constraints. A stakeholder analysis illustrates the 'playing field' of stakeholder perspectives (in terms of goals and beliefs), describes some examples of perspective change, and highlights stakeholder dynamics (in terms of conflict, cooperation and coalition forming) observed. Moreover, a short analysis of the more strategic long term study Integral Exploration of the Meuse signals new goals (e.g. spatial quality), new perspectives (e.g. based on flood adaptation rather than flood protection) and additional stakeholder dynamics (e.g. conflict between the national government and regional parties) that may possibly play an role in the future management of the River Meuse. Concluding, it is argued that the complex and dynamic nature of river management requires a flexible planning approach in which uncertainties and the possibility of changing boundary conditions are explicitly taken into account.
\end{abstract}




\section{The Maaswerken project}

\subsection{INTRODUCTION}

Dutch water management is renowned for its successful 'struggle' against the water over the past centuries. Through polders and dikes, land was gained, protected and maintained from the water. Over the past decades, however, there has been an increasing awareness of the unsustainability of this approach. Increasing environmental concerns, awareness about soil subsidence and climate change, and a number of flood and pollution calamities have all contributed to a shift in the Dutch water management style (Rotmans, 2003; Van der Brugge et al., 2005). In terms of content, this new water management style is focussed on 'accommodating water' and giving 'room for water', rather than the traditional 'fighting the water' approach. It calls for improved water retention (i.e. through natural retention or artificial retention areas), the increase of the discharge capacity of rivers, and a strict consideration of water management aspects in spatial planning, and the multiple use of space (e.g. for water storage, nature and recreation) (CWB21, 2000). In terms of process, the new management style calls for a more society based decision-making process, based on stakeholder participation, the consideration of multiple perspectives, and preventive actions.

The support for the new management style is overwhelming. It is reflected in numerous national policy documents covering the domains of spatial planning (e.g. the $5^{\text {th }}$ memorandum on Spatial development (VROM, 2001)), water management (e.g. the 4th memorandum on Water management' (V\&W, 1998)), and in particular river management (e.g. the 'Delta plan Main Rivers' (V\&W, 1995) and the policy line 'Room for the River' (VROM \& V\&W, 1997)). Moreover, it is in line with European water management policy, formulated in the EU Water Framework Directive of 2000 and recently the EU Flood Directive of 2007 that typically calls for improving the ecological status of water bodies, river basin management, stakeholder participation and increased flood awareness. Finally, it is in line with recent efforts to better coordinate internationally the management of the Meuse (WHM, 2002) through the International Commission for the Meuse ${ }^{35}$.

The Maaswerken project can be regarded one of the first large-scale implementations of this new water management style in the Netherlands. The Maaswerken project - comprising two main subprojects Grensmaas and Zandmaas/Maasroute - aims to reduce flood risk, to develop new nature areas, to improve the shipping route, and to extract significant quantities of gravel for national use, but also to cover project costs. Its starting points - as formulated at its official initiation by the national government and the Province of Limburg in 1997 (V\&W, 1997) - were to fulfil these ambitions through a river widening and natural river restoration approach. Stakeholder participation was considered essential to develop an integrated strategy and a broad societal support.

Despite the apparent support for the new management style, the implementation of the Maaswerken project was not without problems. As described in Section 2 of this chapter, the planning processes of both the Grensmaas and Zandmaas/Maasroute projects turned out to be

\footnotetext{
${ }^{35}$ See www.cipm-icbm.be accessed April 2009.
} 
long and complex. Both planning processes were highly dynamic and changeable, and seemed to suffer from a 'lack of convergence' over time ${ }^{36}$. Also the final outcomes of the planning process were disputed. The final Grensmaas plan was subject to strong critique by regional parties for excessive gravel extraction, which was necessary to make the project financially feasible. In the Zandmaas project, the focus of the project shifted towards dike reinforcement, with river widening measures postponed, causing strong disappointment with nature organisations, citizens, provinces, and municipalities involved.

In this chapter we try to analyse why this was the case. We present a historical analysis of the Maaswerken project, highlighting developments and events that were of main influence for its course. Then - reporting on the results of a stakeholder analysis - we zoom in on the perspectives of the stakeholders involved. What were their goals, how did they perceive the uncertainties involved, which type of river management measures did they support, and how (if at all) did their perspectives change over time? We try to assess stakeholder influence on the planning process, and highlight some of the cases of conflict, cooperation and coalition forming that have taken place. Finally, a short analysis of a 'follow-up' strategic river management project 'Integral Exploration of the Meuse' ${ }^{37}$ is included to gain additional insight in possible perspective changes and stakeholder dynamics on the longer term.

\subsection{HISTORICAL ANALYSIS}

In this section we present a short historical analysis of the Maaswerken project, focussing specifically on the two subprojects Grensmaas and Zandmaas/Maasroute. The analysis covers the time period $1990-2003$, which is referred to as the 'planning period ${ }^{38}$. During this period, a number of consecutive river management strategies (or 'river management alternatives') were formulated. The historical analysis attempts to put the development of those strategies in a time perspective. The analysis is based on a literature review, including project documents, newspaper articles, and various other sources.

Although both subprojects followed relatively separated trajectories, their development illustrated in Figure 4.1 - shows a strong analogy. Both projects started around 1990 with relatively little complexity. The Grensmaas project was about nature development and gravel extraction, leading to the so-called river management strategy Green for Gravel of 1991. The Zandmaas/Maasroute project concerned only shipping; the main subject of the planning study 'Modernising Meuse Route' (MoMaRo) of 1990. After the floods of 1993 and 1995, and the initiation of the project organisation Maaswerken in 1997, both projects developed into integrated, complex projects with numerous stakeholders and objectives involved. Both projects achieved a successful cooperation with the stakeholders involved, receiving broad stakeholder support for the so-called Preferred Alternatives of 1998 (Grensmaas) and the Combination Alternative of 1999 (Zandmaas/Maasroute). However, after these successful periods, both

\footnotetext{
${ }^{36}$ A remark of the Grensmaas project manager during an informal discussion.

${ }^{37}$ In Dutch: Integrale Verkenningen Maas

${ }^{38}$ Although the Maaswerken project was officially initiated only in 1997, it builds upon previous studies from the early 1990s. In this thesis, the entire period 1990 - 2003 is referred to as the planning period of the Maaswerken project.
} 
projects (for different reasons) experienced crises during which stakeholder support to a large extent collapsed. These periods correspond to the Reference Alternative of 2001 (Grensmaas) and the 'changing insights' (Zandmaas/Maasroute) in Figure 4.1. These periods of crisis were overcome through rather pragmatic approaches and compromising, reflected in the Preferred Alternative of 2003 (Grensmaas) and the Plan Meuse Valley of 2001 (Zandmaas/Maasroute).

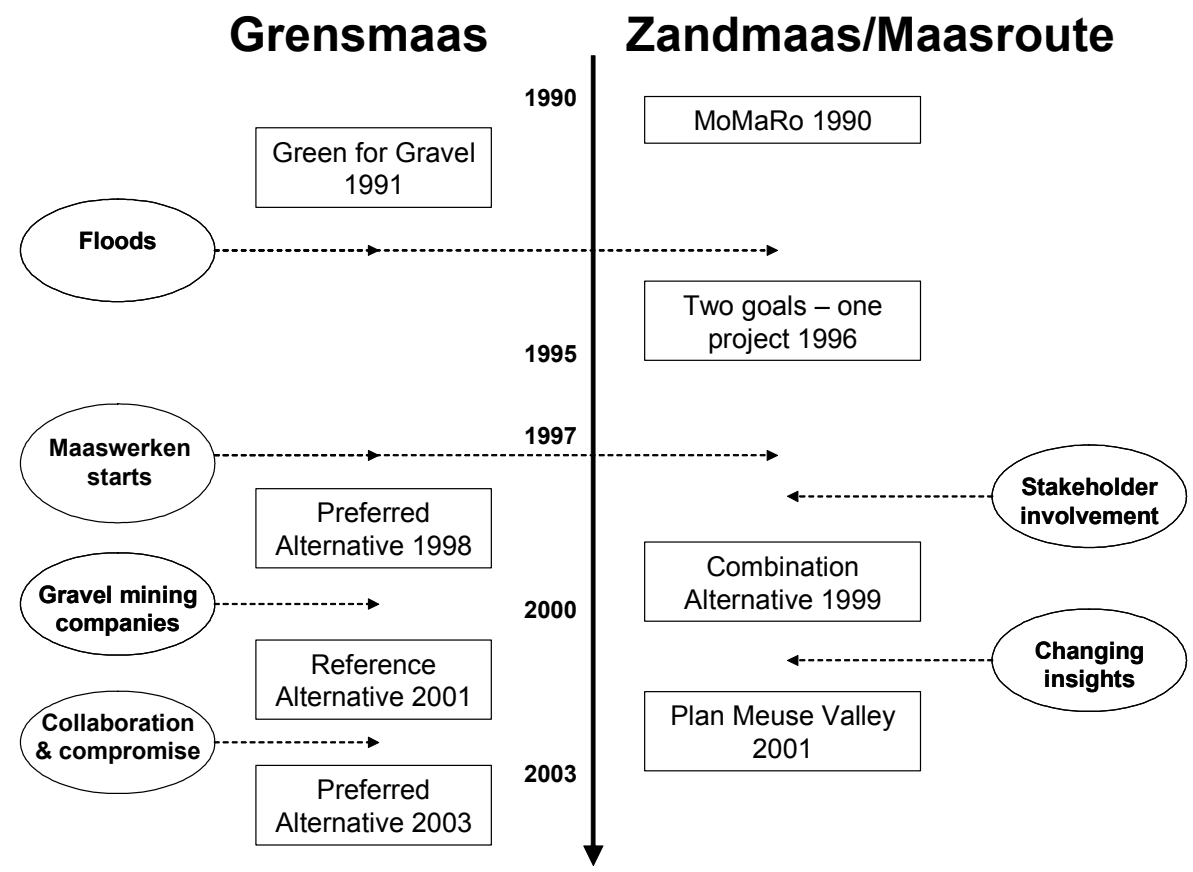

Figure 4.1: Schematic overview of the development of the Maaswerken project from $1990-2003$. The boxes indicate the consecutive river management strategies proposed. The circles indicate the main events or developments that caused the project to change. See also Tables 4.1 and 4.2.

The trajectories of both projects were influenced by various events, changing insights, and increasing stakeholder involvement. Two main aspects of specific relevance to both projects are highlighted here. The first aspect concerns the floods of 1993 and 1995, after which - in both projects - flood protection became a dominant concern. After the floods, the national government quickly responded with the Delta plan Main Rivers (V\&W, 1995). The Delta plan provided for the immediate construction of embankments to achieve a minimal safety level of 1:50 yrs. These works were quickly performed and finished within the year at several locations alongside the Meuse. Moreover, it proposed the accelerated implementation of the river widening strategies proposed by the commission Boertien (WL, 1994a) to achieve a safety level of $1: 250$ yrs by 2005 .

The second aspect concerns the initiation of the Maaswerken project organisation in 1997. Following the increasing number of objectives (i.e. flood protection, nature development, shipping, gravel extraction) and increasing project scale and complexity, the Maaswerken organisation was set up. Their main task was to manage the various ongoing river management projects in an integrated way, and to engage with the various stakeholders involved to achieve 
broad societal support. The initiation of the Maaswerken can thus be considered a marker of the new water management style - from 'sectoral' and 'government centred' to 'integrated' and 'participatory' - with significant implications for the development of both the Grensmaas and the Zandmaas/Maasroute projects.

In the following, the development of both subprojects Grensmaas and Zandmaas/Maasroute are described in more detail:

\subsubsection{Grensmaas}

The Grensmaas project has its origins in the advisory study 'Toekomst voor een grindrivier' (future of a gravel river) of 1991 (Stroming, 1991). In this study, the possibilities are investigated to combine gravel extraction with nature development in the river Grensmaas. This combination was sought, on the one hand, to comply with the national policy for ecological recovery in the Meuse valley, and on the other hand to fulfil an obligation of the Province of Limburg to extract 35 million tons of gravel for national use. To this end, the nature and landscape development consultancy firm Stroming (1991) developed an innovative concept later referred to as Green for Gravel: riverbed widening in combination with ecological rehabilitation as an ideal solution for reaching both the ecological and economic objectives. Concretely, the concept contains the following elements: 1) river bed widening through floodplain excavation and main channel broadening, 2) storage of extracted top layer of river clay in so-called 'clay storage areas' in the floodplain, and 3) elevation of the main channel bed (optional) through restoring a fraction of the extracted gravel in the main riverbed.

After the floods of 1993 and 1995, the aspect of flood protection came strongly into play. Besides the immediate construction of embankments, the Delta plan Main Rivers proposed the accelerated implementation of river widening, following the so-called strategy $2 \mathrm{~B}$ of the commission Boertien (WL, 1994a). This strategy was similar to the original Green for Gravel concept of Stroming (1991), albeit excluding the option of main channel elevation to ensure the flood standard to be reached.

After the initiation of the Maaswerken project organisation in 1997, it took roughly one year before the first detailed river engineering plan was published: the Preferred Alternative of 1998 (Maaswerken, 1998a). With this plan, the original Green for Gravel concept was further adapted. Notably, the area of floodplain excavation was significantly smaller, which was compensated by additional nature area outside the excavated floodplain. The Preferred Alternative was subject to stakeholder participation in the summer of 1998 (Maaswerken, 1999d). Some stakeholders expressed their worries - for example citizen groups that feared serious noise as a result of the excavation works and farmers who objected to the loss of agricultural land. But overall, the Maaswerken organization concluded that 'the majority of stakeholders agree with the underlying objectives and the approach of river widening' (Maaswerken, 1999d), implying that the Preferred Alternative 1998 received considerable support among the stakeholders involved.

This successful phase of the planning process ended in 1999, when the Maaswerken started the negotiations with the gravel-extracting companies for the execution of the proposed river engineering works. The gravel extraction companies hold a powerful position, since they own the land and are therefore entitled to perform the works. Unfortunately, they found the proposed works not sufficiently profitable and required more gravel to be extracted. After cumbersome negotiations, an intermediate agreement was reached in the beginning of 2001 
between the Province of Limburg, the national government, and the gravel extracting companies: the so-called Reference Alternative (e.g. see Adams, 2001a). With a total extraction of some 70 million tons of gravel $(20$ million tons more than proposed in the Preferred Alternative of 1998, and the double amount compared to the original Green for Gravel plan) it seemed that the gravel extractors would get what they required. However, because of the expected noise pollution and damage to the landscape and the natural environment as a result of the additional gravel extraction, this agreement led to such a strong opposition from nature organizations, inhabitants, farmers, and governmental parties that is was abandoned in June 2001 (De Waal-Malefijt, 2002).

Quickly thereafter, the Province of Limburg took the initiative to bring all parties together in an ultimate effort to design a broadly accepted plan. In only a few months, a new river management strategy was designed in close collaboration with all parties involved (De WaalMalefijt, 2002). Eventually, it led to the Preferred Alternative of 2003 (Maaswerken, 2003a): a compromise in which both the objectives of the Preferred Alternative of 1998, and the objective of profitability were sufficiently met. This was achieved, amongst others, by increasing the volume of gravel extraction from clay shield construction, allowing the surface of the clay shield to be 2-3 meters below the original surface level, and decreasing the area of floodplain excavation. In this way the same amount of gravel could be extracted in a more profitable fashion with lesser amounts of the by-products clay and sand.

From the description above, we distinguish four phases presented in Table 4.1. The first phase of the project (before 1991) was characterized by a combination of ecological goals and the economic goal of gravel extraction (a so-called win/win situation). The most influential parties were the Province of Limburg and the nature and landscape development consultancy firm Stroming (included as a 'nature organisation' in Table 4.1). After the publication of the initial report, a broader societal engagement was initiated, entering a second phase (1992-1998). This phase wat dominated by the occurrence of floods in 1994 and 1995, with flood mitigation turning into a primary objective. The planning process became more integrative in character and included more stakeholders, in particular citizens and farmer associations, and the national government as the primary responsible for flood prevention. The third phase (1999-2001) refers to the phase of negotiation between the national government and Province of Limburg on the one hand, and the gravel extracting companies on the other, in which the objective of profitability came stronger to the fore. The fourth phase (2001-2003), finally, was characterized by strong collaboration and compromise, under the guidance of the Province of Limburg. The four phases are represented by different policy outcomes in the form of proposed river management strategies. These are the original Green for Gravel plan of 1991 (Stroming, 1991), the Preferred Alternative of 1998 (Maaswerken, 1998a), the Reference Alternative of $2001^{39}$, and finally the Preferred Alternative of 2003 (Maaswerken, 2003a).

\footnotetext{
${ }^{39}$ Since this strategy was not officially published, a precise description was not available for this study.
} 


\begin{tabular}{|c|c|c|c|}
\hline & Main stakeholders & Main goals & Policy outcome \\
\hline 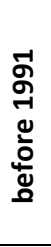 & $\begin{array}{l}\text { - Province of Limburg } \\
\text { - Nature organizations }\end{array}$ & $\begin{array}{l}\text { - Nature development } \\
\text { - Gravel extraction }\end{array}$ & $\begin{array}{l}\text { Green for Gravel } 1991 \\
\text { - Main channel broadening } \\
\text { - Floodplain excavation } \\
\text { - Clay shield construction } \\
\text { - Main channel elevation }\end{array}$ \\
\hline 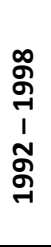 & $\begin{array}{l}\text { - Province of Limburg } \\
\text { - National government } \\
\text { - Nature organizations } \\
\text { - Citizen groups } \\
\text { - Farmer associations }\end{array}$ & $\begin{array}{l}\text { - Flood protection } \\
\text { - Nature development } \\
\text { - Gravel extraction }\end{array}$ & $\begin{array}{l}\text { Preferred Alternative } 1998 \\
\text { - Main channel broadening } \\
\text { - Floodplain excavation } \\
\text { - Clay shield construction } \\
\text { - Additional nature area }\end{array}$ \\
\hline 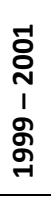 & $\begin{array}{l}\text { - Province of Limburg } \\
\text { - National government } \\
\text { - Gravel extractors }\end{array}$ & $\begin{array}{l}\text { - Flood protection } \\
\text { - Nature development } \\
\text { - Gravel extraction } \\
\text { - Profitability }\end{array}$ & $\begin{array}{l}\text { Reference Alternative } 2001 \\
\text { - Additional gravel extraction }\end{array}$ \\
\hline $\begin{array}{l}\text { m } \\
\text { ㅇ } \\
1 \\
\text { - } \\
\text { ㅇ }\end{array}$ & $\begin{array}{l}\text { - Province of Limburg } \\
\text { - National government } \\
\text { - Nature organizations } \\
\text { - Citizen groups } \\
\text { - Farmer associations } \\
\text { - Gravel extractors }\end{array}$ & $\begin{array}{l}\text { - Flood protection } \\
\text { - Nature development } \\
\text { - Gravel extraction } \\
\text { - Profitability }\end{array}$ & $\begin{array}{l}\text { Preferred Alternative } 2003 \\
\text { - Main channel broadening } \\
\text { - Floodplain excavation } \\
\text { - Clay shield construction } \\
\text { with lowered surface level } \\
\text { - Additional nature area }\end{array}$ \\
\hline
\end{tabular}

Table 4.1: A schematic overview of the development of the Grensmaas project from 1991 to 2003 . The table illustrates the development of the consecutive river management strategies as a consequence of growing stakeholder involvement and changing goals.

\subsubsection{Zandmaas/Maasroute}

The origin of the Zandmaas/Maasroute project lies in the planning study 'Modernising Meuse Route' (MoMaRo) of 1990. This study investigated the possibilities for improving the shipping route along the Meuse. These improvements were necessary to comply with the national traffic and mobility policy objective ${ }^{40}$ to shift the modus of the transport of goods from road to the more environmentally friendly modes of rail and navigation. The MoMaRo study developed a number of concrete proposals for improving river infrastructure (harbours, bridges, sluices) and investigated further improvements along the entire Meuse route (Maaswerken, 1999a).

\footnotetext{
${ }^{40}$ Formulated in the so-called 'Tweede Structuurschema Verkeer en Vervoer' of 1990.
} 
After the floods of 1993 and 1995, also in the Zandmaas, the aspect of flood mitigation came strongly into play. The Delta plan Main Rivers provided for the immediate construction of embankments and proposed a strategy of river bed deepening in combination with limited nature development' (WL, 1994a; V\&W, 1995). A few months later, the planning activities for flood protection and navigation were merged and in October 1995 the coordinating project Zandmaas/Maasroute officially started (Van Leussen, 2000). According to Van Leussen, the ambiguous objective of 'limited nature development' was 'a struggle' for the planners and engineers of Rijkswaterstaat. Although nature development is taken into account in the planning process, none of the nature development measures appear in the final river management plan. At that time (1996), the Zandmaas/Maasroute project can be characterized as 'two goals - one project': essentially a technical river engineering plan on the basis of the two main project goals safety and shipping (Van Leussen, 2000).

With the founding of the Maaswerken project organisation in 1997, the Zandmaas/Maasroute project entered a new phase. More actors became involved and the planning process became a much more participative and integrated task (Van Leussen, 2000). Following a broad consultation round with stakeholders on three preliminary river management alternatives (the 'Meuse Variants' (Maaswerken, 1997a)) and the development of a spatial vision on the Meuse valley (Maaswerken, 1998c), the Maaswerken project organisation set out to combine the various interests and concerns in an integrated plan. This so-called Combination Alternative was published in 1999. It combined river bed deepening - as the primary measure to reduce flood risk - with a significant amount of nature development measures as a way to achieve both a safe and yet attractive river management alternative. Also, it explicitly aimed for locally adapted solutions by connecting to ongoing local initiatives of private parties and municipalities. Despite some remaining scepticism regarding the actual implementation of the nature development measures, this alternative was well supported by the various stakeholders involved (Van Leussen, 2000).

Unfortunately, shortly after the publication of the Combination Alternative new insights came to the fore that largely removed the foundations upon which the assessment was based. First, a supervising body ${ }^{41}$ required a hydraulic recalculation with the state-of-the-art $2 \mathrm{D}$ model WAQUA replacing the original 1D model ZWENDL, in particular to assess possible water level increases due to the embankments built in 1995. The recalculations showed that - overall - the water level decrease of the Combination Alternative was less than previously thought. Second, a new design discharge had been imposed as part of the regular five-year update. The flood wave that had to be accommodated in the river was of much longer duration than the previous one. Under these new conditions, the Maaswerken team realized that an average of 6 meter deepening would be required to meet the flood mitigation objective, instead of the average of 3 meter originally thought! Third, to make things even worse, further morphological research indicated a high risk of morphological instability, due to the presence of fine sands. These new insights and ongoing uncertainties led the Zandmaas/Maasroute project into a period of crisis (Van Leussen, 2000). A period of reflection was decided to revaluate the direction the project should go.

During the course of 2000 and 2001 a new approach was formulated: the Plan Meuse valley (Maaswerken, 2001a). The pragmatic starting point was that the main project goal of safety

\footnotetext{
${ }^{41}$ the so-called 'Commissie MER'
} 
should be achieved within the given time and budget constraints. The planning process thus far had shown that these goals simply could not be met through a river widening approach. Therefore, in contrast to the original idea, the construction and heightening of embankments became the new 'pillar' under the Zandmaas/Maasroute plan (Maaswerken, 2001a). In practice, the Plan Meuse valley identified two packages of measures. Package 1 - with an allocated budget of some $360 \mathrm{M} €$ - was centred around the construction and heightening of embankments to reach a safety level of $1: 250$ for $70-80 \%$ of the population living behind embankments before 2006, and for $92 \%$ of the population before 2015. Package 2 included most river widening and nature development measures to provide protection for the remaining $8 \%$. The actual implementation of package 2, however, could not be guaranteed. It remained to be decided whether the envisioned safety standard would be reached through the implementation of package 2, or through an additional heightening of the embankments in the final project stage (Maaswerken, 2001a).

The proposed plan was received with storm of criticism. Already in the build-up to the plan, the Province of Limburg had temporarily withdrawn from the project to express their dissatisfaction with the trimmed-down plan (Adams, 2001b). The local newspaper wrote that "Nature in the Zandmaas would be better off without the Zandmaas project" (Anonymous, 2001). Also in the participation procedure that followed (Maaswerken, 2001b), strong opposition came to the fore. Amongst others, citizens and provinces pointed out that this plan no longer complied with the Room for the River approach. Nature organisations collectively rejected the plan since it did not contribute to nature development in the Meuse valley at all. The municipality of Venlo criticized the fact that the plan did not take their initiative Maascorridor ${ }^{42}$ into account. Despite these criticisms, the final strategy presented in 2002 (Maaswerken, 2002a, 2002b) did not show major changes. Implementation could start, but the broad societal support sought throughout the project was no longer there.

We can thus distinguish four phases of the Zandmaas/Maasroute project, see Table 4.2. The first two phases of the project (1990-1993 and 1993-1996) were characterized by the main goals of shipping and - later - flood protection. The most influential party was clearly the national government. The decision to integrate the project in the Maaswerken brought in a third phase (1997-1999). This phase can be characterized as participative and integral, with multiple objectives and stakeholders involved. The fourth phase (2000-2002) was marked by the collapse of the 1999 plan - due to changing insights in the river system - and the dominance of the main project goal of safety under time and budget constraints. Throughout those phases, the policy outcome has developed from a strategy for improving river infrastructure (MoMaRo), to a strategy with additional main channel deepening (Two goals-one project), to a more integrated river widening strategy (Combination Alternative), towards a strategy with a much stronger focus on embankments (Plan Meuse valley).

\footnotetext{
${ }^{42}$ Maascorridor is a local initiative in the area of Venlo developing various small-scale river restoration and infrastructure projects for the benefit of safety, nature, and tourism, see http://www.maascorridor.nl/
} 


\begin{tabular}{|c|c|c|c|}
\hline & Main stakeholders & Main goals & Policy outcome \\
\hline 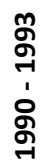 & - National government & - Shipping & $\begin{array}{l}\text { MoMaRo } \\
\text { - River infrastructure }\end{array}$ \\
\hline 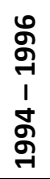 & - National government & $\begin{array}{l}\text { - Flood protection } \\
\text { - Shipping }\end{array}$ & $\begin{array}{l}\text { Two goals - one project } \\
\text { - Main channel deepening } \\
\text { - River infrastructure }\end{array}$ \\
\hline 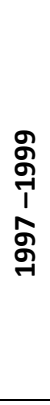 & $\begin{array}{l}\text { - National government } \\
\text { - Province of Limburg } \\
\text { - Other governments: } \\
\text { provinces, municipalities, } \\
\text { water boards } \\
\text { - NGOs: citizen groups, nature } \\
\text { organisations } \\
\text { - Farming associations, } \\
\text { businesses }\end{array}$ & $\begin{array}{l}\text { - Flood protection } \\
\text { - Shipping } \\
\text { - 'Limited' nature } \\
\text { development }\end{array}$ & $\begin{array}{l}\text { Combination Alternative } \\
1999 \\
\text { - Main channel deepening } \\
\text { - Floodplain excavation } \\
\text { - Natural areas/riverbanks } \\
\text { - Retention areas } \\
\text { - Waterlevel increase } \\
\text { - River infrastructure }\end{array}$ \\
\hline 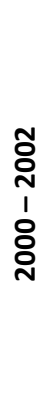 & $\begin{array}{l}\text { - National government } \\
\text { - Province of Limburg } \\
\text { - Other governments: } \\
\text { provinces, municipalities, } \\
\text { water boards } \\
\text { - NGOs: citizen groups, nature } \\
\text { organisations } \\
\text { - Farming associations, } \\
\text { businesses }\end{array}$ & $\begin{array}{l}\text { - Flood protection } \\
\text { - Shipping } \\
\text { - 'Limited' nature } \\
\text { development }\end{array}$ & $\begin{array}{l}\text { Plan Meuse valley } \\
\text { - Embankments } \\
\text { - Limited river widening } \\
\text { - Nature development } \\
\text { partly postponed } \\
\text { - Retention areas } \\
\text { - Water level increase } \\
\text { - River infrastructure }\end{array}$ \\
\hline
\end{tabular}

Table 4.2: A schematic overview of the development of the Zandmaas/Maasroute project from 1990 to 2002. The table illustrates the development of the consecutive river management strategies as a consequence of growing stakeholder involvement and changing goals. In particular towards the last phase, changing insights in the river system (not shown in the table) were crucial as well.

\subsection{STAKEHOLDER ANALYSIS}

The historical analysis illustrates how changing river management strategies are related to changing stakeholder involvement, changing goals, and - notably in the Zandmaas/Maasroute project - changing insights about the river system. To gain a deeper understanding of the role of stakeholders in the Maaswerken project, and to collect data for the modelling work ahead, a stakeholder analysis was carried out.

The stakeholder analysis is based first on semi-structured interviews carried out in the early stages of this research - in the fall of 2001 - with a selection of key stakeholders of the 
Maaswerken project (both Grensmaas and Zandmaas/Maasroute) (Valkering, 2005a). Eight stakeholder representatives were selected (see Appendix D) including representatives from three municipalities, the Province of Limburg, a farmer association, a nature organisation, and two citizen groups. They were selected on the basis of suggestions by our contacts at the Maaswerken project organisation, reports of previous stakeholder participation sessions, newspaper articles, and suggestions of stakeholder representatives already involved. Two main criteria applied: does the stakeholder have a high stake in the Maaswerken project, and is it considerably influential in the planning process. The set of stakeholders included in the interviews can be considered fairly representative for the main stakeholder playing field. The main absentees, however, were representatives of the gravel extracting companies and the national Ministry of Transport, Public Works and Water Management. The interviews aimed first to clarify stakeholder perspectives - in terms of their goals, beliefs (i.e. interpretation of uncertainty) and preferred river management options - and second to provide insight in the stakeholder dynamics in the planning process, in terms of the stakeholders' role and power, and the role of conflict, cooperation and coalition forming.

To broaden the knowledge base, this information was supplemented with a content analysis of the documentation of the various rounds of stakeholder participation carried out by the Maaswerken project organisation. These stakeholder participation rounds are part of the legal procedure of the planning process (see Box 4.1), allowing a large number of stakeholders to react to the proposed river management alternatives. For the Grensmaas project, stakeholder participation was organised after the proposal of the Preferred Alternative of 1998 (Maaswerken, 1999d) and the Preferred alternative of 2003 (Limburg, 2003). For the Zandmaas/Maasroute project, these took place after the presentation of Meuse Variants (Maaswerken, 1997b) and the Plan Meuse valley (Maaswerken, 2001b). These four reports contain a wealth of information on exactly which stakeholders were involved, their goals and concerns, their support for river engineering options, and - to a limited extent - how the uncertainties were perceived. These aspects were elicited from the summaries of the stakeholder reactions provided by the Maaswerken project organisation. Statements of stakeholders that reflected a goal, a belief, or a preference for a river engineering measure or approach were highlighted and counted to arrive at an indication of the perspectives of the various stakeholder groups. The material of the four stakeholder participation rounds was averaged, arriving at a broad inventory reflecting 'average' stakeholder perspectives for the period $1997-2003^{43}$.

\subsubsection{Stakeholders and stakeholder influence}

The stakeholders of the Maaswerken project fall into several categories. First, these are the responsible government organisations (the Ministry of Transport, Public Works and Water Management, the Ministry of Agriculture, Nature, and Food Quality, and the Province of Limburg) that have taken the initiative to set-up the Maaswerken project organisation and provide funding. The responsible governments have a decisive voice in the final approval of the

\footnotetext{
43 The content analysis thus did not aim at a comparative analysis of Grensmaas versus Zandmaas/Maasroute project, nor at a longitudinal analysis of the development of stakeholder perspectives over time.
} 
river management plans, with The Province of Limburg bearing the end-responsibility for the Grensmaas project, and the Ministry Transport, Public Works and Water Management bearing the end-responsibility for the Zandmaas/Maasroute project.

Besides these responsible governments, the Maaswerken project involved various other governmental groups (including several provinces, municipalities, water boards, and Belgian governments), non-governmental groups (NGOs, including citizen groups and nature organisations), and businesses (e.g. the shipping sector, farmers, the tourism and recreation branch, the gravel and sand mining industry, and drinking water supply sector). Each group generally refers to a number of individuals and organisations, which are to a large extent listed in Table 4.3. The stakeholder groups (from here on referred to as 'stakeholders') are generally represented in both the Grensmaas and Zandmaas/Maasroute projects, with two exceptions: the shipping sector (only involved in Zandmaas/Maasroute) and the Belgian governments (only involved in Grensmaas). The role of the Maaswerken project organisation is one of planner and mediator. It receives boundary conditions from the responsible governments, develops the river engineering plans, and communicates about these plans with the other stakeholders involved.

On a scale of 'information', 'consultation', and 'active involvement' (see Ridder et al., 2005), the level of stakeholder participation is best characterized as 'consultation'. Stakeholders are informed, for example through brochures, news letters, and public meetings. Moreover, stakeholders are consulted through the official public participation sessions, written reactions to the Environmental Impact Assessment reports (see Box 4.1), and through more informal bilateral discussions. However, stakeholders are not involved in the design of river management strategies, and do not have official co-decision-making power. In that sense, stakeholders (besides the responsible government organisations) are in general not 'actively involved'.

Nonetheless, the stakeholders have various means of power to influence the process. First, their power originates from the official government standpoint to involve stakeholders in the decision-making process. The Maaswerken has expressed an explicit desire to achieve broad societal support which grants the stakeholders a significant voice in the process. Second, there are various other means of power, such as their decision-making authority in related fields (such as municipalities, provinces, and water boards), knowledge (for example nature organisations), landownership (such as the farmers), and legal procedures (accessible to all). Most stakeholders do indicate that they would only utilize these means of power (e.g. to obstruct the decisionmaking process) only as a last resort (Valkering, 2005a).

The stakeholders often indicated to be generally satisfied with the participatory process, in particular with the level of communication. However, they do consider their position in the process to be weak. They complain that their objections are being heard, but often not sufficiently taken into account in the updated river management plan. In particular the position of the citizens is considered to be weak, but also the municipalities, farmers, and nature organisations consider their influence to be limited. There are two parties that seem to hold a particularly dominant position. On the one hand these are the responsible government organisations, in particular the Ministry of Transport, Public Works and Water Management for the Zandmaas, and the Province of Limburg for the Grensmaas project. On the other hand, these are the gravel extraction companies in the Grensmaas. As landowners of many river areas they are by law entitles perform the works, which gives them a powerful negotiation position (Valkering, 2005a). 


\begin{tabular}{|c|c|c|}
\hline & Stakeholder groups & Individuals and organisations \\
\hline 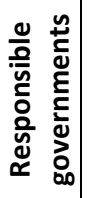 & - & $\begin{array}{l}\text { Ministry of Transport, Public Works and Water } \\
\text { Management, Province of Limburg, Ministry of } \\
\text { Agriculture, Nature, and Food Quality }\end{array}$ \\
\hline \multirow{2}{*}{ Oొ } & Citizens & $\begin{array}{l}\text { Individual citizens and citizen groups, e.g. the citizen } \\
\text { association 'Ontgrinden nooit', and the community } \\
\text { council Borgharen. }\end{array}$ \\
\hline & Nature organisations & $\begin{array}{l}\text { E.g. 'Milieufederatie Limburg', 'Staatsbosbeheer', } \\
\text { World Nature Fund, and several Belgian nature } \\
\text { organizations }\end{array}$ \\
\hline \multirow{6}{*}{ 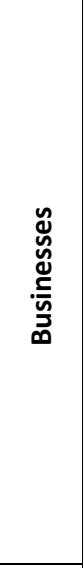 } & Shipping sector & E.g. the shipping association 'Schuttevaer' \\
\hline & Farmers & $\begin{array}{l}\text { Individual farmers and farmer groups, e.g. the Limburg } \\
\text { Agriculture and Horticulture Association (LLTB) }\end{array}$ \\
\hline & $\begin{array}{l}\text { Tourism-recreation } \\
\text { branch }\end{array}$ & $\begin{array}{l}\text { Various interest groups for water sports, recreational } \\
\text { shipping. Fishing, and hotel/catering industry }\end{array}$ \\
\hline & $\begin{array}{l}\text { Gravel/sand mining } \\
\text { industry }\end{array}$ & $\begin{array}{l}\text { Interest groups (e.g. the Dutch Association for Regional } \\
\text { Industrial Sand- and Gravel producers - NEVRIP) and } \\
\text { companies/consortia (e.g. L'Ortye Stein and Consortium } \\
\text { Grensmaas) }\end{array}$ \\
\hline & $\begin{array}{l}\text { Drinking water supply } \\
\text { sector }\end{array}$ & $\begin{array}{l}\text { Drinking water supply company Limburg - WML, the } \\
\text { Association of River and Water companies - RIWA }\end{array}$ \\
\hline & Other businesses & $\begin{array}{l}\text { Various industries, harbours, shopkeepers, pipeline } \\
\text { companies, and chemical industry }\end{array}$ \\
\hline \multirow{5}{*}{ 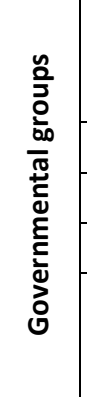 } & National governments & $\begin{array}{l}\text { Several state departments other than he responsible } \\
\text { Ministries (e.g. state department for protection of } \\
\text { monuments) }\end{array}$ \\
\hline & Provinces & Provinces of Noord-Brabant, and Gelderland \\
\hline & Municipalities & Some 24 municipalities from Maastricht to Grave \\
\hline & Water boards & E.g 'Peel en Maasvallei', and 'Roer en Overmaas' \\
\hline & Belgian governments & $\begin{array}{l}\text { Including municipalities (e.g. the community of } \\
\text { Maasmechelen), and several national governments } \\
\text { (E.g. Ministry of the Flemish Community) }\end{array}$ \\
\hline
\end{tabular}

Table 4.3: Stakeholders of the Maaswerken project. The table lists various stakeholder groups from the field of state, market and civil society, linking various individuals and specific organisation to the considered stakeholder groups. 


\section{Box 4.1: Maaswerken - Some legal aspects}

The planning process of Maaswerken is based upon several official Dutch decision-making procedures. The planning of the Grensmaas project takes place on the basis of spatial planning procedures, because this project involves extensive gravel extractions in the river floodplain. The measures should thus be laid down in the Provincial spatial plan and in the local spatial plans from municipalities. Furthermore, activities such as gravel extraction require the publication of an Environmental Impact Assessment (EIA). Further important procedures are the issuing of permits for gravel extraction, procedures for expropriation, and the cooperation with the Belgian authorities. Public participation is organized at several stages within the decision-making process (Maaswerken, 1998a, p 30).

The Zandmaas/Maasroute project was originally planned to be carried out following the socalled 'tracéwet' procedure. This procedure generally applies in the Netherlands for enlargements or shifts of 'main navigation routes' (under which falls the Maasroute). This procedure involves the publication of an EIA with an assessment of a suite of alternatives, leading to a preliminary choice of the most desirable alternative in the 'OntwerpTracébesluit', and the final decision laid down in the 'Tracébesluit'. Public participation takes place after the publication of the 'Trajectnota/EIA' and after the 'Ontwerp-Tracebesluit'. During the course of the Zandmaas/Maasroute it became clear that the 'tracéwet' regulation did not cover all the planned changes in the riverbed, specifically changes in the river floodplains. To this end, a combined spatial planning - 'tracéwet' procedure is currently followed.

\subsubsection{Stakeholder perspectives}

Following the conceptual model of Chapter 2, the stakeholder analysis focussed on the goals stakeholders pursued, their beliefs in terms of their perception of the relevant uncertainties, and their support for various river management options.

\section{Goals}

A large number of goals were derived form the stakeholder interviews and content analysis. A goal was broadly interpreted as any aspect of the Maaswerken project considered important for a stakeholder, including both positive aspects (i.e. an interest, something to achieve) and negative aspects (i.e. a concern, something to avoid). A large number of important aspects were identified, ranging from river management targets like 'flood protection', to process aspects like 'proper communication'. These aspects were classified into a number of goal categories, each containing a number of goals, each characterized by a number of specific aspects. Five goal categories were identified (see Table 4.4):

- Project goals: These goals are actively pursued by means of the river management project. The project goals are flood protection, nature development, improvement of the shipping route, and gravel extraction.

- Secondary goals: These are significant (other) effects of river engineering measures on the river system that are not actively pursued, but occur as a 'secondary' product of project goal achievement. Side impacts are often valued negatively (for example drought problems and loss of agricultural land), but can also be positive (for example an increasing groundwater table in a too dry area). 
- Process goals ${ }^{44}$ : These involve aspects of the process and planning, such as clarity (regarding the plan, its effects, and possibly compensation) and the term of finalisation.

- Strategic goals: These goals are related to developments and issues extending the direct scope of the Maaswerken project. Examples are spatial development, road traffic reduction, and the so-called sustainability of the river engineering solution.

- Costs: Costs do not refer to a structural change, but rather to temporary (negative) effects. Examples are monetary costs, but also hindrance.

\begin{tabular}{|c|c|c|}
\hline & Goal & Description and specific aspects \\
\hline \multirow{4}{*}{$\begin{array}{l}\frac{n}{\pi} \\
\stackrel{0}{0} \\
\stackrel{0}{0} \\
\frac{\mathbb{d}}{0} \\
\frac{0}{0}\end{array}$} & Flood protection & $\begin{array}{l}\text { Flood probability, the sustainability of flood protection, } \\
\text { accessibility during floods. }\end{array}$ \\
\hline & Nature development & $\begin{array}{l}\text { Area, type, morphological dynamics, fish population, } \\
\text { brooks, drought damage, water damage. }\end{array}$ \\
\hline & Shipping route & Improved sluices and wider channels. \\
\hline & Gravel / sand extraction & Volume and proceeds. \\
\hline \multirow{12}{*}{ 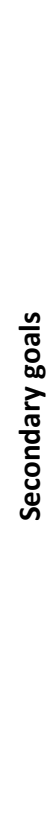 } & Agriculture & $\begin{array}{l}\text { Loss of area, reduction } \mathrm{nr} \text {. of farms, economic perspective } \\
\text { remaining farms, drought damage, water damage. }\end{array}$ \\
\hline & Tourism / recreation & $\begin{array}{l}\text { Accessibility and facilities for fishing, recreational shipping, } \\
\text { and water sports. }\end{array}$ \\
\hline & Landscape & $\begin{array}{l}\text { Openness, historical/geographical elements, avoiding litter } \\
\text { (transported by the river) to remain in the new nature } \\
\text { areas. }\end{array}$ \\
\hline & Historical values & Geo-morphological, cultural, and archaeological values. \\
\hline & Drinking water supply & Various aspects. \\
\hline & Infrastructure & High tension lines, pipelines. \\
\hline & Traffic and mobility & E.g. regarding the steepness of bridges and sluices. \\
\hline & Living environment & $\begin{array}{l}\text { Groundwater damage cellars, view blocked by } \\
\text { embankments, vermin }\end{array}$ \\
\hline & Economic activities & $\begin{array}{l}\text { Harbours/industry (water level changes), shops } \\
\text { (accessibility). }\end{array}$ \\
\hline & Downstream effects & Water level increases downstream. \\
\hline & Groundwater & Groundwater level and quality \\
\hline & River water & River water level and quality \\
\hline
\end{tabular}

Table 4.4: A comprehensive set of stakeholder goals derived from the interviews and, in particular, the content analysis

\footnotetext{
${ }^{44}$ Note that the conceptual model of Chapter 2 does not take process goals explicitly into account. From a modelling perspective, the importance of process goals might be considered surprising, although from a policy analysis perspective, it is probably not.
} 


\begin{tabular}{|c|c|c|}
\hline & Goal & Description and specific aspects \\
\hline \multirow{5}{*}{ 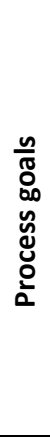 } & Clarity & $\begin{array}{l}\text { Both in relation to the plan, its effects, and compensation } \\
\text { arrangements. }\end{array}$ \\
\hline & Term of finalisation & $\begin{array}{l}\text { The term at which the river engineering measures are } \\
\text { completed. }\end{array}$ \\
\hline & $\begin{array}{l}\text { Relation to existing } \\
\text { policy }\end{array}$ & $\begin{array}{l}\text { The extent too which the river engineering solution is } \\
\text { synchronised with existing policy. }\end{array}$ \\
\hline & Integral planning & $\begin{array}{l}\text { The extent too which the various interest are covered in } \\
\text { an integrated way. }\end{array}$ \\
\hline & Societal support & $\begin{array}{l}\text { The extent too which there is broad support for the river } \\
\text { management strategy amongst the stakeholders involved. }\end{array}$ \\
\hline \multirow{5}{*}{ 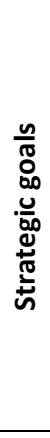 } & Spatial development & Notably for housing and recreation. \\
\hline & Drought reduction & $\begin{array}{l}\text { Overall drought reduction, both on the Dutch and Belgian } \\
\text { sides. }\end{array}$ \\
\hline & Road traffic reduction & $\begin{array}{l}\text { Reduction of goods traffic by shifting the capacity to } \\
\text { shipping. }\end{array}$ \\
\hline & Economic development & In relation to tourism and the various economic activities. \\
\hline & Sustainable solution & $\begin{array}{l}\text { Generally interpreted as the extent too which the river } \\
\text { engineering solution is in conformity with the river } \\
\text { widening approach. See also the project goal 'flood } \\
\text { protection'. }\end{array}$ \\
\hline \multirow{4}{*}{ 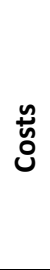 } & Costs effectiveness & $\begin{array}{l}\text { Cost of river engineering works, benefits from gravel/sand, } \\
\text { profitable exploitation, reduction of costs. }\end{array}$ \\
\hline & Hindrance & $\begin{array}{l}\text { In relation to primarily sound, and to a lesser extent dust, } \\
\text { and vibrations. }\end{array}$ \\
\hline & Project related damage & Damage to buildings and (current) excavation sites. \\
\hline & Compensation & Monetary compensation for negative effects. \\
\hline
\end{tabular}

Table 4.4 continued.

A selection of the most relevant goals, and an indication of their support amongst the various stakeholder groups, is presented in Table 4.5. The listed goals are generally the ones mentioned in the stakeholder interviews. Goals that frequently recurred in the content analysis are added and are marked with a plus ${ }^{+}$. The table illustrates that the official project goals of flood protection, nature development, and the improvement of the shipping route are broadly supported among the stakeholders involved. The goal of gravel extraction, however, is generally not. Most interviewees indicated it is for them only a means for achieving other goals, not a goal per se (Valkering, 2005a). Considering the secondary effects of the river widening approach, two main negative aspects stand out: negative effects for agriculture (in the form of loss of land and farms, and groundwater level change) that form an obvious concern for farmers, and hindrance 
(in terms of sound, dust, and low-frequency vibrations) which is a main culprit for citizens. Other relevant secondary effects, which may turn out positively or negatively - include implications for tourism and recreation ${ }^{45}$, the landscape, living environment and more. Finally, the sustainability of the river management solution and societal support are important strategic and process goals, in particular for the governmental stakeholders.

\section{Uncertainties}

The uncertainties mentioned by the stakeholders are listed in Table 4.6. In line with the conceptualisation of the river system in Chapter 2 and Chapter 3, we distinguished three main categories of uncertainty (in both the interviews and content analysis) regarding a) context developments (e.g. related to the pressures in the PSIR scheme), b) the effects of river engineering (regarding the various causal relations in the river system), and c) the river management process (regarding the dynamics of the actor system). Table 4.6 illustrates that the stakeholders are concerned with a variety of uncertainties. The following uncertainties were mentioned:

- Context developments: These included climate change (mentioned by various stakeholders), the development of the agricultural sector (mentioned by the farmer representative), and the extent to which - in the future - alternatives for gravel mining will be found (mentioned by a citizen representative).

- $\quad$ River engineering effects: These included hydraulic uncertainties (e.g. concerning the effect of vegetation growth on the river water level), morphological uncertainties (e.g. regarding sedimentation, riverbank erosion, and general morphological developments), uncertainty related to groundwater table and quality (notably concerning the effects of the clay storage areas), the possibility of litter polluting the new natural areas, and uncertainty in the gravel/ sand extraction yield and benefits (e.g. related to a possible saturation of the gravel/sand market).

- Process aspects: These include uncertainty in finances (e.g. regarding the actual allocation of budget), legal aspects (e.g. concerning the legal basis for the storage of polluted sediments), stakeholder relations (e.g. a possible conflict between the national government and the Province of Limburg), and societal response (e.g. concerning the reaction of the general public to new nature development).

The uncertainties mentioned by stakeholders are often related to their concerns and the goals they pursue. The citizens, for example, question whether alternatives for gravel mining will be found in the future, reflecting their objection to further gravel extraction along the Meuse. The nature organisations stress the uncertainty of the actual budget allocation, since they fear that nature development will be sacrificed when budget becomes restricted. The farmer representative argued that the river water level increase due to vegetation growth is underestimated, basically reflecting his frustration with the nature development strategy, while farmers are subject to building restrictions in the floodplain area. The gravel extractors, finally,

\footnotetext{
${ }^{45}$ The impulse for tourism and recreation is actually often mentioned as one of the main reasones for supporting nature development.
} 
refer to the uncertainty in gravel/sand extraction yield and benefits reflecting their obvious concern for the profitability of the river management strategy ${ }^{46}$.

\begin{tabular}{|c|c|c|c|c|c|c|c|c|c|c|c|c|c|}
\hline Stakeholders & $\begin{array}{l}\tilde{N} \\
\stackrel{N}{N} \\
\stackrel{N}{ \pm}\end{array}$ & 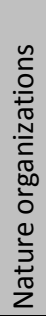 & 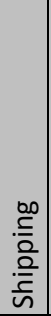 & 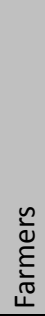 & 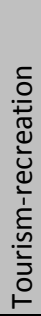 & 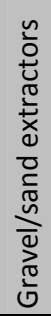 & 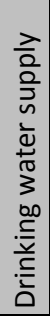 & 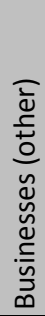 & 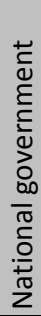 & $\begin{array}{l}\mathscr{d} \\
\tilde{U} \\
. \frac{c}{2} \\
\frac{0}{2} \\
\frac{2}{2}\end{array}$ & 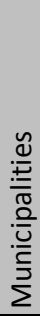 & 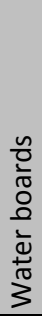 & 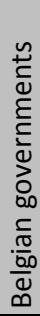 \\
\hline Flood protection & $*$ & $*$ & & $*$ & & & & $*$ & $*$ & $*$ & $*$ & $*$ & \\
\hline Nature development & $*$ & $*$ & & & $*$ & & $*$ & $*$ & $*$ & $*$ & $*$ & $*$ & $*$ \\
\hline Shipping route & & & $*$ & & $*$ & & & $*$ & $*$ & $*$ & $*$ & & \\
\hline Gravel/sand extraction & & & & & & $*$ & & & $*$ & $*$ & & & \\
\hline Agriculture & & & & $*$ & & & & & & $*$ & $*$ & & $*$ \\
\hline Hindrance & $*$ & & & & & & & & & & $*$ & & \\
\hline Tourism/recreation & & * & & & $*$ & & $*$ & $*$ & & $*$ & $*$ & & \\
\hline Groundwater table & & $*$ & & $*$ & & & $*$ & & & $*$ & & & \\
\hline Landscape & $*$ & & & & & & & & & & $*$ & & $*$ \\
\hline Living environment & $*$ & & & & & & & & & & $*$ & & \\
\hline Drinking water supply ${ }^{+}$ & & & & & & & $*$ & & & $*$ & $*$ & & $*$ \\
\hline $\begin{array}{l}\text { Economic activities and } \\
\text { development }^{+}\end{array}$ & & & & & & & $*$ & $*$ & & $*$ & $*$ & & \\
\hline Societal support & & & & & & & & & $*$ & $*$ & $*$ & & \\
\hline Sustainable solution & & $*$ & & & & & & & $*$ & $*$ & $*$ & & \\
\hline Cost effectiveness $^{+}$ & & & & & & $*$ & & & $*$ & $*$ & & & \\
\hline
\end{tabular}

Table 4.5: Main goals in the Maaswerken project expressed by the different stakeholder groups. The goals listed here were generally mentioned in the stakeholder interviews; additional goals that appeared from the content analysis are marked with a plus ${ }^{+}{ }^{47}$

\footnotetext{
${ }^{46}$ Or, possibly, as a way to improve their negotiation position.

${ }^{47}$ The stakeholder groups correspond to the ones mentioned in Table 4.3, with the 'responsible governments' Province of Limburg and the two national Ministries included in the stakeholder groups 'Provinces' and 'National government' respectively. The table content is based on stakeholder interviews and a content analysis of relevant documentation, as explained in the text.
} 


\begin{tabular}{|c|c|c|c|c|c|c|c|c|c|c|c|c|c|c|}
\hline & $\begin{array}{l}\text { Stakeholders } \\
\text { Uncertainties } \\
\end{array}$ & $\begin{array}{l}\tilde{n} \\
\frac{N}{N} \\
\stackrel{N}{ \pm} \\
\end{array}$ & 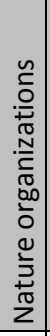 & 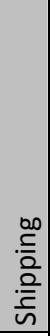 & $\begin{array}{l}\stackrel{\sim}{\frac{\pi}{\sigma}} \\
\frac{c}{2} \\
\stackrel{\pi}{\leftarrow}\end{array}$ & 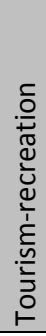 & 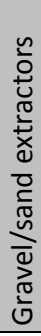 & 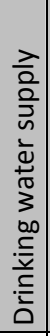 & 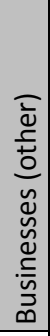 & 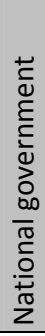 & 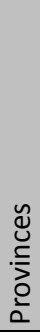 & 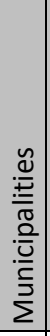 & $\begin{array}{l}n \\
0 \\
\frac{n}{\pi} \\
0 \\
0 \\
\frac{1}{2} \\
\frac{1}{\pi} \\
3 \\
3\end{array}$ & 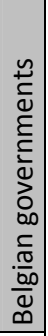 \\
\hline \multirow{3}{*}{ 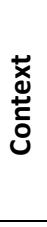 } & Climate change & $*$ & $*$ & & & & & $*$ & & & $*$ & $*$ & & \\
\hline & $\begin{array}{l}\text { Development } \\
\text { agricultural sector }\end{array}$ & & & & $*$ & & & & & & & & & \\
\hline & $\begin{array}{l}\text { Alternatives for gravel } \\
\text { mining }\end{array}$ & $*$ & & & & & & & & & & & & \\
\hline \multirow{5}{*}{ 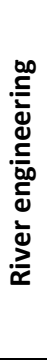 } & Hydraulic uncertainties & $*$ & & & $*$ & & & & & & & $*$ & & \\
\hline & $\begin{array}{l}\text { Morphological } \\
\text { uncertainties }\end{array}$ & $*$ & & & & & & & & & $*$ & & $*$ & \\
\hline & $\begin{array}{l}\text { Groundwater table and } \\
\text { quality }\end{array}$ & $*$ & $*$ & & $*$ & & & & $*$ & & $*$ & $*$ & & $*$ \\
\hline & Litter & & & & & & & & & & & $*$ & & \\
\hline & $\begin{array}{l}\text { Gravel/sand yield and } \\
\text { profit }\end{array}$ & & & & & & $*$ & & & & $*$ & $*$ & & \\
\hline \multirow{4}{*}{ 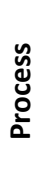 } & Finances & & $*$ & & & & & & & $*$ & $*$ & $*$ & & \\
\hline & Stakeholder relations & $*$ & & & & & & & & & & $*$ & & \\
\hline & Legal issues & & & & & & & & & & $*$ & & & \\
\hline & Societal response & & $*$ & & & & & & & & & & & \\
\hline
\end{tabular}

Table 4.6: Uncertainties in the Maaswerken project as expressed by the different stakeholder groups. Three categories of uncertainty are distinguished, regarding context developments, river engineering effects, and the river management process. ${ }^{47}$

Although there is a clear awareness of various uncertainties among the stakeholders, the actual role of uncertainty in the planning process of Maaswerken seems relatively small. An uncertainty like climate change, for example, is neither explicitly considered in the planning procedures, nor subject to strong debates amongst the stakeholders involved. It seems that the goal of achieving a safety level 1:250 for the given design discharge (which is not based on climate change considerations) is accepted as a basis to work from. In general, it appears that the models and assumptions adopted by the Maaswerken project organisation are not explicitly challenged with alternative uncertainty interpretations. One of the few exceptions, probably, is the challenging uncertainty interpretation of the gravel extractors on profitability (adopting a more moderate estimate) that came to the for in the negotiation phase of the Grensmaas project (1999 - 2001), which - as described in the historical analysis - had a significant impact on the project's course. 


\section{Support for river management options}

Finally, the interviews and content analysis provided insight in the preference of the stakeholders for the various river management approaches. Table 4.7 provides a rough indication of stakeholder support for various river engineering - and other - measures that are potentially part of a river management strategy. The table illustrates that, in particular, the citizens, nature organizations and governmental parties hold a positive attitude towards river widening and new nature development. Their views differ, but in a nuanced way. The nature organizations, for example, focus more explicitly on specific nature development measures and generally aim to avoid main channel deepening for its negative effect on groundwater. The citizen groups (thereby supported by the Province of Limburg and the various municipalities) stress in particular that additional gravel extraction should be avoided and that clay storage should be minimal.

Dike-building is judged negatively by the nature organizations, citizens and governments alike. The governments and nature organizations, in particular, strongly consider dike-building an unsustainable solution for flood protection, which - according the representative of the municipality of Venlo - only delivers a 'fake security' (Valkering, 2005a). The citizens, moreover, use the more practical argument that dike-building will block the view from their houses and argue that dismountable embankments may be the best solution after all ${ }^{48}$. The Province of Limburg, finally, was the only governmental party that expressed a possible acceptance of dikebuilding in the future, as an additional measure for flood protection in case of climate change.

The farmers are the main opponents of the river widening approach. Not surprising, since it conflicts directly with their interest of avoiding the loss of agricultural land. Nonetheless, the interviewed farmer representative accepted widening to some extent, arguing for a mix of river widening and dike-building to achieve a 'realistic' solution (Valkering, 2005a). Also, he stressed the need for clear agreements regarding financial compensation for individual farmers, also in case of unexpected effects. From the content analysis, it appeared that also the drinking water supply sector is critical towards the river widening approach. They claim that the possible impacts on water quality have been insufficiently taken into account. A final interesting observation from the content analysis is that the artificial water level increase, needed to compensate water level decrease and for the benefit of shipping, are negatively judged by a variety of stakeholders, including citizens (that fear water damage in their cellars), the tourism and recreation sector (that fears flooding of ship landing-stages), en farmers (that fear water related damage to their crops).

\footnotetext{
${ }^{48}$ This statement was made by a citizen group representative while the confidence for achieving a river widening solution in the Zandmaas area was at its lowest ebb.
} 


\begin{tabular}{|c|c|c|c|c|c|c|c|c|c|c|c|c|c|}
\hline $\begin{array}{l}\text { Stakeholders } \\
\begin{array}{l}\text { River management } \\
\text { options }\end{array} \\
\end{array}$ & 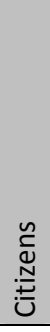 & 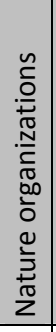 & 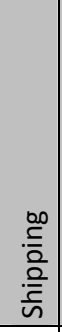 & 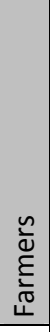 & 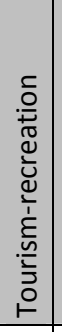 & 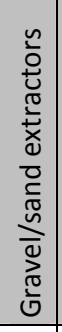 & 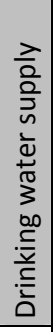 & 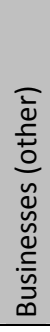 & 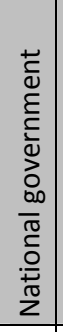 & 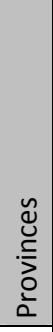 & 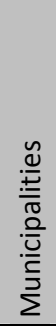 & 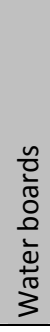 & 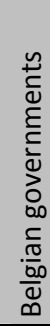 \\
\hline Main channel broadening & + & + & & - & & & - & & + & + & + & & \\
\hline Main channel deepening & + & - & & o & & & - & & + & + & + & & \\
\hline Main channel elevation & & + & & & & & & & - & & & & \\
\hline Flood plain excavation & + & + & & - & & & & & + & + & + & & \\
\hline Natural riverbanks & & + & & & & & & & + & + & + & & \\
\hline Additional nature area & & + & & & & & & & & + & + & & \\
\hline Clay storage & & o & & & & + & & & + & + & 0 & & \\
\hline $\begin{array}{l}\text { Additional gravel } \\
\text { extraction }\end{array}$ & - & & & & & + & & & & - & - & & \\
\hline Water level increase & - & $\mathbf{0}$ & & - & - & & & - & & & - & & \\
\hline Heightening embankments & - & & & + & & & & & & 0 & - & & \\
\hline $\begin{array}{l}\text { Dismountable } \\
\text { embankments }\end{array}$ & + & & & & & & & & & & & & \\
\hline Retention upstream & & + & & & & & & & & + & & & \\
\hline Compensation & + & & & + & & & & & & & & & \\
\hline
\end{tabular}

Table 4.7: An indication of the support for different river management options of the various stakeholders involved. A ' + ' indicates a positive attitude, a '-' a negative attitude, and a ' 0 ' indicates acceptance. ${ }^{47}$

\subsection{PROCESS ANALYSIS}

The conceptual model of Chapter 2 furthermore focuses on perspective changes through processes of social learning as a key to understanding changes of river management strategies over time. Perspective changes were said to occur through learning mechanisms referred to as 'Learning about the environment' and 'Learning from agent interaction'; the latter involving processes of cooperation, conflict and coalition-forming. Re-examining the course of the Maaswerken project on the basis of the stakeholder analysis, a number of examples of those processes can be identified, see Figure 4.2. In the following, these are shortly discussed. 


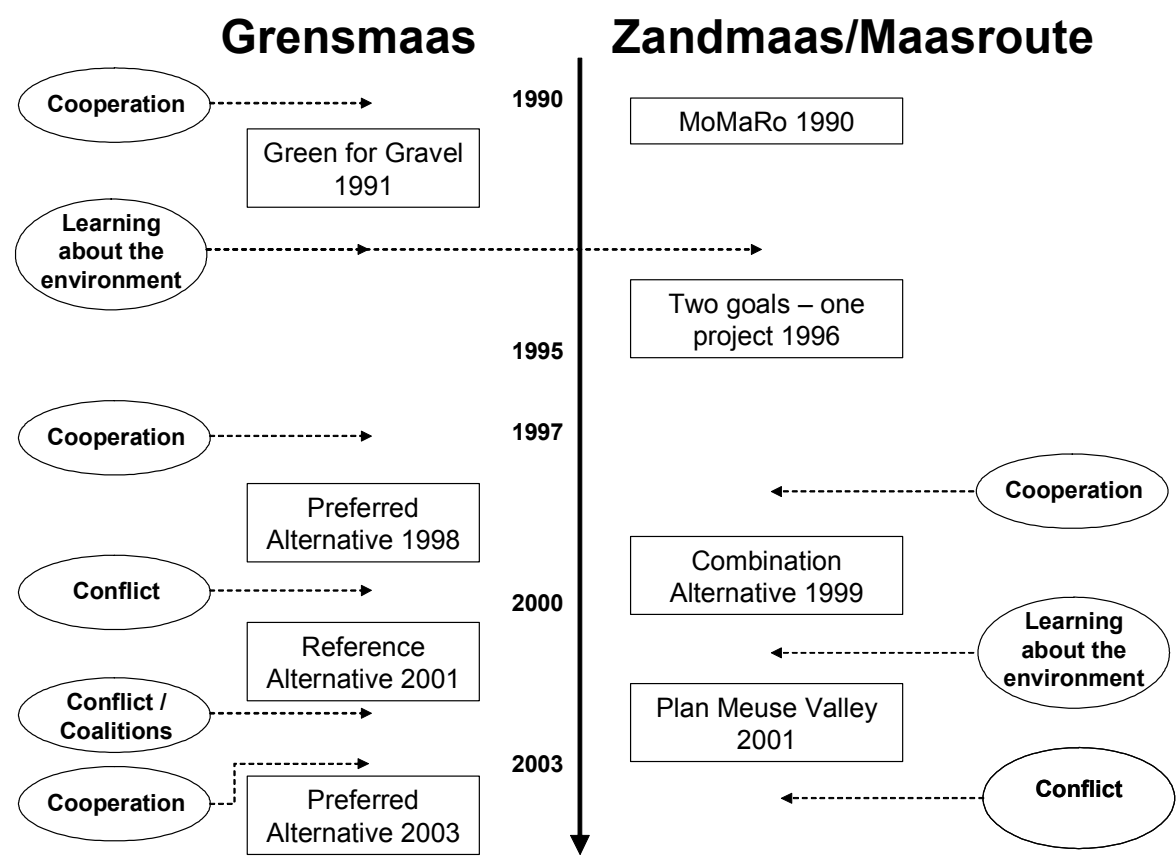

Figure 4.2: Social learning over the course of the Maaswerken project. The analysis identifies two main examples of learning about the environment, and various stages of cooperation, conflict, and coalitionforming. The stakeholders interviews - upon which the analysis is largely based - were held in the fall of 2001, a few months after the Reference Alternative and Plan Meuse Valley had come out.

\section{Learning about the environment}

Learning about the environment was defined as perspective changes initiated through a changing perception of the river system. A first main example of learning about the environment is the broad adoption of the goal of flood protection after the floods of 1993 and 1995. Before that time, flood protection was 'not under discussion at all ${ }^{49}$ while after the floods it quickly became a broadly supported main project goal. Obviously, the sudden increase of flood risk awareness was the main driver behind the adoption of this goal. In the language of our modelling concept, it refers to a rather fundamental change of perspective in the form of an updated set of goals, and more concretely, to an emerging interest due to a sudden event.

A second main example of learning about the environment concerns the changing insights into the hydraulics, the morphology, and the design discharge in the Zandmaas/Maasroute project around 1999. These changing insights, one might say, led to an 'updated river model' of the planners of the Maaswerken project organisation. In the words of our modelling concept, it refers to a sudden perspective change in the form of changing beliefs about the river system, notably as a result of study. Due to this perspective change, the former river management

\footnotetext{
${ }^{49}$ Statement of the Province of Limburg representative, see (Valkering, 2005a).
} 
strategy based more on river widening and nature development (the Combination Alternative) turned out to be inadequate and not feasible. Eventually, it led the design of a new river management strategy (the Plan Meuse valley) that focussed much more on the heightening of embankments to reach the flood norm within the time and budget constraints.

Note that in both cases, learning about the environment put pressure on stakeholder support. Concerning the first case, a citizen group representative for the Grensmaas project expressed frustration that the goal of flood protection had been added to the project, but without the allocation of more budget: 'the government wants more, but for the same money' (Valkering, 2005a). Concerning the second case, it was clear that many stakeholders (municipalities, citizens, nature organisations) were strongly opposed to the new river management plan. See also the section 'conflict' later on.

\section{Cooperation}

Cooperation was said to occur when stakeholder agents are willing to change their goals and beliefs for the common goal of reaching a broadly supported river management strategy.

A first main example of cooperation concerns the citizen perspective in the early stages of the Grensmaas project. According to the representative of a citizen group, citizens were originally sceptic about further gravel mining in their area along the Meuse, in particular when this concerned the traditional, deep gravel extraction approach. When the new concept Green for Gravel was presented, it took them three years before the concept of gravel mining in combination with nature development was accepted (Valkering, 2005a). Currently, nature development is clearly considered one of their main goals. The exact mechanism behind this 'goal update' is difficult to trace. Probably it relates to growing insight in the benefits of nature development, a growing trust towards the provincial government, and probably good 'marketing' of the Green for Gravel concept. According to the citizen representative, it relates very much to 'working together, thinking together, and taking each other seriously; seeing that suggestions made recur in the river management plan'.

Later on, cooperative stages appear to have taken place in the Grensmaas project towards the development of the Preferred Alternative of 1998, and in the Zandmaas/Maasroute project in the development of the Combination Alternative of 1999. During these stages, there appears to have been a constructive atmosphere in the planning process in which stakeholders were willing to trade some of their self-interest for the common good. The stakeholder analysis did not allow for a detailed description of changes in goals and beliefs that may have possibly occurred. Nonetheless, it was clear from the stakeholder interviews that notably the Combination Alternative was cooperatively designed. Support for the Combination Alternative was mentioned by various interviewees, and also the high level of communication during that period was praised.

A final example of cooperation concerns the renewed negotiation effort after the rejection of the Reference Alternative. In June 2001, the Province of Limburg took the initiative to bring all parties together and design an acceptable plan within a time period of only half a year. To this end, the various parties were actively involved in intensive, interactive, and transparent negotiation sessions, working simultaneously 'at different tables' under the guidance of the Province (De Waal-Malefijt, 2002). The process successfully led to a new and accepted river management strategy, which was more cost effective, and included various regulations for minimizing hindrance and compensating damage. Interestingly, one of the reported factors of success was a coalition of regional parties (the so-called Grensmaas Discussion group, see 
'coalition-forming') - that emerged out of opposition to the Reference Alternative - that turned out to be an effective negotiation and discussion partner. Note, however, that 'supported' and 'accepted' is not the same. According to a representative of the Grensmaas Discussion group, the budget neutrality and additional gravel extraction remained a reason for being very critical to the final plan (Van Echoud, 2002).

\section{Conflict}

Conflict - rather the opposite from cooperation - was interpreted as a situation where stakeholder agents express their discontent with a proposed river management plan and are unwilling to change their goals and beliefs for reaching a more broadly supported solution.

During the stakeholder interviews various smaller and larger conflicts were reported, out of which only a few main ones are discussed here. In the Grensmaas project, a first main conflict occurred between the Province of Limburg and the Gravel extracting companies during the negotiation about the implementation of the Preferred Alternative of 1998. According to the Province representative, the conflict basically concerned the estimation of the gravel benefits and the consequent project profitability: 'We felt that the project could be implemented this way, that there were sufficient gravel revenues for paying the costs. The consortium ${ }^{50}$ estimated that this was not the case and required additional money. We couldn't reach an agreement.' In the terms of the conceptual model, this conflict thus originated from different beliefs about the river system, concretely regarding the gravel benefits and (possibly) the project costs, which apparently - could not be reconciled at the time.

When the Reference Alternative finally came out, it directly fuelled another conflict between various regional parties on the one hand, and the Province of Limburg and the gravel extractors on the other. The main reason for this conflict was the unacceptable high amount of gravel extraction (much higher than previously agreed) required for implementing the project in a budget neutral way. The associated hindrance and damage to the landscape would be too high. According to the citizen representative, the envisioned gravel extraction had already increased from an acceptable 35 million tons in the carefully negotiated Green for Gravel plan, to 52 million tons in the Preferred Alternative of 1998. The Reference Alternative (providing for 66 million tons of gravel) was simply unacceptable. Also, the lack of communication during the negotiation period $1998-2001$ was reported by practically all stakeholders to have fuelled the conflict.

In the Zandmaas, a similar situation occurred. Here, the broadly accepted Combination Alternative of 1999 was revised into the Preferred Alternative of 2001. Although there were good reasons for this revision (the unforeseen new hydraulic calculations, new design discharge, and new morphological insights), many stakeholders were highly disappointed with the proposed alternative. According to municipalities, the Plan Meuse valley was considered 'an artifice', 'not sustainable', 'too much budget-based', and 'hard to explain to our citizens' (Valkering, 2005a). A citizen representative expresses her discontent since 'at some places the embankments will reach $2 \mathrm{~m}$ in height'. Unlike the conflict over the Reference Alternative, this

\footnotetext{
50 The 'consortium' refers to the so-called Consortium Grensmaas: an association of contractors, gravel extracting companies and a nature organisation ('Natuurmonumenten') that together are responsible for the implementation o the river management plan.
} 
conflict did not lead to a rejection of the Meuse valley Plan. Rather, it caused a feeling of 'resignation' ${ }^{51}$ regarding the acceptance of the new river management plan.

\section{Coalition forming}

Coalition forming was interpreted as the process where distinct stakeholders or stakeholder groups start to collaborate closely, operating and communicating in a unanimous way, and advocating a single set of goals and beliefs.

Coalition forming was reported to occur first between parties with a similar role and perspective. Some examples are coalitions among municipalities, among different nature organisations, and among the national and provincial governments. Coalition forming is more remarkable when occurring among stakeholders with a-priori different, and possibly even conflicting, perspectives. A typical example of the latter was the Grensmaas Discussion group formed in reaction to the Reference Alternative in the beginning of 2001. This group presented a coalition among some 30 different parties, including citizen groups, local nature organisations, and farmer representatives. The coalition was formed to create a balance of power against the gravel extracting companies and provincial government, and in particular to protest against the Reference Alternative. This coalition thus resulted from a situation of conflict.

\section{Conclusion}

Concluding, both cooperative and conflictive stages have occurred. The cooperative stages were associated with a constructive atmosphere, with good communication, in which stakeholders both accepted the perspectives of others, and felt that their own perspectives were seriously taken into account. The conflictive stages, on the other hand, were associated with stalemate, bad communication, and a situation in which stakeholder perspectives were not mutually accepted, both in terms of goals (e.g. the citizen in the Grensmaas not accepting the criterion of budget neutrality) and beliefs (e.g. the Province of Limburg not accepting the cost-benefit calculation of the gravel extractors). Conflict was clearly fuelled by the various changes of plans that occurred both in the Grensmaas and Zandmaas/Maasroute projects. Due to the flood events, the increasingly important role of the gravel extractor, and changing insights in the river system, previously accepted plans had to be revised into much less attractive solutions. It typically led to compromising on (apparently) lower priority goals (e.g. avoiding hindrance, nature development, and a river widening approach) for the sake of higher priority boundary conditions (budget constraints and flood norm), which was generally not well accepted by the stakeholders involved. Finally, conflict can lead to coalition forming, which later can be part of the solution, as the Grensmaas example shows.

\subsection{BEYOND THE MAASWERKEN: SOME RESULTS FROM THE INTEGRAL EXPLORATION OF THE MEUSE}

A more elaborate picture of stakeholder perspectives and an outlook towards possible stakeholder dynamics on the longer term were obtained from an analysis of the project 'Integral Exploration of the Meuse' (IEM) (in Dutch: 'Integrale Verkenningen Maas'). IEM was initiated by Rijkswaterstaat in response to the increasing awareness that climate change may change the

\footnotetext{
${ }^{51}$ Statement of the municipality of Roermond
} 
discharge pattern of the Meuse, with possibly significantly higher peak discharges. The specific aim of IEM was to investigate if and how these peak discharges could be accommodated through a river widening approach. To this end, Rijkswaterstaat organised a participatory process with a broad set of stakeholders to discuss and evaluate potential river widening options that could possibly be taken on the longer term (i.e. after the implementation of Maaswerken). This participatory process was analyzed as part of the EU project HarmoniCOP ${ }^{52}$ on the basis of a number of stakeholder interviews (Valkering, 2005b) and real-time observations during a number of IEM workshops (Otter et al., 2004).

The project IEM can be regarded as a strategic follow-up on the Maaswerken project. The project applies to the same river stretch, is guided by the same main goal of flood protection, and follows the same approach of river widening. The first main difference with Maaswerken is the magnitude of the so-called design discharge. The Maaswerken does not take into account climate change and thereby adopts a design discharge of $3800 \mathrm{~m}^{3} / \mathrm{s}$, which is estimated to occur 1:1250 years. IEM does take climate change into account, adopting a worst case discharge scenario for 2050 and consequently a design discharge of $4600 \mathrm{~m}^{3} / \mathrm{s}$. The second main difference is that IEM operates on a strategic level, while the Maaswerken project is well advanced in the planning phase and works on an operational level.

Comparing the goals expressed by the stakeholders of Maaswerken and IEM, one striking difference can be observed. In IEM the goals of 'spatial quality' and 'spatial development' having only a small importance in Maaswerken - stand out. These goals are expressed in particular by the municipalities and the Province of Limburg, having spatial developments as their policy responsibility. Apparently, the magnitude of the design discharge requires such large-scale river widening measures that it may threaten their spatial development plans.

The conflict between the goals of flood protection and spatial development culminated in a discussion on the legitimacy of the adopted design discharge. Multiple perceptions could be observed. One perception, associated primarily with the Province of Limburg, is that the problem could be (partly) solved through land use planning and river management in the upstream part of the catchment, i.e. in Belgium. This perspective is not shared by the national government. Firstly, model studies indicate that the effectiveness of such an approach is limited. Secondly, such approach requires co-operation of the Belgium authorities that is not expected in the short term. In the view of the national government, we should thus take our own responsibility and solve the problem here, rather than shifting the problem abroad.

A second perception is one of flood adaptation, rather than flood protection. This perception is not part of any established organization, but resides with a number of relevant individuals (a historian, a retired alderman). It is argued that, rather than taking the safety norm as a boundary condition, one should adopt an integrated approach with a priori equal importance for all river functions, including safety. In this approach much more emphasis is placed on resilience towards flooding. Possible measures include avoid building in flood prone areas, adaptation of existing houses in order to limit flood damage, and the construction of bridges (rather than tunnels) to keep evacuation routes opened in case of floods. Furthermore, the responsibility for the flood problem should shift from the government towards citizens and companies.

\footnotetext{
${ }^{52}$ Harmonizing Collaborative Planning, see www.harmonicop.info accessed July 2009
} 
The differences in perspective are illustrated by a significant conflict between the national and provincial government regarding the policy line Room for the River (VROM \& V\&W, 1997). This policy line, developed by the national government, restricts spatial developments in floodplain areas, which may 1) obstruct water flow, 2) obstruct any potential future river widening measures, and 3) increase potential flood damage. The Province of Limburg (supported by the municipalities) does not agree with restrictions and proposed to ease the regulation. The national government, however, does not comply. It fears that when spatial development continues, and a flood occurs, it will bear the responsibility for the flood damage. Moreover, the national government fears that in this case, societal pressure may lead to further dike enlargements in contrast to the envisioned river widening approach.

In summary, there appeared to be a 'mutual fear' among the national government on the one hand, and the provincial and municipal governments (the 'region') on the other. The national government fears the region to be accused of negligence when flood norms are not guaranteed, and to be forced to further dike-building when a flood might hit. The region, on the other hand, fears the national government for imposing large-scale river widening measures and restrictions on spatial development, which it doesn't support. These observations illustrate how new goals, perspectives, conflicts and coalitions may emerge in future river management.

\subsection{CONCLUSIONS}

The analysis of the Maaswerken process - presented in this chapter - aims to provide a basic understanding of the course of the Maaswerken planning process from 1990 to 2003. The historical analysis showed that both planning process started with relatively little complexity, and that they have grown into integrated, complex projects with numerous stakeholders and objectives involved. Both planning processes were initially successful and received broad stakeholder support. However, both projects experienced crises - where stakeholder support to a large extent collapsed - which were overcome through a rather pragmatic approach.

However, reflecting on the original starting points (i.e. the Room for the River management style), one must conclude both projects were only partly successful. In terms of content, the Grensmaas project significantly deviated from the original Green for Gravel approach, allowing significantly more gravel extraction than needed for safety and natural river restoration. In the Zandmaas, the focus of the project shifted towards the heightening of embankments, with river widening measures postponed. In terms of process, both projects lacked the broad societal support initially sought. In the Grensmaas, the main dissatisfaction lies with citizens - who criticize the (in their opinion) excessive gravel extraction and hindrance -, and farmers that suffer from an extensive loss of agricultural area. In the Zandmaas, the main dissatisfied parties are the nature organisations, various regional governments, and citizens. The lack of nature development and choice for embankments are their main points of critique.

The analysis presented here highlights stakeholder perspectives - in terms of their goals and uncertainty interpretation - as a way to explain the course of events. The assessment of stakeholder perspectives has shown that stakeholders adhere to a variety of goals, including project goals (like flood protection), secondary effects (e.g. loss of agricultural land), monetary ad non-monetary costs (e.g. hindrance), and strategic goals (e.g. modal shift for transport). Their support for the various river management options can generally be consistently related to those goals. The stakeholders do acknowledge the existence of uncertainty, both regarding external 
developments (e.g. climate change), the effects of river engineering (e.g. the expected water level change), and the process (e.g. related to the allocation of budget). However, the stakeholders tend not to formulate explicit interpretations of those uncertainties (e.g. they do not use formulations like 'I expect a strong increase in the design discharge due to climate change'). ${ }^{53}$

The changing course of the Maaswerken can be related to changes in stakeholder perspectives over the course of the planning process. For example, the flood events of 1993 and 1995 were important, after which flood protection became a leading goal. In the Zandmaas project, the changing insights in hydraulics, design discharge, and river morphology (reflecting changing uncertainty interpretations) changed the perceived feasibility of the river widening approach. Moreover, the inclusion of new (influential) stakeholders in the process - bringing a new perspective 'on the table' - can shift the course of the planning process, as the example of the gravel extractors in the Grensmaas project has show. The changing perspectives, however, didn't lead to an overall reconsideration of goals. It rather led to a weakening of, apparently, lower priority goals (nature development, hindrance, room for the river approach), for the sake of higher priority boundary conditions (flood norm, budgetary constraints). This clearly created tensions in terms of stakeholder support and fuelled conflict.

Indeed, after the successful and cooperative project stages (i.e. up to the EIAs of 1998 and 1999 in Grensmaas and Zandmaas respectively) periods of conflict occurred. Apparently, stakeholder perspectives could not be reconciled in a broadly supported river management plan. This analysis highlights three main factors that fuelled conflict. The first factor is the acceptance of each others goals and/or uncertainty interpretations. The second factor relates to the changing river management plans, in particular the fact that previously accepted plans had to be revised into much less attractive plans. The third relates to the lack of communication in the Grensmaas project in the period following the initial successful stage. Conflict, amongst others, can lead to coalition forming. An example is the coalition of 26 different NGO's representing the citizens, farmers, and nature organisations formed in the Grensmaas project to protest the Reference Alternative of 2001.

The analysis of the strategic project Integrated Exploration Meuse, finally, has shown that - on the long term - new goals may emerge (e.g. spatial quality) and that more fundamentally different perspectives may come to light (e.g. the flood adaptation perspective). Also, new conflicts and coalitions may come to the fore, such as a conflict between the national government and regional parties on the trade-off between flood protection and spatial quality.

Several main discussion points can be formulated regarding the analysis above. First, a thorough analysis of the planning period from 1990 to 2003 would have required a longitudinal stakeholder research, which was outside the scope of this study. The stakeholder interviews were conducted in 2001, and the content analysis reflected the state of affairs in the years 1998 and 2003, and 1997 and 2001 for the Grensmaas and Zandmaas respectively. Second, the representativity of the group of stakeholders could be improved. Some key players, like the

\footnotetext{
${ }^{53}$ A main expectation, probably, is the uncertainty regarding gravel benefits. Here, the gravel extraction companies and the Province of Limburg seem to hold explicitly different interpretations, although this could not be tested in a direct way.
} 
gravel extracting companies, were not willing to participate in interviews and did not recur in the official stakeholder reactions. Precise insight in their perspectives can thus only be derived from statements of other stakeholders, or by inference form the course of events. Third, the analysis is rather superficial; the analysis focuses on perspectives - in terms of goals and uncertainty interpretations - but doesn't go in detail into the underlying beliefs. For example, the analysis does not clarify whether goals originate from relations of interest, personal values, perceived social norms, or some other belief. Fourth, the analysis only touches upon the role of stakeholder interactions, such as cooperation, conflict and coalition forming. In particular, it is unclear to which extent these interactions have affected the final outcome of the planning process $^{54}$.

Concluding, the analysis has shown that the process of river management is an inherently dynamic and uncertain. Due to the complexity, the multiple actors, and uncertainties involved new developments - like unforeseen events, new actors, changing insights, and emerging goals - are to be reckoned with. This holds especially for large infrastructure projects like the Maaswerken with a planning time horizon of multiple years. The dynamic nature of the river management problem calls for planning approaches in which flexibility, multiple perspectives and uncertainties play a central role.

The remaining question is: How to model all that? This will be the subject of the next chapters.

\footnotetext{
${ }^{54}$ The impression is that the final outcome is rather an easy to understand compromise between various perspectives, than the emergent outcome of complex stakeholder interaction. But more research would be required to better address that question.
} 
Chapter 5

AN INTEGRATED RIVER MODEL 


\begin{abstract}
This chapter describes a simple modelling tool for the order of magnitude analysis of river management options and their impacts. The model typically represents a short river stretch as a river cross-section, and was applied and tested for the Maaswerken / Grensmaas location of Borgharen. The model aims to be compatible with stakeholder perspectives, by including the most relevant impacts (flood risk, nature development, agriculture, excavation, hindrance and costs) and river engineering options (river widening, floodplain excavation, dike-building, and clay storage) as considered by the various stakeholders involved. Also, it addresses main uncertainties regarding, for example, climate change, nature development, flood damage, and project costs. Despite the inherent limitations of the cross-section approach, the model is calibrated and validated to form a realistic description of the river management issues of concern. Due to its transparent and interactive nature, the model is well-suited to reflect upon various trade-offs, uncertainties, and long term context developments in an integrated way. The model may be used on the strategic policy level to reflect on various river management approaches, in participatory settings to support communication amongst the stakeholders of river management, and as a scientific tool to advance the understanding of human-environment systems through application in combination with a participatory Agent-Based modelling approach.
\end{abstract}




\section{An integrated River Model}

\section{$5.1 \quad$ INTRODUCTION}

In their assessments of river management alternatives, the Maaswerken project organisation relies heavily on models. These include, amongst other, hydraulic models to calculate the effect on water level and flow velocities, groundwater models to assess changes in groundwater table, ecosystem generators that project vegetation patters, and excavation and cost modules that calculate gravel and sand extractions, and the associated cost and benefits (e.g. see Maaswerken, 1999c). Although these model studies represent state-of-the-art knowledge on various domains, it remains difficult to connect the various insights into an integrated assessment. Also, although stakeholders are engaged in the river management planning process in various ways, stakeholders have relatively little access to the available knowledge, for example to engage in model explorations themselves. The integrated River Model (iRM), presented in this chapter, aims to overcome those limitations by providing an integrated, interactive, and simple modelling tool for the order of magnitude analysis of river management options and their impacts.

\subsection{MODEL OVERVIEW}

\subsubsection{Model requirements}

One of the main objectives of the river model is to be applied in combination with the participatory Agent-Based modelling (ABM) approach. For this application, three main design requirements were deduced:

1. The model should be compatible with stakeholder perspectives. To support the stakeholder agents in their river management planning task, the river model should include the salient decision-making criteria ('goals') and river management options ('actions') considered by the various stakeholder agents involved. Moreover, salient uncertainties should be made explicit, allowing the stakeholder agents to implement their uncertainty interpretations in the model.

2. The model should be interactive. To be of use in a participatory ABM approach, both the stakeholder agents and real-life stakeholders should be able to interact with the river model in a satisfactory way. To this end, the model should be rapid, transparent, and easy to operate.

3. The model should be valid. Bearing in mind that "all models are wrong, but some are useful $^{\prime 55}$, validity here refers to the overall adequacy of the model. The validity of Integrated assessment models are generally tested through practical validation (to which extent do model results match the available data?) and conceptual validation (is

\footnotetext{
${ }^{55}$ This quote is attributed to the statistician George Box (1919 - ), who - amongst others - pioneered the development of the Response Surface Methodology for developing approximate models.
} 
the use of underlying concepts theories and assumptions justified?) (Janssen, 1996; Rotmans \& de Vries, 1997).

These criteria are admittedly ambiguously defined. Each criterion individually may, or may not, be fulfilled depending on the standards set. Regarding the first criteria, for example, one might argue that the model should include not only those decision-making criteria, policy options, and uncertainties that are relevant now, but also the ones that might become relevant in the future (and these are clearly more difficult to find!). Also, trade-offs may have to be made in fulfilling the set of design criteria as a whole. Increasing the representative detail of modelled phenomena ('disaggregation'), for example, might increase model validity, but may also go the cost of transparency and interactivity. Nonetheless, these criteria provided proper guidance for model design and evaluation. It is considered 'the art' of IA modelling to find the right balance between those criteria in a satisfactory way.

\subsubsection{Conceptual design}

The Pressure State Impact Response (PSIR) model of Chapter 3 (Figure 3.12) forms the basis of the more specific conceptual model design of Figure 5.1 that zooms in on the Grensmaas case. Given the first of the design criteria described above, it aims to represent as much as possible the goals, uncertainties and river management options that came to the fore in the analysis of the Maaswerken project (see Tables 4.5 - 7). The goals - regarding flood protection, nature development, agriculture, excavation and costs - typically recur as impacts. River management options - including various riverbed widening options, clay storage, and dike-building - appear as responses. Uncertainties in the river management context - notably climate change and spatial pressure - have been included as pressures, while other (model) uncertainties are considered in the various model relations. The intermediary between pressures and responses on the one hand, and impacts on the other, is the state in terms of water (discharge, hydraulics and groundwater) and land (e.g. the elevation, land use and soil composition of the river bed).

The conceptual model covers the most salient issues of the Grensmaas project. Nonetheless, given the full inventory of goals, uncertainties and river management options of Chapter 4, some omissions can obviously be observed as well. Shipping ${ }^{56}$, landscape, and drinking water supply are examples of relevant issues that unfortunately are not covered in (the current version of) the iRM. Some included issues, on the other hand, were not mentioned by the stakeholders at all. Notably, the issue of flood damage has not been explicitly considered in the Maaswerken project that focussed on the criterion of flood recurrence alone. The recent National Water plan (V\&W, 2008), however, does highlight flood damage reduction (besides flood prevention) as an important element of the future Dutch water safety policy. Also, from the flood adaptation perspective that came to the fore in the Integral Exploration of the Meuse (see Chapter 4), flood damage reduction would play an essential role. Flood damage reduction (as opposed to only flood prevention) is thus a criterion that may well become more important over the coming decades.

\footnotetext{
${ }^{56}$ Although of no specific relevance for the Grensmaas project, shipping is a main issue for the Zandmaas/Maasroute project
} 


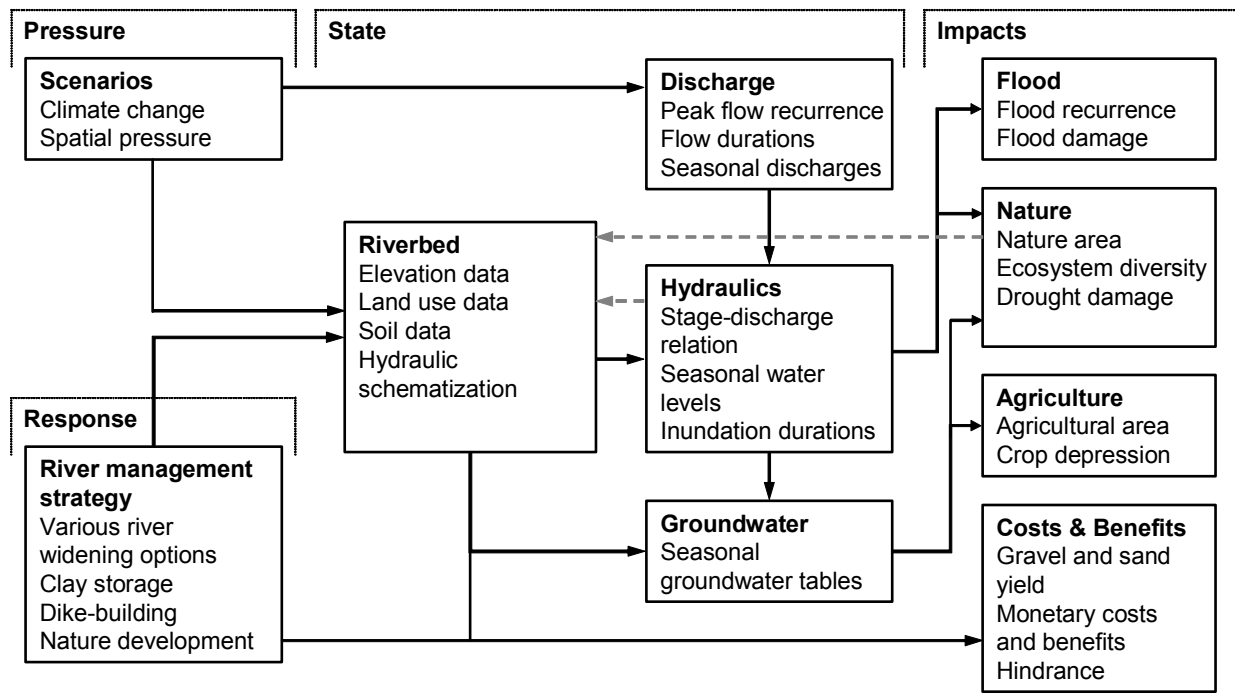

Figure 5.1: The concept of the integrated River Model showing all modules and the main relations between them. The dotted lines represent two 'minor' feedback loops regarding nature development and morphology.

Note that the model presented here is not so much a dynamic model - like the ones in the system dynamics and IA modelling traditions generally are- but rather a static one. The model primarily describes how a changed river bed state (e.g. through river widening), possibly in combination with specific context developments (e.g. climate change), leads to various state changes and impacts for the river functions. The model also includes few feedback loops. The two feedback relations (represented by the dotted lines) represent relatively 'minor' ones. Both the nature development feedback (river widening $\rightarrow$ nature development $\rightarrow$ increased hydraulic roughness $\rightarrow$ water level decrease) and the quite uncertain morphology feedback (river widening $\rightarrow$ increased morphological dynamics $\rightarrow$ further river bed changes) may to some extent reduce (or enhance) the effectiveness of the water level decrease obtained through river widening. However, they are not representative of the complexity of the river-actor system as a whole. The main complexities are assumed to emerge from the interaction between the river and actor system $^{57}$, which can be represented by applying the iRM in combination with a participatory ABM approach.

\footnotetext{
${ }^{57}$ One main feedback loop, for example, might be the spatial development feedback loop. Here, river system changes, through changes of land use suitability, influence actor decisions on spatial development, influencing the river system in turn. Another example might be the flood-learning feedback, where increased flood occurrence may lead to better abilities to cope with flooding, consequently decreasing flood damage (e.g. see Kok et al., 2005).
} 


\subsubsection{Model implementation}

The conceptual model was implemented for the case of a river cross-section representing a river engineering location, see Figure 5.2. This approach was chosen to be able to represent the interrelations between a variety of river management issues (e.g. flood protection, nature development, agriculture etc.) in a simple and transparent way, while avoiding the spatial complexity of a 2D spatial model.

Geographic data on elevation, land use and soil is represented on a '1D grid' (an array of data points). The land use model includes a limited number of main land use categories aggregated from the original LGN3 land use map (Alterra, 1999). Soil data specifies the thicknesses of the layers of clay and the so-called 'toutvenant'; the raw material that consists of a mixture of gravel, sand, and a non-marketable rest material. In addition, a hydraulic schematisation is adopted in the form of a composite rectangular cross-section, specifying for each section average elevation, width, hydraulic roughness, and (possibly) the elevation of a protecting dike. The following sections are distinguished (see Figure 5.2): the main channel (referring to the current flow channel), broadened main channel, excavated floodplain, and additional nature area (all created through river widening), the floodway and flood fringe (parts of the floodplain that respectively do and do not contribute to river flow), and housing area. The cross-section may contain a clay storage area, which - in Figure 5.2 - is located inside the 'additional nature area' section. Appendix B illustrates how an iRM cross-section is constructed on the basis of the available geographical data and SOBEK $^{58}$ hydraulic profiles (RWS, 2000a) for the river engineering location of Borgharen.

Table 5.1 presents an overview of the implementation of the various modules, specifying the main inputs and outputs, and methods applied. The implementations are based on a variety of sources, including existing expert models (such as INUNDA, AGRICOM, and Rhineflow/Meuseflow), textbook knowledge (for example for the hydraulics and groundwater calculations), project methodology from Maaswerken (for example in the EOW-index), and expert judgement from Maaswerken project managers (for example for calculating cost and benefits). The model was implemented in $\mathrm{C}++$ with a user interface in Java.

\subsubsection{Working with the model}

The iRM forms part of an overall framework to assess the interaction process between stakeholder agents and the river system. This process involves multiple iterations of 'action' (i.e. implementing a river management strategy) and 'perception' (i.e. evaluating river system change), as outlined in Figure 2.1. Here, we focus on the river model in its simplest form as a stand-alone application, working from input to output in a single iteration. As input, a user specifies a river management strategy and the settings for various model uncertainties, referred to as an uncertainty interpretation. As output, a user typically explores the various state and impact variables presented in Figure 5.1 for a given time horizon of, say, 25 years.

\footnotetext{
${ }^{58}$ SOBEK is a 1D hydraulic model, which has been made operational for the Meuse.
} 


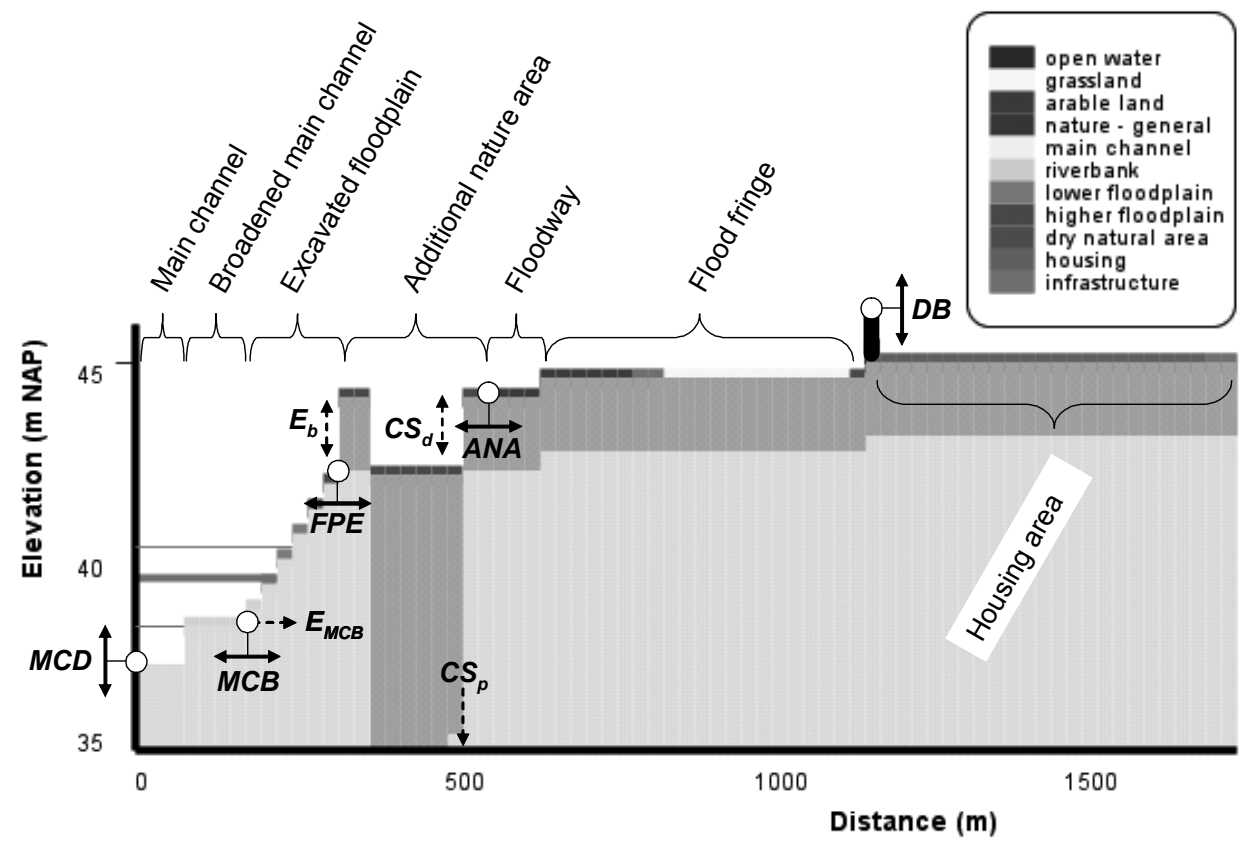

Figure 5.2: A typical iRM river cross-section after river widening. The cross-section model includes geographic data on elevation, land use, and soil (thickness of 'toutvenant' and clay). In addition, a composite rectangular hydraulic schematisation specifies average elevation, width, hydraulic roughness, and (possibly) dike elevation for a number of sections. A river management strategy may include main channel deepening $(M C D)$, main channel broadening $(M C B)$, flood plain excavation (FPE), additional nature area $(A N A)$, and dike-building $(D B)$. Also, it needs to specify the elevation of main channel broadening $\left(E_{M C B}\right)$, the brink elevation $\left(E_{b}\right)$, and the position $\left(C S_{p}\right)$ and depth $\left(C S_{d}\right)$ of the clay storage area.

\section{Specifying a river management strategy}

A river management strategy is represented with values for a number of strategy variables and strategy constants. The strategy variables indicate what should be done in terms of main channel deepening, main channel broadening, flood plain excavation, allocating additional nature area, and dike-building. The strategy constants further specify how this is done, including a specification of the main channel broadening elevation, the brink elevation, and the position and depth of clay storage (see Figure 5.2). The model user can modify the strategy variables as desired, and/or choose between several predefined strategies, such as the historical Green for Gravel strategy of 1991 (GFG1991) (Stroming, 1991), the Preferred Alternative of 1998 (PA1998) (Maaswerken, 1998a), and the Preferred Alternative of 2003 (PA2003) (Maaswerken, 2003a). Appendix $B$ illustrates how these historical river management strategies are schematised into an iRM cross-section for the location Borgharen. 


\begin{tabular}{|c|c|}
\hline Module & Description \\
\hline Riverbed & $\begin{array}{l}\text { The riverbed module updates the geographic data and hydraulic } \\
\text { schematization for a given river management strategy, and possibly a spatial } \\
\text { development scenario. It keeps track of the excavated volumes of clay and } \\
\text { toutvenant, and the final yields of gravel and sand. The calculations rely on a } \\
\text { number of soil parameters obtained through expert judgement (Expert } \\
\text { meeting 2002, see Appendix D). }\end{array}$ \\
\hline Discharge & $\begin{array}{l}\text { The discharge module calculates peak flow recurrence, flow durations of low- } \\
\text { to-moderate discharges, and average seasonal discharges, for a given } \\
\text { historical time-series of average monthly discharges. Peak flow recurrence is } \\
\text { calculated with the conditional peak method of Kwadijk (1993). A similar } \\
\text { approach is adopted for calculating flow durations. Climate change scenarios } \\
\text { are implemented as projected changes of the average monthly discharge } \\
\text { series as previously calculated with the Meuseflow model (Van Deursen, } \\
\text { 1999, 2000). }\end{array}$ \\
\hline Hydraulics & $\begin{array}{l}\text { The hydraulics module calculates the stage-discharge relation on the basis of } \\
\text { the Chezy equation for a composite rectangular cross-section (e.g. see Shaw, } \\
\text { 1994). To account for the backwater effect of bottlenecks, the calculated } \\
\text { water level changes are corrected with a discharge dependent 'effectiveness } \\
\text { parameter'. Using data on discharge and elevation, the module consequently } \\
\text { calculates average seasonal water levels, and inundation durations and flood } \\
\text { recurrences for the floodplain area. }\end{array}$ \\
\hline $\begin{array}{l}\text { Ground- } \\
\text { water }\end{array}$ & $\begin{array}{l}\text { The groundwater module calculates the change of average seasonal } \\
\text { groundwater tables in the floodplain area on the basis of the change of } \\
\text { seasonal river water levels obtained from the hydraulics module. Too this } \\
\text { end, a simple 1D solution of Darcy's equation is applied (e.g. see Strack, } \\
\text { 1989). }\end{array}$ \\
\hline Flood & $\begin{array}{l}\text { The flood module calculates flood damage for the different land use types } \\
\text { considered. The method for calculating flood damage is taken from the } \\
\text { INUNDA model (De Blois, 2000) and the Dutch 'standard method' (Kok et al., } \\
\text { 2005). The calculations rely on damage functions that specify damage as a } \\
\text { function of inundation depth. }\end{array}$ \\
\hline Nature & $\begin{array}{l}\text { The nature module calculates nature area, indicators of ecosystem diversity, } \\
\text { and average groundwater decrease in nature areas in the flood fringe as a } \\
\text { proxy for drought damage. Ecosystem types are allocated on the basis their } \\
\text { inundation duration, according to the ecosystem classification of Stroming } \\
\text { (1995). Consequently, ecosystem diversity is assessed with the so-called EOW } \\
\text { index (Stroming, 1995) and Shannon index (Maaswerken, 1998a). }\end{array}$ \\
\hline Agriculture & $\begin{array}{l}\text { The agricultural module calculates agricultural area and crop depression. } \\
\text { Following the methodology of the AGRICOM model (WL, 1995), crop } \\
\text { depression factors are determined with the so-called HELP tables (Brouwer \& } \\
\text { Huinink, 2002) that specify crop depression (due to both drought and wet } \\
\text { damage) as a function of groundwater table for different soil and crop types. }\end{array}$ \\
\hline
\end{tabular}

Table 5.1: An overview of the implementation of the various modules 


\begin{tabular}{|c|c|}
\hline $\begin{array}{l}\text { Costs \& } \\
\text { Benefits }\end{array}$ & $\begin{array}{l}\text { The cost \& benefits module calculates a variety of monetary costs (for } \\
\text { excavation, processing, and dike-building) and monetary benefits (from } \\
\text { exploitation of gravel and sand) which are summarized in a net cost and } \\
\text { profitability. The module also includes a non-monetary cost in the form of } \\
\text { sound hindrance from toutvenant processing. The calculations rely on a } \\
\text { number of cost and benefit parameters obtained through expert judgement } \\
\text { (Expert meeting 2002, see Appendix D). }\end{array}$ \\
\hline
\end{tabular}

Table 5.1 continued.

\section{Specifying the uncertainty interpretation}

The projected consequences of the river management strategy depend on the interpretation of various uncertainties involved (see Table 5.2). First, the uncertainty interpretation reflects anticipated pressures, here referred to as context uncertainty. Too this end, a user can choose between various climate scenarios (i.e. the so-called G, W, G+, W+ scenarios currently adopted as a standard in Dutch water management) and alternative projections for the development of built-up and agricultural land. Second, the uncertainty interpretation relates to choices for uncertain model parameters, here referred to as model uncertainty. Relevant uncertain parameters are grouped into categories like 'cost parameters', 'morphological parameters', 'hydraulic parameters', and so on. For each parameter group, the user can adopt - on a continuous scale - an estimate between a 'low' (-1) and 'high' value $(+1)$, corresponding to the upper or lower ends of the so-called 'typical ranges' of the model parameters specified in Table 5.7. Given those typical ranges, the chosen estimates are readily used to specify the settings of the corresponding model parameters in the iRM.

\begin{tabular}{|l|l|}
\hline Context uncertainty & Description \\
\hline Climate scenario & G, W, G+, W+ (KNMI, 2006; Van Deursen, 2006, 2007) \\
\hline $\begin{array}{l}\text { Spatial development } \\
\text { scenario }\end{array}$ & $\begin{array}{l}\text { Alternative projections for built-up and agricultural area (Van } \\
\text { Asselt et al., 2001) }\end{array}$ \\
\hline Model uncertainty & Description \\
\hline Soil parameters & Parameters related to soil density and content \\
\hline Cost parameters & Parameters related to excavation and processing cost \\
\hline Benefit parameters & Parameter related to gravel and sand benefits \\
\hline $\begin{array}{l}\text { Conditional peak } \\
\text { parameters }\end{array}$ & $\begin{array}{l}\text { Statistical parameters of the conditional peak method that } \\
\text { determine the recurrence times of peak discharges }\end{array}$ \\
\hline $\begin{array}{l}\text { Hydraulic roughness } \\
\text { parameters }\end{array}$ & The hydraulic roughness of the various ecosystem types \\
\hline $\begin{array}{l}\text { Morphology } \\
\text { parameter }\end{array}$ & $\begin{array}{l}\text { Specifies the amount of erosion of the broadened main } \\
\text { channel }\end{array}$ \\
\hline Economic values & Economic values of the various land use types \\
\hline
\end{tabular}

Table 5.2: Specifying the uncertainty interpretation. A user can specify the settings for various context and model uncertainties in the iRM. 


\section{Analysing the model results}

After testing the strategy, the model results can be analysed. The state variables are visualized in the 'Show River' view of Figure 5.3. The updated river cross-section shows the implications for elevation, land use, soil, average river water and groundwater levels, and inundation durations and frequencies in the floodplain area. A graph displays the updated discharge characteristics (i.e. directly related to the adopted climate scenario), and a detailed view on the new stagedischarge relation. A second view (not shown here) is used to show the main impact variables ${ }^{59}$, e.g. regarding flood risk, nature development, agriculture, and costs (see Table 5.3). More detailed background information - for example on flood damage per economic sector - can be investigated by clicking through to yet another view.

\begin{tabular}{|l|l|l|}
\hline Variable & Unit & Description \\
\hline$F_{\text {rec }}$ & yrs & Flood recurrence time \\
\hline$D_{y}$ & $\mathrm{k} € / \mathrm{yr}$ & Yearly average flood damage \\
\hline$\Delta H_{Q=3275}$ & $\mathrm{~m}$ & $\begin{array}{l}\text { Water level decrease at the current 1:250 design discharge } \\
\left(Q=3275 \mathrm{~m}^{3} / \mathrm{s}\right)\end{array}$ \\
\hline$N_{\text {new }}$ & ha & $\begin{array}{l}\text { New nature area (change in natural area compared to } \\
\text { current state) }\end{array}$ \\
\hline$E O W$ & - & Nature diversity measured with the EOW index \\
\hline$S$ & - & Nature diversity measured with the Shannon index \\
\hline$\Delta A S G_{\text {nature }}$ & $\mathrm{m}$ & $\begin{array}{l}\text { Change of average spring groundwater table (ASG) in } \\
\text { existing natural area compared to the current state }\end{array}$ \\
\hline$A A_{\text {loss }}$ & ha & $\begin{array}{l}\text { Agricultural area loss (change in agricultural area compared } \\
\text { to the current state) }\end{array}$ \\
\hline$\Delta A S G_{\text {agri }}$ & $\mathrm{m}$ & $\begin{array}{l}\text { Change of average spring groundwater table (ASG) in } \\
\text { agricultural area compared to current state }\end{array}$ \\
\hline$B_{\text {net }}$ & M€ & Net benefits \\
\hline$P$ & $\%$ & Profitability \\
\hline$H$ & pers*yrs & Hindrance \\
\hline$Y_{\text {gravel }}$ & Mton & Gravel yield \\
\hline
\end{tabular}

Table 5.3: Default set of main impacts included in the iRM

\footnotetext{
${ }^{59}$ Naturally, what exactly constitutes a main impact is a subjective choice. Therefore, a user can redefine its list of main impacts as pleased.
} 


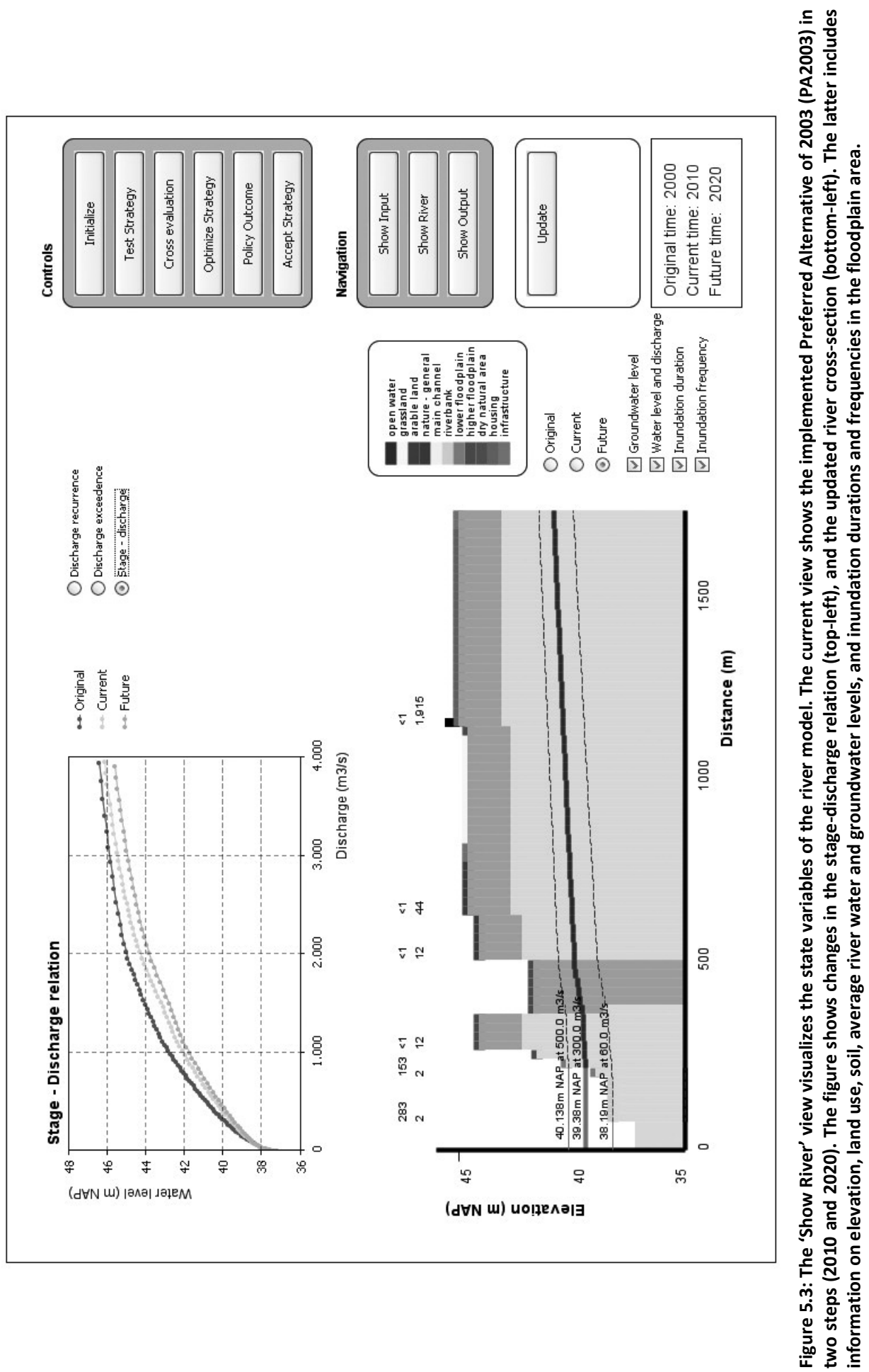




\subsection{MODEL DESCRIPTION}

In the following, the various iRM modules are further described.

\subsubsection{Excavation, costs, and hindrance}

The 'riverbed' and 'cost and benefits' modules are used to calculate the excavated volumes and net yields of gravel, sand, and clay, and the associated costs and benefits. In this thesis, costs and benefits refer to any temporary effects of river engineering, evaluated negatively (costs) or positively (benefits). This includes monetary cost and benefits, and non-monetary costs, like hindrance for the surrounding inhabitants.

\section{Gravel and sand yield}

River widening entails the excavation of significant amounts of 'toutvenant' (TV) and clay, eventually leading to a net yield of marketable gravel and sand. TV contains a mixture of gravel, sand and rest material that are separated through some processing procedure. The excavated amounts of clay and rest material are stored in a pit in the floodplain area, here referred to as the clay storage area, thus increasing the amount of excavated TV.

After implementing a river widening strategy, the riverbed module is readily used to calculate the excavated volumes of toutvenant $\left(T V_{\text {wide }}\right)$ and clay $\left(C L A Y_{\text {wide }}\right)$. Correcting for the expansion of the clay volume, and adding to this volume the toutvenant rest material, this results in a total storage volume:

$$
S_{V}=E X P_{\text {clay }}{ }^{*} C L A Y_{\text {wide }}+F_{\text {rest }}{ }^{*} T V_{\text {wide }},
$$

with $E X P_{\text {clay. }}$ the expansion coefficient for the excavated clay (some $10 \%$ ), and $F_{\text {rest }}$ the fraction of TV rest material. Consequently, the riverbed module is used to update the schematisation data for storing the volume $S_{V}$, keeping track of the excavated volume of toutvenant $T V_{\text {store }}{ }^{60}$ The total excavated volume of toutvenant $T V_{t o t}$ then includes the two contributions from clay storage and river widening:

$$
T V_{\text {tot }}=T V_{\text {wide }}+T V_{\text {store }}
$$

Part of this volume may be directly used (so before processing) for main channel elevation, as part of the river management strategy. In that case, the total volume is corrected with the elevation volume $T V_{\text {elevation }}$ to yield the net excavated volume:

$$
T V_{\text {net }}=T V_{\text {tot }}-T V_{\text {elevation }}
$$

\footnotetext{
${ }^{60}$ The amount of $T V_{\text {store }}$ is generally somewhat higher than the storage volume $S V$, since, again, this procedure takes clay expansion and the addition of toutvenant rest volume into account. $T V_{\text {store }}$ can be further increased by lowering the clay storage surface elevation.
} 
Finally, the mass yields $Y$ of gravel and sand are calculated on the basis of the soil density $S D$ (mass per unit volume) and the respective weight fractions $F_{\text {gravel }}$ and $F_{\text {sand }}$ :

$$
Y_{\text {gravel/sand }}=T V_{\text {net }}{ }^{*} S D * F_{\text {gravel/sand }} \text {. }
$$

\section{Monetary costs and benefits}

The total monetary costs of the river management strategy consist of the excavation costs $C_{\text {exc }}$ processing costs $C_{\text {proc }}$, as well as a possible contribution from dike-building $C_{\text {dike: }}$ :

$$
C_{\text {tot }}=C_{\text {exc }}+C_{\text {proc }}+C_{\text {dike }} \text {. }
$$

The different contributions are calculated as

$$
\begin{gathered}
C_{e x c}=T V_{\text {tot }}{ }^{*} E C_{T V}+C L A Y_{\text {tot }}{ }^{*} E C_{\text {clay }}, \\
C_{\text {proc }}=T V_{\text {net }}{ }^{*} P C_{T V}, \\
C_{\text {dike }}=V_{\text {dike }}{ }^{*} C_{\text {dike }}^{\prime},
\end{gathered}
$$

with $E C_{T V}$ the extraction cost per unit volume of TV $\left(€ / \mathrm{m}^{3}\right), E C_{\text {clay }}$ the extraction cost per unit volume of clay $\left(€ / \mathrm{m}^{3}\right), P C_{T V}$ the processing cost per unit volume of TV $\left(€ / \mathrm{m}^{3}\right), V_{\text {dike }}$ the total volume required for dike-building $\left(\mathrm{m}^{3}\right)^{61}$, and $C_{\text {dike }}^{\prime}$ the cost for dike-building per unit volume $\left(€ / \mathrm{m}^{3}\right)$. Finally, the total costs are multiplied with an overhead factor $C_{O H}$ representing additional costs for miscellaneous civil works (roads, pipes etc.):

$$
C_{t o t} \rightarrow C_{t o t}{ }^{*} \mathrm{C}_{\mathrm{OH}} \text {. }
$$

The total monetary benefits $B_{\text {tot }}$ are directly related to the mass yields of gravel and sand:

$$
B_{\text {tot }}=Y_{\text {gravel }}{ }^{*} P_{\text {gravel }}+Y_{\text {sand }}{ }^{*} P_{\text {sand }} \text {, }
$$

with $P_{\text {gravel }}$ and $P_{\text {sand }}$ the gravel and sand price respectively ( $€ /$ ton). The net benefits $B_{\text {net }}$ are then calculated as:

$$
B_{\text {net }}=C_{\text {tot }}-B_{\text {tot }} \text {, }
$$

and the profitability $P$ is given by

$$
P=C_{n e t} / C_{t o t} .
$$

\section{Hindrance}

Hindrance, finally, is considered as a main non-monetary cost. At the location of Borgharen, hindrance originates primarily from noise pollution as a result of TV processing. Following

\footnotetext{
${ }^{61}$ Assuming a triangular shape of the dike
} 
(Maaswerken, 1998a), this sound hindrance is expressed in terms of hindered persons * years. Neglecting the spatial aspects of TV processing (e.g. the choice of processing location), sound hindrance is assumed to be linearly related to the net excavated (i.e. the processed) volume of toutvenant:

$$
H=T V_{\text {net }}{ }^{*} H_{\text {proc }},
$$

with $H_{\text {proc }}$ the hindrance per unit volume of processed toutvenant (person*years $/ \mathrm{Mm}^{3}$ ).

\begin{tabular}{|l|l|l|}
\hline Parameter & Description & Estimated value \\
\hline$E X P_{\text {clay }}$ & Expansion coefficient for clay (-) & 1.1 \\
\hline$S D$ & Soil density (ton $\left./ \mathrm{m}^{3}\right)$ & 1.9 \\
\hline$F_{\text {gravel }}$ & Mass fraction gravel in toutvenant (-) & 0.71 \\
\hline$F_{\text {sand }}$ & Mass fraction sand in toutvenant (-) & 0.18 \\
\hline$F_{\text {rest }}$ & Mass fraction rest material in toutvenant (-) & 0.11 \\
\hline$E C_{T V}$ & Excavation costs toutvenant $\left(€ / \mathrm{m}^{3}\right)$ & 3.5 \\
\hline$E C_{\text {clay }}$ & Excavation costs clay $\left(€ / \mathrm{m}^{3}\right)$ & 3.0 \\
\hline$P C_{T V}$ & Toutvenant processing costs $\left(€ / \mathrm{m}^{3}\right)$ & 4.5 \\
\hline$C_{\text {dike }}^{\prime}$ & Costs dike-building $\left(€ / \mathrm{m}^{3}\right)$ & 200 \\
\hline$C_{O H}$ & Overhead costs $(-)$ & 1.1 \\
\hline$H_{\text {proc }}$ & Hindrance toutvenant processing (person*years $\left./ \mathrm{Mm}^{3}\right)$ & 27 \\
\hline$P_{\text {gravel }}$ & Gravel price ( $($ ton) & 7.0 \\
\hline$P_{\text {sand }}$ & Sand price $(€ /$ ton) & 4.0 \\
\hline & & \\
\hline
\end{tabular}

Table 5.4: Overview of the main model parameters for calculating gravel excavation, costs, and hindrance. The estimated values are partly based on the judgement of Maaswerken experts, and partly obtained from various Environmental Impact Assessment reports (Maaswerken, 1998e; Maaswerken, 2003a). See also Table $\mathbf{5 . 7}$ for an overview of all model parameters in the iRM.

\subsubsection{Discharge}

The discharge module calculates peak flow recurrence, the flow durations of low-to-moderate discharges, and average seasonal discharges, for a given historical time-series of average monthly discharges.

\section{Peak flow recurrence}

The recurrence time of peak flows is defined as the average time span between the occurrence of peak discharges, for the Meuse typically $>1500 \mathrm{~m}^{3} / \mathrm{s}$. Peak flow recurrence is an important criterion in Dutch river management, because - given a flood norm - it determines the so-called 'design discharge' used for flood management. In the current situation, peak flow recurrence is assessed on the basis of statistical analysis of the historical time series of daily discharges (RIZA, 2001), which is updated every 5 years. Climate change, which is projected to cause increased precipitation intensity and variability across the Meuse catchment, will most probably lead to an increase in the recurrence times of peak flows. Changes in average monthly discharge as a result 
of climate change are assessed with rainfall-runoff models such as Rhineflow (Kwadijk, 1993) and Meuseflow (Van Deursen, 1999, 2000). Change of peak flow recurrence, however, is not easily assessed, since it depends on the occurrence of extreme rather then average values.

One way to assess changes of peak flow recurrence as a result of climate change is the 'conditional peak method' (CPM). This method was designed to estimate the impacts of climate change on the occurrence of peak discharge of the River Rhine (Kwadijk, 1993). The key assumption underlying the CPM is that the statistical relation between average discharges and the occurrence of peak discharges remains invariant under climate change. This statistical relation is derived from historical data, specifying series of monthly average discharge values and the observed peak discharges in that month ${ }^{62}$. This results in a number of probability density functions that specify the probability of occurrence of a peak discharge $Q_{p}$, given an average monthly discharge $Q_{m}$, for a number of discharge ranges (or 'discharge classes'). The distribution functions are fitted to a log normal distribution, parameterized by a mean $\mu$ and a standard deviation $\sigma$. Once the various probability density functions are known (i.e. when the $\mu^{\prime} s$ and $\sigma$ 's for all discharge classes have been derived), given changes in average monthly discharges are readily translated to changes in the probability of peak discharges. A detailed description of the conditional peak method and its application for the River Meuse is presented in Appendix A.

\section{Flow durations}

The flow duration curve specifies the number of days per year a given discharge is exceeded. The current flow duration curve can be expected to change as a result of climate change, and the consequent changes in the average monthly flow pattern. However, it is not a priori clear how projected changes in monthly average discharge values can be downscaled to projected changes on the daily level.

To do so, a methodology is adopted similar to the CPM. From the historical daily discharge data, first the monthly flow duration curves $f d_{Q m}$ were derived that specify the average fraction of time a critical discharge $Q_{c}$ is exceeded for a month with a given average discharge $Q_{m}$ for a selected number of discharge classes. Eventually, only two discharge classes were distinguished $\left(Q_{m}<100 \mathrm{~m}^{3} / \mathrm{s}\right.$ and $\left.Q_{m}>100 \mathrm{~m}^{3} / \mathrm{s}\right)$, since the monthly flow duration curves were found to be strongly homogeneous for average monthly discharges larger than $100 \mathrm{~m}^{3} / \mathrm{s}$. The associated $f d_{Q m}$ 's are incorporated directly in the river model as predefined functions, without the parameterization used in the CPM. Again, under the assumption that the monthly flow duration curves are invariant under climate change, a change in yearly flow duration is readily calculated once projected changes in average monthly discharges are given. A detailed description of the method and its application for the River Meuse is presented in Appendix A.

\section{Seasonal discharges}

Seasonal discharges are readily determined from the historical time series of average monthly discharges. Three seasons are defined: winter (October - March), spring (April - June), and summer (July - September).

\footnotetext{
${ }^{62}$ One can choose also smaller time units, like 10-day periods.
} 


\subsubsection{Hydraulics}

The hydraulics module calculates the stage-discharge relation, and, consequently, the average seasonal water levels, and inundation durations and flood recurrences for the floodplain area.

\section{Stage-discharge relation}

The stage-discharge relation specifies the relation between the discharge and water level in a flow channel. Under conditions of a) one dimensional flow (in the direction of river alone without perpendicular components), b) stationary flow (constant over time), and c) uniform flow (constant in the flow direction), this relation is well estimated with the equation of Chézy (see e.g. Shaw, 1994; Ribberink et al., 1999):

$$
Q=A * \sqrt{R} * C * \sqrt{i_{B}} .
$$

Here, $Q$ is the discharge $\left(\mathrm{m}^{3} / \mathrm{s}\right), A$ is the wetted surface $\left(\mathrm{m}^{2}\right), R$ the wetted radius $(\mathrm{m})$, and $i_{B}$ the river bottom slope. The Chézy coefficient is a measure of the bottom friction of water flow. For a hydraulically rough surface it is expressed in terms of the Nikuradse roughness coefficient $k_{s}$ as:

$$
C=18 *{ }^{10} \log \left(12 R / k_{s}\right)
$$

The value of $k_{s}$ is related to surface topography, ranging from $1 \mathrm{~cm}$ for relative smooth sandy riverbeds, to several meters for rough vegetated terrains (Ribberink et al., 1999). For a given composite rectangular cross-section, Chezy's equation is readily applied to calculate the stagedischarge relation.

\section{Backwater effects}

In its current state, the river channel of the Grensmaas can be considered sufficiently homogeneous to consider river flow uniform. The Chézy equation then gives a fair representation of the stage-discharge relation (see the calibration results for the current state). After river engineering, however, the assumption of a homogeneous cross-section will no longer hold. The river stretch will consist of a sequence of widened sections, alternated with relatively tight sections ('bottlenecks'), due to which significant backwater effects will occur.

These backwater effects are taken into account by introducing a discharge dependent hydraulic effectiveness parameter:

$$
E_{H}(Q) \equiv \frac{\Delta h_{a c t}}{\Delta h_{\max }}
$$

It represents the ratio between the maximum water level decrease $\Delta h_{\max }$ that would be obtained when river widening would occur homogeneously over a river stretch, and the actual water level decrease $\Delta h_{a c t}$ in the situation with remaining bottlenecks.

The effectiveness parameter is calculated in the following way. Assume that the river stretch is composed of an alternating sequence of widened sections of length $I_{w}$ and narrow sections of length $I-I_{w}$, see Figure 5.4. The widened and narrow sections are characterized by their respective equilibrium water levels $h_{e}=h_{w}$ and $h_{e}=h_{n}$ (both as a function of the discharge $Q$ ). 
The actual water level curve $h(x)$ then consists of a series of so-called 'backwater curves' fluctuating between $h_{w}$ and $h_{n}$, constrained by the downstream boundary condition $h(0)=h_{n}$.

The backwater curves can be calculated on the basis of the so-called equation of Bélanger, which applies to stationary, non-uniform flow. For the case of a locally homogeneous cross-section, (Nieuwkamer, 1995) presents an approximate solution to this equation:

$$
h(x)=h_{e}+\left[h(0)-h_{e}\right] \exp \left(-x / L_{a}\right)
$$

with $x$ the distance measured in the direction opposite to river flow, $h_{e}$ the local equilibrium depth, $h(0)$ a downstream boundary condition, and $L_{a}=h_{e} / 3 i_{b}$ the discharge dependent adaptation length ${ }^{63}$. Using this equation, the water levels at the consecutive nodes $i$ in Figure 5.4 can be iteratively calculated. Starting from the downstream boundary condition $h_{0}=h_{n}$, one easily applies Equation 5.15 to calculate the water level $h_{1}$, which forms the next boundary condition for calculating $h_{2}$, and so on. Now, consider the water level at the troughs (i.e. for odd i) far away from the original downstream boundary (i.e. in the limit $i \rightarrow \infty$ ) to be an adequate proxy for the actual water level $h_{\text {act }}$. Substituting in Equation 5.14, one then finds for the hydraulic effectiveness parameter (see Appendix C):

$$
E_{H}(Q)=\frac{h_{n}-\lim _{i \rightarrow \infty} h_{2 i+1}}{h_{n}-h_{w}}=\frac{1-\exp (-f / L)}{1-\exp (1 / L)},
$$

with $f \equiv I_{w} /$ I the fraction of widened river length and $L \equiv L_{a} / /$ the dimensionless adaptation length. The hydraulic effectiveness is thus a function of the (locally determined) and discharge dependent adaptation length, mediated by the two parameters $f$ and $/$ that describe the river widening profile in the longitudinal direction.

Note that the adaptation length increases with discharge, thus decreasing the effectiveness of river widening for higher discharges. This is illustrated in Figure 5.5, which displays the effectiveness parameter as a function of $L$ for a number of values of $f$. For small values of $L$ $(\sim 0.1)$, the effectiveness approaches unity. For large values of $L(\sim>10)$, the effectiveness approaches the value of $f$. For typical values of $I=5 \mathrm{~km}$ and $f=0.6$, and for discharges between 500 and $3000 \mathrm{~m}^{3} / \mathrm{s}$, the corresponding effectiveness ranges between some 70 and $80 \%$.

\footnotetext{
${ }^{63}$ The adaptation length intuitively represents the distance over which an in-homogeneity in the riverbed (e.g. a 'bottleneck') significantly affects the water level in the upstream direction. For the Grensmaas it typically varies between $1 \mathrm{~km}$ for low discharges $\left(\sim 100 \mathrm{~m}^{3} / \mathrm{s}\right)$ and $6 \mathrm{~km}$ for extreme discharges $\left(\sim 4000 \mathrm{~m}^{3} / \mathrm{s}\right)$.
} 


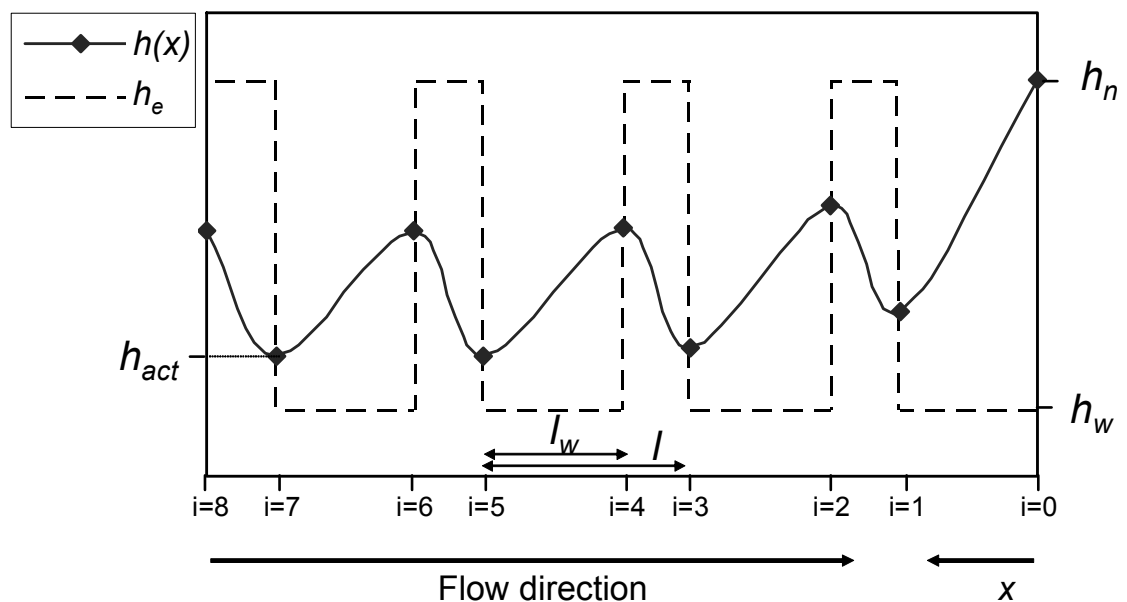

Figure 5.4: Schematic representation of a river stretch in the longitudinal direction for determining the effectiveness parameter $E_{H}$.

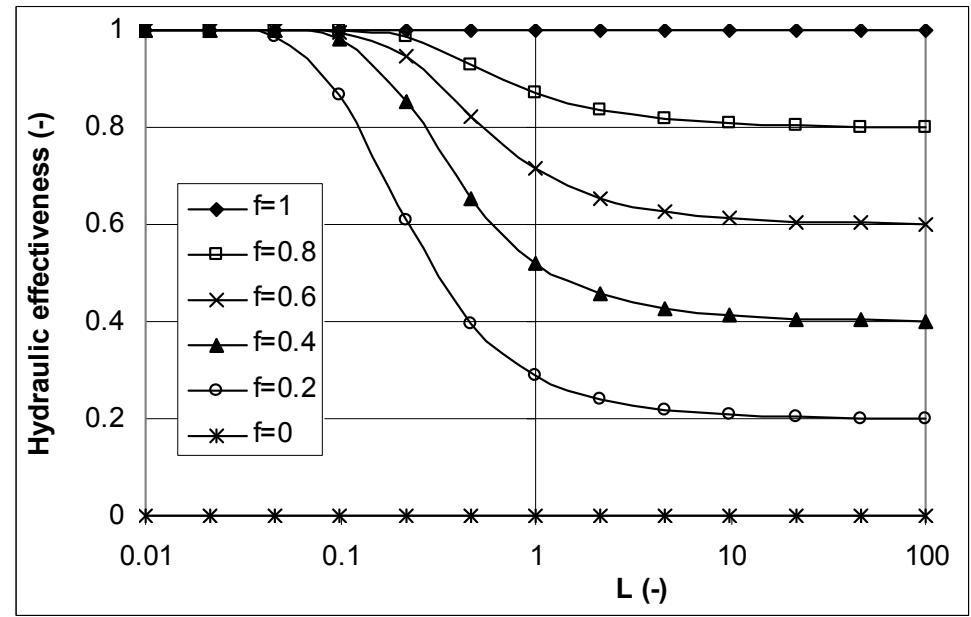

Figure 5.5: The hydraulic effectiveness parameter of Equation 5.16 as a function of $L$ for different values of $f$.

\section{Vegetation roughness and morphology}

The stage-discharge relation that applies directly after river widening will change further due to nature development (changing the hydraulic roughness) and morphological processes (modifying the river bed geometry) on the long-term. Therefore, the stage-discharge calculation is iterated twice. First, the initial stage-discharge relation is calculated. Second - after nature development, morphological changes, and the updated values for hydraulic roughness and schematisation are obtained - the calculation is repeated to find the stage-discharge relation on the long-term. 
The change in hydraulic roughness due to nature development is assessed, first, by applying the nature module to allocate the proper ecosystem types to the widened river sections on the basis of the initial stage-discharge relation. Following, the hydraulic schematisation is readily updated on the basis of the corresponding vegetation roughness values (see Table 5.7). Change in riverbed geometry due to morphological processes is implemented through the so-called morphological parameter $E R_{B M C}$ that specifies the level of erosion in the broadened main channel bed (Maaswerken, 2003a).

\section{Seasonal water levels, inundation duration, and flood recurrence}

On the basis the stage-discharge relation, the seasonal water levels, and the inundation durations and flood recurrences in the floodplain area are readily obtained. The inundation durations and flood recurrences are assessed in the following way. First, for each grid cell the critical water level at which the cell would be flooded is assed from the elevation data, possibly taking the height of a protecting dike into account. The critical water levels are compared to the stage-discharge relation to find the critical discharges at which inundation occurs. Consequently, by comparing the critical discharges to the flow duration and peak flow recurrence curves, the inundation duration and flood recurrence are found for each grid cell. The seasonal water levels, finally, are obtained through a direct comparison of the seasonal discharges (obtained from the discharge module) with the stage-discharge relation.

\subsubsection{Groundwater}

The groundwater module calculates the change of seasonal groundwater tables as a result of changes in the average seasonal river water levels. We distinguish the average spring groundwater table (ASG), the average low groundwater table (ALG) in summer, and the average high groundwater table (AHG) in winter.

\section{Modelling groundwater flow}

A simple representation of groundwater flow is adopted, based on the following starting points: groundwater flow is unconfined (no impervious top-layer), stationary (time independent), horizontal (the vertical dimension of the aquifer is neglected), and occurs only in the direction perpendicular to the river stretch (1D). Under these conditions, the basic equations for groundwater (the equations of Darcy and continuity) flow take a simple form (Strack, 1989). Defining a discharge potential:

$$
\Phi(x) \equiv \frac{1}{2} k h(x)^{2}
$$

one finds:

$$
\Phi=Q x+C
$$

with $h(x)$ the groundwater table $(\mathrm{m}), k$ the hydraulic conductivity $(\mathrm{m} / \mathrm{s}), Q$ the specific discharge (discharge per unit width) $\left(\mathrm{m}^{2} / \mathrm{s}\right)$, and $C$ an integration constant. For a uniform hydraulic conductivity $k$, the groundwater table is thus readily calculated, given two boundary conditions to solve for $Q$ and $C$. For given groundwater tables $h_{0}$ at the river bank and $h_{L}$ at a far distance $L$, one obtains the groundwater level curve illustrated in Figure 5.6 a). In the iRM, these boundary conditions are given by the seasonal river water levels $\left(h_{0}\right)$ obtained from the hydraulics module 
and constant seasonal groundwater tables $\left(h_{\mathrm{L}}\right)$ at the boundary where the influence of the river water level on the groundwater table ceases ( $10 \mathrm{~km}$, see Maaswerken, 2003a).

\section{Representing clay storage}

A clay storage area implies a local change in the hydraulic conductivity $k$. Given the boundary conditions continuity of the specific discharge $Q$, and continuity of the groundwater table $h$, this implies a jump in the discharge potential (De Lange, 1996). At the interface of two volumes with hydraulic conductivities $k_{1}$ and $k_{2}$, the jump in discharge potential is given by:

$$
\Phi_{2}-\Phi_{1}=\Phi_{1} *\left(\frac{k_{2}}{k_{1}}-1\right)
$$

For solving Equation 5.18, one can thus no longer assume a uniform constant $C$ over the considered length. Rather, one needs to consider three different constant values before $\left(C_{1}\right)$, within $\left(C_{2}\right)$, and behind $\left(C_{3}\right)$ the clay storage area. The problem is thus reduced to solving four unknowns $\left(Q, C_{1}, C_{2}, C_{3}\right)$, given four boundary conditions $\left(h_{0}, h_{L}\right.$, and the two interface conditions), which is readily done. Figure $5.6 \mathrm{~b}$ ) illustrates how the clay storage acts as a barrier to groundwater flow, pushing up the groundwater table behind the storage area.

\section{Correction factor for lateral flow}

In the discussion above, it is implicitly assumed that the clay storage area pertains over the entire cross-section length. In reality, however, the clay shield only stretches along a part of it. A significant fraction of groundwater flow will occur alongside the clay barrier, reducing the effectiveness of the clay storage as a barrier to groundwater flow. To account for this effect, the hydraulic conductivity of clay is multiplied with a so-called correction factor for lateral flow $C_{L F}$ :

$$
k_{\text {clay }}^{\prime}=C_{L F} * k_{\text {clay }}
$$

with $k_{\text {clay }}$ the real hydraulic conductivity of clay, and $k_{\text {clay }}^{\prime}$ the value used in the model. In other words, the hydraulic conductivity of clay is 'artificially' increased. The value of $C_{L F}$ follows from calibration, see Section 5.4.3.

\section{Representing seepage}

It is an explicit aim of Maaswerken to create seepage areas in the excavated floodplain (e.g. see Stroming, 1991). Seepage occurs when the groundwater table exceeds the ground level, so that part of the groundwater flow occurs along the ground surface. In the model, this is implemented in the following way. First, Equation 5.18 is solved given the initial river side boundary condition $h(0)=h_{0}$. Starting at the river side, the groundwater table is calculated for consecutive grid points. When the calculated table at grid point $i$ exceeds the ground elevation (indicating seepage) the calculation is 'overruled', and the groundwater table is set equal to the ground elevation $E_{i}$. The groundwater calculation then proceeds starting from grid point $i$, solving Equation 5.18 again for the new left hand side boundary condition $h(i)=E_{i}$. This procedure may be repeated several times until the groundwater water table falls again below the ground elevation. In a seepage area, the groundwater table thus follows the ground level, as illustrated in Figure $5.6 \mathrm{c}$ ). 


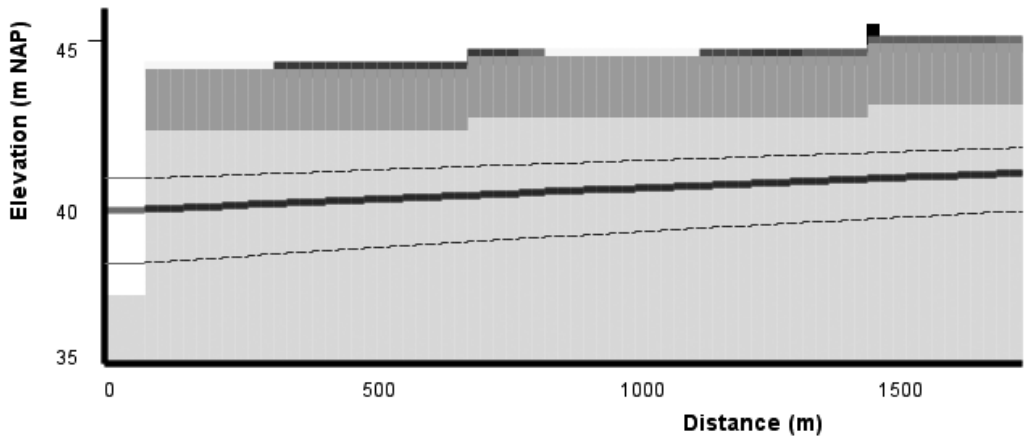

a)

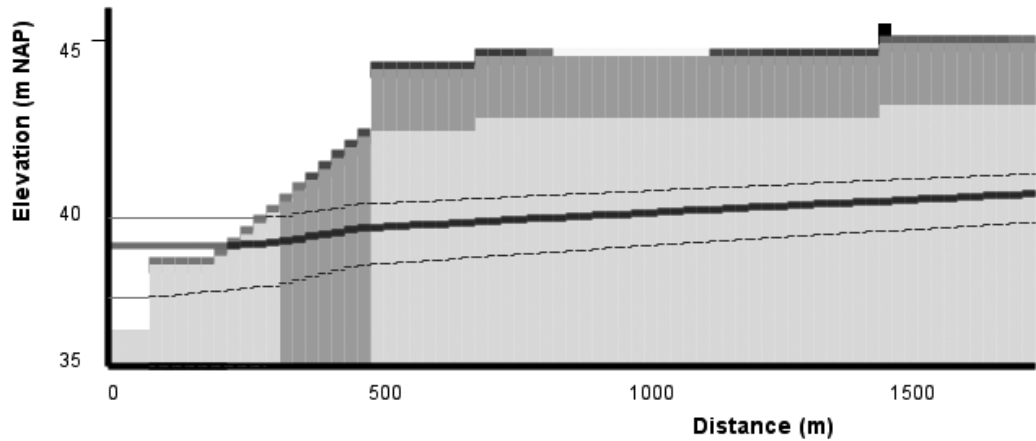

b)

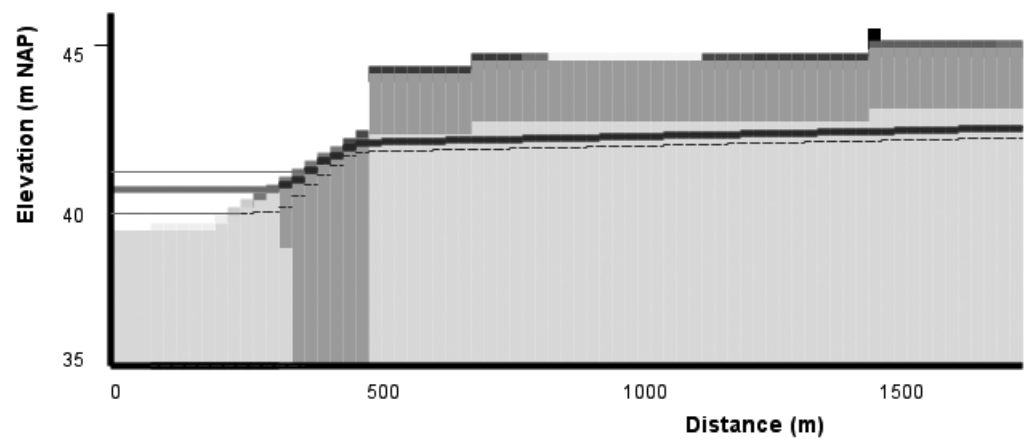

c)

Figure 5.6: Three cases of groundwater flow: a) current state, b) after river widening with clay storage, and c) with seepage.

\subsubsection{Flood damage}

The flood module calculates yearly average flood damage for the different land use types considered. 


\section{Calculating flood damage}

Flood damage is calculated following the so-called 'standard method' for calculating flood damage in the Netherlands (De Blois, 2000; Kok et al., 2005). This method is based on the assumption that flood damage depends primarily on the inundation depth and the economic value of the inundated area. For a given flood - characterised by some peak discharge $Q$ - one calculates first the inundation depth $i d$ at each grid point $i$ as the difference between the ground elevation and the river water level $h$ (taking possible dike protecting into account). The damage at each grid point is then calculated as the product of its maximum economic value $E V_{l u}$ and a damage function $D F_{l u}$ that specifies the fraction of economic value lost as a function of the inundation depth, where both the economic value and damage function depend on the land use type lu under concern. The total damage $D_{Q}$ - if desired specified per land use type - is obtained by summarizing the individual contributions over the grid:

$$
D_{Q}=\sum_{i} E V_{l u}^{*} D F_{l u}\left(i d_{i}\right)
$$

This conceptually simple approach for calculating flood damage is sufficiently detailed for our purpose. ${ }^{64}$ Note, however, that it depends critically on the economic values and damage functions used. These data are clearly location specific and may change over time, for example as a result of improved flood preparedness (e.g. timely evacuation) and - on the longer term new land use designs (e.g. floating houses). In the iRM, two sets of damage functions/economic values have been considered: the ones derived as part of the flood assessment of the ' 93 flood (WL, 1994c) and the ones currently used as part of the standard method (Kok et al., 2005). Eventually, the damage functions from the standard method were adopted (see Figure 5.7), with the economic values calibrated to best reproduce the observed damage for the ' 93 flood (see the Sensitivity analysis of Section 5.4.2). The uncertainty in the economic values is further reflected in their typical range, which - following (Kok et al., 2005) - allows for a reduction of economic values of $25 \%$ (see Table 5.7 ).

\section{Yearly average damage}

Yearly average flood damage is then calculated as follows. We consider a range of damage values $D_{n}$ calculated for discharges with increasing recurrence times $R T_{n}$. The highest recurrence time considered is denoted $R T_{\max }$. The average yearly flood damage $D_{y}$ over the period $R T_{\max }$ is then calculated as a weighted sum of all damages $D_{n}$ :

$$
D_{y}=\frac{1}{R T_{\max }} \sum_{n=0}^{n_{\max }} D_{n}{ }^{*} W_{n} .
$$

\footnotetext{
${ }^{64}$ For a more detailed assessment of flood damage, taking into account, for example, the influence of flow velocities and the rate at which water rises, see (Jonkman et al., 2008).
} 


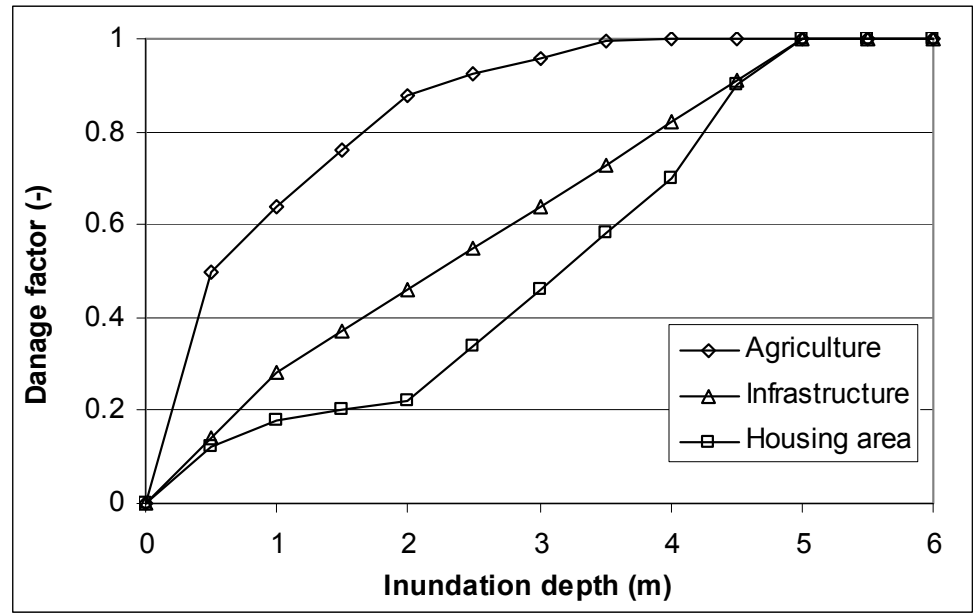

Figure 5.7: Damage functions for the land use types 'agriculture' (equal for arable land and grassland), 'infrastructure' and 'housing area' specify the fraction of the economic value lost as a function of inundation depth. After (Kok et al., 2005).

The weights $W_{n}$ intuitively correspond to the number of times the flood damage $D_{n}$ occurs over the period considered. This number is obviously related to the ratio $R T_{\max } / R T_{n}$; i.e. a 20 year flood occurs on average 5 times in 100 years. However, this ratio overestimates the weights, since flood damages of higher recurrence times are counted double. Therefore, the weights are recursively calculated as (starting at $n_{\max }$ ):

$$
W_{n}=\frac{R T_{\max }}{R T_{n}}-\sum_{n}^{n_{\max }} W_{m} .
$$

In words: Each damage $D_{n}$ occurs $R T_{\max } / R T_{n}$ times minus the total number of occurrences of damages with a higher recurrence times.

\subsubsection{Nature development}

The nature module calculates nature area ${ }^{65}$, assesses ecosystem types and ecosystem diversity, and calculates average groundwater decrease in nature areas in the flood fringe as a proxy for drought damage.

\section{Ecosystem types}

The types of ecosystems that will arise in the new nature areas are assess on the basis of the ecosystem classification of Stroming (1995). Their classification distinguishes a number of

\footnotetext{
${ }^{65}$ Area calculation is performed with a simple routine, which is not further described.
} 
ecosystem types characterized by different inundation durations, see Table 5.5. The ecosystem type of a grid cell allocated to the land use type 'nature' is thus readily calculated by comparing its inundation duration (from the hydraulics module) to the values specified in Table 5.5.

\begin{tabular}{|l|l|l|l|}
\hline $\begin{array}{l}\text { Ecosystem } \\
\text { type }\end{array}$ & Description & $\begin{array}{l}\text { Inundation } \\
\text { duration } \\
\text { (days/yr) }\end{array}$ & $\begin{array}{l}\text { Desired } \\
\text { area (ha) }\end{array}$ \\
\hline Riverbed & $\begin{array}{l}\text { Constantly inundated: characterised by } \\
\text { alternately slow and fast flowing water; an } \\
\text { ideal habitat for fish, insects and birds. }\end{array}$ & 365 & $400-500$ \\
\hline Gravel banks & $\begin{array}{l}\text { Frequently inundated: dynamic gravel } \\
\text { islands and riverbanks where pioneering } \\
\text { flora will arise. }\end{array}$ & $200-365$ & $50-100$ \\
\hline $\begin{array}{l}\text { Lower } \\
\text { floodplain }\end{array}$ & $\begin{array}{l}\text { Frequently inundated: typical area for } \\
\text { riparian forests and aquatic grasslands. }\end{array}$ & $20-200$ & $200-300$ \\
\hline $\begin{array}{l}\text { Higher } \\
\text { floodplain }\end{array}$ & $\begin{array}{l}\text { Sporadically inundated: a habitat for hard } \\
\text { wood forest, shrubs and grassland. }\end{array}$ & $0-20$ & $200-300$ \\
\hline Dry area & $\begin{array}{l}\text { Outside the inundation reach of the river. } \\
\text { High relevance as a refuge for mammals } \\
\text { and amphibians during high water periods. }\end{array}$ & $<0.01$ & $100-200$ \\
\hline
\end{tabular}

Table 5.5: Ecosystem types considered in the iRM, characterized by their yearly inundation durations. The 'desired areas' correspond to the ecologically optimal distribution for the Grensmaas area (see also 'EOW index'). After (Stroming, 1995).

\section{EOW index}

One way to assess ecosystem diversity is using the so-called EOW index ${ }^{66}$. This index is based upon a reference ecosystem distribution designed by (Stroming, 1995) and listed in Table 5.5. The reference distribution is inspired on the ecology of comparable, but more natural gravel rivers, such as the Allier in France, taking the limited availability of space and the flood mitigation objectives specific to the Grensmaas area into account. The EOW index is a measure of the extent to which the reference ecosystem distribution is realized. It is calculated as (Maaswerken, 1998a):

$$
E O W=\frac{1}{N} * \sum_{i} \min \left(A_{i} / T_{i}, 1\right)
$$

with $A_{i}$ the area of ecosystem type $i, T_{i}$ the target area specified in the reference distribution, and $N$ the number of ecosystem types considered.

\footnotetext{
${ }^{66}$ 'Ecosysteem OntWikkelings index' translated as Ecosystem Development index
} 


\section{Shannon index}

A second way of assessing ecosystem diversity is using the Shannon index $S$. This index gives a more generic measure for ecosystem diversity. It is calculated as (Maaswerken, 1998a):

$$
S=-\sum_{i} f_{i} \ln \left(f_{i}\right)
$$

with the $f_{i}^{\prime}$ s the fractions of ecosystem area of type $i$, relative to the total natural area. The maximum value of $S$ equals $\ln (N)$ for a homogeneous distribution of $N$ ecosystem types; so 1.6 in our case $(N=5)$.

\section{Drought damage}

Drought damage to nature may result from groundwater level decrease. As a proxy for drought damage, therefore, the nature module calculates the average change of the average spring groundwater table (ASG) for (existing) nature areas in the flood fringe:

$$
\triangle A S G_{\text {nature }}=\operatorname{AVERAGE}\left(\triangle A S G_{i}\right) \text { for } i \in \text { ' nature area' AND ' flood fringe' } .
$$

\subsubsection{Agriculture}

The agriculture module calculates agricultural area ${ }^{65}$, crop depression, and average groundwater level change in agricultural area as an additional measure of agricultural damage due to groundwater table change.

\section{Crop depression}

Crop damage is assessed with the methodology of the expert model AGRICOM (WL, 1995). A total crop depression factor $D F_{\text {tot }}$ is defined as the fraction of potential financial benefit lost due to non-optimal groundwater conditions (Brouwer \& Huinink, 2002). It is calculated from depression factors for water shortage $D F_{d r y}$ and water surplus $D F_{\text {wet }}$ :

$$
D F_{\text {tot }}=D F_{d r y}+\left(1-D F_{d r y}\right)^{*} D F_{\text {wet }} \text {. }
$$

The sub factors $D F_{d r y}$ and $D F_{\text {wet }}$ are estimated on the basis of the so-called HELP-tables. These tables specify the depression factors for specific combinations of the average groundwater table in winter (AHG) and summer (ALG). The values of $D F_{d r y}$ and $D F_{\text {wet }}$ for arbitrary AHG / ALG combination are determined using the interpolation scheme described in (WL, 1995). The HELP tables for the two agricultural land use categories 'arable land' and 'grassland' (for soil type 'clay') are obtained from (Brouwer \& Huinink, 2002). The HELP table for 'arable land' is taken as the average of the HELP tables for potatoes, cereals, and sugar beets (see Table 5.6). 


\begin{tabular}{|l|l|l|l|}
\hline $\begin{array}{l}\text { AHG (m relative to } \\
\text { ground level) }\end{array}$ & $\begin{array}{l}\text { ALG (m relative to } \\
\text { ground level) }\end{array}$ & $\boldsymbol{D F}_{\text {dry }}$ & $\boldsymbol{D F _ { \text { wet } }}$ \\
\hline 0.15 & 1.05 & 0.01 & 0.28 \\
\hline 0.3 & 1.1 & 0.01 & 0.18 \\
\hline 0.5 & 1.1 & 0.01 & 0.08 \\
\hline 0.25 & 1.4 & 0.02 & 0.16 \\
\hline 0.35 & 1.5 & 0.02 & 0.11 \\
\hline 0.6 & 1.7 & 0.03 & 0.06 \\
\hline 1 & 2 & 0.1 & 0.03 \\
\hline 1.6 & 2.6 & 0.22 & 0.03 \\
\hline
\end{tabular}

Table 5.6: The HELP table for the land use type 'arable land'. The table specifies crop depression factors for different combination of the average groundwater table in winter (AHG) and summer (ALG). After (Brouwer \& Huinink, 2002).

\section{Groundwater level change}

As a further indicator for agricultural damage due to groundwater level change, we adopt the average change in spring groundwater level in agricultural areas $\triangle A S G_{\text {agri }}$. It is readily calculated as the average $\triangle A S G$ (relative to the current state) for grid cells of the agricultural land use categories 'arable land' and 'grassland':

$$
\triangle A S G_{\text {agri }}=\operatorname{AVERAGE}\left(\triangle A S G_{i}\right) \text { for } i \in \text { ' arable land' OR ' grassland' } .
$$

\subsection{MODEL APPLICATION AND ANALYSIS}

The iRM was applied and analysed for the river engineering location 'Borgharen' of the Maaswerken project. Model analysis is understood as the process of sensitivity analysis, calibration, and validation (Janssen et al., 1990). Sensitivity analysis refers to the process of gaining insight in the model properties and behaviour and the sensitivity of the model results. Model calibration is the process of tuning specific unknowns, so as to reproduce as closely as possible the available data, supposedly giving a valid estimate of the calibrated parameter under concern. Model validation refers to the process of testing the model. In IA modelling, two types of validation are distinguished (Janssen, 1996; Rotmans \& de Vries, 1997): practical validation by comparing the model results to the available date (other than calibration data set) and conceptual validation by testing the validity of model theories and concepts used. The ultimate aim of the model analysis is to gain trust and understanding of the developed model, both in terms of its weaknesses and strengths.

In this study, the following approach was taken. First, data was gathered. This included schematisation data for representing the location Borgharen in its current state, model data regarding model parameters, functions and tables used in the calculations, and calibration/validation data for tuning and testing the model results. Second, a sensitivity analysis was performed for the current state model results and the projected effects of the Preferred Alternative of 2003 (PA2003). This analysis provided both a first test of the validity of the un- 
calibrated model, as well as insights in the sensitivity of the model results. Third, the model was calibrated and fine-tuned in order to find those model and schematisation parameters that best represent the calibration data set. Fourth, the model was partly practically validated through a comparative analysis of the three historical river management strategies Green for Gravel (GFG 1991), the Preferred Alternative of 1998 (PA1998), and the PA2003. Fifth, a conceptual validation was performed through a critical evaluation by Maaswerken experts of the methodologies used, addressing some fundamental flaws of the cross-section approach, and the extent to which these were overcome.

In support of the model application and analysis, experts of Maaswerken have been involved in two stages, see Appendix D. A first expert meeting was conducted in 2002 for a first model verification, and to obtain data on relevant model parameters (see 'data gathering'). A second round of interviews was conducted in 2005 with the specific objective to gain criticism on the modelling approach that by then had reached its almost final form (see 'conceptual validation').

\subsubsection{Data gathering}

Gathered data included schematisation data, model data and calibration/validation data as described above. The schematisation and model data include both estimated values, as well as a so-called 'typical range' reflecting the uncertainty in this data. The typical ranges are partly derived from the available documentation, often based on expert judgment, and, in other cases, a standard variation of $10 \%$ was assumed. The typical ranges do not reflect a thorough uncertainty assessment, but do provide an impression of the uncertainty in the model results subject to further discussion.

\section{Schematisation data}

Model results critically depend on the precise schematisation of the cross-section under concern, in terms of its elevation, soil, land use, and hydraulic schematisation. Schematisation data for the location of Borgharen was obtained from a variety of sources, including the AHN elevation model (RWS, 1999a), the LGN3 land use map (Alterra, 1999), and SOBEK hydraulic profiles (RWS, 2000a). Deriving the schematisation from the available data (see Appendix B) generally involved aggregation: merging multiple SOBEK profiles into a single iRM hydraulic schematisation, and aggregating 2D spatial data (e.g. on elevation and land use) to the 1D iRM grid. To avoid unnecessary ambiguity, the schematisation remained deliberately 'schematic'. Elevations and soil thicknesses, for example, were assumed constant within the various river sections, ignoring topographic detail in the direction perpendicular to the river. The corresponding schematisation parameters were assumed subject to an uncertainty range and were partly subject to calibration. Various schematisation parameters and their typical ranges are listed in Table 5.7.

\section{Model data}

An overview of all model parameters is given in Table 5.7. Besides these, the calculations are based upon a number of functions and tables: the damage functions (Figure 5.7), the ecosystem classification and target areas (Table 5.5), the HELP tables (Table 5.6), and the flow duration curves (Figure A6). The model parameters are grouped in a number of categories, related to, for example, soil, costs, benefits, discharge, hydraulics, and so on. The values of most parameters have been estimated from various sources; only the groundwater parameters were determined on the basis of calibration alone. 
Chapter 5

\begin{tabular}{|c|c|c|c|c|c|c|c|}
\hline Category & Description & Unit & Symbol & \begin{tabular}{|l|}
$\begin{array}{l}\text { Estimated } \\
\text { value }\end{array}$ \\
\end{tabular} & \begin{tabular}{|l}
$\begin{array}{l}\text { Typical } \\
\text { range }\end{array}$ \\
\end{tabular} & \begin{tabular}{|l|}
$\begin{array}{l}\text { Adopted } \\
\text { value }\end{array}$ \\
\end{tabular} & Source \\
\hline \multirow[t]{4}{*}{ Soil parameters } & soil density & $\operatorname{ton} / \mathrm{m}^{3}$ & $S D$ & 1.9 & 1.8-2.1 & & \multirow{12}{*}{$\begin{array}{l}\text { Expertmeeting 2002; } \\
\text { Maaswerken, 1998e; } \\
\text { Maaswerken, 2003a }\end{array}$} \\
\hline & $T V$ fraction gravel & - & $F_{\text {gravel }}$ & 0.71 & 0.69-0.75 & & \\
\hline & $T V$ fraction sand & - & $F_{\text {sand }}$ & 0.18 & $0.17-0.25$ & & \\
\hline & expansion coefficient clay & - & $E X P_{\text {clay }}$ & 1.1 & - & & \\
\hline \multirow[t]{6}{*}{ Cost parameters } & cost $T V$ excavation & $€ / \mathrm{m}^{3}$ & $E C_{T V}$ & 3.5 & $+/-0.7$ & & \\
\hline & cost clay excavation & $€ / \mathrm{m}^{3}$ & $E C_{\text {clay }}$ & 3 & $+/-0.6$ & & \\
\hline & cost $T V$ processing & $€ / \mathrm{m}^{3}$ & $P C_{T V}$ & 4.5 & $+1-0.9$ & & \\
\hline & costs dikebuilding & $€ / \mathrm{m}^{3}$ & $C_{\text {dike }}^{\prime}$ & 200 & - & & \\
\hline & overhead factor & - & $\mathrm{C}_{\mathrm{OH}}$ & 1.1 & - & 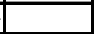 & \\
\hline & $\begin{array}{l}\text { sound hindrance per unit } \\
\text { processed } T V\end{array}$ & $\begin{array}{l}\mathrm{prs}^{\star} \mathrm{yrs} / \\
\mathrm{Mm}^{3}\end{array}$ & $H_{\text {proc }}$ & 27 & - & & \\
\hline \multirow{2}{*}{$\begin{array}{l}\text { Benefit } \\
\text { parameters }\end{array}$} & gravel price & $€ /$ ton & $P_{\text {gravel }}$ & 7 & $+/-1.4$ & & \\
\hline & sand price & $€ /$ ton & $P_{\text {sand }}$ & 4 & $+/-0.8$ & & \\
\hline \multirow{5}{*}{$\begin{array}{l}\text { Conditional peak } \\
\mu\end{array}$} & $Q \in 100-300$ & - & $\mu_{100-300}$ & 0.71 & $+/-0.02$ & & \multirow{10}{*}{$\begin{array}{l}\text { Statistical analysis of historic time } \\
\text { series of daily discharges, see } \\
\text { Appendix A }\end{array}$} \\
\hline & $Q \in 300-500$ & - & $\mu_{300-500}$ & 0.69 & $+/-0.04$ & & \\
\hline & $Q \in 500-700$ & - & $\mu_{500-700}$ & 0.68 & $+1-0.04$ & & \\
\hline & $Q \in 700-900$ & - & $\mu_{700-900}$ & 0.63 & $+/-0.09$ & & \\
\hline & $Q>900$ & - & $\mu_{>900}$ & 0.70 & $+/-0.1$ & & \\
\hline \multirow{5}{*}{$\begin{array}{l}\text { Conditional peak } \\
\sigma\end{array}$} & $Q \in 100-300$ & - & $\sigma_{100-300}$ & 0.29 & $+1-0.02$ & & \\
\hline & $Q \in 300-500$ & - & $\sigma_{300-500}$ & 0.24 & $+1-0.02$ & & \\
\hline & $Q \in 500-700$ & - & $\sigma_{500-700}$ & 0.21 & $+/-0.03$ & & \\
\hline & $Q \in 700-900$ & - & $\sigma_{700-900}$ & 0.22 & $+1-0.06$ & & \\
\hline & $Q>900$ & - & $\sigma_{>900}$ & 0.21 & $+/-0.07$ & & \\
\hline \multirow[t]{3}{*}{\begin{tabular}{|l} 
Hydraulic \\
parameters
\end{tabular}} & river slope & - & $i_{b}$ & $4.5^{\star} 10^{-4}$ & - & & $\begin{array}{l}\text { Average river slope km } 15-55 \text {, } \\
\text { e.g. see Maaswerken, } 1998 \mathrm{~d}\end{array}$ \\
\hline & \begin{tabular}{|l|}
$\begin{array}{l}\text { characteristic length between } \\
\text { bottlenecks }\end{array}$ \\
\end{tabular} & $\mathrm{m}$ & 1 & 5000 & $+/-1000$ & & \multirow{2}{*}{$\begin{array}{l}\text { Estimated values for PA2003, see } \\
\text { Appendix B. Also calibration } \\
\text { parameters }\end{array}$} \\
\hline & fraction of widened river stretch & - & $f$ & 0.6 & $+/-0.1$ & 0.26 & \\
\hline \multirow{11}{*}{$\begin{array}{l}\text { Hydraulic } \\
\text { roughnesses }\end{array}$} & main channel & $\mathrm{m}$ & $k_{10}$ & 0.12 & 0.06-0.18 & & \multirow{11}{*}{$\begin{array}{l}\text { SOBEK schematisation (RWS, } \\
2000 a) \text { for current floodplain } \\
\text { roughness }\left(k_{20}, k_{30}, k_{60}\right) ; \\
\text { WAQUA roughness values for } \\
\text { main channel and new nature } \\
\left(k_{10}, k_{4 \times}\right)\end{array}$} \\
\hline & grassland & $\mathrm{m}$ & $k_{20}$ & 0.2 & $0.1-0.3$ & & \\
\hline & arable land & $\mathrm{m}$ & $k_{30}$ & 0.2 & $0.1-0.3$ & & \\
\hline & nature - undeveloped & $\mathrm{m}$ & $k_{40}$ & 0.12 & - & & \\
\hline & \begin{tabular}{|l} 
nature - main channel \\
\end{tabular} & $\mathrm{m}$ & $k_{41}$ & 0.12 & - & & \\
\hline & nature - riverbank & $\mathrm{m}$ & $k_{42}$ & 0.12 & $0.06-0.24$ & & \\
\hline & nature - lower floodplain & $\mathrm{m}$ & $k_{43}$ & 0.56 & $0.28-1.12$ & & \\
\hline & nature - high floodplain & $\mathrm{m}$ & $k_{44}$ & 7.6 & $3.8-15.2$ & & \\
\hline & nature - dry area & $\mathrm{m}$ & $k_{45}$ & 11.3 & $5.7-22.6$ & & \\
\hline & housing area & $\mathrm{m}$ & $k_{50}$ & $\infty$ & - & & \\
\hline & infrastructure & $m$ & $k_{60}$ & 0.2 & $0.1-0.3$ & & \\
\hline \begin{tabular}{|l|}
$\begin{array}{l}\text { Morphology } \\
\text { parameter }\end{array}$ \\
\end{tabular} & $\begin{array}{l}\text { erosion broadened main } \\
\text { channel }\end{array}$ & $\mathrm{m}$ & $E R_{B M C}$ & 0.1 & $0-0.4$ & & Maaswerken, 2003b \\
\hline \multirow{6}{*}{$\begin{array}{l}\text { Groundwater } \\
\text { parameters }\end{array}$} & hydraulic conductivity $T V$ & m/day & $k_{T V}$ & 2000 & - & & \multirow[t]{2}{*}{ Maaswerken, 2003c } \\
\hline & hydraulic conductivity clay & m/day & $k_{\text {clay }}$ & 15 & - & & \\
\hline & correction factor lateral flow & - & $C_{L F}$ & 50 & $1-100$ & 42 & \multirow[t]{4}{*}{ Calibration } \\
\hline & $\begin{array}{l}\text { far distance boundary condition } \\
\text { - spring }\end{array}$ & m NAP & $h_{L=10 \mathrm{~km}}$ & 44.95 & +-0.5 & 44.9 & \\
\hline & $\begin{array}{l}\text { far distance boundary condition } \\
\text { - winter }\end{array}$ & m NAP & $h_{L=10 \mathrm{~km}}$ & 45.3 & +-0.5 & 45.5 & \\
\hline & $\begin{array}{l}\text { far distance boundary condition } \\
\text { - summer }\end{array}$ & m NAP & $h_{L=10 \mathrm{~km}}$ & 44.6 & +-0.5 & 44.3 & \\
\hline \multirow[t]{4}{*}{ Economic values } & grassland & $\mathrm{k} \in / \mathrm{ha}$ & $E V_{20}$ & 15 & $-25 \%$ & 0.42 & \multirow[t]{4}{*}{ Kok, 2005 and calibration } \\
\hline & arable land & $k \in / h a$ & $E V_{30}$ & 15 & $-25 \%$ & 0.42 & \\
\hline & housing area & $k \in / h a$ & $E V_{50}$ & 4639 & $-25 \%$ & 354 & \\
\hline & infrastructure & $k € /$ ha & $E V_{60}$ & 110 & $-25 \%$ & 17 & \\
\hline & main channel elevation & m NAP & - & 37.2 & & & SOBEK schematisation, RWS, \\
\hline parameters: & main channel width & $\mathrm{m}$ & - & 89 & 9 & 81 & 2000a; Digital elevation model \\
\hline Elevation & floodway elevation & m NAP & - & 44.4 & $44-44.6$ & 44.1 & AHN, RWS, 1999a; Maaswerken \\
\hline & floodway width & $\mathrm{m}$ & - & 550 & 55 & 575 & expert judgement \\
\hline & flood fringe elevation & m NAP & - & 44.6 & 0.4 & & \\
\hline & housing area elevation & m NAP & - & 45 & 0.4 & & \\
\hline & dike elevation & $\mathrm{m}$ & - & 0.7 & 0.1 & 0.6 & \\
\hline Schematisation & TV thickness & $\mathrm{m}$ & - & 7.2 & $7-8$ & & Expert meeting 2002; \\
\hline parameters: Soil & clay thickness & $\mathrm{m}$ & - & 1.9 & $1.7-2.7$ & & Maaswerken, 2003c \\
\hline & soil base & m NAP & - & 35.3 & 1 & 35.0 & \\
\hline
\end{tabular}

Table 5.7: Overview of model parameters and schematisation parameters in the iRM; their estimated values, typical ranges, and adopted values after calibration (if different from the estimated value). 


\begin{tabular}{|c|c|c|c|}
\hline Module & Data & Type & Source \\
\hline \multirow[t]{2}{*}{$\begin{array}{l}\text { Excavation, } \\
\text { costs and } \\
\text { hindrance }\end{array}$} & $\begin{array}{l}\text { Excavated } \\
\text { volumes and } \\
\text { gravel yield }\end{array}$ & $\begin{array}{l}\text { Projected (PA1998/ } \\
\text { PA2003/ GFG1991) }\end{array}$ & $\begin{array}{l}\text { (Stroming, 1991; Maaswerken, } \\
\text { 1998a; Maaswerken, 2003a) }\end{array}$ \\
\hline & Hindrance & Projected (PA1998) & (Maaswerken, 1998a) \\
\hline \multirow[t]{2}{*}{ Discharge } & $\begin{array}{l}\text { Peak flow } \\
\text { recurrence } \\
\text { times }\end{array}$ & $\begin{array}{l}\text { Current state } \\
\text { (observed) }\end{array}$ & $\begin{array}{l}\text { Statistical analysis of the daily } \\
\text { discharge series at Borgharen } \\
\text { (RIZA, 2001) }\end{array}$ \\
\hline & $\begin{array}{l}\text { Flow } \\
\text { duration } \\
\text { curves }\end{array}$ & $\begin{array}{l}\text { Current state } \\
\text { (observed) }\end{array}$ & $\begin{array}{l}\text { Directly derived from the daily } \\
\text { discharge series at Borgharen } \\
\text { (RWS, 2003) }\end{array}$ \\
\hline \multirow[t]{2}{*}{ Hydraulics } & $\begin{array}{l}\text { Stage- } \\
\text { discharge } \\
\text { relation }\end{array}$ & $\begin{array}{l}\text { Current state } \\
\text { (observed) }^{67}\end{array}$ & $\begin{array}{l}\text { Stage-discharge relation at } \\
\text { Borgharen, state } 2000 \text { (RWS, } \\
\text { 2000b) }\end{array}$ \\
\hline & $\begin{array}{l}\text { Projected } \\
\text { water level } \\
\text { change }\end{array}$ & $\begin{array}{l}\text { Projected (PA2003 / } \\
\text { PA1998 / GFG1991) }\end{array}$ & $\begin{array}{l}\text { Calculated with various hydraulic } \\
\text { models }{ }^{68} \text { (Stroming, 1991; } \\
\text { Maaswerken, 1998a; Maaswerken, } \\
\text { 2004). }\end{array}$ \\
\hline \multirow[t]{2}{*}{$\begin{array}{l}\text { Ground- } \\
\text { water }\end{array}$} & $\begin{array}{l}\text { Seasonal } \\
\text { groundwater } \\
\text { tables }\end{array}$ & $\begin{array}{l}\text { Current state } \\
\text { (calculated) }\end{array}$ & $\begin{array}{l}\text { Calculated with the Triwaco } \\
\text { model }^{69} \text { (Maaswerken, 2003a) }\end{array}$ \\
\hline & $\begin{array}{l}\text { Groundwater } \\
\text { table change }\end{array}$ & Projected (PA2003) & $\begin{array}{l}\text { Calculated with the Triwaco model } \\
\text { (Maaswerken, 2003a) }\end{array}$ \\
\hline Flood & $\begin{array}{l}\text { Flood } \\
\text { damage }\end{array}$ & $\begin{array}{l}\text { Current state } \\
\text { (observed) }\end{array}$ & $\begin{array}{l}\text { Flood damage for the '93 and '95 } \\
\text { floods (Nierop, 1997) }\end{array}$ \\
\hline \multirow[t]{2}{*}{ Nature } & $\begin{array}{l}\text { Ecosystem } \\
\text { diversity }\end{array}$ & $\begin{array}{l}\text { Current state } \\
\text { (observed) }\end{array}$ & $\begin{array}{l}\text { EOW and Shannon indices for the } \\
\text { current state (Maaswerken, } \\
\text { 1998a; Maaswerken, 2003a) }\end{array}$ \\
\hline & $\begin{array}{l}\text { Ecosystem } \\
\text { diversity } \\
\text { change }\end{array}$ & $\begin{array}{l}\text { Projected (PA2003/ } \\
\text { PA1998) }\end{array}$ & $\begin{array}{l}\text { EOW and Shannon indices after } \\
\text { river widening (Maaswerken, } \\
\text { 1998a; Maaswerken, 2003a) }\end{array}$ \\
\hline Agriculture & $\begin{array}{l}\text { Crop } \\
\text { depression } \\
\text { change }\end{array}$ & $\begin{array}{l}\text { Projected (PA2003/ } \\
\text { PA1998) }\end{array}$ & $\begin{array}{l}\text { Maaswerken calculations } \\
\text { (Maaswerken, 1998a; } \\
\text { Maaswerken, 2003a) }\end{array}$ \\
\hline
\end{tabular}

Table 5.8: Overview of main calibration/validation data sets used

\footnotetext{
${ }^{67}$ The stage-discharge relation is based on discharge measurements for discharges up to $\sim 3100 \mathrm{~m}^{3} / \mathrm{s}$, and the series has been extended (using an interpolation scheme) for discharges up to $\sim 4300 \mathrm{~m}^{3} / \mathrm{s}$.

${ }^{68}$ For the PA2003, the Maaswerken hydraulic calculations are performed with the $2 \mathrm{D}$ hydraulic model WAQUA, see www. waqua.nl accessed April 2009

${ }^{69}$ www.triwaco.com accessed April 2009
} 


\section{Calibration/validation data}

Available calibration and validation data for the various modules is listed in Table 5.8. We distinguish a number of data types. Data included both current state data (e.g. the current state ecosystem diversity), as well as data for the projected river engineering effects (e.g. the estimated ecosystem diversity change). Current state data was partly observed data (e.g. the current stage-discharge relation) and partly based on expert model calculations (e.g. the groundwater level). Projected river engineering effects were mostly known for the strategy PA2003, and to a lesser extent for the strategies PA1998 and GFG1991. The quality of the obtained data varies. The groundwater data, for example, was obtained through a rather rough approximation from the calculated groundwater maps, whereas the various estimates for excavation were accurately specified. Sometimes, data was location specific (e.g. projected water level change) and sometimes it was not (e.g. ecosystem diversity was generally specified for the Grensmaas area as a whole). Overall, the calibration and validation data forms a rather complete set, sufficient for an order of magnitude assessment of the iRM model results. The main missing aspect is insight in the projected monetary benefits and costs.

\subsubsection{Sensitivity analysis}

The sensitivity analysis aims to provide both insight into the sensitivities of model results, as well as insight into the validity of the un-calibrated model. To this end, model results are compared to the calibration/validation data, with the PA2003 as the reference alternative for the projected river engineering effects. For each module, relevant model and schematisation parameters are varied between the boundaries of their typical range to assess the consequent range in the model output. The discharge module is analysed separately in Appendix A.

\section{Excavated volumes, gravel yield, costs and benefits}

The sensitivity analysis of excavated volumes, gravel yield, costs and benefits is displayed in Figure 5.8 a). The sensitivities of the various results were tested for variations in schematisation (floodway elevation, soil layer thicknesses) and model parameters (soil, cost/benefit parameters). As far as data was available (for costs and benefits this was generally not the case) one observes that the Maaswerken results generally fall within the typical ranges specified by the iRM. In general, the sensitivities appear relatively small and linear. For example, the excavated TV volume $T V_{\text {net }}$ shows little sensitivity to the adopted TV and clay layer thicknesses ${ }^{70}$ and variations in the cost and benefit parameters have a predictable linear effect on the various contributions. The net benefits and profitability, however, do appear to be very sensitive. This illustrates the fragile balance between the high and uncertain contributions of costs and benefits. Here, the soil parameters appear most influential by affecting cost and benefits at the same time (and in opposite directions). A 10\% range of soil parameters makes a difference between a profit of 10 , or a loss of $6 \mathrm{M} €$.

\footnotetext{
${ }^{70}$ A thicker clay layer limits the amount of $T V$ initially extracted $\left(\mathrm{TV}_{\text {wide }}\right)$, but this is compensated with more TV extraction from clay storage afterwards.
} 


\section{Hydraulics}

The calculated current stage-discharge relation - displayed in Figure 5.8 b) - shows a remarkably good correspondence with the observed relation, with a root-mean-square (RMS) error in water level of some $20 \mathrm{~cm}$. The sensitivity of the water level calculation was tested for variations of the main channel and floodway dimensions, and their hydraulic roughness. The calculations were found to be relatively robust, with deviations of some $7 \mathrm{~cm}$ for low discharges $\left(\sim 60 \mathrm{~m}^{3} / \mathrm{s}\right.$ ), some $40 \mathrm{~cm}$ for moderately high discharge $\left(\sim 1500 \mathrm{~m}^{3} / \mathrm{s}\right)$, and some $20 \mathrm{~cm}$ for extreme discharge ( $\left.3275 \mathrm{~m}^{3} / \mathrm{s}\right)$.

The calculated water level change show larger errors compared to the Maaswerken model results (WAQUA). Water level change is underestimated for low discharges $\left(<500 \mathrm{~m}^{3} / \mathrm{s}\right)$ and overestimated for high discharges $\left(>500 \mathrm{~m}^{3} / \mathrm{s}\right.$ ), with overestimations up to $1 \mathrm{~m}$ in the extremely high discharge range. Sensitivity of water level change was tested for variations of the ecosystem roughness, morphology, and hydraulic effectiveness parameters. The typical ranges of the model results (up to $\sim 7 \mathrm{~cm}$ for $Q<500 \mathrm{~m}^{3} / \mathrm{s}$; up to $\sim 29 \mathrm{~cm}$ for $Q>500 \mathrm{~m}^{3} / \mathrm{s}$ ) are moderate and can not account for the mismatch between the iRM and Maaswerken results, in particular not in the high discharge range. Apparently, the estimated hydraulic effectiveness parameters ( $I$ $=5 \mathrm{~km} ; f=0.6)$ are insufficient to account fully for the backwater effects of bottlenecks. See also the calibration (Section 5.4.3) and conceptual validation (Section 5.4.5).

\section{Groundwater}

The initially calculated groundwater tables for the current situation significantly deviate from the calculated water tables obtained from Maaswerken (Figure $5.8 \mathrm{c}$ ). This deviation, however, can be largely explained by the different representative seasonal water levels adopted by Maaswerken as the boundary condition at the river bank ${ }^{71}$. An investigation of the typical ranges - obtained through a variation of the schematisation parameter 'soil base' and the far distance boundary conditions - shows further that the water table calculations are robust near the river bank and subject to a somewhat larger variation at a farther distance.

The calculated water table changes - for a preliminary calibrated value of $C_{L F}$ - are in reasonable correspondence with the Maaswerken results. This holds, in particular, at far distance from the riverbank ( $>800 \mathrm{~m})$, where the calculated values of Maaswerken fall within - or are close to the typical range of the iRM results (originating from the variation of the correction factor for lateral flow $C_{L F}$ ). The local effect of the clay storage area on the water table, however, is not well represented. The projected groundwater table increase inside and just behind the clay storage area is not reproduced. This mismatch points to a fundamental flaw in the 1D cross-section approach, which is further addressed in the conceptual validation (Section 5.4.5) later on.

\section{Flood damage}

The flood damage calculations were tested against the observed damages of the '93 and '95 floods, see Figure $5.8 \mathrm{~d}$ ). A preliminary assessment indicated that for both available sets of damage functions and economic values (WL, 1994c; Kok et al., 2005), the damage at Borgharen

\footnotetext{
${ }^{71}$ The Maaswerken adopts specific time ranges as representative for the average summer, winter, and spring situation, rather then the standard hydrological seasons adopted in the iRM. This leads to different seasonal discharges, seasonal water levels, and, hence, seasonal groundwater tables. To maintain consistency with the Maaswerken results, this mismatch is 'corrected' as part of the calibration procedure.
} 
was strongly overestimated. For pragmatic reasons, it was decided to adopt the damage functions of the standard method, and to choose the economic values so as to reproduce the observed damage for the ' 93 flood. The figure indicates that the iRM then still overestimates the observed flood damage of '95. This finding, previously reported in (De Blois, 2000), is most probably due to learning from the experience of ' 93 , due to which damage in '95 could be avoided to some extent. The sensitivity of calculated damage was tested for variations in floodplain elevation (the 'floodway', 'floodplain', and 'housing area elevation' in Table 5.7). Interestingly, the sensitivity of the calculated damage for the ' 95 flood ( 30-40\%) is higher than the one from '93 ( 20\%). The sensitivity of flood damage thus significantly depends on the magnitude of the peak discharge (i.e. compare $Q \sim 3120 \mathrm{~m}^{3} / \mathrm{s}$ and $Q \sim 2870 \mathrm{~m}^{3} / \mathrm{s}$ for the respective '93 and '95 floods).

\section{Nature diversity}

In the current situation the natural values at the location Borgharen are considered to be low. In the model this is reflected with the presence of only a two ecosystem types ('main channel' and 'high floodplain') and corresponding low values for the diversity indices (see Figure 5.8 e). The calculated diversity indices after implementing the PA2003 show - as expected - a significant increase. The diversity indices appear relatively robust. Their sensitivity - tested for changes in the ecosystem roughness and morphology parameters - result in only minor typical output ranges. Although the values projected by Maaswerken do not generally fall precisely within those typical ranges, the general correspondence is considered good. Particularly the increase in ecosystem diversity after implementing PA2003 is well represented.

\section{Agriculture}

The calculated agricultural damage on the basis of the HELP tables (see Section 5.3.7) appears of lesser relevance for the location of Borgharen. In the current situation, the groundwater tables are so low ( 3-4 meter below surface level) that the maximum depression factor for water shortage is obtained. This depression factor is invariant under both a further decrease, as well as a moderate increase of the groundwater table. A potential reduction of depression factor only occurs for an (unrealistic) seasonal river water level increase of some 3 meters or more. This observation is in line with the Maaswerken results (Maaswerken, 2003a) projecting an insignificant change of depression factor $(<5 \%)$ over the area considered after implementation of PA2003. As an alternative, we adopt the groundwater table change in agricultural area as an indirect proxy for agricultural damage.

\subsubsection{Calibration}

We have observed that - overall - the un-calibrated version gives reasonably accurate and fairly robust results. The current task is to fine-tune the model so that it represents the available calibration data set as close as possible. Two modes of fine-tuning were applied: superposition and calibration. Superposition implies that the calculated changes in model variables are superposed to their currently known (or assumed) values to achieve more accurate results, and improve consistency with the Maaswerken results. Superposition was applied in the calculation of peak discharge recurrence, seasonal discharge, and the stage-discharge relation. Model calibration is the process of tuning unknown model and schematisation parameters. Calibration was performed for hydraulics, groundwater, and flood damage modules (for the latter, see the sensitivity analysis above). Here, the calibration of the hydraulics and groundwater modules is described. 

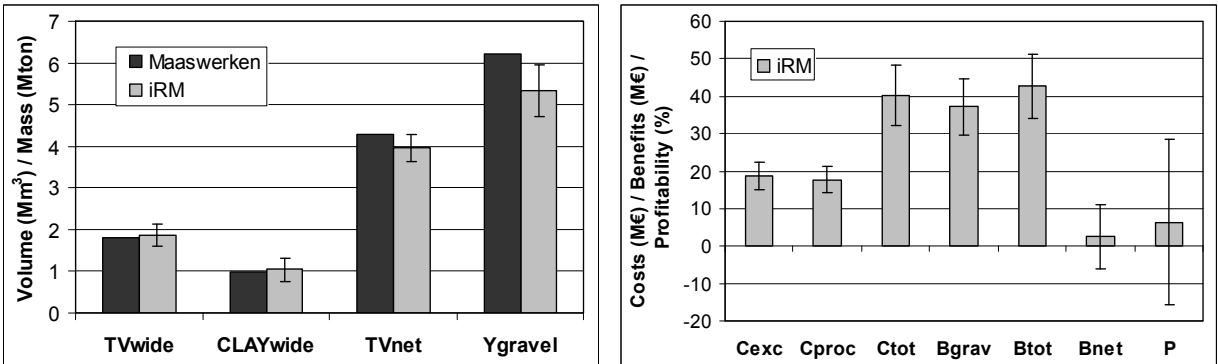

a)
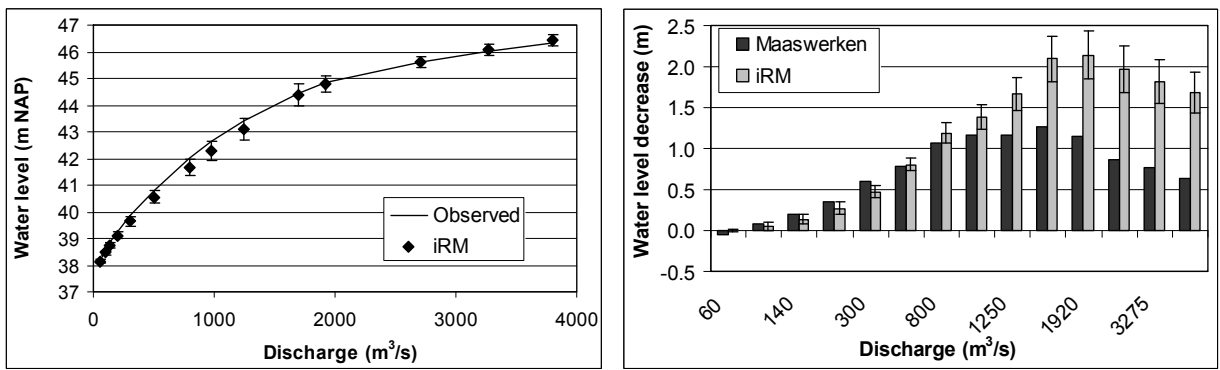

b)
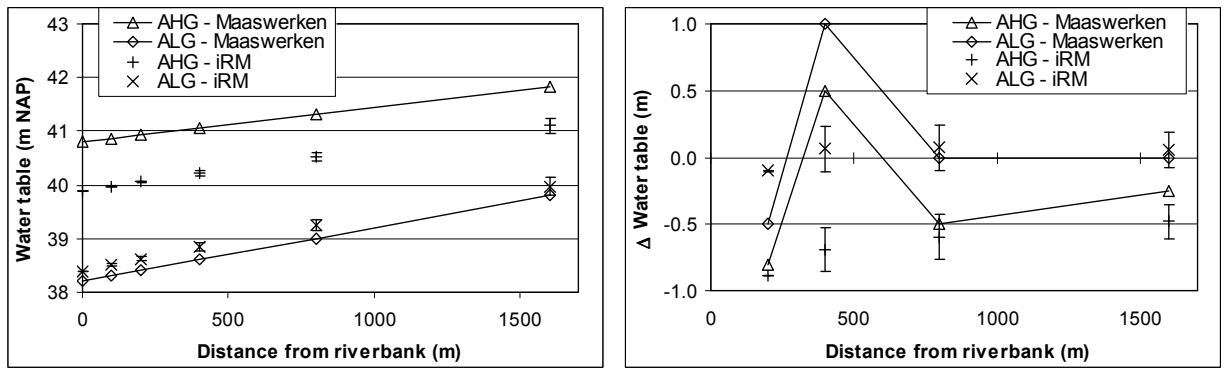

c)
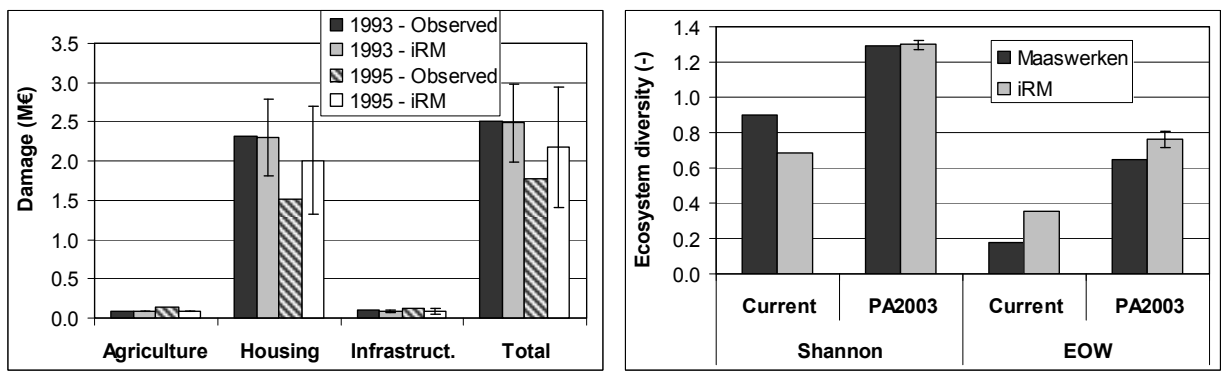

d)

e)

Figure 5.8: Sensitivity analysis for a) excavation and costs, b) hydraulics, c) groundwater, d) flood damage, and e) ecosystem diversity 


\section{Hydraulics}

The calculated current stage-discharge was calibrated through a variation of the estimated flow profile. ${ }^{72}$ Concretely, the main channel width $M C_{W}$, and the width and elevation of the floodway (respectively $F W_{w}$ and $F W_{e}$ ) were adopted as calibration parameters, and the relative RMS error between the calculated and observed discharges (for given water levels) as the criterion for calibration success. It appears that the current stage-discharge relation is best reproduced when the main channel dimensions are somewhat reduced compared to their estimated values, allowing for relatively more flow through the floodway area. See Table 5.9 and Figure 5.9 for the calibration results.

The calculated water level changes were calibrated through a variation of the hydraulic effectiveness parameters / and $f$ of Equation 5.16. The absolute RMS error between the iRM and Maaswerken model results are adopted as the criterion for calibration success. Four calibration runs are shown in Figure 5.9. The first shows that without correction for backwater effects $(f=$ 1 ), the projected water level changes are indeed strongly overestimated (error of about $1 \mathrm{~m}$ ). By adopting the estimated values for $/$ and $f$, the error is reduced to some $60 \mathrm{~cm}$, but this still is not a satisfying result. With a full calibration (adopting arbitrarily wide ranges of $I$ and $f$ ), a good fit was obtained (error $\sim 5 \mathrm{~cm})$. However, the corresponding values of $I(28 \mathrm{~km})$ and $f(0.06)$ seem unrealistic. In a partial calibration, finally, with a constant $I=10 \mathrm{~km}$, also a good fit was obtained (error $\sim 10 \mathrm{~cm}$ ) for a more realistic $f=0.26$. The significant difference between the estimated and calibrated values of $I$ and $f$ suggest that the differences between the 2D (WAQUA) and OD (iRM) approaches are not overcome through the correction for backwater effect alone (see also the conceptual validation of Section 5.4.5). Nonetheless, the calibration presented here does allow for a numerical accuracy sufficient for our purpose.

\section{Groundwater}

The calculated current groundwater table and project water table change were calibrated with respect to the Triwaco model results of Maaswerken (Maaswerken, 2003a). With respect to the previous calculation (Figure $5.8 \mathrm{c}$ ), accuracy was improved first by adopting in the iRM the same seasonal river water levels as groundwater table boundary conditions at the river bank $\left(h_{0}\right)$. Consequently, the calculated current groundwater tables (AHG and ALG) were calibrated through variation of the far-distance water table boundary conditions $h_{10 \mathrm{~km}}$. Figure 5.10 and Table 5.9 show that the Triwaco results are well reproduced, indicating that, in order of magnitude, the current groundwater tables are adequately represented.

\footnotetext{
72 Variation of hydraulic roughness was considered as well, but finally not adopted in the calibration procedure. First, the roughness estimates from the hydraulic expert models were considered accurate. Second, the initial tests indicated only a minor potential improvement of the stage-discharge curve.
} 

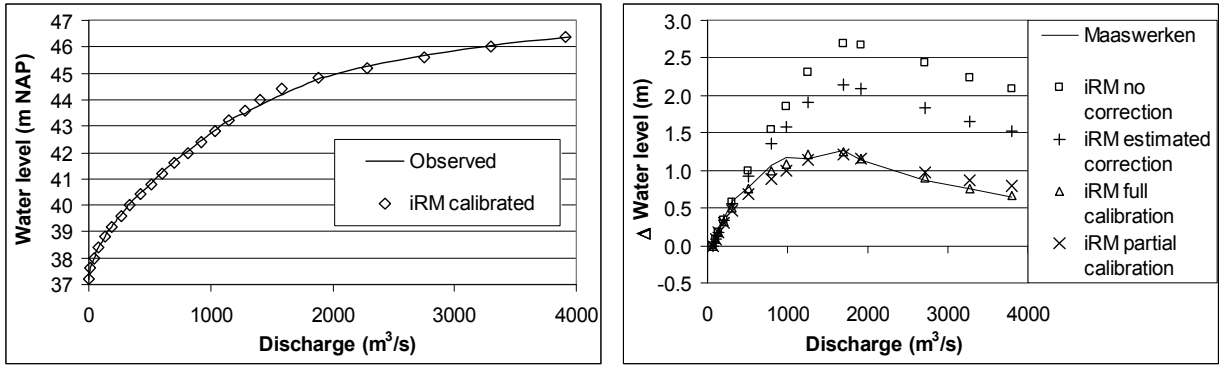

Figure 5.9: Calibration of the hydraulics module: current stage-discharge relation (left) and projected water level changes for the river engineering alternative PA2003 (right). For the latter, the figure shows a number of calibration runs. These include 1) the case without correction for backwater effects, 2) with correction on the basis of the estimated values of the effectiveness parameters, 3) a full calibration allowing the effectiveness parameters to vary without constraints, and 4) a partial calibration in which the value of the effectiveness parameter $/$ is fixed. The partial calibration is adopted in the iRM.
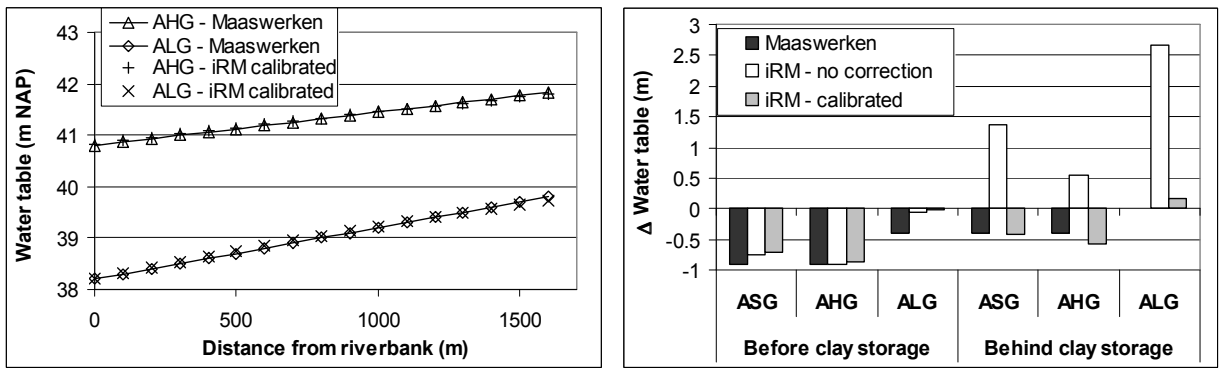

Figure 5.10: Calibrated groundwater water tables for (left) the current situation in summer (ALG) and winter (AHG), and (right) groundwater table changes after implementation of PA2003. The latter shows average water table changes 'before' (riverside) and 'behind' (floodplain side) the clay storage area for three seasons spring $(A S G)$, summer $(A L G)$, and winter $(A H G)$. The figure includes both the case without correction for lateral flow $\left(C_{L F}=1\right)$ and the case after calibration $\left(C_{L F}=42\right)$.

The projected water table changes were calibrated through variation of the correction factor for lateral flow $C_{L F}$. As calibration data, we adopted the average groundwater table changes 'before' and 'behind' the clay storage area for representative spring (ASG), summer (ALG) and winter (AHG) situations approximated from the available groundwater maps. The Triwaco results are best reproduced for a considerable $C_{L F}=41$ (see Table 5.7). This high value indicates that groundwater flow occurs primarily around, rather than through, the clay storage area; an issue which is further addressed in the conceptual validation of Section 5.4.5. Nonetheless, the calibration does allow for a numerical accuracy appropriate for our purpose. 


\begin{tabular}{|l|l|l|l|l|}
\hline $\begin{array}{l}\text { Calibrated } \\
\text { function }\end{array}$ & $\begin{array}{l}\text { Calibration } \\
\text { parameters }\end{array}$ & Error $(E)$ & $E_{\text {bef }}$ & $E_{\text {aft }}$ \\
\hline $\begin{array}{l}\text { Current stage- } \\
\text { discharge } \\
\text { relation }\end{array}$ & $\begin{array}{l}M C_{\mathrm{w}}, F F_{\mathrm{w}}, \\
F F_{e}\end{array}$ & $\begin{array}{l}\text { Relative RMS deviation between } \\
\text { the calculated and observed } \\
\text { discharges (for given water levels) }\end{array}$ & $10 \%$ & $3.5 \%$ \\
\hline $\begin{array}{l}\text { Projected water } \\
\text { level change }\end{array}$ & $I, f$ & $\begin{array}{l}\text { Absolute RMS deviation between } \\
\text { the iRM and Maaswerken model } \\
\text { results }\end{array}$ & $60 \mathrm{~cm}$ & $10 \mathrm{~cm}$ \\
\hline $\begin{array}{l}\text { Current } \\
\text { groundwater } \\
\text { table (AHG, ALG) }\end{array}$ & $h_{10 \mathrm{~km}}$ & $\begin{array}{l}\text { Absolute RMS deviation between } \\
\text { the iRM and Maaswerken model } \\
\text { results }\end{array}$ & - & $2 \mathrm{~cm} \mathrm{(AHG)}$ \\
\hline $\begin{array}{l}\text { Projected } \\
\text { ground-water } \\
\text { table change }\end{array}$ & $C_{\mathrm{LF}}$ & $\begin{array}{l}\text { Absolute RMS error between the } \\
\text { iRM and Maaswerken model } \\
\text { results for average groundwater } \\
\text { table changes 'before' and } \\
\text { 'behind' the clay storage area }\end{array}$ & - & $20 \mathrm{~cm}$ \\
\hline
\end{tabular}

Table 5.9: Overview of the calibration results: calibrated functions, calibration parameters, the adopted calibration criterion (the error), and the errors before and after calibration. For calibrating projected water level and groundwater table change, the PA2003 is adopted as the reference alternative. Parameters in the groundwater module are based purely on calibration, so that errors 'before calibration' are absent.

\subsubsection{Practical validation and comparative assessment}

Practical validation is the procedure of comparing the model results to the available validation data (other than calibration data set) to get a measure of the accuracy of the model results. For the iRM, this would ideally imply a comprehensive assessment of the projected effects of various river management strategies with respect to the model results of Maaswerken (for the PA1998 and PA2003) and Stroming (for the GFG1991). Given the limited availability of data (Table 5.8), however, such a formal practical validation is outside our scope. Therefore, a more qualitative, comparative assessment is provided of the three strategies GFG1991, PA1998, and PA2003. The assessment aims to show that the model adequately illustrates key features of the various strategies, that it provides realistic order of magnitude quantitative estimates of the various river management impacts, and that the differences between the river management alternatives are properly described.

The effects of the respective river management strategies on the river cross-section are visualized in Figure 5.11. The figure basically presents the river state, in terms of land use, elevation, soil, river water level, groundwater table, inundation duration characteristics. One achieves a quick impression of the strategies' key features; the shallow river bed and floodplain excavation of the GFG1991, the additional nature area to the cost of floodplain excavation of the PA1998, and the deepened clay storage area of the PA2003. The strategies' main impacts regarding flood protection, nature development, agriculture, excavation, and costs are listed in Table 5.10. As far as data was available, the corresponding values reported by Maaswerken are listed as well. Note that for the GFG1991, the embankment is removed, since at that time it did not yet exist. 


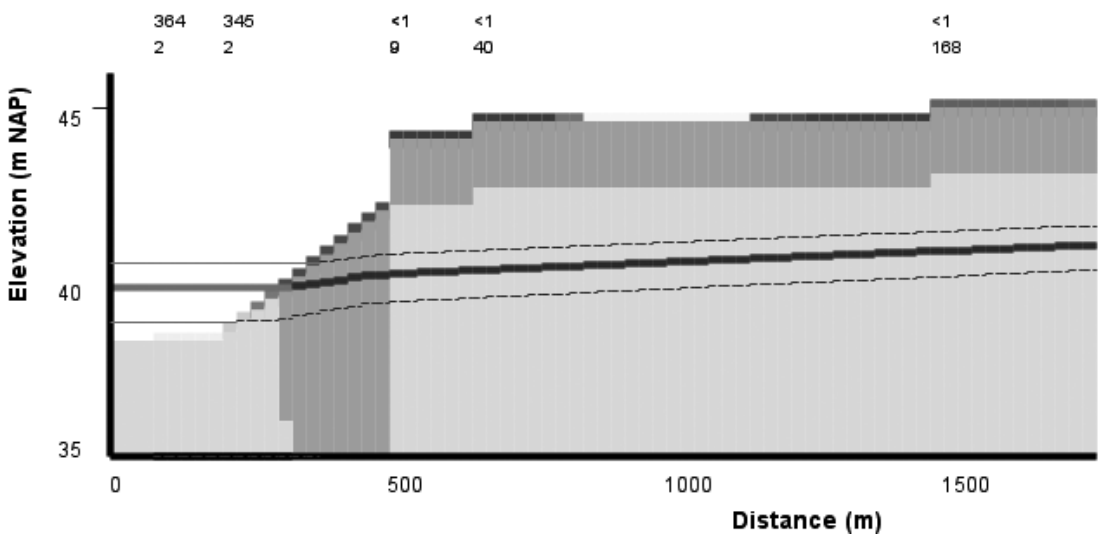

a)

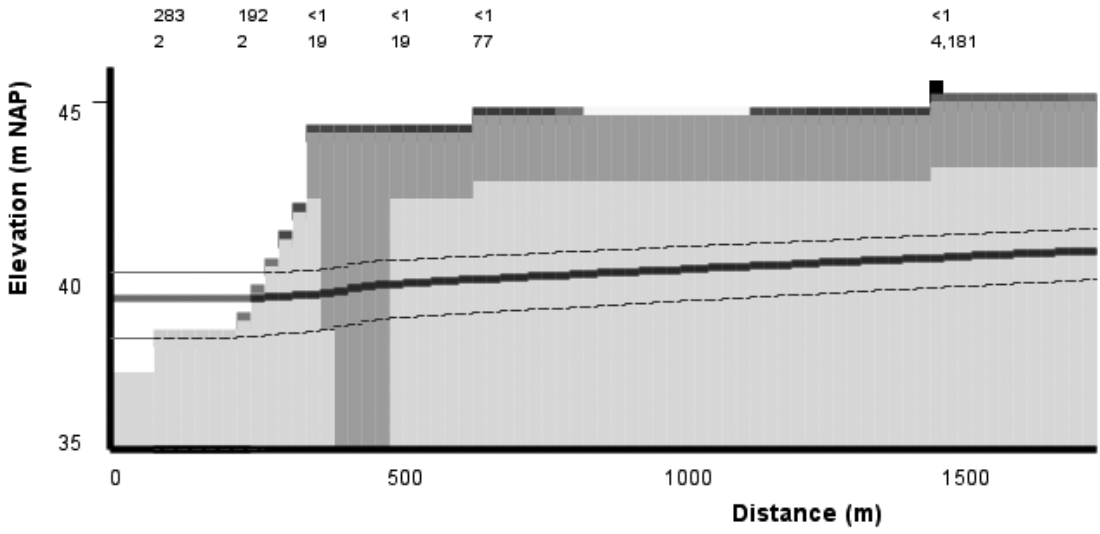

b)

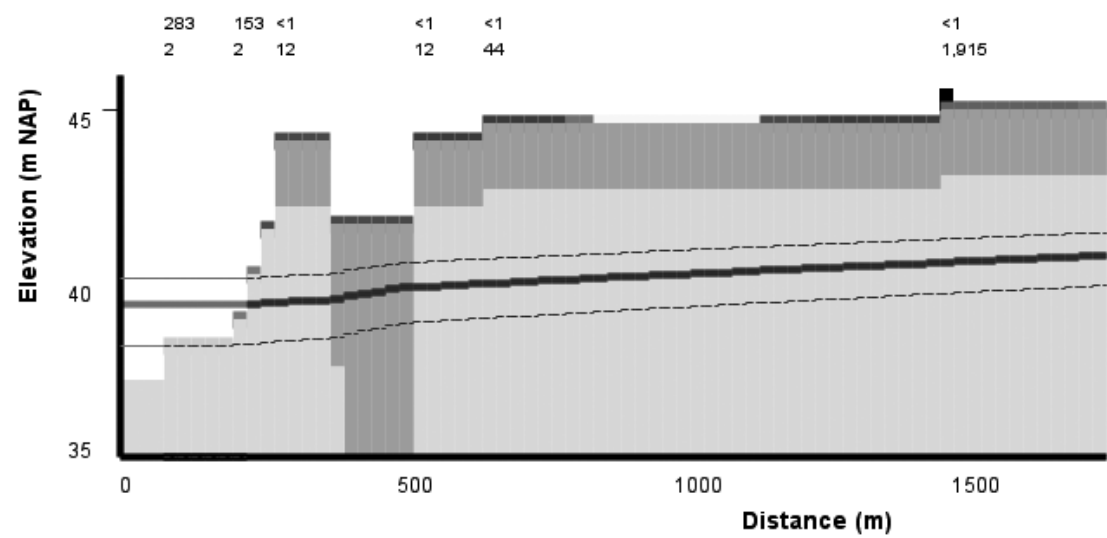

c)

Figure 5.11: Projected river cross-sections at Borgharen for the river management strategies GFG1991, PA1998, and PA2003. The cross-sections show projected land use, elevation, soil, groundwater table (ALG, ASG, AHG), and inundation durations (days/year) and frequencies (year ${ }^{-1}$ ). 


\begin{tabular}{|l|l|l|l|l|l|l|l|l|l|}
\hline \multirow{2}{*}{ Variable } & \multirow{2}{*}{ Unit } & \multicolumn{2}{l}{ Current } & \multicolumn{2}{l|}{ PA2003 } & \multicolumn{2}{l|}{ PA1998 } & \multicolumn{2}{l|}{ GFG1991 } \\
\cline { 2 - 10 } & & iRM & MW & iRM & MW & iRM & MW & iRM & Str. \\
\hline$F_{\text {rec }}$ & yrs & 45 & $\sim 50^{\mathrm{a}}$ & 1916 & $\sim 1250^{\mathrm{a}}$ & 4181 & $>10^{5 \mathrm{a}}$ & $168^{\mathrm{b}}$ & $\sim 60^{\mathrm{a}, \mathrm{b}}$ \\
\hline$D_{y}$ & $\mathrm{k} / \mathrm{yr}$ & 52 & & 1.7 & & 0.7 & & 4.3 & \\
\hline$\Delta H_{Q=3275}$ & $\mathrm{~m}$ & 0.00 & & 0.87 & 0.76 & 1.06 & 1.80 & 0.89 & 0.64 \\
\hline$N_{\text {new }}$ & ha & 0 & & 118 & 123 & 112 & 115 & 112 & 111 \\
\hline$E O W$ & - & 0.16 & 0.18 & 0.52 & 0.65 & 0.57 & 0.75 & 0.67 & \\
\hline$S$ & - & 0.69 & 0.90 & 1.14 & 1.29 & 1.26 & 1.50 & 1.15 & \\
\hline$\Delta A S G_{\text {nature }}$ & $\mathrm{m}$ & 0 & & -0.27 & -0.4 & -0.36 & & 0.00 & \\
\hline$A A_{\text {loss }}$ & ha & 0 & & 118 & 123 & 112 & 115 & 112 & 111 \\
\hline$\Delta A S G_{\text {agri }}$ & $\mathrm{m}$ & 0 & & -0.28 & -0.4 & -0.38 & & 0.04 & \\
\hline$B_{\text {net }}$ & M€ & 0 & & 2.8 & & 2.0 & & 2.9 & \\
\hline$P$ & $\%$ & 0 & & 6.5 & & 4.6 & & 5.2 & \\
\hline$H$ & $\begin{array}{l}\text { pers* } \\
\text { yrs }\end{array}$ & 0 & & 115 & & 116 & 107 & 147 & \\
\hline$Y_{\text {gravel }}$ & Mton & 0 & & 5.7 & 6.2 & 5.8 & 5.5 & 7.4 & 4.7 \\
\hline
\end{tabular}

${ }^{a}$ The flood recurrence levels of Maaswerken / Stroming are derived from the reported water level change

${ }^{\mathrm{b}}$ For the GFG1991, flood recurrence levels correspond to the situation without embankment

Table 5.10: Comparative assessment of the main impacts of the river management strategies GFG1991, PA1998, and PA2003. The table lists both the results of the iRM, and the results of the project organisation Maaswerken (MW) and the consultancy firm Stroming (Str.) for the strategies PA1998/PA2003 and GFG1991 respectively, and as far as data was available.

Let's first indicate some main similarities amongst the three strategies. All strategies are based on the principle of river widening, with no (further) dike-building applied, and with excavated clay being stored within the location area. Consequently, all strategies provide for a major decrease of flood recurrence and flood damage compared to the current state, a significant increase of natural area and nature diversity, which, however, goes to the cost of a significant amount of agricultural land. All strategies, finally, allow for the exploitation of gravel, with investments being roughly balanced by the profits. Striking in Table 5.10 is that the flood norm (1:250 yrs) is amply fulfilled for both the PA1998 and PA2003, and almost fulfilled for the GFG1991. Indeed, at the location of Borgharen, the projected water level decreases reported by Maaswerken are such that the flood recurrence time will be considerably higher than $250 \mathrm{yrs}^{73}$ Also for the GFG1991, the flood norm would be amply reached when the embankment would be installed.

\footnotetext{
${ }^{73}$ Note that the projected flood recurrence is strongly sensitive to the water level change, due to the logarithmic shape of the discharge recurrence function and the 'flat' stage-discharge relation for high discharges. For recurrence times $\sim 250 \mathrm{yrs}$, an additional water level reduction of $10 \mathrm{~cm}$ will increase the flood recurrence time with some $70 \%$.
} 
Looking at the differences between the strategies, a number of features catch the eye. First, considering the projected water level decreases (Figure 5.12), the GFG1991 is the only strategy that implies a water level increase for low discharges as a result of the projected elevation of the main channel bed. From a discharge $Q>\sim 300 \mathrm{~m}^{3} / \mathrm{s}$ on, water level decrease starts to occur. In the range of high discharges, the obtained water level decreases converge. However, still it is clear that the PA1998 achieves the largest water level decrease, with the highest flood recurrence time, and lowest average yearly flood damage. Consequently, the PA1998 can be considered the safest alternative. The iRM further indicates that the water level decrease of the GFG1991 is higher than the one of PA2003. This is not in line with the results of Maaswerken and Stroming and points to an overestimation in the iRM of water level decrease as a result of floodplain excavation.

Regarding nature development, the GFG1991 receives the highest scores. In particular, the high EOW value stands out. The PA1998 and PA2003 follow, in that order, in line with the Maaswerken results. Surprisingly, the GFG1991 does not stand out through a particularly high Shannon index: the PA1998 scores better on that respect. Since the GFG1991 study does not list values for the diversity indices, it is difficult to test formally whether this observation is a model artefact or an accurate representation of the GFG1991 plan. However, it seems reasonable that the GFG1991 was more directed towards creating the EOW reference distribution, than on achieving diversity per se. Overall, the ecosystem diversity index values calculated by Maaswerken are somewhat higher than the ones from the iRM. This could be explained from a different number of ecosystem types considered (concerning the Shannon index) or from the absence of the nature type 'dry area' in the iRM (due to its lack of topographic detail, the entire floodplain area remains of the type 'higher floodplain'). In terms of drought damage, finally, the GFG1991 is the only strategy for which a groundwater table decrease is fully compensated by the clay storage area.

In terms of agricultural impacts, the differences between the strategies are small, since the loss of agricultural land is similar in all cases. Here, also the GFG1991 should be noted as most desirable, as the groundwater table increase is considered beneficial for agriculture as well.

Finally, looking at excavation, costs, and hindrance it appears that the PA2003 is indeed the most efficient and profitable alternative according to the iRM results. The $6.5 \%$ profitability of PA2003 stands out, compared to the $4.6 \%$ and $5.2 \%$ profitability of the PA1998 and GFG1991. Regarding the net gravel yield, however, the iRM results are not in line with the expert model results. While the expert models indicate increasing gravel yields from the GFG1991 to the PA1998 to the PA2003, the iRM indicates that the gravel yield is roughly equal for PA1998 and PA2003, and significantly higher for the GFG1991. This mismatch is not yet well understood and requires further attention. 


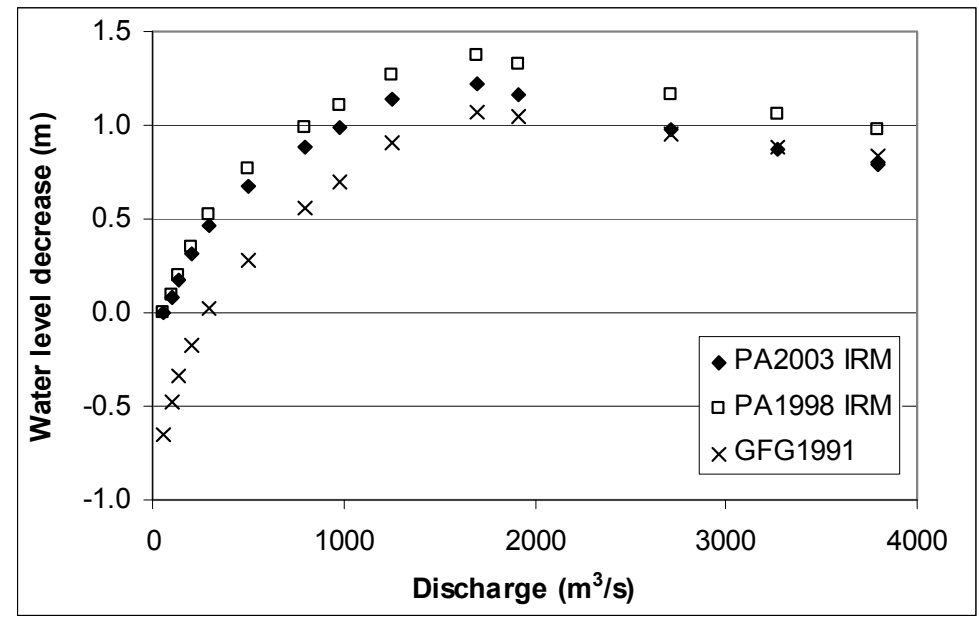

Figure 5.12: Projected water level decreases at Borgharen for the three river management strategies GFG1991, PA1998, and PA2003.

\subsubsection{Conceptual validation}

According to experts of the Maaswerken, the methods and concepts used are generally valid and have been properly applied. Nonetheless, a number of key critical conceptual issues remain, which are discussed here:

\section{Limitations due to the cross-section approach}

A main limitation of the cross-section approach is obviously that it neglects the spatial dimension in the direction parallel to the river. In the hydraulics module, for example, this implies that the calculation of water level change is essentially reduced to a OD problem (i.e. the water level at some location depends on the state of that location alone) while in reality backwater effects are known to be crucial as well. To some extent, these backwater effects are represented through the introduced hydraulic effectiveness parameter. Yet, this procedure presents a crude simplification of the real river state, assuming, for example, that all widening locations and bottlenecks are identical, that they form an infinite sequence, and that inhomogeneities within the widening locations are negligible. In other words, there are various reasons with which the initial overestimation of projected water level decrease can be explained.

The groundwater module suffers from this same problem. According to a Maaswerken groundwater expert, groundwater flow through the floodplain area is intrinsically a 2D phenomena; water flow is generally not in the direction perpendicular to the river alone. The groundwater table thus depends on the river water level at multiple river locations, rather than at the single river location considered here. Also, the effect of a clay storage area depends more on its shape and location, and not so much on its hydraulic conductivity as the model calculations suggest. In particular, groundwater flow around the clay storage area can not be represented, causing a strong overestimation of the groundwater table in the floodplain area. The adopted solution (increasing the modelled hydraulic conductivity of clay through the correction factor for lateral flow $C_{L F}$ ) presents a numerically adequate correction for the 
groundwater table at a relatively far distance from the clay storage area. However, it bears little scientific basis ${ }^{74}$, and fails to represent more detailed groundwater effects, such as the projected groundwater table increase just behind the clay storage area. In other words, while some main features of groundwater flow are represented in the model, the predictive value of the groundwater calculation is small.

A similar argument, finally, can be made for the calculation of excavated volumes. To some extent, these depend on the detailed topography of the landscape which is ill-represented in the schematic cross-section approach.

\section{Limitations due to the under-representation of phenomena}

Another source of error is the under-representation of certain phenomena. A Maaswerken nature development expert, for example, pointed out that nature development depends on much more than inundation durations alone. The ecosystem classification adopted provides only a rough assessment framework. Within each defined ecosystem type, 'everything is still possible' depending primarily on the morphological dynamics of the area under concern. In general, indices are considered fundamentally limited for measuring natural quality. Nature's nuanced features can not be represented in a single value alone ${ }^{75}$. Having said so, the EOW index seems more suitable measure of natural quality than the Shannon index.

In particular for the Grensmaas, the morphological dynamics plays an important role. It is considered crucially important for nature development (as pointed out above). Moreover, morphological development can lead to drastic changes in the river channel geometry with various possible consequences. However, as a hydraulic expert points out: 'the issue is extremely complicated'. The iRM - therefore - only attempts to cover a relatively minor effect: the stabilisation of the broadened main channel causing a minor change in channel geometry. A more detailed assessment of morphological changes is outside the scope of this thesis.

The calculation of flood damage - on the basis of inundation depths and damage functions - is conceptually simple and transparent. However, it is critically based on various simplifying assumptions. For example, it neglects the role of flood duration, which - the hydraulic expert points out - is critically important for flood damage. Also, it doesn't consider flow velocities and the rate at which water rises, factors which might be considered as part of more detailed flood damage studies (Jonkman et al., 2008). Finally, by adopting damage functions as model parameters, it implicitly assumes them to be constant over time. However, in frequently flooded areas, one can expect learning to take place (Kok et al., 2005) ${ }^{76}$, e.g. leading to better flood preparedness (e.g. timely evacuation) and less vulnerable housing and infrastructure designs. The included damage reduction factor (Kok et al., 2005) is obviously a very simple way to represent the possible learning effect. This representation might be improved by including investment in housing and infrastructure for modifying damage functions as response options in the iRM.

\footnotetext{
${ }^{74} \mathrm{~A}$ better solution might be to represent the clay storage area as if it were a bottleneck: an impermeable volume restricting groundwater flow over a given fraction of the river stretch considered.

${ }^{75}$ This limitation, however, applies to any nature development computer model

${ }^{76}$ According to the Blois (2000), this was the main reason why the flood damage of '95 turned out significantly lower than the INUNDA model would project.
} 


\section{Limitation due to the dependency on expert models}

A final critique, posed by a Maaswerken expert, is the fact that the model relies on calibration on the basis of expert model results. The model has a great potential for gaining 'quick-and-dirty' insight in the effects of river engineering measures. However, due to its dependency on expert model results, this potential can only partly be exploited. It thus advisable to develop a model approach which is independent from the expert model results. However, this does imply that some of the fundamental limitations described above need to be overcome.

\subsection{MODEL RESULTS: QUESTIONS AND ANSWERS}

In this section, some model results are presented. The model is suitable to support reflection on concrete river management issues that might come up during a participatory process with policymakers, experts and the broader community of stakeholders involved. Three types of issues can be distinguished. The first concern the implications of various river management strategies, and specific river engineering measures, and the extent too which these affect the trade-offs between the different river management targets. The second concerns the implications of specific model uncertainties, such as the uncertainty in the hydraulic calculations and costs. The third concerns the possible implications of uncertain context developments (such as climate change and spatial pressure) that might have important consequences on the long term. Box 5.1 presents an illustrative set of relevant questions, which are further discussed below on the basis of the iRM results.

\section{Box 5.1: Illustrative set of questions addressed with the iRM}

\section{Strategies}

- What are the differences between a river widening and a dike-building approach in terms of safety and costs?

- What would be considered a most natural river management approach? To which extent would this go to the cost of safety, agriculture and profitability?

\section{Model uncertainty}

- What is the uncertainty in flood recurrence due to the uncertainty in vegetation roughness and peak discharge probability?

- How uncertain are the calculations of benefits and cost? To which extent can the PA2003 be considered financially more secure than the PA1998?

\section{Context developments}

- What are the potential impacts of climate change on the river Meuse? And what does that potentially mean for future river management? 


\section{Strategies}

- What are the differences between a river widening and a dike-building approach in terms of safety and costs?

It is often stated that river widening provides a more sustainable safety than the creation and elevation of embankments. Various arguments are used: 1) embankments may breach - with potentially more inflicted flood damage then without the dikes, 2) embankments are responsible for further water level increases by reducing the river flow capacity, and 3) that dikes have a negative effect on the landscape and block the view for the inhabitants behind the dikes. On the other hand, the creation and elevation of embankments has proven to be a relatively simple measure to achieve a flood norm at relatively low cost, and in a relatively short period of time. These arguments turned out to be very important in the development of the Zandmaas plan (Maaswerken, 2001a).

Here, we aim to provide some quantitative underpinning to this debate. We do so by comparing a strategy of dike-building to a strategy river widening (i.e. the PA2003) on the criteria of flood recurrence, flood damage and investment costs. Let's first point out that the flood recurrence level - e.g. of the inhabited area - is highly sensitive to elevation change, whether this concerns a water level reduction, a ground elevation, or an elevation of the protecting dikes. For example, with a $10 \mathrm{~cm}$ elevation of the dikes, the flood recurrence level would increases from 45 years in the current situation to 68 years then. To achieve the flood recurrence target of 1:250 years would require some $40 \mathrm{~cm}$ elevation. And to obtain a flood recurrence level comparable to the PA2003, an elevation of $80 \mathrm{~cm}$ would amply suffice. These measures would constitute a relatively small investment cost, compared to the one of the PA2003 (see $C_{\text {tot }}$ in Table 5.11). ${ }^{77}$

\begin{tabular}{|l|l|l|l|l|}
\hline Criterion & Unit & Current & Dike-building $(\mathbf{7 9 c m})$ & PA2003 \\
\hline$F R$ & $\mathrm{yrs}$ & 45 & 1975 & 1916 \\
\hline$D_{y}$ & $\mathrm{k} € / \mathrm{yr}$ & 52 & 19 & 1.7 \\
\hline$C_{\text {tot }}$ & $\mathrm{M} €$ & - & 0.35 & 43.25 \\
\hline
\end{tabular}

Table 5.11: the effects of dike-building and river widening on flood recurrence $F R$, yearly average flood damage $D_{y}$, and total costs $C_{\text {tot }}$

However, regarding the criterion of flood damage, the widening strategy does a better job. While the dike-building approach significantly reduces damage with more than half, still a significant flood damage contribution remains (19 k€/yr). The main reason is that the embankments only protect the housing area, while the agricultural area remains flooded. Moreover, the widening strategy allows for damage reduction is range of extremely high discharges, while the dike-building approach no longer contributes to damage reduction when the dike has been flooded. These arguments are illustrated in Figure 5.13 that shows flood

\footnotetext{
${ }^{77}$ Here, we neglect - for the sake of general argument - the benefits of the PA2003, which - at other locations - might be much smaller or even non-existent.
} 
damage as a function of discharge for the current situation, and the PA2003 and D75 alternatives. The dike-building strategy only reduces flood damage for discharge in the range $2500-3700 \mathrm{~m} 3 / \mathrm{s}$. The river widening strategies reduce flood damage for the entire discharge range. On the other hand, advocates of the dike-building (or 'do nothing') approach might argue that in any case the flood damage reduction of PA2003 is insignificant compared to the overall investment cost. E.g. assuming a discount rate of $5 \%$, the overall benefit of flood damage reduction amounts to some $1 \mathrm{M} €$ for the PA2003, indeed a small amount compared to the total investment cost.

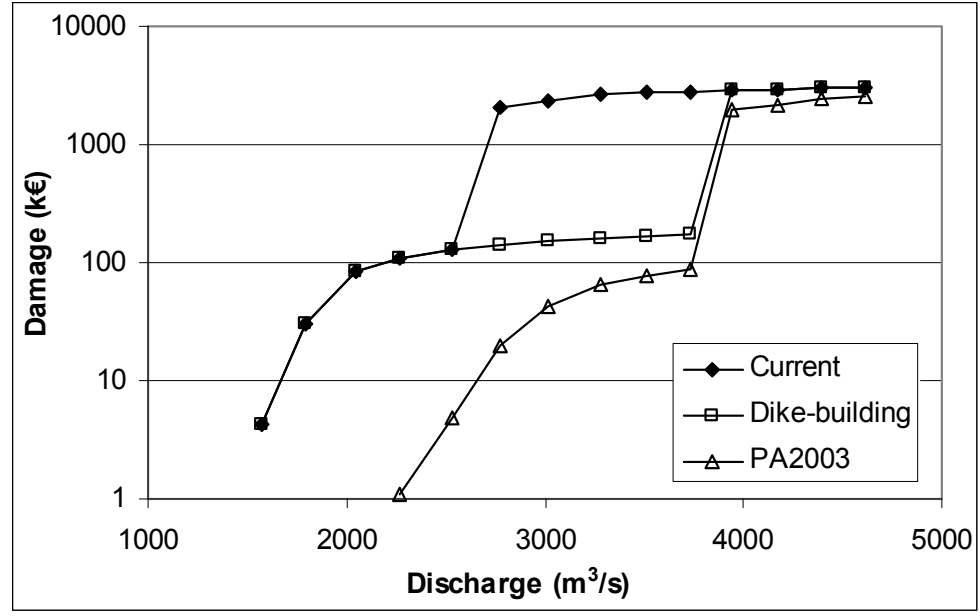

Figure 5.13: Calculated average yearly flood damage as a function of discharge for the current situation, and the PA2003 and D75 river management alternatives

- What would be considered a most natural river management approach? To which extent would this go to the cost of safety and profitability?

There are various ways a 'most natural' river management approach can be perceived. Important criteria are natural area, nature diversity (EOW and/or Shannon index), groundwater table changes, and - considering a criterion unfortunately not present in the model - the morphological dynamics. Here, a most natural river management alternative was constructed by optimizing ecosystem diversity measured by the EOW index, for a given available area (in between 110 and $130 \mathrm{ha}$ ), while avoiding a groundwater table decrease in natural areas.

The resulting strategy shows a balanced combination of main channel broadening, floodplain excavation, and additional nature area, while providing for a main channel bed elevation of $2 \mathrm{~m}$. The corresponding impacts shown in Figure 5.14 - indicate that nature and safety go together well: in the most natural strategy, flood recurrence remains higher than the current norm. Since the EOW index foresees in a significant increase in main channel area, the river flow capacity will significantly increase. Between nature and profitability, however, a sharper trade-off seems to exist. With a loss of some $0.7 \mathrm{M} €$, the most natural alternative could not be implemented in a budgetary neutral way. The main culprit is the elevation of the main channel bottom, which goes to the cost of a significant amount of profitable toutvenant. A natural follow-up question is then; to which extent can nature and profitability be combined? Therefore, the optimization was 
repeated, with the additional boundary condition of a minimum of $4 \%$ profitability. The solution is found through a relative increase of flood plain excavation, and a moderation of main channel bed elevation $(1 \mathrm{~m})$. The results indicate that these boundary conditions can be mutually satisfied, however through increased gravel extraction and associated hindrance for the inhabitants. In other words, there exists a subtle balance between the criteria of nature, safety, profitability, and hindrance. Satisfactory trade-offs have to be sought, for which the iRM may provide a useful tool.

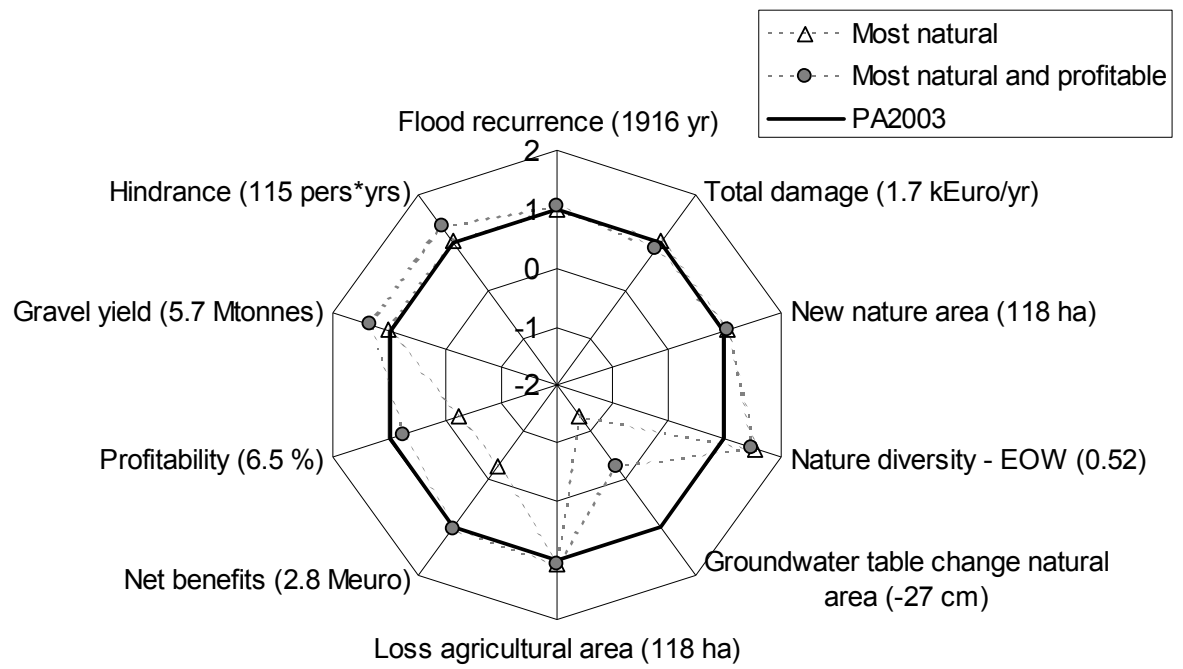

Figure 5.14: Assessing the trade-offs between nature, safety, profitability and hindrance through a comparison of a most natural strategy, and a strategy that combines natural value and profitability. The PA2003 is included as a reference alternative.

\section{Model uncertainty}

- What is the uncertainty in flood recurrence due to the uncertainty in vegetation roughness and peak discharge probability?

The main goal of Maaswerken project is to obtain a flood recurrence norm of 1:250 years. However, there are many uncertainties due to which the exact flood recurrence level is difficult to specify. One source of uncertainty, for example, is the limited knowledge on the hydraulic roughness of new nature areas, due to which the calculation of water level reduction may be imprecise. Another source of uncertainty originates from the finite length of the peak discharge statistical record, due to which the probability of occurrence of peak discharges is not precisely known. The question that arises is: can we quantify the uncertainty in the flood recurrence level, and what is the relative contribution of the two uncertainties considered above?

To assess the uncertainty range, a simple Monte Carlo simulation was performed. For the given river management strategy PA2003, a set of flood recurrence estimates was generated through repeated model calculations, with the values of the ecosystem roughness and peak discharge parameter groups of Table 5.2 drawn from a normal distribution. The uncertainties in vegetation roughness contribute to a standard deviation of some $5 \mathrm{~cm}$ around the estimated water level 
decrease $(\Delta H \sim 86 \mathrm{~cm})$ at the design discharge $Q=3275 \mathrm{~m}^{3} / \mathrm{s}$. This seemingly minor range, however, implies a range ${ }^{78}$ of some 450 years around the estimated recurrence level $(F R=1916$ years), see Figure 5.15. The uncertainty in peak discharge probability provides an even larger range - some 850 years - while the combination of vegetation roughness and peak discharge uncertainty implies a standard deviation $>1000$ years. Off course, the interpretation of these results, and in particular the typical uncertainty ranges in the parameters specified before, is subject to debate. Nonetheless, these results do indicate these uncertainties are significant and should probably be better taken into account in the river management planning process.
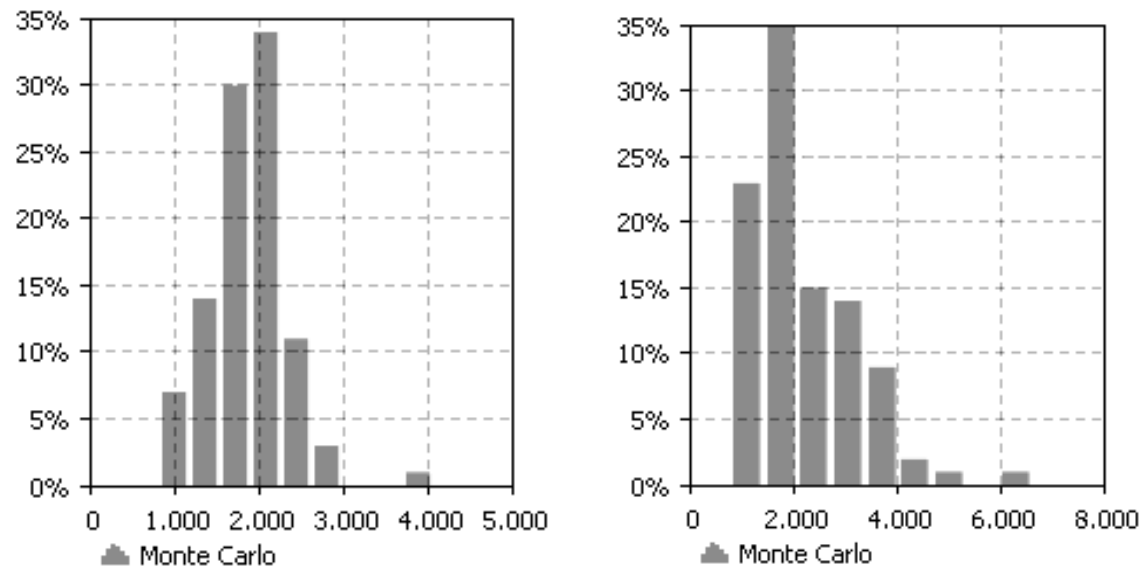

Figure 5.15: Monte Carlo simulation of the flood recurrence level with respect to variations in ecosystem roughness (left) and peak discharge probability (right). The associated standard deviations lie around 450 yrs and 850 yrs respectively.

- How uncertain are the calculations of benefits and cost? And to which extent can the PA2003 be considered financially more secure than the PA1998?

The planning process of the Grensmaas project has been strongly influenced by financial issues. The criterion of budget neutrality has been difficult to fulfil, as illustrated by the cumbersome negotiations between the Province of Limburg and the gravel extracting companies in the period after the presentation of the PA1998. A complicating factor in the negotiation might have been the large uncertainty in the estimation of benefits and costs. Uncertainty arises, for example, due to limited data on soil composition, such as the soil-density and the fraction of profitable gravel in the toutvenenant. Also, various cost and benefit parameters (e.g. the costs of soil excavation and the future gravel market price) can not be precisely known. The question that arises is, on the one hand, how uncertain the calculations of cost and benefits really are, and on the other hand to which extent the PA2003 can be considered financially more secure than the PA1998?

\footnotetext{
${ }^{78}$ Derived from the standard deviation of the distribution of the $\log 10$ flood recurrence values
} 
To address this question, again a simple Monte Carlo simulation was performed. The simulation tested the two strategies PA1998 and PA2003 under variation of the soil, cost and benefit parameters groups of Table 5.2. The results - displayed in Figure 5.16 - indicate that the uncertainty ranges in the net benefits $(\sim 5 \mathrm{M} €)$ are significantly larger than the expected net benefits of both strategies ( $\sim \mathrm{M} €$ and $\sim 2.8 \mathrm{M} €$ respectively). This suggests that the probability of a loss is significant in both cases, and that the PA2003 can thus only be considered marginally more secure. Again, this assessment of costs, benefits and associated uncertainties should be interpreted with care, given the simple cross-sectional model used. Nonetheless, the results clearly show that managing financial risks is equally or more important than a detailed consideration of expected benefits and costs.
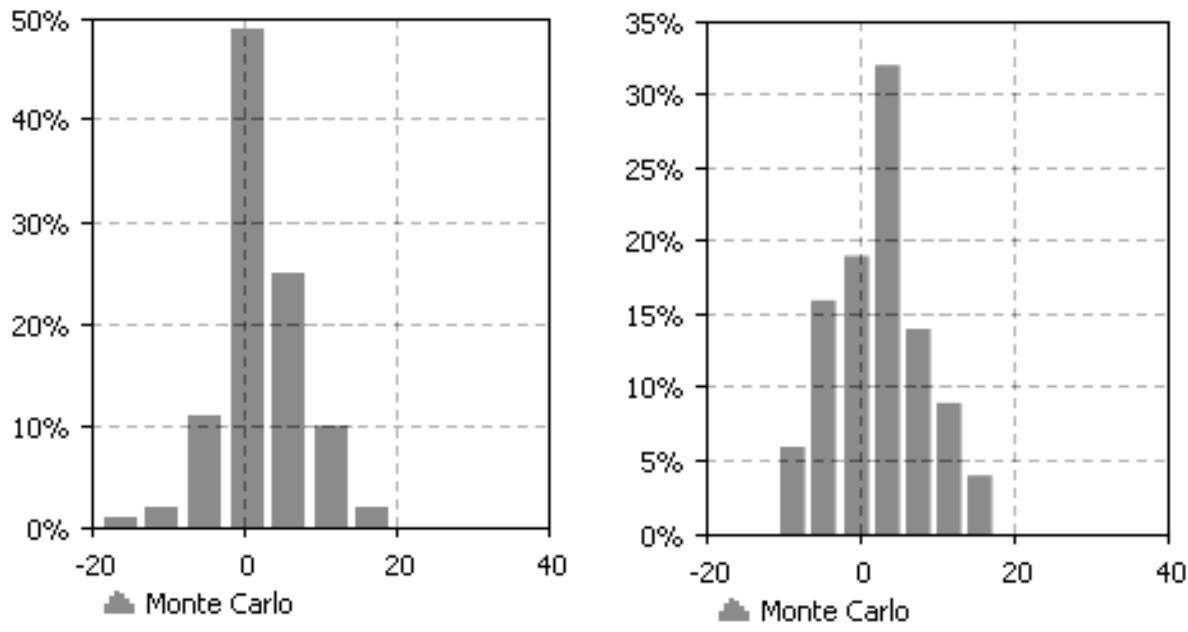

Figure 5.16: Monte Carlo simulation of the net benefits for the PA1998 (left) and PA2003 (right) for variations of the soil, cost, and benefit parameter groups. The associated standard deviations lie around $5 \mathrm{M} €$.

\section{Context developments}

- What are the potential impacts of climate change on the river Meuse? And what does that potentially mean for future river management?

Finally, the model can be used to reflect on the impacts of context developments, such as climate change and spatial development. Climate change, in particular, is currently high on the Dutch policy agenda, as illustrated by the recent policy assessment of climate change and water management of the so-called Delta Commission (Deltacommissie, 2008). Nonetheless, climate change has not been explicitly considered in the Maaswerken planning process. This raises the question: what are the potential impacts of climate change on the river Meuse? And what does that potentially mean for future river management?

To assess the impacts of climate change on the river Meuse, a user can choose between the socalled G, W, G+, W+ climate scenarios currently adopted as a standard in Dutch water management. The implications of the various scenarios - for the given strategy PA2003 - are illustrated in Figure 5.17. It is clear that the main impact of climate change - as projected by the 
iRM - pertains to the criteria of flood recurrence and flood damage. Under the $W$ scenario (providing the highest projected increase of peak flow probability, see Appendix A), a fourfold increase of flood recurrence and a two-fold increase of the average yearly flood damage are foreseen in 2050. However, the flood recurrence level (656 years) remains above the current flood norm. Regarding nature diversity, the model projects minor changes of the inundation durations of natural area. These changes, however, are insufficient to alter the ecosystem distribution defined by Table 5.5. Also, the impacts related to the groundwater table can be considered small. The minor increases of seasonal average discharges foreseen under the $\mathrm{G}$ and W scenarios are too small to significant contribute to groundwater table change. The strong summer discharge decrease of the $\mathrm{G}+$ and $\mathrm{W}+$ scenarios does show a significant effect on the Average Low Groundwater table (ALG). Note, however, that this effect is only a moderation of the ALG increase induced by the PA2003 compared to the current state.

Summarizing, the PA2003 can be considered fairly 'climate proof' on the basis of the information provided here. A future increase of flood probability is at least to some extent 'covered' by the high flood recurrence level obtained after implementing the PA2003. The possible effect of a decreasing of summer discharge on the groundwater table is sufficiently compensated with a groundwater table increase due to the clay storage area. Note that the significant increase of low flow periods foreseen in the $\mathrm{W}+$ scenarios might have more significant impacts when considering, for example, functions like shipping and drinking water supply. This illustrates that the current exercise is only a small step towards a more comprehensive assessment of the impacts of climate change on the Limburg Meuse.

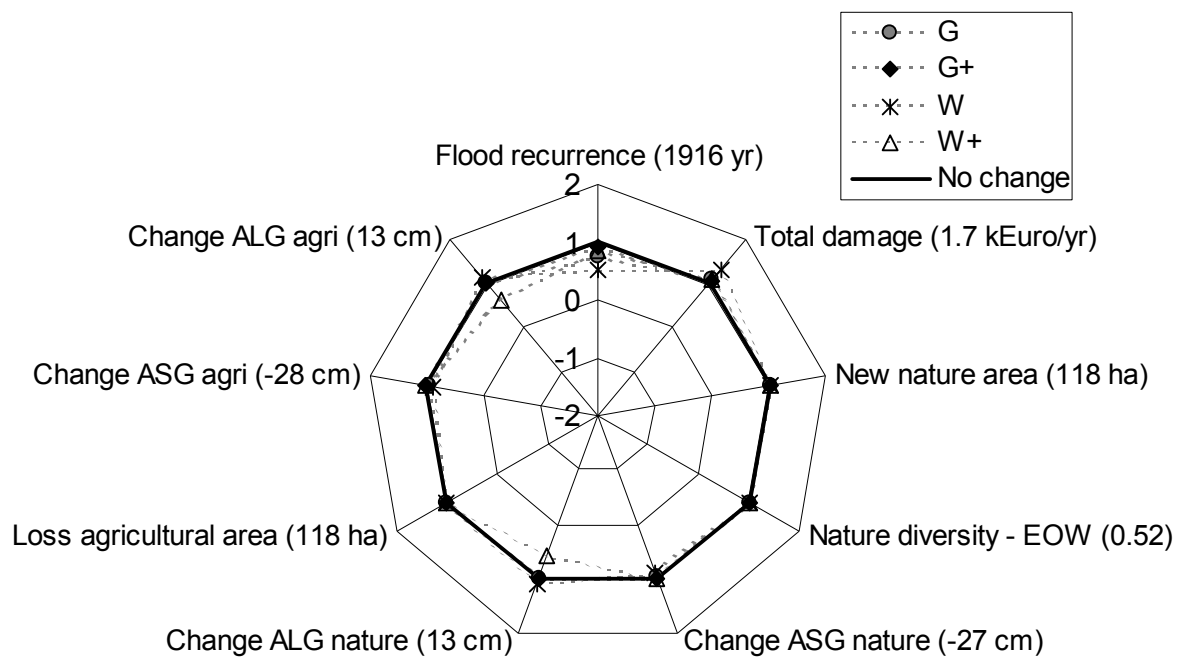

Figure 5.17: Selected impacts of the PA2003 under various climate change scenarios. 


\subsection{CONCLUSION}

In this chapter, a simple cross-section model was presented for the order of magnitude analysis of river management options and their impacts. Given the requirements defined in Section 5.2, how well does the model perform?

The first criterion - being compatible with stakeholder perspectives - has been partly fulfilled. On the one hand, stakeholder knowledge on salient impacts and uncertainties has been included in the model design, so that the model - according to our best judgment - covers some of the core issues of the Grensmaas project according to the stakeholders involved. On the other hand, due to both practical and more fundamental constraints, only a subset of all stakeholder considerations has been included in the model, let alone those that might become relevant in 50 or 100 years from now. Maybe the question is not so much whether the current model reflects the salient impacts and uncertainties in an adequate way, but rather whether it is flexible enough to be updated when new insights and issues emerge. Indeed, the simplicity of the model design allows for such flexibility: it is relatively easy to introduce new decision-making criteria, new variables and uncertainties in the model when considered necessary. For the process of model application and development, a continuous interaction with model experts and stakeholders is recommended to keep the model up to date.

The second criterion - interactivity - is amply fulfilled. The calculations run rapidly; a single model run takes about 0.1 second, allowing instantaneous calculations (for example during a workshop) and leaving room for optimization type of model runs, testing many strategies within a reasonable amount of time. Also, the model results are transparent, in the sense that model assumptions and results are relatively easy to understand.

Regarding the third criterion - validity - the model has been found to provide a conceptually valid tool, suitable for order of magnitude projections of river management effects on the local level. Nonetheless, the cross-section approach poses some fundamental restrictions. We distinguished limitations due to the cross-section approach (for example in the water level and groundwater calculations), due to the under-representation of phenomena (for example regarding morphological processes and a changing flood damage potential) and due to the dependency on expert models (for calibration). The main issue of validity is that the modelling concept has been tested for a single cross-section alone. The 'proof of concept' would be much stronger when the model would be applied to multiple locations, representing similar yet different issues, for example in the Zandmaas area. Further model application and testing for various river management locations is recommended to get a better judgement of the generic applicability of the approach.

Summarizing, the model shows promise for use in several contexts. The model may be used on the strategic policy level to reflect on various river management approaches. Its short calculation time, and the explicit consideration of uncertainties and various impacts, allows for an open reflection on the targets and risks of a river management project like Maaswerken. Such a reflection process should always be complemented with results from expert models and/or expert judgments, for interpreting and clarifying the iRM model results. In participatory settings, the model can be used to support communication and contribute to a social learning process amongst policymakers, river management planners, scientists, and stakeholders. An iRM facilitated discussion may allow for a straightforward discussion of river management issues, where the 'experts' can clarify the main scientific and planning issues, whilst 'lay-people' have 
Chapter 5

the ability to contribute their knowledge and concerns. Last but not least, the model is to be used as a scientific tool to advance the understanding of human-environment systems through application in combination with a participatory ABM approach. 


\section{Chapter 6}

SIMULATING STAKEHOLDER SUPPORT IN THE MAASWERKEN PLANNING PROCESS 


\begin{abstract}
In this chapter we present an Agent-Based Model representing a policy process among stakeholders of river management. The stakeholders are represented as computer agents whose support for a river management strategy is modelled on the basis of their goals and beliefs in the form of their interpretation of uncertainty. Plausible policy outcomes are then derived as the river management strategy with maximum stakeholder support. For evaluating the different river management strategies, the Agent-Based Model is coupled to the integrated River Model that describes the impacts of river management, such as flood risk, nature development and costs. The model is applied to the case of the ongoing Dutch river management project 'Grensmaas'. We analyse stakeholder support for the various river management strategies proposed and reconstruct the observed policy outcomes of the Grensmaas project over the last fifteen years to provide a first validation of the model. We then assess how stakeholder support and the policy outcome might change when stakeholders would change their goals, or would take climate change into account. We conclude that the main virtue of the developed modelling framework lies in its application within participatory processes, to support stakeholders to reflect upon their goals and uncertainty interpretations in a social context.
\end{abstract}

This chapter was published as:

Valkering, P., Rotmans, J., Krywkow, J., and Van der Veen, A. (2005). Simulating Stakeholder Support in a Policy Process: An Application to River Management. SIMULATION, 81 (10), 701 718. 


\section{Simulating Stakeholder Support in the Maaswerken Planning Process}

\section{$6.1 \quad$ INTRODUCTION}

Agent-Based modelling (ABM) is a promising technique for interpreting actor perspectives and simulating actor behaviour in policy relevant research. In particular, Agent-Based models may be incorporated into Integrated Assessment (IA) modelling frameworks for a better representation of stakeholder behaviour, for example in IA models of climate change (Moss et al., 2001) and land use development (Van der Veen \& Rotmans, 2001). Such model frameworks may be used to explain actions of actors from their perspectives, expressed in terms of their goals and beliefs, and show the implications of these actions on the environment and for other stakeholders. Moreover, the models could be used to investigate stakeholder-environment interaction by simulating changing perspectives and behaviour in response to environmental change. Finally, the models could aid to investigate stakeholder-stakeholder interaction by modelling processes such as co-operation and competition. The ABM approach is especially relevant in combination with participatory methods. Stakeholders could be involved in the model design to ensure that the model captures the issues of relevance and the subjective stakeholder perceptions. Furthermore, Agent-Based models can be used to structure participatory processes, supporting social learning by making viewpoints among stakeholders explicit (Pahl-Wostl, 2002).

In this chapter we aim to apply the approach of ABM for a case study of river management. We will focus on the river engineering project 'Grensmaas' which is currently ongoing in the Dutch province of Limburg. The Grensmaas project has three main goals (V\&W, 1997; Maaswerken, 1998a): 1) reduction of flood probability to $1: 250^{79}$ for inhabited areas, 2) the development of a minimum of 1000 ha of riparian nature, and 3) the extraction of a minimum of 35 million tons of gravel for national use. To this end, measures are planned to widen the Meuse to the North of the city of Maastricht over a length of some $40 \mathrm{~km}$. The Grensmaas project affects many stakeholders with a variety of interests. The main stakeholder groups of the Grensmaas project are the inhabitants of the region, farmers, nature organizations, and the gravel extracting companies. It is an explicit aim of the Maaswerken project organization to involve these stakeholders as much as possible in the decision-making process in order to develop an integrated strategy and a broad societal interest and support.

The planning process of the Grensmaas project - described in Chapter 4 - can be characterized as long and complex, involving many uncertainties and conflicting interests. It dates back to the early nineties when the first plan for riverbed widening was formulated, and has continued up till roughly $2003^{80}$. During this period, the river management plan was adapted multiple times under the influence of changing goals and an increasing number of stakeholders in the policy process - which often went to the costs of stakeholder support. To model those developments, we will present a coupled integrated River Model - Agent-Based Model that represents the policy process of the Grensmaas project. This model implements a first, essential part of the

\footnotetext{
${ }^{79}$ A safety level of 1:250 indicates that floods are expected to occur on average once every 250 years.

${ }^{80}$ The implementation phase of Grensmaas officially started in 2008.
} 
model concept of Chapter 2: modelling stakeholder support and the outcome of the policy process (a preferred river management strategy) among a specific group of stakeholders with given goals and beliefs. Modelling adaptive cognition as a result of stakeholder-environment and stakeholder-stakeholder interaction is left for future work.

\subsection{THE SIMULATION MODEL}

\subsubsection{Model overview}

The simulation model is designed to represent the course of the Grensmaas planning process from 1991 to 2003 (see Table 4.1 in Chapter 4). Starting from a given set of stakeholders, the model is used to calculate stakeholder support and the policy outcome in the form of a preferred river management strategy. To this end, the stakeholders of the Grensmaas project are represented with computer agents endowed with goals and beliefs. In our application, the goals of the stakeholder agents are related to the various impacts of river engineering. Typical goals are flood protection for the inhabitants, nature development for nature organisations, profit for the gravel extracting companies, and so on. The agents are endowed with quantitative goal standards to evaluate their goals as described later on.

The stakeholder agents in our model are informed by the integrated River Model (iRM) to assess the main impacts of river management options, and hence to be able to evaluate their goals. The iRM results, however, are subject to various uncertainties (see Table 5.2) related to uncertain model parameters (e.g. the cost and benefit parameters), and context developments (e.g. climate change). Following the concept of pluralistic uncertainty management (Van Asselt, 2000; Rotmans \& Van Asselt, 2001), it is assumed that each stakeholder agent may hold different, legitimate interpretations of these uncertainties as part of its belief system. This implies that the agent can adopt specific settings for uncertain parameters and context developments in the iRM.

The procedure for calculating agent support and the policy outcome is illustrated in Figure 6.1. For a given range of river management strategy proposals, the iRM is used by the agents to calculate impacts in relation to flooding, nature development, agriculture, and costs. The impact values generally differ among agents since they are endowed with different uncertainty interpretations. The impact values pertaining to each individual agent's goals are referred to as their goal values. These values form the input for the agents' support evaluations performed on the basis of their goal standards. Total agent support is then calculated as a function of the individual stakeholder agent supports. The policy outcome, finally, is calculated as the river management strategy with maximum total agent support. 


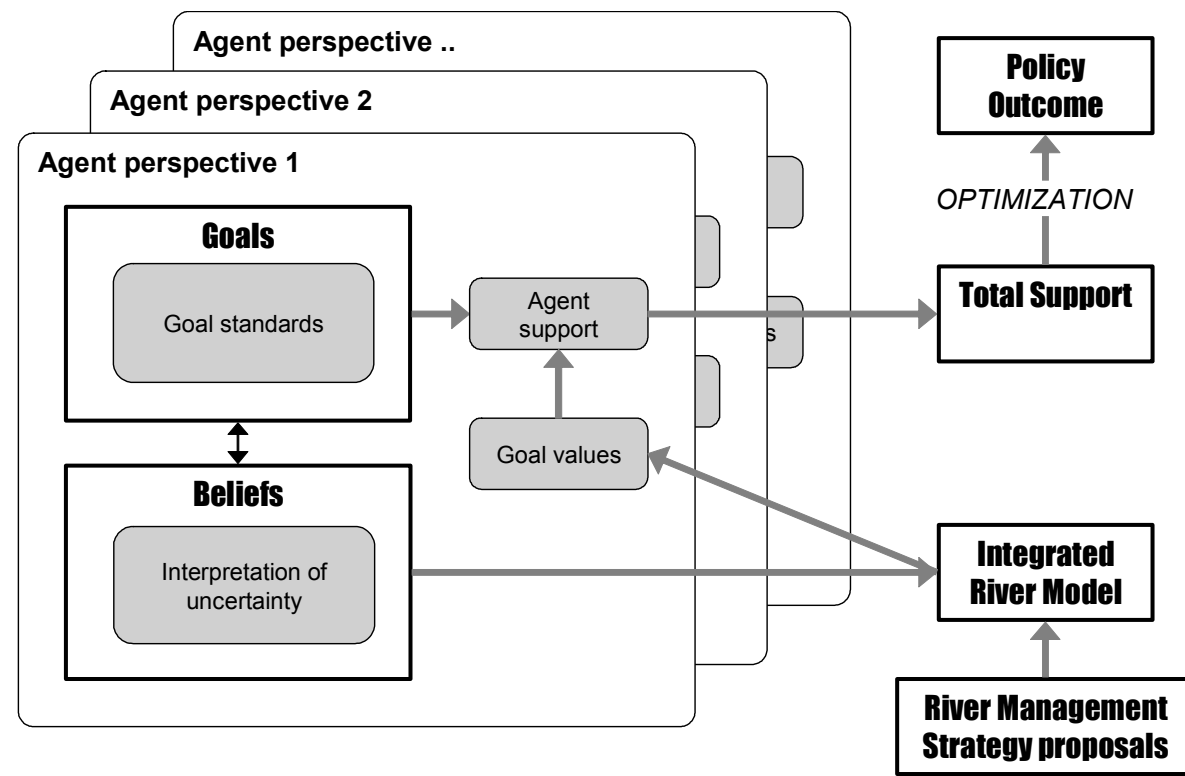

Figure 6.1: Overview of the simulation model. For a given range of river management strategy proposals, the iRM is used to calculate the goal values for the various stakeholder agents. Consequently, the agents evaluate their support for the proposal on the basis of their goal standards. The policy outcome is then calculated as the river management strategy with maximum total agent support. The relations between the agents on the one hand, and the integrated River Model and total support function on the other, are for clarity only shown for agent 1.

\subsubsection{Calculating support and policy outcome}

In the following we describe the sequential modelling steps in the ABM as concisely as possible. In our notation we use bold italic print to denote sets of variables and italic print to denote single variables.

\section{Step 1: Assessment of the river management strategy}

We consider a set of agents $\boldsymbol{A}$, each one having a set of goals $\boldsymbol{G}_{\boldsymbol{A}}$. The agents and their goals for our case study are displayed in Table 6.1. For a given river management strategy, each agent applies the iRM to calculate the impacts of the strategy corresponding to their goals (e.g. the level of flood recurrence). These values are denoted 'goal values', i.e. the set $G \boldsymbol{V}_{\boldsymbol{A}}$. For calculating the goal values an agent passes two sets of arguments to the iRM: 1) the river management strategy $\mathbf{R M S}$ : a set of river engineering parameters specifying main channel deepening, main channel broadening, floodplain excavation, surface elevation of the clay shield, and additional nature area, and 2 ) its uncertainty perspective $\boldsymbol{U} \boldsymbol{P}_{\mathbf{A}}$ : settings for the uncertain iRM model parameters and for a climate change scenario. In formula form we could (cryptically) write for the set of goal values $G V_{A}$ :

$$
\boldsymbol{G} \boldsymbol{V}_{\boldsymbol{A}}=\mathrm{EVALUATE} \mathrm{iRM}\left(\boldsymbol{R} \boldsymbol{M S}, \boldsymbol{U} \boldsymbol{P}_{\boldsymbol{A}}\right) .
$$




\section{Step 2: Individual goal evaluation}

Each agent now determines its so-called goal satisfactions $G S_{A}$ with the goal values calculated in the previous step. To this end, each one of its goal values $G V_{A, i}$ is evaluated on the basis of a goal satisfaction curve:

$$
G S_{A, i}=\text { GOAL_SATISFACTION }\left(G V_{A, i}, \text { standards }_{A, i}\right) .
$$

Goal satisfaction is expressed on a continuous scale of -1 to 1 representing evaluations ranging from 'unacceptable' (-1), to 'neutral' (0), to 'full satisfaction' (1). The shape of the goal satisfaction curve is determined by parameters, called goal standards. This is described and interpreted below.

\section{Step 3: Agent support}

The support an agent attaches to a river management strategy RMS is now calculated as the weighted average of its goal evaluations $G_{A}$. Moreover, if one of its goal satisfactions indicates 'unacceptable' (-1) the overall evaluation of the river management strategy is equally considered 'unacceptable' and support is set to -1 . So,

$$
\begin{gathered}
S_{A}=\text { WEIGHTED_AVERAGE }\left(G S_{A}\right), \\
\text { if }\left(\exists G S_{A, i}=-1\right) \text { then }\left(S_{A}=-1\right) .
\end{gathered}
$$

Observe that a goal satisfaction of -1 cannot be compensated with a positive satisfaction for another goal. An 'unacceptable' judgement is thus fundamentally different from a negative judgement arbitrarily close to -1 which can be compensated.

\section{Step 4: Total support}

Total agent support $S_{\text {tot }}$ is calculated as the un-weighted average of the individual agents' supports. However, there is one requirement to this rule related to the power of stakeholder agents. Some stakeholders have a much larger influence over the decision-making process than the other parties and are considered 'essential' for supporting a final decision. In the practice of the Grensmaas project, these are responsible governments and the gravel extracting companies, see Section 4.3.1. Those parties must support the river management strategy (i.e. $S_{A \rightarrow \text { essential }}>0$ ) for the strategy to be approved. If not so, total support is set to -1 . In other words:

$$
\begin{gathered}
S_{t o t}=\operatorname{AVERAGE}\left(S_{A}\right), \\
\text { if }\left(\exists S_{A \rightarrow \text { essential }}<0\right) \text { then }\left(S_{t o t}=-1\right) .
\end{gathered}
$$

\section{Step 5: The policy outcome}

Finally, the so-called 'optimum' strategy $\boldsymbol{R} \boldsymbol{M} \boldsymbol{S}_{\text {opt }}$ is obtained by varying the parameters $\boldsymbol{R} \boldsymbol{M S}$ within predefined ranges to find the absolute maximum in $S_{\text {tot }}$ :

$$
\boldsymbol{R M S}_{\text {opt }}=\operatorname{MAXIMUM}\left(S_{\text {tot }}(\boldsymbol{R M S})\right)
$$

This optimum strategy is assumed to represent the outcome of the policy process. 


\subsubsection{The goal satisfaction curves}

The goal satisfaction curves of Equation 6.2 are defined by applying different types of goal standards. We adopt three possible types of curves as represented in Figure 6.2. In the simplest possibility an agent applies only a so-called 'conditional standard' (CS). For such a 'conditional goal' the goal satisfaction GS is a step function flipping from -1 ('unacceptable') to 1 ('fully satisfied') at the conditional standard CS. As a second possibility, the agent only specifies two socalled 'optimisation standards': an optimisation zero point value $O S_{0}$ (the goal value for which their goal satisfaction is 'neutral') and an optimisation high value $O S_{H}$ (the goal value for which their goal satisfaction is 'high'). For such an 'optimisation goal' the goal satisfaction is calculated as

$$
\begin{gathered}
G S=1-\exp (-|X|) \text { for } G V \geq O S_{0}, \text { and } \\
G S=-(1-\exp (-|X|)) \text { for } G V<O S_{0},
\end{gathered}
$$

with $X \equiv\left(G V-O S_{0}\right) /\left(O S_{H}-O S_{0}\right)$. Finally, an agent can choose to apply both types of standards which leads to a truncated preference curve as illustrated in Figure 6.2. Agents thus seek the river management strategy for which the set of optimisation goal values provide maximum satisfaction, within the constraints posed by the conditional standards.

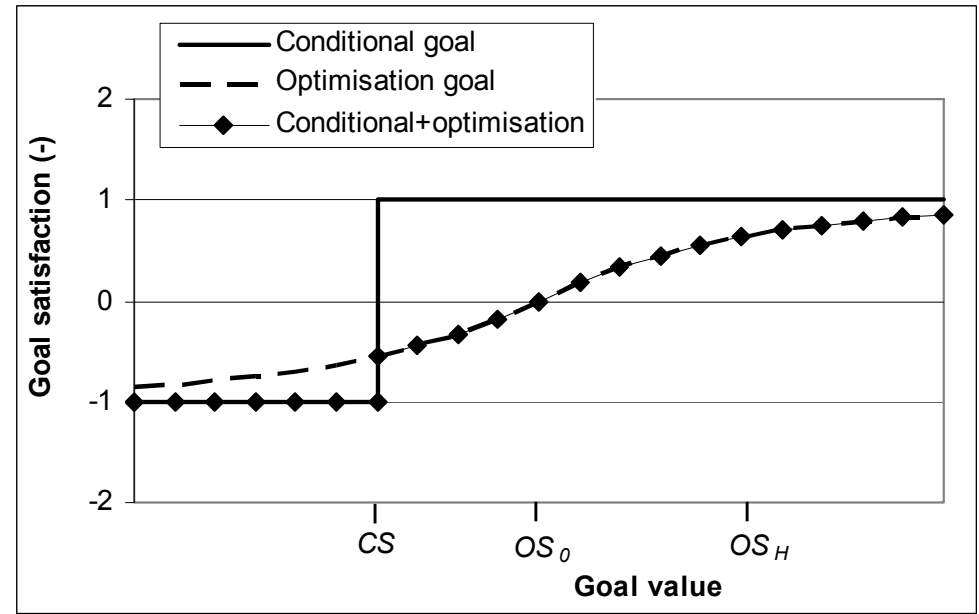

Figure 6.2: Three typical goal evaluation curves that specify goal satisfaction as a function of the expected goal value. A 'conditional goal' is evaluated only on the basis of a conditional standard CS, an 'optimisation goal' is evaluated on the basis of the optimisation standards $O S_{0}$ and $O S_{H}$. Agents may also specify both conditional and optimisation standards.

The goal satisfaction curves are interpreted as follows. We observe from the Grensmaas project that decisions are made firstly on the basis of a set of minimal, 'conditional' requirements (main project goals and specific boundary conditions) after which optimization occurs on the basis of other 'optimization' criteria. For example, flood probability and costs are subject to minimal requirements (1:250 yrs and budget neutral respectively), whereas hindrance should be 
minimized within the constraints that the primary goals are realized ${ }^{81}$. This dichotomy between conditional and optimisation standards corresponds to the economic debate on substitutability of utility (Van den Bergh et al., 2000). Optimisation goals are substitutable: since a negative goal satisfaction never reaches 'unacceptable' (-1) it can always be 'substituted' with a positive satisfaction for another goal. For conditional goals, however, this is not the case. The conditional goals form the 'hard' conditions that are probably more decisive for the final policy outcome then the 'softer' optimisation goals.

\subsection{THE GRENSMAAS PROJECT IN RETROSPECT}

In this section we apply the simulation model to analyse the Grensmaas project in retrospect. We firstly assess the perspectives of the stakeholders of the Grensmaas project in terms of their goals and uncertainty interpretation. On the basis of these perspectives we calculate agent support for the observed, historical policy outcomes of the Grensmaas project. Consequently, we assess so-called 'ideal' strategies: the optimum strategies from the perspectives of the individual stakeholders involved. Finally, we reconstruct the observed course of the Grensmaas project to provide a first validation of the ABM.

\subsubsection{Implementing agent perspectives}

\section{Agents and goals}

The implementation of the agent perspectives is based on the stakeholder analysis of Chapter 4 . We consider the following main stakeholder groups: 1) parties representing the national and provincial government (i.e. the responsible government organisations) and municipalities 2) citizen organizations representing the inhabitants of Borgharen, 3 ) the farmers organized in a regional farmer association, 4) the nature organizations involved, and 5) the gravel extraction industries. These are represented by the corresponding stakeholder agents 'policymaker', 'citizen', 'farmer', 'nature organization', and 'gravel extractor'.

To these agents, we associated the goals shown in Table 6.1. Table 6.1 identifies various 'goal categories' (e.g. flood protection), which are further specified in terms of concrete 'goals' (e.g. the level of flood recurrence) ${ }^{82}$. These goal categories and goals form a salient subset of the full goal inventory of the stakeholder analysis of Chapter 4 (see Tables 4.4 and 4.5). In correspondence with Table 4.5, the policymaker agent is assumed to support all the main objectives of the Grensmaas project. It basically aims to achieve its main objectives of flood protection $^{83}$, nature development, and gravel extraction, while avoiding negative effects for agriculture and hindrance, at affordable costs. For the other stakeholder agents, a selection is made on the basis of Table 4.5.

\footnotetext{
${ }^{81}$ This is referred to as the ALARA principle (As Low As Reasonably Achievable) (Maaswerken, 1998a, p. 39).

${ }^{82}$ Note that, what is referred to as 'goal categories' here, was labelled as 'goals' in Chapter 4

${ }^{83}$ The goal flood recurrence only applies for the second and third phase of the policy process. During the first phase the issue of flood reduction was not important yet.
} 


\begin{tabular}{|l|l|c|c|c|c|c|}
\hline Goal category & Goal & pm & cit & no & farm & ge \\
\hline Flood protection & flood recurrence & $*$ & $*$ & $*$ & $*$ & \\
\hline \multirow{2}{*}{$\begin{array}{l}\text { Nature } \\
\text { development }\end{array}$} & new nature area & $*$ & $*$ & $*$ & & \\
\cline { 2 - 8 } & ecosystem diversity & $*$ & $*$ & $*$ & & \\
\cline { 2 - 8 } & $\Delta$ groundwater table & $*$ & & $*$ & & \\
\hline \multirow{2}{*}{ Gravel extraction } & gravel yield & $*$ & & & & $*$ \\
\hline \multirow{2}{*}{ Agriculture } & loss agricultural area & $*$ & & & $*$ & \\
\cline { 2 - 8 } & $\Delta$ groundwater table & $*$ & & & $*$ & \\
\hline Hindrance & sound hindrance & $*$ & $*$ & & & \\
\hline Cost effectiveness & profitability & $*$ & & & & $*$ \\
\hline
\end{tabular}

Table 6.1: Stakeholder agents and associated goals for the case study of the Grensmaas project. The abbreviations 'pm', 'cit', 'no', 'farm', and 'ge' refer to the agents policymaker, citizen, nature organisation, farmer, and gravel extractor respectively.

\section{Goal standards}

The quantitative standards the agents attach to their goals are displayed in Table 6.2. The conditional standards for the main project goals flood protection, new nature area, and gravel extraction are stated clearly by the government: a maximum flood recurrence of 1:250, minimally 1000 ha of new nature, and minimally 35 million tons extracted gravel ${ }^{84}$. All stakeholder agents adopt these standards for their corresponding goals. With respect to the goal of profitability, we assume that both the gravel extractor and policymaker adopt a conditional standard of $4 \%$. This value corresponds to the discount rate of $4 \% / y e a r$ considered to be profitable by the Dutch government for risk-free investments (Eijgenraam et al., 2000).

Regarding the various other goal standards, no explicit data was available from the project documentation or stakeholder analysis. The rationale for deriving those standards was as follows. For a 'positive' goal (like ecosystem diversity) that generally creates a positive satisfaction, the $O S_{O}$ corresponds to the current state value and the $O S_{H}$ corresponds to a value at the high end of spectrum of previously documented goal values from the various river management alternatives. Agents holding a self-interests are assumed to adopt a CS value as well, namely a value exactly in between $O S_{O}$ and $O S_{H}$. In words this would be interpreted as "we now have $O S_{O}$, we would ideally like to create $O S_{H}$, and at least we need $50 \%$ from that". For ecosystem diversity, for example, the $O S_{O}(0.2)$ corresponds to the current value, the $O S_{H}(0.8)$ is just higher than the EOW value of the Preferred Alternative of 1998, and the CS (0.5) - adopted by the policymaker and nature organisation - corresponds to the average of $O S_{O}$ and $O S_{H}$. For a 'negative' goal (like hindrance) that generally creates a negative satisfaction, the $O S_{O}$ and $O S_{H}$ values equally correspond to the current state and high end spectrum of previously documented goal values respectively. But here, the $C S$ is assumed to equal $O S_{H}$. In words: "we now have $O S_{0}$,

\footnotetext{
${ }^{84}$ Note that the standards of nature area and gravel extraction - which corresponds to the Grensmaas project as a whole - are in Table 6.2 downscaled with a factor 10 to match the specific location of Borgharen.
} 
we would be really dissatisfied with $O S_{H}$, and anything higher than $O S_{H}$ is unacceptable". For hindrance, for example, the $O S_{0}(0)$ corresponds to the current value, and the $O S_{H}$ and CS (120 person*years) are just higher than the hindrance value of the Preferred Alternative of 1998, where the $C S$ is adopted only by the citizen agent.

The goal standards for groundwater table change form a special case. Regarding the agricultural interests, both an increase and a decrease of the groundwater table can cause crop damage (Maaswerken, 1998a; Maaswerken, 2003a). Therefore, the standards $\left(O S_{0}=0, O S_{H}=C S=0.4 \mathrm{~m}\right)$ apply to the absolute value of groundwater level change. For nature development, only a decrease of the groundwater table is generally considered negative (Maaswerken, 1998a; Maaswerken, 2003a). Therefore, the standards $\left(O S_{0}=0, O S_{H}=C S=-0.4 \mathrm{~m}\right)$ apply only to groundwater level change values in the negative range, while values in the positive range are valued neutrally (goal satisfaction $=0$ ).

\begin{tabular}{|c|c|c|c|c|c|c|}
\hline Agent & Goal & Unit & Sign & CS & $O S_{0}$ & $O S_{H}$ \\
\hline \multirow{9}{*}{$\begin{array}{l}\text { Policy- } \\
\text { maker }\end{array}$} & flood recurrence & yrs & $\min$ & 250 & - & - \\
\hline & new nature area & ha & $\min$ & 100 & - & - \\
\hline & ecosystem diversity & EOW & $\min$ & 0.5 & 0.2 & 0.8 \\
\hline & $\Delta$ groundwater table & $\mathrm{m}$ & $\min$ & - & 0 & -0.4 \\
\hline & gravel yield & Mton & $\min$ & 3.5 & - & - \\
\hline & loss agricultural area & ha & $\max$ & - & 0 & 120 \\
\hline & $\mid \Delta$ groundwater table $\mid$ & $\mathrm{m}$ & $\max$ & - & 0 & 0.4 \\
\hline & sound hindrance & pers*yrs & $\max$ & - & 0 & 120 \\
\hline & profitability & $\%$ & $\min$ & 4 & - & - \\
\hline \multirow[t]{4}{*}{ Citizen } & flood recurrence & yrs & $\min$ & 250 & - & - \\
\hline & new nature area & ha & $\min$ & 100 & - & - \\
\hline & ecosystem diversity & EOW & $\min$ & - & 0.2 & 0.8 \\
\hline & sound hindrance & pers*yrs & $\max$ & 120 & 0 & 120 \\
\hline \multirow{4}{*}{$\begin{array}{l}\text { Nature } \\
\text { org. }\end{array}$} & flood recurrence & yrs & $\min$ & 250 & - & - \\
\hline & new nature area & ha & $\min$ & 100 & - & - \\
\hline & ecosystem diversity & EOW & $\min$ & 0.5 & 0.2 & 0.8 \\
\hline & $\Delta$ groundwater table & $\mathrm{m}$ & $\min$ & -0.4 & 0 & -0.4 \\
\hline \multirow[t]{3}{*}{ Farmer } & flood recurrence & yrs & $\min$ & 250 & - & - \\
\hline & loss agricultural area & ha & $\max$ & 120 & 0 & 120 \\
\hline & $\mid \Delta$ groundwater table $\mid$ & $\mathrm{m}$ & $\max$ & 0.4 & 0 & 0.4 \\
\hline \multirow{2}{*}{$\begin{array}{l}\text { Gravel } \\
\text { extr. }\end{array}$} & gravel yield & Mton & $\min$ & - & 0 & 7 \\
\hline & profitability & $\%$ & & 4 & - & - \\
\hline
\end{tabular}

Table 6.2: Conditional standards (CS) and optimisation standards $\left(O S_{0}, O S_{H}\right)$ associated with the different goals. The standards determine the evaluation curve an agent uses to evaluate its goal, see Figure 6.2. The 'sign' indicates whether the standard refers to minimal or maximal requirements. 
The goal weights, finally, are chosen in such a way that each goal category is weighted with a value 1 in the total support evaluation. This was considered transparent, and a way to avoid that a goal category such as nature development - which is strongly represented with three specific goals - receives an unrealistically high weight in the total support evaluation.

\section{Interpretation of uncertainty}

As described in Section 4.3.2, the stakeholders of the Grensmaas project acknowledge a number of uncertainties, but there are few explicitly conflicting views on the interpretations of those uncertainties. Consequently, the stakeholder agents are generally endowed with 'central' estimates for the uncertain model parameters, and do not consider climate change. An exception to this rule occurs for the case of gravel extraction. As described in Section 5.5, the calculation of the amount of extracted gravel depends critically on the values of the so-called soil parameters: the soil density and relative fraction of gravel in the soil. The estimated uncertainty ranges of these parameters are some $8 \%$ and $4 \%$ respectively, see Table 5.7 . These ranges alone ${ }^{85}$ amply legitimate the real-life difference in opinion between the policymaker and the gravel extractor on the profitability of the PA1998. In the policymaker's view, the amount of extracted gravel was sufficient to reach its primary goals without additional expenditure. According to the gravel extractor, additional gravel extraction was required to reach an acceptable level of profitability. Therefore, the gravel extractor agent adopts a 'conservative' estimate ${ }^{86}$ for the amount of extracted gravel, while the policymaker and other agents adopt the 'central' estimate.

\subsubsection{Analysing support}

As a first application of the simulation model we assess goal satisfactions and stakeholder support for the observed policy outcomes, see Figure 6.3. Recall that in Table 4.1 we distinguished four phases in the planning process with different objectives and stakeholders involved. The respective policy outcomes are the river management strategies Green for Gravel of 1991 (GFG1991), the Preferred Alternative of 1998 (PA1998), the Reference Alternative of 2001 (REF2001), and the Preferred Alternative of 2003 (PA2003). Here, we focus on three of those strategies (GFG1991; PA1998; PA2003) that were sufficiently well documented for our purpose. These 'observed' river management strategies are represented by the river engineering parameters main channel deepening, main channel broadening, floodplain excavation, additional nature area, and surface elevation of the clay shield, as derived in Appendix B and shown in Table 6.3. Note that for the assessment of the GFG1991, the standards for flood recurrence (see Table 6.2) were omitted, because in this phase of the planning process the issue of flood protection was not important yet.

\footnotetext{
${ }^{85}$ Further uncertainty in the cost and benefit parameters are not considered here.

${ }^{86}$ The conservative estimate was chosen in such a way that the gravel extractor would just comply with the PA2003. This implied a soil parameter value of -0.29 .
} 


\section{GFG1991}

The calculated stakeholder goal satisfactions and stakeholder support for the strategy GFG1991 are shown in Figure 6.3. The initiators of the plan, the policymaker and nature organization, are indeed supportive of the strategy, since their goals of gravel extraction and nature development are sufficiently met. All other stakeholder agents, however, are unsupportive of the strategy. The farmer objects to the loss of agricultural land, whereas the potential negative effect of groundwater level decrease is sufficiently mitigated through the elevation of the river's main channel. For the citizen, the strategy fails because the hindrance levels are considered to be too high. The gravel extractor, in turn, would object to the insufficient profitability, in particular due the significant amount of profitable material that is restored in the river for main channel elevation.

\section{PA1998}

After the floods of 1993 and 1995 the aspect of flood protection is added as a primary objective. The proposed strategy PA1998 meets this objective, which is reflected in a maximum goal satisfaction on the criterion 'flood recurrence' for all owners of this goal. As a whole, the strategy PA1998 is more 'efficient' than the previous GFG1991. With somewhat more riverbed broadening and a smaller emphasis on floodplain excavation, and by omitting the measure of main channel elevation, the main project objectives are reached with less gravel extraction and correspondingly smaller hindrance levels and consequently higher citizen support. The changes do go to the cost of nature development: goal satisfaction on ecosystem diversity decreases and a negative contribution on groundwater emerges due to a significant groundwater table decrease. The farmer is more supportive of the PA1998. Although the current groundwater table decrease is undesired, overall, meeting the objective of flood protection adds to the farmer's support. Figure 6.3 also shows that the strategy lacks support of the gravel extractor, because in his view the standard for profitability is still not met.

\section{PA2003}

When the gravel extractor was included in the planning process, the PA 1998 was revised again in order to increase its profitability, leading to the PA 2003. The solution was found by allowing the surface level of the clay shield to be 2-3 meters below the original surface level. Hereby more gravel could be extracted in a more profitable fashion with smaller amounts of the byproducts clay and sand. Indeed, the gravel extractor now observes a sufficiently high profit, which is displayed in Figure 6.3. Due to lesser river widening measures the flood recurrence is smaller compared to the PA1998, but the standard of 1:250 years is still amply met. The compromise with the gravel extractor does go to the cost of ecological objectives, with a further decreasing ecosystem diversity. But ecosystem diversity remains at an acceptable level, and overall, the support of the other stakeholders remains constant compared to the PA1998. 


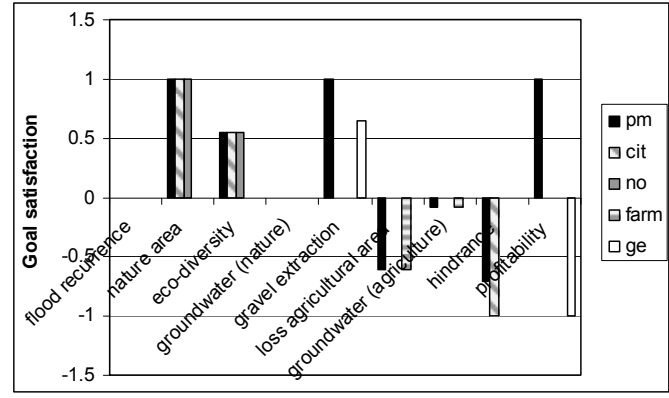

GFG1991

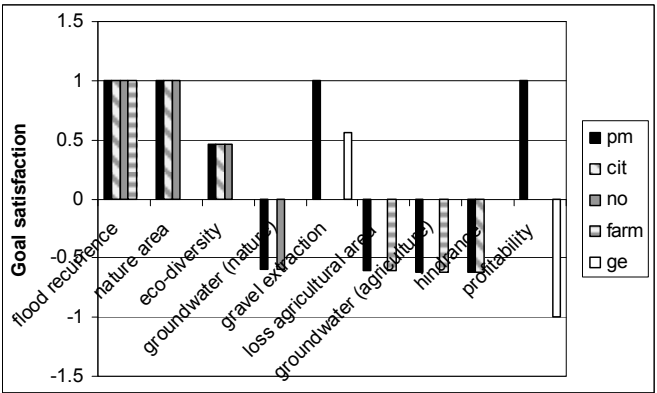

PA1998

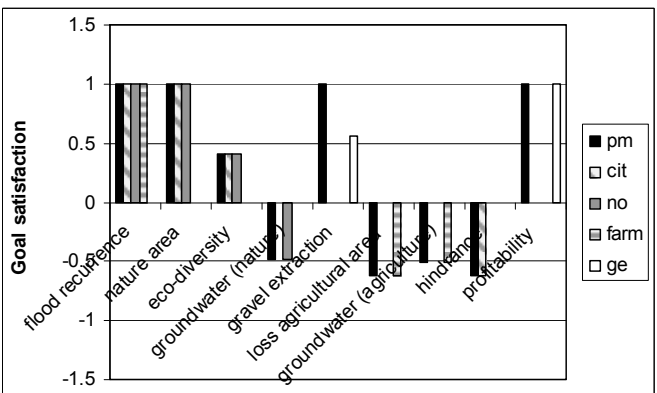

PA2003

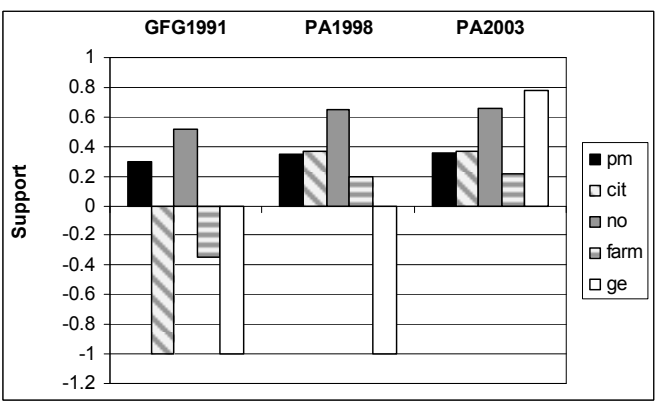

Agent

support

Figure 6.3: Assessment of stakeholder support for the three historical river management strategies Green for Gravel (GFG1991), the Preferred Alternative of 1998 (PA1998), and the Preferred Alternative of 2003 (PA2003). The above three figures show goal satisfaction of stakeholders for each goal considered. The figure below summarizes the results by displaying total stakeholder support for each river management strategy. The abbreviations 'pm', 'cit', 'no', 'farm', and 'ge' refer to the agents policymaker, citizen, nature organisation, farmer, and gravel extractor respectively. 


\subsubsection{Calculating policy outcomes}

As a second application we calculate policy outcomes, which are compared to the corresponding observed policy outcomes for each policy phase of Table 4.1. For calculating the policy outcomes we consider only those goals and stakeholders involved in that phase of the planning process. Furthermore, we apply the condition that the policymaker and, for the last phase, the gravel extractor are 'essential' stakeholders who must have at least positive support. The main purpose of this exercise is to provide a first validation of the ABM. To this end, we calculate a formal model error $E_{R M S}$ as the least-squares difference between the 5 observed and calculated river management parameters displayed in Table 6.3. Denoting these parameters $R O_{i}$ and $R C_{i}$ respectively, the error is written as:

$$
E_{R M S}=\sqrt{\frac{1}{5} \sum_{i=1}^{5}\left(\frac{R O_{i}-R C_{i}}{R R_{i}}\right)^{2}}
$$

The reference values $R R_{i}$ are taken as the mean of all non-zero absolute values of the observed river management parameters $R O_{i}$. For a model error of 1 , the differences between the river management parameters roughly equal the reference values. Given the complexity of the policy process, this model error is considered an upper bound for an acceptable correspondence between the observed and calculated strategies. For a model error $<0.5$ the correspondence is considered good.

\begin{tabular}{|l|l|l|l|l|l|l|l|l|}
\hline & \multicolumn{2}{|c|}{ GFG1991 } & \multicolumn{3}{c|}{ PA1998 } & \multicolumn{3}{c|}{ PA2003 } \\
\hline Goal category & Obs. & Calc. & Obs. & Calc. $^{\text {a }}$ & Calc. $^{\text {b }}$ & Obs. & Calc. $^{\text {a }}$ & Calc. $^{\text {b }}$ \\
\hline $\begin{array}{l}\text { Main channel } \\
\text { deepening (m) }\end{array}$ & -1 & -1 & 0 & 0 & 0 & 0 & 0 & 0 \\
\hline $\begin{array}{l}\text { Main channel } \\
\text { broadening (m) }\end{array}$ & 125 & 125 & 150 & 25 & 75 & 125 & 25 & 100 \\
\hline $\begin{array}{l}\text { Floodplain } \\
\text { excavation (m) }\end{array}$ & 300 & 175 & 125 & 150 & 200 & 75 & 125 & 75 \\
\hline $\begin{array}{l}\text { Additional nature } \\
\text { area (m) }\end{array}$ & 0 & 100 & 150 & 225 & 125 & 250 & 250 & 225 \\
\hline $\begin{array}{l}\text { Clay storage depth } \\
\text { (m) }\end{array}$ & 0 & 2 & 0 & 3 & 1 & 2.4 & 4 & 3 \\
\hline Error (-) & & 0.55 & & 0.72 & 0.38 & & 0.47 & 0.15 \\
\hline
\end{tabular}

${ }^{\mathrm{a}} \mathrm{CS}$ flood recurrence $=250 \mathrm{yrs}$

${ }^{\mathrm{b}} \mathrm{CS}$ flood recurrence $=1000 \mathrm{yrs}$

Table 6.3: Calculated river management strategies compared to the historically observed strategies Green for Gravel (1991), the Preferred Alternative (1998), and the Preferred Alternative (2003). 
Policy outcomes for the PA1998 and PA2003 were tested for multiple values of the CS for flood recurrence. For the original value ( $250 \mathrm{yrs})$ it appeared that both strategies were not adequately reconstructed. The calculated PA1998, for example, contains only a relatively small amount of riverbed widening, which - apparently - would be sufficient to reach the safety norm of $250 \mathrm{yrs,}$ while optimizing over the various other goals. However, given that the model tends to overestimate the flood recurrence level (see Chapter 5), it does not seem plausible that this strategy in reality would suffice. At a higher CS (1000 yrs), correspondence between the observed and calculated strategies was significantly improved (see Table 6.3). Therefore, this higher value is adopted in the further experiments.

Given the higher CS for flood recurrence, the results show a good correspondence for the PA2003 and the PA1998 and an acceptable correspondence for the GFG1991 ${ }^{87}$. The difference between the observed and calculated GFG1991 is primarily related to an overall improvement on criteria like hindrance, groundwater level change, and ecosystem diversity. The simulation error for the PA1998 is primarily related to the criterion of flood recurrence. The calculated strategy shows significantly less main channel broadening and consequently a significantly lower level of flood recurrence (although in both cases the CS for flood recurrence is met). This allows for minor improvements on the criteria of ecosystem diversity and groundwater level change. The simulation error for the PA2003 is particularly small; no significant differences between the observed and calculated strategy exist.

Overall, the general characteristics of the river engineering strategies are reproduced to a satisfactory degree. The calculated GFG1991 is a nature friendly strategy with a large area of floodplain excavation, and main channel elevation. The calculated PA1998 is an integrated strategy, with a mix of river engineering measures. The calculated PA2003 corresponds particularly well to the observed strategy and represents a compromise among the different interests within the boundary conditions of a high profitability. Especially, the lowered clay shield surface, necessary for reaching a sufficient profitability, is well reproduced.

To further illustrate the model results, we compare calculated stakeholder supports for the observed and calculated river management strategies in Figure 6.4. Observe that in all cases total support ${ }^{88}$ for the optimised strategies is higher than the support for the observed strategies, which is a natural and correct consequence of the adopted optimisation approach. The patterns of support between the observed and calculated strategies generally correspond well, which reflects the correspondence between the calculated and optimised river management strategies.

\footnotetext{
${ }^{87}$ Note that the error between the observed and calculated GFG1991 is partly an optimisation artefact. The combination of a clay storage surface level of $2 \mathrm{~m}$ below ground level and a relatively minor component of additional nature area is essentially the same as additional flood excavation. Given this observation, the error between the observed and calculated GFG1991 can be interpreted as being smaller than the one listed in Table 6.4.

${ }^{88}$ The (often negative) evaluations of the parties not involved in that phase of the planning process are not included for the assessment of total support.
} 


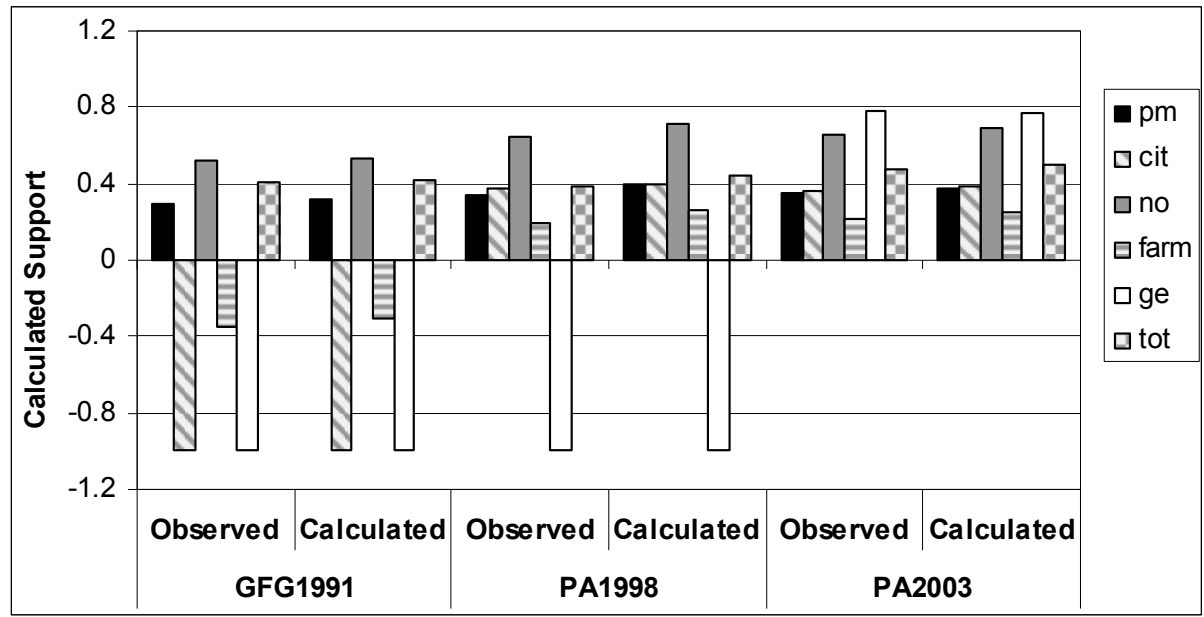

Figure 6.4: A comparison between the calculated stakeholder support for the 'observed' and 'calculated' river management strategies. The abbreviation 'pm', 'cit', 'no', 'farm', and 'ge' refer to the agents policymaker, citizen, nature organisation, farmer, and gravel extractor respectively; 'tot' refers to total agent support.

So, can we consider our model to be valid? On the one hand, we showed that the general characteristics of the observed river management strategy are reproduced well. On the other hand, we observe significant model errors. These may be related, for example, to the validity of the iRM or inaccuracy in the values of the different goal standards. Moreover, the errors may be related to the $A B M$ structure, for example the assumption that the outcome of the policy process is the river management strategy with maximum stakeholder support. Our model must therefore not be considered a 'truth machine' that predicts policymaking for river management with considerable accuracy. Rather, the tool should be applied to explore different river management options and reflect upon these as part of a participatory process with stakeholders. For such an application, we conclude that the model is a satisfying way to describe the policy process.

\subsection{SENSITIVITY FOR CHANGING GOAL STANDARDS}

In this section we investigate the sensitivity of the model results (support and policy outcomes) to changes in the agent's goal standards. We focus on the conditional standards, since the effects of changing the optimisation standards are expected to be small.

\subsubsection{Sensitivity of support}

That the effects of changing optimisation standards are small can be seen on the basis of the following argument. We consider small changes in the optimisation standards $\triangle O S_{O}$ and $\triangle O S_{H}$ pertaining to a given goal of any agent $A$. The change in total support will then read (see Equations 6.3, 6.4, and 6.6): 


$$
\Delta S_{t o t}=\exp (-|X|) * \frac{1}{N_{G}} * \frac{1}{N_{A}}\left\{(X+1) \frac{\Delta O S_{0}}{O S_{H}-O S_{0}}-X \frac{\Delta O S_{H}}{O S_{H}-O S_{0}}\right\}
$$

with $N_{G}$ the number of goals of agent $A$ and $N_{A}$ the number of agents considered. Since the changes in optimisation standards are scaled with the factor $\left(O S_{H}-O S_{0}\right)$, the corresponding change in support will generally be small. Even for large relative changes $\sim\left(O S_{H}-O S_{0}\right)$, the effective change in the total support is maximally of the order $1 /\left(N_{G} * N_{A}\right)$. A small change in a conditional standard, however, may cause a sharp change in agent support of the order 1 , and a corresponding change of total support $\Delta S_{\text {tot }} \sim 1 / N_{A}$. Consequently, largest effects are expected from the change of conditional standards.

Next, consider the effect of changing a conditional standard on the support of an agent $A$ with an acceptable support evaluation $\left(S_{A}>-1\right)$ for some river management strategy. It is a priori clear that for infinitesimal changes in one of its conditional standards its support will remain constant. For larger changes, a sudden drop in support occurs when the conditional standard exceeds the goal value so that the adopted river management becomes unacceptable. The sensitivity of support to the conditional standards is thus best expressed as the relative difference $D_{C S}$ between the goal value $G V$ and the conditional standard $C S$ :

$$
D_{C S} \equiv\left|\frac{G V-C S}{G V}\right|
$$

When the difference is small $(G V \sim C S)$ the conditional standard is considered an important constraint in the policy process.

Using this parameter, we can analyse support for a given river management strategy on its stability for changing conditional goal standards. As an example we consider the case of the calculated PA2003. In Table 6.4, it is shown that for this case, the expected value of gravel extraction ( 5.5 Mtons) is much higher than the value required by the policymaker (3.5 Mtons). This indicates that the criterion of gravel extraction is not the primary constraint for finding an acceptable river management strategy. Much larger constraints originate from the conditional standards for flood recurrence $\left(D_{C S}=0.05\right)$, nature area $\left(D_{C S}=0.05\right)$, and ecosystem diversity $\left(D_{C S}=0.04\right)$. Also hindrance for the citizen $\left(D_{C S}=0.09\right)$ and profitability for the gravel extractor $\left(D_{C S}=0.09\right)$ are shown to be significant constraints in the policy process. Change of support obviously may lead to change in the optimal strategy. This effect will be investigated in detail in the next section.

\subsubsection{Sensitivity of the policy outcome}

In this section we study the sensitivity of the optimal river management strategy PA2003 for changes in various conditional goal standards. Hereby, the different conditional standards are varied for all agents in the same way, with the conditional standard 'flood recurrence', for example, referring to the conditional standards of the policymaker, citizen, nature organisation, and farmer. The results of the sensitivity analysis are displayed in Figure 6.5. The figures show total stakeholder support $S_{\text {tot }}$ and the model error $E_{R M S}$ with respect to the observed PA2003 for the calculated optimal strategies as a function of the conditional goal standard. 


\begin{tabular}{|c|c|c|c|c|c|}
\hline Agent & Goal & Unit & CS & GV & $D_{C S}$ \\
\hline \multirow{5}{*}{$\begin{array}{l}\text { Policy- } \\
\text { maker }\end{array}$} & flood recurrence & yrs & 1000 & 1057 & 0.05 \\
\hline & new nature area & ha & 100 & 105 & 0.05 \\
\hline & ecosystem diversity & EOW & 0.5 & 0.52 & 0.04 \\
\hline & gravel yield & Mton & 3.5 & 5.5 & 0.36 \\
\hline & profitability & $\%$ & 4 & 6.9 & 0.42 \\
\hline \multirow[t]{3}{*}{ Citizen } & flood recurrence & yrs & 1000 & 1057 & 0.05 \\
\hline & new nature area & ha & 100 & 105 & 0.05 \\
\hline & sound hindrance & pers*yrs & 120 & 110 & 0.09 \\
\hline \multirow{4}{*}{$\begin{array}{l}\text { Nature } \\
\text { org. }\end{array}$} & flood recurrence & yrs & 1000 & 1057 & 0.05 \\
\hline & new nature area & ha & 100 & 105 & 0.05 \\
\hline & ecosystem diversity & EOW & 0.5 & 0.52 & 0.04 \\
\hline & $\Delta$ groundwater table & $\mathrm{m}$ & -0.4 & -0.20 & 0.95 \\
\hline \multirow[t]{4}{*}{ Farmer } & flood recurrence & yrs & 1000 & 1057 & 0.05 \\
\hline & loss agricultural area & ha & 120 & 105 & 0.14 \\
\hline & $\mid \Delta$ groundwater table $\mid$ & $\mathrm{m}$ & 0.4 & 0.22 & 0.82 \\
\hline & profitability & $\%$ & 4 & 4.4 & 0.09 \\
\hline
\end{tabular}

Table 6.4: Sensitivity of support to changes in the conditional standards for the case of the calculated PA2003. Sensitivity is expressed as the relative difference $D_{c s}$ between the goal value $G V$ and the conditional standard CS.

In Figure 6.5 one recognizes some general features. Note that the points marked with open squares refer to our estimates of the actual conditional standards of stakeholders presented in Table 6.2. For all cases, these points lie at the (often unique) minimum of the error function. This indicates that the estimates of the actual conditional standards are plausible and supports the general validity of the ABM.

A second feature is that total support $S_{\text {tot }}$ is always a monotonic function of the conditional standard CS; increasing, or decreasing. This can be understood as follows. A conditional standard may change in two directions: 1 ) constraining the range of acceptable river management strategies, or 2) enlarging the acceptable range. Constraining the acceptable range can only lead to decreasing or constant support, while enlarging the acceptable range can only lead to increasing or constant support, as illustrated in Figure 6.5.

We now consider the effect of changing the acceptable range on the policy outcome. The curves indicate ranges for which the policy outcome remains constant, as well as gradual (linear) changes and stepwise (non-linear) shifts. A constant range is illustrated for the case of gravel extraction in Figure $6.5 \mathrm{~g}$ ). For a conditional standard $\leq 5.5$ Mtons, the optimal strategy is invariant and equal to the calculated PA2003 as indicated for point $J$. This model behaviour is easily explained from the differences between the GV and CS for the goal of gravel extraction displayed in Table 6.4. In a constant range, the original optimum in support is thus unaffected by the changing conditional standard. A gradual change occurs, for example, in the case of flood 
recurrence in Figure 6.5 a). Here, a decrease in CS from the original 1000 to 500 yrs leads to the new optimal strategy $A$, which slightly deviates from the calculated PA2003 by including somewhat less main channel broadening, somewhat more additional nature area, and a lower clay storage area surface elevation. For these types of gradual changes, the original optimum is affected by the changing conditional standard, but the new optimum lies on the same local support maximum in river management space.

A typical example of a stepwise shift occurs for the case of ecosystem diversity. When the conditional standard for the EOW index exceeds the critical point $C S=0.52$, the optimum solution shows a stepwise shift. The new optimal river management strategy $E$ strongly differs from the calculated PA2003, with a much higher contribution of floodplain excavation. Our model results indicate that the citizen does not accept the strategy $E$, because the hindrance levels associated with this strategy are too high. This explains why the new optimum is so different. Since citizen support is fixed at -1 it becomes effectively irrelevant for the optimisation procedure. The new optimum thus represents a significantly different situation of optimisation amongst the interests of the remaining stakeholders.

A further illustrative example is the case of profitability Figure $6.5 \mathrm{~h}$ ). Increasing the required profitability to $5 \%$ or $6 \%$ results in a stepwise shift towards the new optimum strategy $N$. This strategy is similar to the previously discussed strategy $E$ - albeit including somewhat more main channel broadening and a lower clay storage surface level - and is equally unacceptable for the citizen agent. A decrease in CS, on the contrary, leads first to a gradual change towards strategy $M$, followed by further stepwise changes towards the more 'natural' strategies $L$ and $K$. These strategies allow for higher ecosystem diversity and lesser groundwater level change, and consequently higher stakeholder support. The reduction in profitability standard, say from 4 to $2 \%$, could be obtained by providing additional expenditure of some $10 \mathrm{M} €$ ( $2 \%$ on a total budget of $500 \mathrm{M€})$. Also, a reduction of the conditional standard for nature area to 75 ha could lead to a different policy outcome (point $C$ in Figure 6.5 b) with much higher support. Enlarging the acceptable range may thus lead to new, strongly supported solutions. However, the current quantitative estimates must be interpreted with care.

We conclude that the calculated policy outcome may show large changes for changes in conditional goal standards. Constraining the range may lead to stepwise shifts in optimal strategies, often accompanied by unacceptable judgements of one or more agents. Enlarging the range, on the other hand, may reveal new optima with significantly higher agent support. These types of model results may provide new, possibly controversial, viewpoints on river management. As such, the model seems useful to explore different river management strategies and stimulate discussions among stakeholders. 


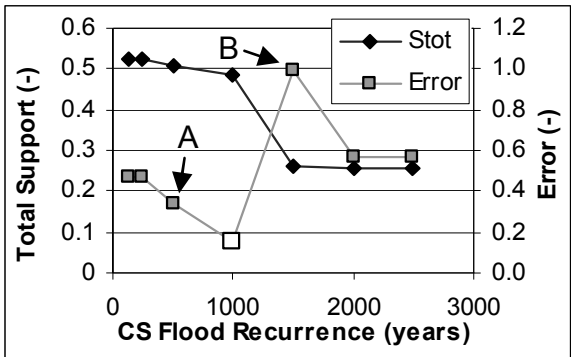

a)

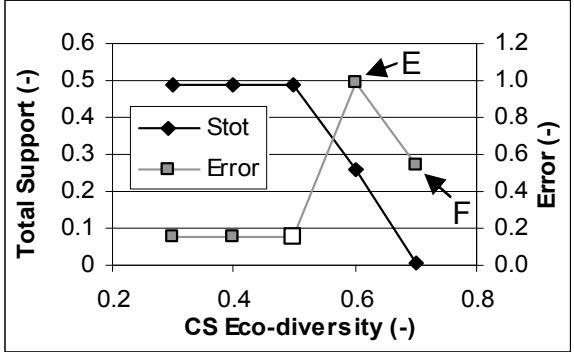

c)

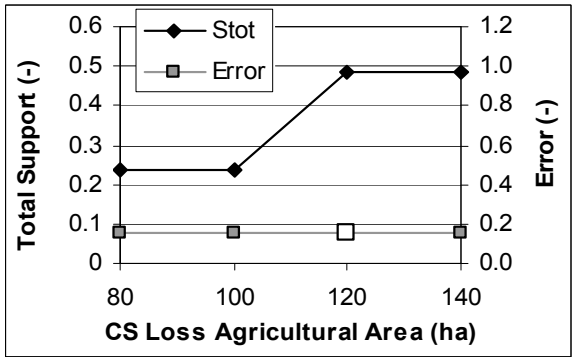

e)

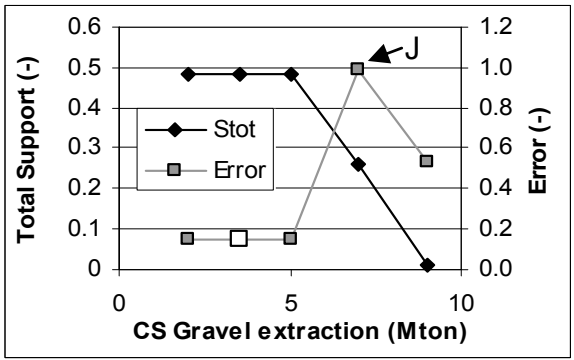

g)

Figure 6.5: Sensitivity of the policy outcome to changes in conditional standards. The figures show total stakeholder support $\left(S_{\text {tot }}\right)$, and the error with respect to the observed PA2003 values of the calculated optimal strategies as a function of the conditional standards. Points marked with open squares refer to the estimated conditional standards for the Grensmaas stakeholders listed in Table 6.2. For points marked with capital letters, the corresponding river management strategies are displayed in Table 6.5. 


\begin{tabular}{|l|l|l|l|l|l|}
\hline & $\begin{array}{l}\text { Main channel } \\
\text { deepening } \\
(\mathbf{m})\end{array}$ & $\begin{array}{l}\text { Main channel } \\
\text { broadening } \\
(\mathbf{m})\end{array}$ & $\begin{array}{l}\text { Floodplain } \\
\text { excavation } \\
(\mathbf{m})\end{array}$ & $\begin{array}{l}\text { Additional } \\
\text { nature area } \\
(\mathbf{m})\end{array}$ & $\begin{array}{l}\text { Clay storage } \\
\text { depth }(\mathbf{m})\end{array}$ \\
\hline $\mathbf{D}$ & 0 & 100 & 75 & 225 & 3 \\
\hline A & 0 & 75 & 75 & 250 & 4 \\
\hline B & 0 & 50 & 375 & 25 & 3 \\
\hline C & 0 & 75 & 75 & 150 & 4 \\
\hline D & 0 & 125 & 75 & 375 & 3 \\
\hline E & 0 & 50 & 375 & 25 & 3 \\
\hline F & -1 & 200 & 175 & 200 & 4 \\
\hline G & 0 & 50 & 375 & 25 & 3 \\
\hline H & 0 & 50 & 250 & 125 & 3 \\
\hline I & 0 & 50 & 375 & 25 & 3 \\
\hline J & 0 & 50 & 375 & 25 & 3 \\
\hline K & -1 & 150 & 75 & 175 & 2 \\
\hline L & 0 & 75 & 250 & 75 & 0 \\
\hline M & 0 & 100 & 125 & 225 & 2 \\
\hline N & 0 & 75 & 325 & 25 & 4 \\
\hline & & & & \\
\hline
\end{tabular}

Table 6.5: River management strategies corresponding to the characteristic points in Figure 6.5.

\subsection{THE CASE OF CLIMATE CHANGE}

As a final model application we assess how stakeholder support and the policy outcome change when all agents would take climate change into account. Climate change is a highly uncertain development, which may cause a significant increase of peak flow probability. Stakeholders are aware of this issue and it is brought up multiple times during the stakeholder interviews described in Chapter 4. For the current model experiment, all agents adopt - from the set of climate scenarios developed by the Royal Netherlands Meteorological Institute (KNMI, 2006) the climate scenario ' $W$ ' for the year 2050. Under this scenario, average discharge is projected to increase with $4-10 \%$ throughout the year, with consequently an increase of the 1:250 year design discharge of $9 \%$ (see Appendix A).

We firstly assessed stakeholder support for the calculated PA2003 under changing climate conditions, see Figure 6.7 a). On comparison with Figure 6.3 (the case without climate change) one observes significant changes in support. The minor increase of groundwater level provides some increased goal satisfaction for nature development and agriculture. But overall, the support of the policymaker, citizen, nature organisation and farmer would drop, because safety standards are no longer met. Secondly, we calculated the new optimal strategy among stakeholders for conditions of climate change. This strategy would contain large-scale main channel broadening, in combination with main channel elevation $(1 \mathrm{~m})$, as shown in Figure 6.6. This strategy would allow society to maintain current safety standards without compromising on the criteria of nature development, groundwater, agricultural area, profitability and gravel 
extraction (see Figure $6.7 \mathrm{~b}$ )). The citizen, however, would not accept this river management strategy, because the hindrance levels are too high.

The model results illustrate that current river management objectives may not be realizable in the case of climate change. A particular dilemma is reaching the required safety level, while adhering to a maximum acceptable level of hindrance. The model thus seems useful for reflecting upon ones goals in the light of uncertain future developments. It may stimulate stakeholders to anticipate on these developments by reconsidering adopted goals and standards.

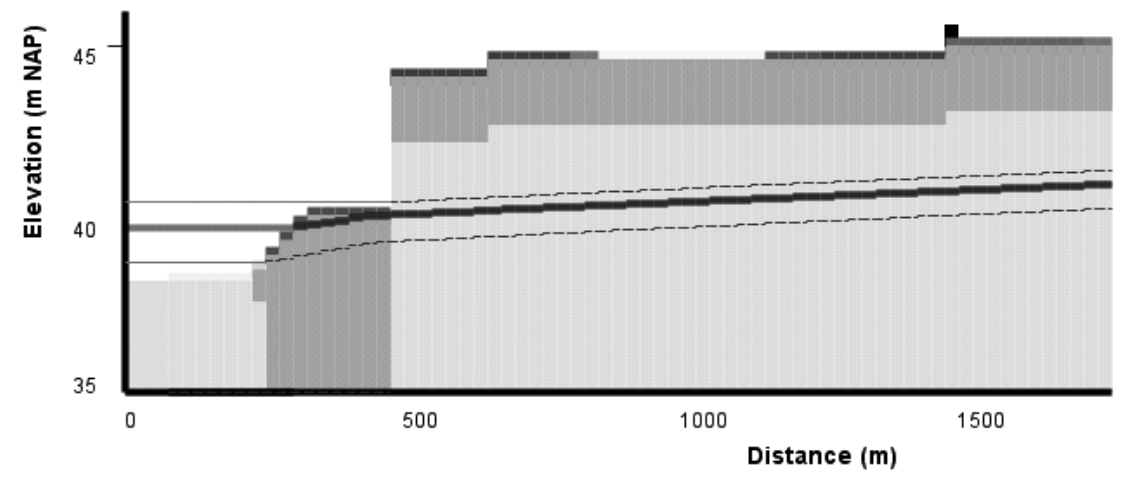

Figure 6.6: A new river management compromise under climate change?

\subsection{CONCLUSION}

In this chapter we have presented a coupled integrated River Model - Agent-Based Model for describing a policy process among stakeholders of river management. The model must not be considered a 'truth machine' that predicts policymaking for river management. It rather provides a framework for a 'what-if' analysis. Given the goals and beliefs of stakeholders, the model calculates stakeholder support for a river management strategy. The outcome of the policy process is then derived as the strategy with maximum stakeholder support. A first and simple model validation was performed by reconstructing the preferred river management strategies that were documented in policy reports along three stages of the Grensmaas project. The validation showed acceptable to good correspondences between the observed and calculated strategies, giving sufficient credibility to the model results for proceeding with some model experiments. 


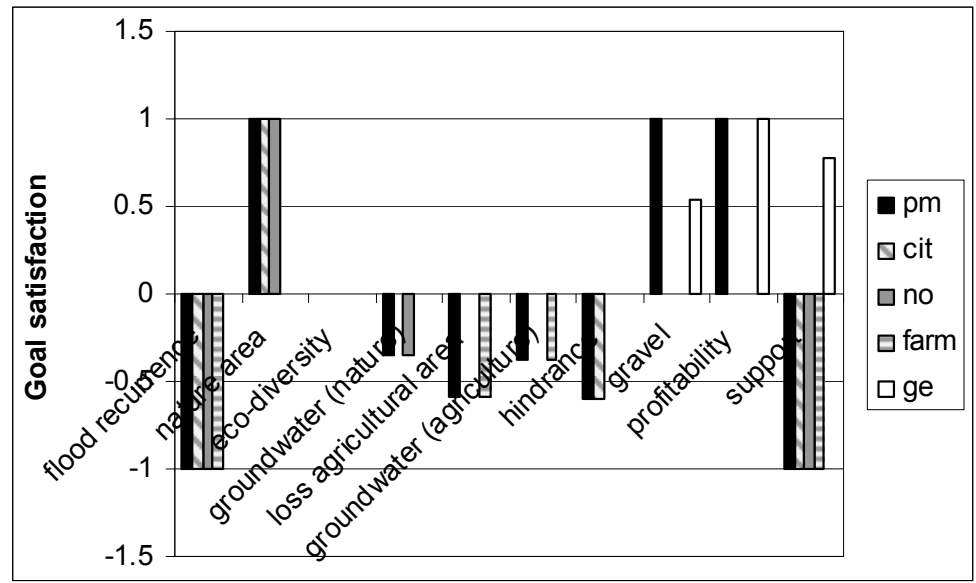

a)

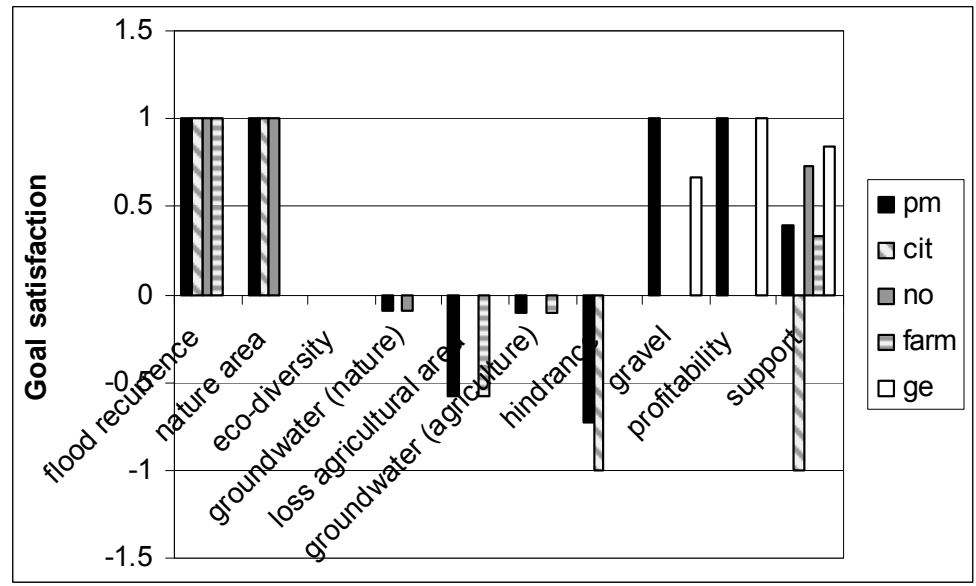

b)

Figure 6.7: Assessment of stakeholder support given climate change conditions for a) the originally simulated river management strategy Preferred Alternative (2003) and b) the optimum strategy given conditions of climate change strategy.

The model results indicate that stakeholder support and the policy outcome depend strongly on the minimal requirements that stakeholders attach to their goals (the so called 'conditional goal standards'). For example, increasing the requirements for ecosystem diversity and profitability could imply new river management strategies that will be unacceptable for one or more stakeholders. Improvements in societal support, on the other hand, may be obtained by reducing the requirements for profitability (for example through additional governmental expenditure) and nature area. The government may thus influence the policy process through shifting its conditional standards in an appropriate way, encouraging other stakeholders to do the same. In a further experiment, we assessed how the policy process would change if stakeholders would take climate change into account. According to our results, climate change 
could imply further main channel broadening to be able to cope with increasingly high peak discharges. The citizen, however, would not accept this river management strategy, because the hindrance levels would be too high.

In the climate change experiment we assumed that the goals and standards derived for the current situation will remain the same. We know from the ABM literature that this assumption is not likely to hold. Cognition is likely to adapt in response to a changing environment and/or social interactions (Conte \& Castelfranchi, 1995a). Adaptive cognition can be incorporated in the $A B M$ by giving the agents autonomy for changing their goals in response to agent-environment, and/or agent-agent interaction. The former may be modelled by defining a proper set of heuristics for changes in the conditional goal standards to represent learning in response to environmental change. The latter may be modelled as mutual goal adoption among agents to represent cooperation. Modelling adaptive cognition is left for future research.

The main potential of the current simulation model is its application within participatory stakeholder processes. In this chapter, we showed that the model is sufficiently well developed and valid for application in such processes to address relevant issues in a realistic way. For instance, it may be used in small working groups to explore different river management options in relation different stakeholder interests and uncertain future developments such as climate change. This may serve to elicit stakeholder perspectives, improve communication, and stimulate the development of shared problem perceptions. A specific feature of the presented model is that goals and goal standards are made explicit. This, we expect, will encourage stakeholders to reflect on their goals in a social context and possibly reconsider adopted goal standards. This may lead to a better agreement about minimal needs and requirements for all stakeholders involved, which could be a small step toward better collaborative and sustainable river management. 


\section{Chapter 7}

MODELLING WATER MANAGEMENT POLICY IN THE BROADER CONTEXT OF CULTURAL AND BEHAVIOURAL CHANGE: AN INTEGRATED, AGENT-BASED, GAMING APPROACH 


\begin{abstract}
Our objective is to develop new ways of modelling the dynamics of water management that provide for exploration and representation of cultural and behavioural change in relation to changes in a water system. Our approach is to develop an interactive computer game. In the game, the water system is modelled using spatially-explicit integrated assessment models, and water management is represented as the dynamic outcome of interactions between water culture, water policy and autonomous actor behaviour. The purpose of the game is to explore future pathways of water management in the Ebro River Basin in Spain, and contribute to a social learning process amongst the players involved. This chapter focuses on the concept of the game, but the conceptual approach has already been translated into a game format, which has been tested and shows promise.
\end{abstract}

This chapter was accepted for publication:

Valkering, P., Tàbara, J.D., Wallman, P., Offermans, A. (in press). Modelling Cultural and Behavioural change in Water Management: An integrated, agent based, gaming approach. The Integrated Assessment Journal. 


\section{Modelling Water Management Policy in the Broader Context of Cultural and Behavioural Change: an Integrated, Agent-Based, Gaming approach}

\subsection{INTRODUCTION}

Our modelling approach so far has focused on reconstructing the planning process amongst stakeholders of the Maaswerken project. Two main challenges were mentioned in the conclusion of the previous chapter: including changing goals and beliefs ('adaptive cognition') in response to agent-environment, and/or agent-agent interaction endogenously in the model, and developing participatory applications of the modelling tool. In this chapter, both challenges are adressed with the development of an integrated, agent-based, gaming approach for modelling the development of water management on the long-term.

For modelling the development of water management on the long-term, however, the conceptual approach developed so far needs an extension. Notably, it requires a better consideration of the dynamics of the societal context within which a planning process like the Maaswerken takes place. This societal context is assumed to define several fundamental starting points of river management, like flood prevention, nature development, budget constraints, and the intention for a river widening and participatory approach. On the long-term, however, one can assume that exactly these fundamental starting points will be subject to change. Van der Brugge (2005) shows how starting points have changed in the past - e.g. from 'pumping, dikes, and drainage' to 'retention and natural storage' - in the context of the overall shift of the Dutch water management style (briefly mentioned in Chapter 4) that started in the 1970s. The analysis of the strategic project Integrated Exploration Meuse (Chapter 4) has indicated possible future changes of starting points, for example moving from 'flood prevention' to 'flood damage control' as part of a fundamentally new way of dealing with floods. Such change of starting points will also allow for drastic changes in goals, beliefs and river management strategies. For example, rejecting the goal of flood recurrence and adopting the goal of flood damage reduction will imply new types of measures like modified housing and sound evacuation routes. For modelling changing river management strategies over the longer-term, one therefore needs an approach in which changes of goals and beliefs are related to changing starting points at a more fundamental level.

The perspective based modelling approach (Rotmans \& de Vries, 1997; De Vries, 2001; Rotmans \& Van Asselt, 2001; Van Asselt \& Rotmans, 2002), applied amongst others for the global water model AQUA (Hoekstra, 1998; Hoekstra, 2000), provides a method for relating those fundamentally different starting points of water management strategies to underlying cultural beliefs. Following a typology of perspectives of Cultural Theory (Thompson et al., 1990), cultural beliefs on 'how the world works' (worldview) and 'how the world should be managed' (management style) are translated to consistent viewpoints in the water management debate (see Table 7.1). These, in turn, are implemented in the AQUA model in the form of consistent interpretations of model uncertainty (regarding various model parameters and equations), and rules for water policy (e.g. regarding alternative rules for inter-basin water transfer) and autonomous behaviours (e.g. regarding alternative equations for water demand). These so- 
called 'model routes' show diverging trends of the global (water) system and illustrate the implication of distinct worldviews and management styles. However, they do not include the dynamics through which these worldviews and management style may change.

The objective of this chapter is therefore to combine the participatory IAM-ABM approach with the perspective modelling approach for a better understanding of long-term change of river management. To this end, change of river management policy is considered within the broader context of societal change, focusing on the interactions between a water system, river management policy, and (additionally) autonomous behaviours and cultural change. To gain insight in the complex dynamics of notably river management policy and cultural change, the approach entails the development of an interactive computer game. In line with the participatory $A B M$ approach, it is assumed that gaming simulations can reveal more insights in these dynamics than computer models alone can do.

The game's design is inspired by recent literature on socio-technical and (broader) societal transitions (Rotmans, 2005; Geels \& Schot, 2007; Loorbach, 2007), in which fundamental societal change is interpreted as the outcome of a competition amongst a dominant actor network (the 'regime') and emerging alternative networks ('niches'). In line with the transition model, the game reflects a societal system in which advocates of different cultural perspectives (i.e. representing the regime and niches) compete over river management policy and the underlying cultural beliefs. Apart from river management policy negotiations, the game explicitly involves reflection phases, in which various cultural assumptions underlying the river management discussion are critically assessed. Also, the game allows for reflection upon conflict and collaboration, and on the emergence of new power structures and institutional rules inherent to societal transitions.

The work presented in this chapter was developed as part of the EU project Matisse ${ }^{89}$. A central concept in the Matisse project was Integrated Sustainability Assessment (ISA): a new concept for sustainability assessment (Weaver \& Rotmans, 2006). ISA complements existing forms of sustainability assessment by supporting longer term, and more strategic policy processes to explore persistent problems of unsustainable development. The gaming approach fits well within the aims of ISA, by supporting reflection on the nature of those persistent problems, and exploring societal transitions though which these problems might be overcome. To some extent, the game is tailored to the ISA approach, for example by adopting the four core ISA stages (scoping, envisioning, experimenting and learning) in the game's practical design.

\footnotetext{
${ }^{89}$ Methods and Tools for Integrated Sustainability Assessment, see www.matisse-project.net
} 


\begin{tabular}{|c|c|c|c|}
\hline & Hierarchist & Egalitarian & Individualist \\
\hline Position of man & $\begin{array}{l}\text { Man partially } \\
\text { dominates nature }\end{array}$ & Man is part of nature & $\begin{array}{l}\text { Man dominates } \\
\text { nature }\end{array}$ \\
\hline $\begin{array}{l}\text { Primary motives } \\
\text { for action }\end{array}$ & Expert norms & Collective interests & Self-interests \\
\hline Myth of nature & Robust within limits & Fragile & Robust \\
\hline Risk & Risk-acceptance & Risk-aversive & Risk-seeking \\
\hline $\begin{array}{l}\text { Management } \\
\text { philosophy }\end{array}$ & Control & Prevention & Adaptation \\
\hline $\begin{array}{l}\text { Management } \\
\text { objectives }\end{array}$ & $\begin{array}{l}\text { Social stability and } \\
\text { safety }\end{array}$ & $\begin{array}{l}\text { Environmental } \\
\text { protection and equity }\end{array}$ & $\begin{array}{l}\text { Economic growth } \\
\text { and self- } \\
\text { realization }\end{array}$ \\
\hline $\begin{array}{l}\text { Management } \\
\text { mechanism }\end{array}$ & $\begin{array}{l}\text { Government } \\
\text { regulation }\end{array}$ & $\begin{array}{l}\text { Participatory } \\
\text { decision-making }\end{array}$ & Free market \\
\hline Water demand & A given need & A manageable desire & Price driven \\
\hline $\begin{array}{l}\text { Water } \\
\text { availability }\end{array}$ & Stable runoff & $\begin{array}{l}\text { Stable runoff in } \\
\text { inhabited areas }\end{array}$ & $\begin{array}{l}\text { Total runoff or no } \\
\text { limits }\end{array}$ \\
\hline $\begin{array}{l}\text { Water quality } \\
\text { evaluation }\end{array}$ & $\begin{array}{l}\text { Functional quality } \\
\text { standards }\end{array}$ & $\begin{array}{l}\text { Pristine quality as } \\
\text { reference }\end{array}$ & Economic value \\
\hline Water scarcity & Supply problem & Demand problem & $\begin{array}{l}\text { A market } \\
\text { problem }\end{array}$ \\
\hline Water sharing & $\begin{array}{l}\text { Meeting various } \\
\text { water demands }\end{array}$ & $\begin{array}{l}\text { Basic supply to } \\
\text { everyone }\end{array}$ & $\begin{array}{l}\text { Economic } \\
\text { optimization }\end{array}$ \\
\hline $\begin{array}{l}\text { Water } \\
\text { conserving } \\
\text { technology }\end{array}$ & $\begin{array}{l}\text { Large scale } \\
\text { technology push }\end{array}$ & $\begin{array}{l}\text { Small scale } \\
\text { technology push }\end{array}$ & Price driven \\
\hline $\begin{array}{l}\text { Water price } \\
\text { policy }\end{array}$ & $\begin{array}{l}\text { Incremental price } \\
\text { increase }\end{array}$ & Water tax & Market pricing \\
\hline $\begin{array}{l}\text { Artificial surface } \\
\text { reservoirs }\end{array}$ & $\begin{array}{l}\text { Solution to water } \\
\text { scarcity }\end{array}$ & Undesirable & $\begin{array}{l}\text { Desirable if cost } \\
\text { effective }\end{array}$ \\
\hline
\end{tabular}

Table 7.1: Three cultural perspectives. General characteristics (upper part) and perspectives on water (lower part). Sources: (Hoekstra, 1998) and (Thompson et al., 1990).

Working on the Matisse project implied a different case study: the Ebro river basin in Spain. This 'case study discontinuity' is merely based on practical reasons. The methodological approach is equally well suited for the case of Dutch river management and is currently being explored in that context (Valkering et al., 2008). Interestingly, the Ebro case study is strongly complementary to the case of Dutch river management, as it entails a focus on drought, rather than on floods. Another difference is that the Maaswerken case study focused on a specific river stretch, while 
the Ebro case focussed on the catchment area as a whole ${ }^{90}$. The experiences so far have shown that the methodological approach is generically applicable to different case study contexts.

This chapter is organised as follows. In Section 7.2, the conceptual model underlying the game's design is developed by elaborating upon the coupled river system - actor response system model described in Chapter 2. A more elaborate discussion of the actor response system dynamics follows, on the basis of a literature review on cultural, behavioural and policy change. Section 7.3 links the model concepts to a concrete game design and presents a first prototype of the game developed for the case of water management in the Ebro river basin in Spain. The discussion and conclusion (Sections 7.4 and 7.5) highlight the limitations and potential of the approach, discuss its role in the ISA, reflect on the developed approach and summarize key lessons learned.

\subsection{MODELLING CONCEPT}

\subsubsection{Pressure, State, Impact, and Response}

The starting point of the analysis of the Ebro case study is formed by the PSIR model (Rotmans \& de Vries, 1997) of Figure 7.1. In the Ebro region (see Torrecilla \& Martinez-Gil, 2005; Tàbara \& Ilhan, 2008) the most relevant socio-economic pressures (P) are an increasing water demand over the past century (mainly due to the expansion of agriculture) as well as water pollution resulting from both agricultural and domestic practice. On the environmental side, the reduced sediment load in the river, land use changes (both resulting from the construction of water reservoirs), and climate change are the main factors to be reckoned with. The pressures result in state changes (S) referring to the availability of water (groundwater, soil water, lakes and channel flow), the water quality, and land stability. These, in turn, lead to various impacts (I) on the water-related functions. These include: ecological functions, such as habitat function and biodiversity, economic functions, such as farming, energy supply and industry; and social functions such as household consumption and water related recreation. The responses (R), finally, are divided between water policy and autonomous responses. Water policy in Spain has traditionally taken an approach of water supply management favouring engineering options like reservoir construction, and - more recently - water transfer and desalination. However, the current approach is directed more towards water demand management, advocating water use efficiency, water re-use, water pricing, and awareness-raising. The autonomous responses of stakeholders may include changes in agricultural practices by farmers and changes in lifestyle and migration patterns by the general public.

\footnotetext{
${ }^{90}$ In this chapter, we therefore adopt the more general terms 'water system' and 'water policy', rather than 'river system' and 'river management policy'.
} 


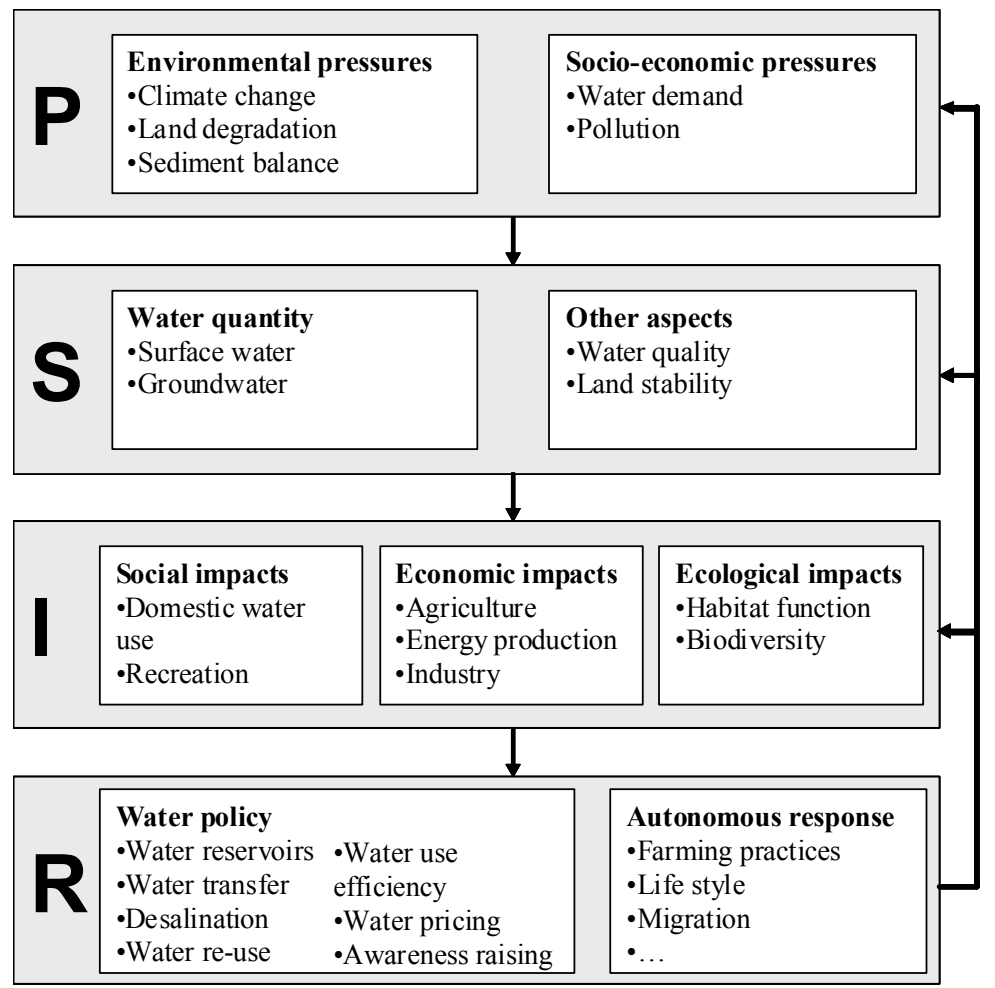

Figure 7.1: The case study of the Ebro river basin framed along the conceptual model of Pressure, State, Impact and Response. Adapted from (Hoekstra, 1998).

\subsubsection{Elements of the response system}

The relations between the pressures, states and impacts of Figure 7.1 are relatively well understood. They can be modelled with environmental modelling techniques such as system dynamics and GIS, drawing upon knowledge from climate science, hydrology, geography, ecology, economy and so on. ${ }^{91}$ The main challenge lies in understanding the dynamical change of the response. The analysis of the Ebro case study (Torrecilla \& Martinez-Gil, 2005; Tàbara \& Ilhan, 2008) suggests that the response dynamics originate from three strongly related societal subsystems:

- In the water culture subsystem, deeply rooted, and broadly shared beliefs in agricultural development as the engine of Spanish economy, in water as an economic good, and dams as a symbol of progress, are slowly being replaced by beliefs in the spiritual value of water

\footnotetext{
${ }^{91}$ By no means, we argue such a modelling exercise is easy. IA modelling involves a number of difficulties, such as information gathering, the choice of aggregation and scale, and the management of uncertainties.
} 
as a source of well-being, in the importance of water ethics, and the necessity of holistic water management.

- In the water policy subsystem, traditional institutions and organisations (river basin authorities, large scale farmers, and farmer organisations) are competing with emerging ones (COAGRET ${ }^{92}$, the platform of the Defense of the River Ebro, and the New Water Culture (NWC) foundation) on the development of the new AGUA water management plan.

- In the system of autonomous response, local farmers, citizens, and other stakeholders play an important role in supporting (or not supporting) the various institutions and organisations, and by adopting (or not adopting) new water related practices (e.g. smallscale biological farming).

These three subsystems feed into the further development of the response module of Figure 2.1 within the PSIR frame. The elaborated PSI-R model of Figure 7.2 equally frames the Ebro river system as composed of two main interacting parts: a water system - including the pressures, states and impacts - and an elaborated actor response system (hence, PSI-R model). In the actor response system, water policy and autonomous behaviour is framed as the outcome of multiactor processes. More specifically, water policy is framed as the output of a policy process amongst representatives of water management institutions and organisations (the so-called 'aggregate stakeholders' operating within a 'policy arena'). The autonomous response results from the behaviour of local farmers, citizens and small-scale companies (the so-called 'individual stakeholders' operating at the 'individual level'). Various interactions are included between water system, water policy, and autonomous response. The water policy may be aimed at changing the water system (e.g. through reservoir construction) or influencing the autonomous response (e.g. through water pricing). The autonomous response influences both the environment (e.g. through a changing water demand) and the policy-arena (e.g. through voting). Both water policy and autonomous response are influenced by the actors' perceptions of the water system on which their actions are generally based.

Both the aggregate and individual stakeholders are assumed to hold a socially-bounded autonomy (Conte \& Castelfranchi, 1995a). They can autonomously decide which goals to achieve and act accordingly. However, they are operating within, and influenced by, a societal context. In the conceptual model of Figure 7.2, this context is characterized by a dominant water culture. The water culture comprises dominant shared societal beliefs in relation to water management, such as the ones listed in Table $7.1^{93}$. These beliefs are assumed to constrain the behaviours of individual stakeholders and policy actors alike. At the same time - considering the duality of structure and agency expressed by Giddens (1984) - it is the same actors who influence what these dominant shared beliefs are. In the conceptual response model this duality is represented as mutual interactions between the water culture (part of Giddens' structure) on the one hand, and the water policy and autonomous response subsystems (agency components) on the other.

\footnotetext{
${ }^{92}$ Association of People Affected by Big Reservoirs

${ }^{93}$ A dominant societal perspective is not restricted to either the stereotypical hierarchist, egalitarian, or individualist views. In principle, any combination of beliefs is possible.
} 


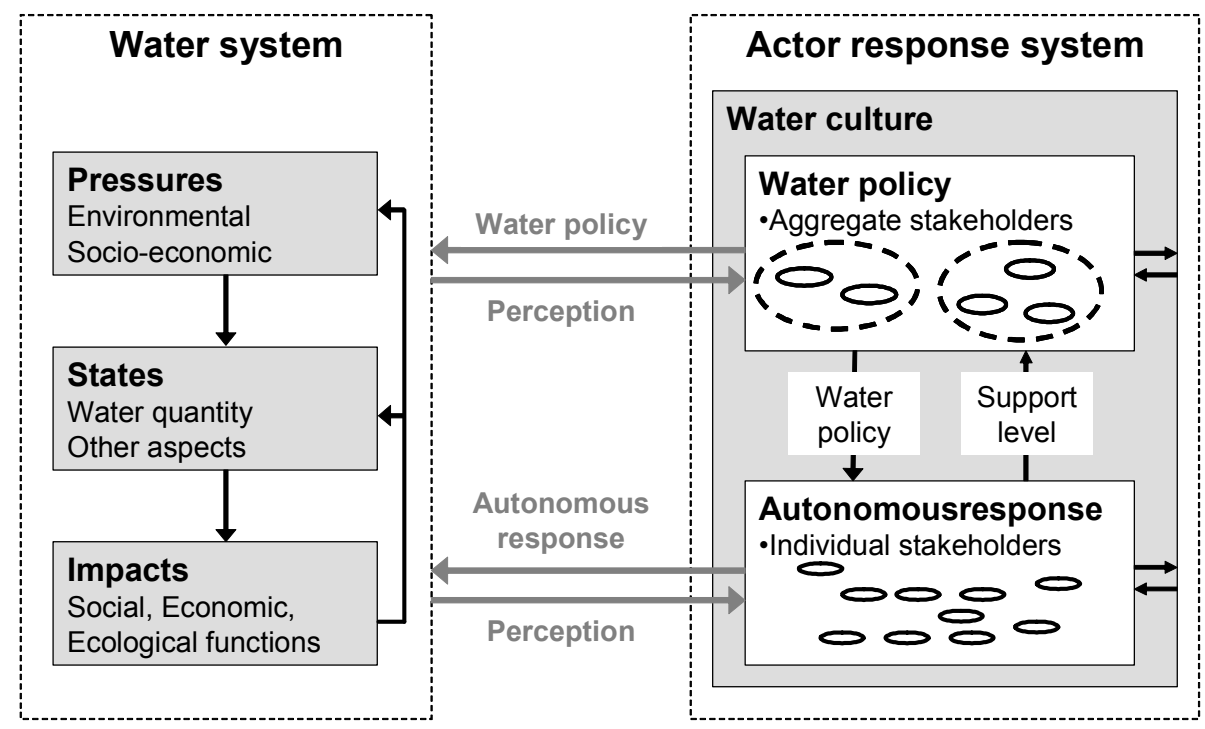

Figure 7.2: The elaborated PSI-R model of the Ebro water system frames the societal response as the outcome of interrelated processes of policymaking, individual behaviour and cultural change in relation to changes in the water system.

Compared to the existing static perspective based modelling approach, our dynamical perspective implies a number of methodological differences in conceptualising the system dynamics. First, it implies that the dominant water culture itself is subject to endogenous changes initiated from within the policy arena or at the individual level. Moreover, the water management culture no longer automatically determines the rules for water policy and autonomous response, it merely influences agency in their adoption. Agents have the ability to reject the dominant water culture. Finally, it implies that consistency between the dominant water culture and the actual water policy and autonomous responses are no longer a given. On the contrary, we assume that - as a society adapts to environmental change - inconsistencies may well arise between our thinking about water (water culture) and the actual water related behaviour (policy, autonomous response). These inconsistencies may point to undesired lock-in situations that form an interesting item for study.

\subsubsection{The dynamics of the actor response system}

Insights into the dynamics of the actor response system were obtained by reviewing the literature across a number of social scientific disciplines; political science, social psychology and sociology. Without pretending to be able to give a complete overview of these fields, we describe a selection of conceptual and theoretical insights that we find particularly relevant for our case. For each subsystem - water policy, autonomous response, and water culture - we thereby identify both external drivers of change (e.g. originating from other subsystems as indicated by the arrows in Figure 7.2), as well as the internal processes that influence the subsystem dynamics. See Table 7.2 for an overview. 


\section{Water policy}

A particularly useful approach for understanding and modelling policy change is the Advocacy Coalition Framework (ACF) (Sabatier \& Jenkins-Smith, 1993). This theory is particularly useful, since - in contrast to other policy theories - it holistically 1) describes policy change over the long term (a decade or more), 2) considers multiple actors involving both public and private organizations, 3) considers actors at multiple levels of government, and 4) it conceptualizes the policy process on the basis of belief systems similar to the ones that Cultural Theory describes. In the ACF, a policy subsystem is defined as the set of actors dealing with a policy problem. These actors - referred to as 'policy elites' - may hold various positions, such as public official, interest group leaders, and researchers. Policy actors that share a particular set of beliefs are assumed to form coalitions that advocate certain policy strategies. The policy process is then modelled as a competition among the advocacy coalitions (internal process) whose relative strengths may vary over time.

The ACF distinguishes two main drivers of policy change. The first is referred to as policy oriented learning (internal process). Policy oriented learning refers to the process through which coalitions seek to improve their understanding of the management problem in order to further their core policy objectives. In practice this means that coalitions subjectively seek and absorb that information that supports their argument and improves their position in the policy debate. Policy oriented learning may thus be strongly driven by changes in the water system (external driver) that are typically uncertain, may be perceived differently by each coalition, and therefore be used to underpin rather different points of view. Second - and actually more important drivers are external factors like socio-economic conditions and technology. Changes in those factors may undermine the causal assumptions of present policies or, by altering the support for various coalitions, may change the relative strengths of advocacy coalitions. These external factors are represented by the external driver 'support level' from the individual level. As a third driver of policy change we add cultural changes (external driver) that may influence the beliefs and values of the coalition members, or restrict their policy actions through specific social norms.

\section{Autonomous response}

For understanding change of autonomous behaviour at the individual level, insights are drawn from social psychology. Social psychology highlights a variety of factors on the basis of which human behaviour in different contexts may be explained (see Jager, 2000; Van den Bergh et al., 2000; Jackson, 2005) for three excellent overviews). A first group of theories thereby focuses on (various forms of) reasoning (internal process). Reasoning implies that agents are actively involved in reflecting upon one's goals and ways to achieve them. Some theories thereby focus on the individual. Rational Choice and Expectancy-value theories, for example, indicate that individual interests are an obvious main driver of human behaviour. Also, the availability of behavioural options, the perceived ability to perform a specific behaviour, as well as the perceived uncertainty in determining the outcomes of ones behaviour may play an important role (Ajzen, 1988; Jager, 2000). Other theories highlight the importance of the social and environmental context. In Ecological Value Theory, for example, altruistic and environmental values are considered influential factors, while Conte \& Castelfranchi (1995a) highlight social norms as important constraints for individual behaviour as well. A second group of theories highlights automated processes (internal process) as the explaining factor of human behaviour. 
This is illustrated by the role of habits (repetition of ones own behaviour) and social imitation (the imitation of someone else's behaviour). The latter is related to theories on social imitation such as Bandura's Social Learning Theory and also Social Identity Theory that highlight the influence of role-models on individual behaviour. ${ }^{94}$

Concerning the external drivers we consider social, economic, and ecological developments (i.e. changes in the water system) to be a main influence (external driver). These developments can be gradual (an increasing income level, environmental degradation, increasing water stress) and also be manifested in sudden events (flood, market crash, spreading disease). According to the rational model of behaviour, such developments will force individuals to change behavioural strategies in order to optimize over their individual interests (e.g. in response to a drought a farmer decides to increase irrigation to maximize his profit). However, as the environmental changes become more pronounced, more fundamental behavioural changes - in the form of goal adoption and goal rejection (Conte \& Castelfranchi, 1995a) - can be expected as well. Some examples are emerging interests (after a two-day water cut, the farmer starts to realize the importance of a secure drinking water supply), triggering environmental and altruistic values (after observing the devastating drought impacts downstream the farmer decides to reduce his irrigation), and a changing perceived ability to reach one's goals (after realizing it is impossible to run a profitable business the farmers gives up farming altogether).

Another external driver is water policy. Water policy may rely on various approaches for influencing human behaviour and stimulating more sustainable water related practices (Jackson, 2005). It may provide economic incentives, such as taxation and subsidies, issue rules and regulations about water use, or provide information about the (water-related) problems at hand. However, Jackson argues that these measures all draw upon a rather self-oriented rational model of behaviour. If - in contrast - one considers social norms to be of main influence on human behaviour, then policy should take a different angle. In that case, policy stimulated changes in the socio-cultural context (i.e. the water culture) (external driver) may be a better approach. Similarly, if one assumes automated process, like repetition, to be a key behavioural mechanism, then role models and government example might be a main external driver of behavioural change.

\section{Water culture}

The notion of cultural change is probably most difficult to grasp. The conceptual model of cultural change is based on the following assumptions. Following Giddens (1984) we first assume that cultural change eventually originates from changes on the level of individual stakeholders operating within the policy arena or at the individual level. The water culture - being defined as the dominant shared core beliefs of the individual stakeholders involved - changes when the core beliefs of those individual stakeholders change. Following Thompson et al. (1990) we also assume that within one society multiple distinguishable water cultures co-exist ${ }^{95}$. Also in a stable

94 Jager (2000) uses similar dimensions of automated versus reasoning processes, and individuallydetermined versus socially-determined processes to delineate different modes of agent behaviour in the 'consumat' approach.

${ }^{95}$ In Cultural Theory, the socio-cultural world is conceptualized in dynamic terms as constituted by multiple perspectives that co-exist and mutually interact. It is argued that each one of the perspectives - although possibly dominant in society - cannot exist without any one of the other perspectives around. The other perspectives are required to fill up the flaws in each particular one and alliances between the perspectives 
state, these cultures are in constant interaction with each other (dynamic equilibrium). Cultural change is then interpreted as a change in the relative importance of the different water cultures (i.e. a shift of dynamic equilibrium), rather than a homogeneous change of core beliefs of all individual stakeholders involved.

For understanding changes in core beliefs at the individual level Cultural theory (Thompson et al., 1990) highlights the importance of surprise (external driver). A surprise is defined as a mismatch between ones world view and an observed real-life event, which potentially may change the worldview of the individual involved. Typical surprises in the water management domain would be 'a collapse of the water market' (for the individualist), 'climate change being a complete hoax' (for the egalitarian), and 'a water supply cut in a carefully planned water transfer' (for the hierarchist). Similarly, the failure of reproduction mechanisms (those observations that support one's perspective as being correct) contribute to perspective change. However, perspectives are inherently robust to change, since events and developments are filtered through a perceptual screen. Those observations that support one's perspective are embraced to prove oneself right; observations that challenge one's perspective are moderated and, if possible, ignored. It is an accumulation of surprises and failure of reproduction mechanisms that will force individuals to adopt perspectives that are better suited to the reality around them.

The internal process of cultural change is interpreted as a process of niche accumulation (Geels \& Schot, 2007). Niche accumulation basically implies that 'fundamental changes start small'. Fundamentally different viewpoints from the current status-quo (the regime) are assumed to arise at individual and local levels forming small networks (niches). Under certain conditions e.g. 'windows of opportunity' at the regime level - these networks may grow to become the dominant one themselves. Following the niche accumulation concept, the internal process of cultural change is represented as a competition between the water culture regime and new water culture niches. This competition is assumed to be strongly influenced by the occurrence of surprise.

The most relevant external drivers and internal processes discussed above are summarized in Table 7.2. Most of the external drivers mentioned in the table are also indicated in the conceptual model of Figure 7.2. The surprises and reproduction mechanisms are not explicitly in the figure, but implicitly contained in the 'perception' arrows originating from the water system. Surprises regarding human behaviour - i.e. originating from policy arena or individual level - are imaginable as well, but not highlighted in the current analysis.

may exist. Cultural change is thus not considered as a sudden revolution, but as a natural process occurring within a viable society. 


\begin{tabular}{|c|c|c|}
\hline & External drivers & Internal processes \\
\hline Water policy & $\begin{array}{l}\text { - } \begin{array}{l}\text { Perceived environmental } \\
\text { changes }\end{array} \\
\text { - } \quad \text { Changing public support } \\
\text { - } \quad \text { Changing water culture } \\
\end{array}$ & $\begin{array}{l}\text { - Competition and coalition } \\
\text { forming } \\
\text { - } \quad \text { Policy oriented learning }\end{array}$ \\
\hline $\begin{array}{l}\text { Autonomous } \\
\text { response }\end{array}$ & $\begin{array}{l}\text { - } \begin{array}{l}\text { Perceived environmental } \\
\text { changes }\end{array} \\
\text { - Water policy } \\
\text { - } \quad \text { Changing water culture }\end{array}$ & $\begin{array}{l}\text { - Automated processes: } \\
\text { imitation, repetition } \\
\text { - Reasoning: goal and strategy } \\
\text { formation focussing on the } \\
\text { self and/or the social and } \\
\text { environmental context }\end{array}$ \\
\hline Water culture & $\begin{array}{l}\text { - } \quad \text { Perceived surprises } \\
\text { - } \quad \text { Failed reproduction }\end{array}$ & $\begin{array}{l}\text { - Competition between the } \\
\text { water culture regime and new } \\
\text { water culture niches }\end{array}$ \\
\hline
\end{tabular}

Table 7.2: External drivers and internal processes considered for modelling the dynamics within and between the subsystems of water policy, autonomous response, and water culture.

\subsection{FROM CONCEPT TO IMPLEMENTATION: AN INTERACTIVE COMPUTER GAME}

\subsubsection{The concept of the game}

The conceptual model of the previous section forms the basis for the design of an interactive computer game. The concept of the game, presented in Figure 7.3, closely follows the conceptual PSI-R model of Figure 7.2. Each subsystem is represented with a different model type. The water system is modelled with IAM techniques such as system dynamics and GIS. The environment model is linked to an Agent-Based model representing autonomous stakeholder responses. Water policy and cultural change are subject to a participatory simulation in the form of the game itself. The water system and Agent-Based model are a closely linked stand-alone application called Linked Agent System model (LASY) and is described elsewhere (Wallman, 2008). Here we focus on the process of playing the game.

Players are typically representatives from policy, interest groups, and businesses having a role in the policy arena. They are responsible for one or more specific water functions and the associated stakeholder agents represented in the ABM. In line with the main water use functions in the Ebro basin we may include a farmer representative (representing agriculture), the director of a power supply company (representing energy production), an influential environmentalist (representing the ecological function), a city mayor (representing domestic water use), an entrepreneur (representing industry), and a leading tourist organisation (representing recreation). 


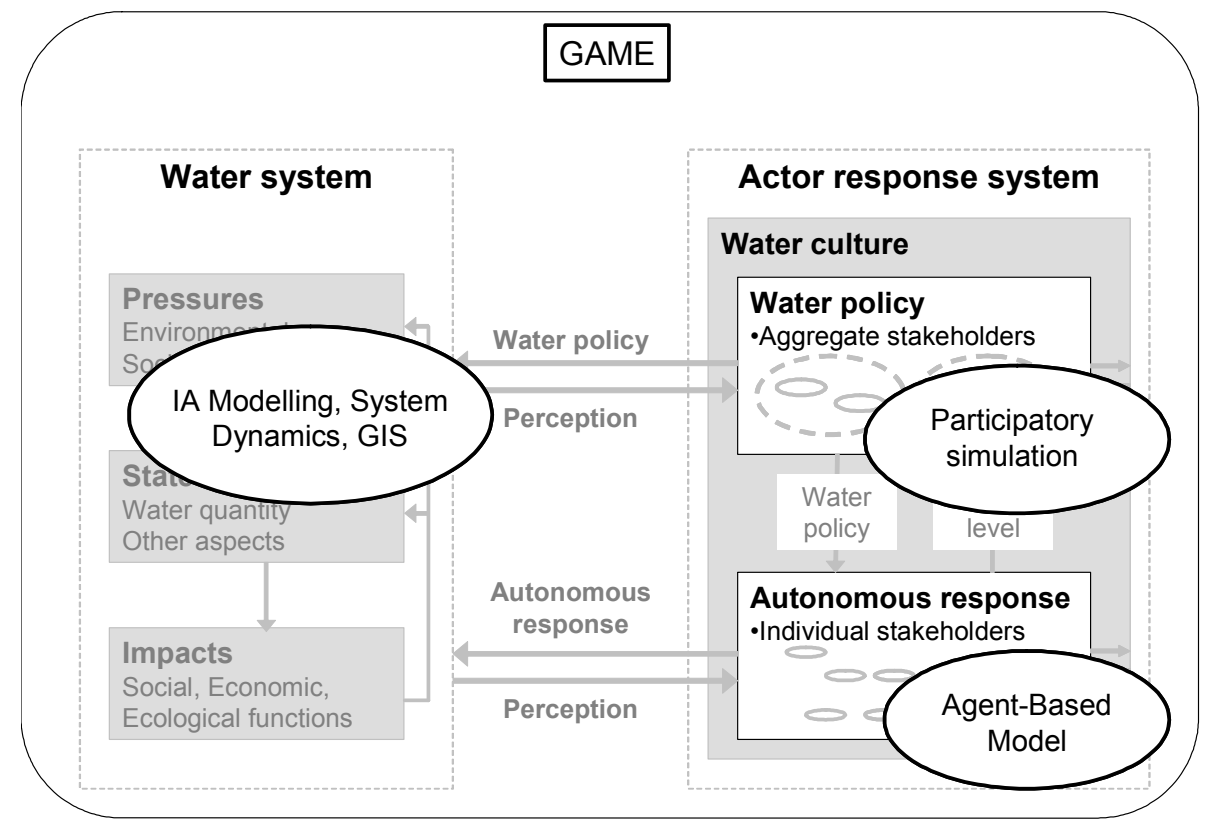

Figure 7.3: The concept of the game closely follows the PSI-R model of Figure 7.2.

The players interact with the LASY model through an interface. This interface allows players to explore the water system and investigate the satisfactions and behaviour of agents. The goal for each player is to 'survive in a sustainable world'. That is, one has to find a balance between one's individual interests (satisfying one's individual needs) and the collective interest of sustainability. To this end, players aim to meet the policy targets that they specify, indicating their individual interests and the ones of the individual agents they represent. Also, each player is responsible for maintaining a high value for a sustainability indicator included in the interface, which relates, for example, to the satisfaction of stakeholder agents and the speed of water resource decline. The exact value of this indicator, however, is not objectively defined, but depends on the dominant water culture.

The water culture is implicitly represented in the interface through the so-called rules of the game illustrated in Figure 7.4. These rules reflect dominant water management beliefs, values, and norms such as the ones expressed in Table 7.1. The rules are particularly important since they determine to a large extent how sustainability is interpreted or 'defined', and how sustainability should be achieved. For example, a water availability rule may impose a projection for climate change and water that players are obliged to adopt; a management approach rule may indicate a preference for supply or demand management options; a voting rule may prescribe the way the negotiation process and voting is carried out; and an equity rule may specify how individual player's satisfactions are aggregated to an overall value for social sustainability. In other words, the rules of the game may impose interpretations of model uncertainty, set preferred management styles, prescribe aspects of the management process, and directly influence the value of the sustainability indicator. 


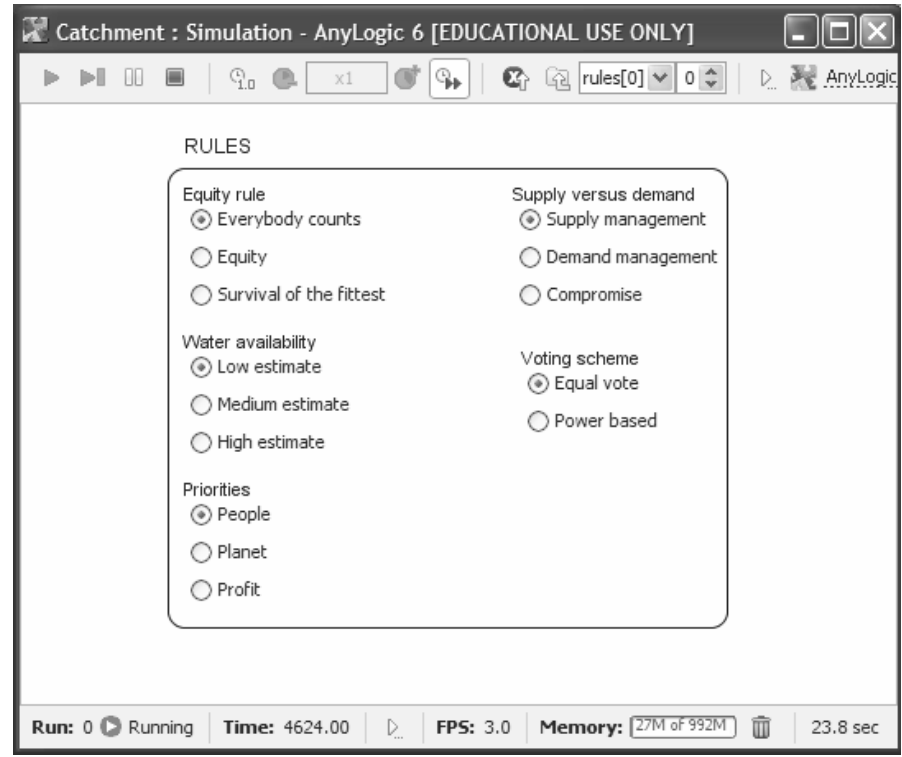

Figure 7.4: Implementation of a water culture in the form of the rules of the game. The rules presented in the figure are illustrative and will be further developed in future prototypes.

Initially, the game unfolds similar to existing policy games (Mayer \& Veeneman, 2002). The players discuss and negotiate water policy options - under the restrictions of the rules of the game - using the LASY model to explore their effects. Players engage in networking and coalition-forming to strengthen their policy positions and eventually come to a shared policydecision through some voting scheme. As the game unfolds, however, players may realize that they are dealing with a persistent problem. They may realize that they are 'loosing the game', either because they repeatedly fail to meet their own interests, or observe a persistent downward trend in the value of the sustainability indicator. Since (apparently) this problem is not being solved through the type of policy negotiations they are currently in, players are encouraged to make a more fundamental change: a reflection on their water culture in the form of a modification of the rules of the game.

The procedure of rule change is similar to the procedure of policymaking and follows out of a process of coalition forming and voting amongst the policy actors. However, the process of rule change is assumed to involve a more profound 'clash' between players than the rejection of water policy, since it refers to more fundamental change. Presumably, it will be niche players that will take the initiative for proposing rule change. Through deliberation - and using the evidence provided through the LASY model - they aim to attract more and more players to join their rule change coalition, reflecting the growth of their niche. When the niche grows strong enough it will succeed in getting the rule change across, reflecting a transitional step. The players may thus be actively involved in pursuing rule changes as part of their water management strategy. The observed rule changes during the game can then be considered 'markers' of a shift in water culture. 


\subsubsection{Playing the game}

The game dynamics are structured along four main stages. In line with the ISA cycle (Weaver \& Rotmans, 2006) we distinguish scoping (problem definition), envisioning (coalition forming and policy design), experimenting (assessment of policy effects) and learning (reflection on sustainability and culture). Some general remarks apply:

- $\quad$ Although the stages correspond to the four stages of ISA, they are not intended to cover a fully fletched ISA cycle. See also the discussion.

- The four phases are a guideline for structuring the process of the game. It is not intended to be a rigid structure and players may choose to deviate from it.

- The game covers a long-term time horizon ( $\sim 50$ years) involving multiple iterations of the various phases. No predetermined endpoint is specified; players can themselves decide when to stop or might agree not to play beyond certain future time (e.g. 2050 or 2100).

- The game is intended to be played in an open fashion, with the computer tool supporting a broad discussion amongst the players extending the variables of the game.

In the following, each phase is described and linked with the internal processes and external drivers of Table 7.2.

\section{Scoping: Defining the problem}

This stage involves an open discussion regarding the current state of the various subsystems. It is intended to specify the starting point of the game and to stimulate a first reflective discussion amongst the players. Typical questions to be addressed include:

- How do we evaluate water availability and water quality? Are we subject to a water stress? Are these aspects represented in the model of the water system?

- Which individual stakeholders exist in relation to the water system? What are their needs and are those needs satisfied? What is their level of support for current water management practice? Are they all adequately represented as agents in the game?

- How would we describe our current water management culture? Is this culture properly reflected with the current rules of the game?

- What future developments are to be reckoned with? Are the current water management practices sustainable? What does sustainable development mean in this context?

In this stage one thus reflects on the current state of the external policy drivers; i.e. perceived environmental changes', 'changing public support', and 'changing water culture'.

\section{Envisioning: Coalition forming and policy design}

This phase represents the process of collaborative or competitive policy design amongst the players. It corresponds closely to the river management policy model described in Chapter 2. Three sub-stages are distinguished: 
Goals, beliefs, and water management options: Each player individually expresses his/her policy position in terms of water management goals ${ }^{96}$, a consideration of specific beliefs about the water system, and consequently ideal water management options. These policy options may be aimed at altering the water system (e.g. dam building), or at changing the behaviour of the stakeholder agents (e.g. taxation). Players are stimulated to reflect on each other's policy positions before a final stance is taken.

Coalition forming: The players are stimulated to form coalitions to increase their power position in the upcoming design of a 'common action plan'. Coalition-forming is advantageous, because the unanimous vote of a coalition weighs stronger than the individual votes of its members.

Towards a common action plan: The players design a common action plan including - or excluding - the various water management options discussed so far. However, only water management options that are in line with the current rules of the game are allowed to enter in the action plan. In the end, the action plan results from a power-weighted vote amongst the different coalitions (again, as specified by the rules of the game).

This policy design and coalition-forming phase thus involves the internal policy processes 'competition and coalition forming' and (possibly) 'policy oriented learning'. Its output in the form of a common action plan represents the external driver 'water policy'. Finally, the constraints of the process in the form of the rules of the game represent the external policy driver 'changing water culture'.

\section{Experimenting: Exploring the policy effects}

The common action plan is entered into the game and the various models are used to calculate the effects on the water system and individual stakeholder behaviour:

The water system: The water system is explored to assess the social, economic, and ecological impacts of the chosen action plan. This includes changes in water availability, water quality, and may include various impacts for water-related functions.

The agents: The agent model is explored to assess individual stakeholder satisfactions, their support level and (changes in) other autonomous stakeholder responses.

This phase thus involves the external policy drivers 'perceived environmental changes' and 'changing public support'. Furthermore, 'surprises' may occur when the effects turn out differently from those expected. These surprises might be further accentuated in the game by adding probabilistic 'events' both in the water system (e.g. droughts) and the agent system (e.g. public uprisings).

\section{Learning: Reflection on sustainability and culture}

In the learning phase, the players are stimulated to reflect on the assumptions underlying the water policy and water management debate. They discuss the sustainability of the water system on the basis of the sustainability indicator, which is explicitly constructed on the basis of the rules of the game. They reflect upon the rules of the game to address the water management

\footnotetext{
${ }^{96} \mathrm{~A}$ distinction between conditional and optimisation goals could be made here.
} 
culture. Since the value of the sustainability indicator depends strongly on the rules of the game, these tasks are carried out in parallel.

Sustainability assessment: The players will reflect on the sustainability of their water management practice. Relevant questions are: Have the targets specified before been met? What is the satisfaction and support level of the agents in the game? Is the stock of freshwater sufficiently stable or sharply in decline? Are developments in the water system sustainable in terms of how sustainability is interpreted and how this interpretation has developed in the course of the game?

Reflection on the water culture: The game players are asked to reflect on the water culture by discussing the rules of the game, see Figure 7.4. Typical questions to be addressed are: How to deal with the issue of equity? Is it acceptable that one of the parties becomes completely dissatisfied or even 'dies' in the game, or do we design an action plan where satisfaction amongst parties is most equally distributed? What is our water management style? Do we support only water supply management, only water demand management, or should we allow for a mix of approaches? How do we organise the voting process for designing the action plan? Is there an equal or a power-weighted vote? Inspiration for other questions can be found in Table 7.1.

Actual changes in the rules of the game result from a vote amongst the game players, similar to the design of the action plan. However, stricter conditions may be applied for a change to be adopted (e.g. a large majority supports the rule change). To get a change in the rules across, a strong coalition is thus required. Game players are thus stimulated to actively build up a network around them or to engage with the network that seems most suitable for them. The game dynamics in the reflection phase thereby represent the internal process of cultural change referred to as 'competition between the water culture regime and new water culture niches'. Its output in the form of a rule change represents the external policy driver 'changing water culture'.

\subsubsection{Preliminary results}

The description of the game in this chapter reflects work in progress. The concept is well defined, but the computer tools required to play the game in the fashion described above are still under development. In the process of developing the game, the underlying concept has been tested twice with Ebro stakeholders in March 2007 and February 2008 (see Tàbara et al., 2008). During these tests, the project-team aimed to facilitate a structured discussion amongst stakeholders along the game phases described above. It focussed notably on the scoping and envisioning phase of problem definition, coalition forming and the design of action plans. The LASY model was not yet sufficiently well developed to be used to facilitate this discussion, but was presented to the stakeholders for reflection. 


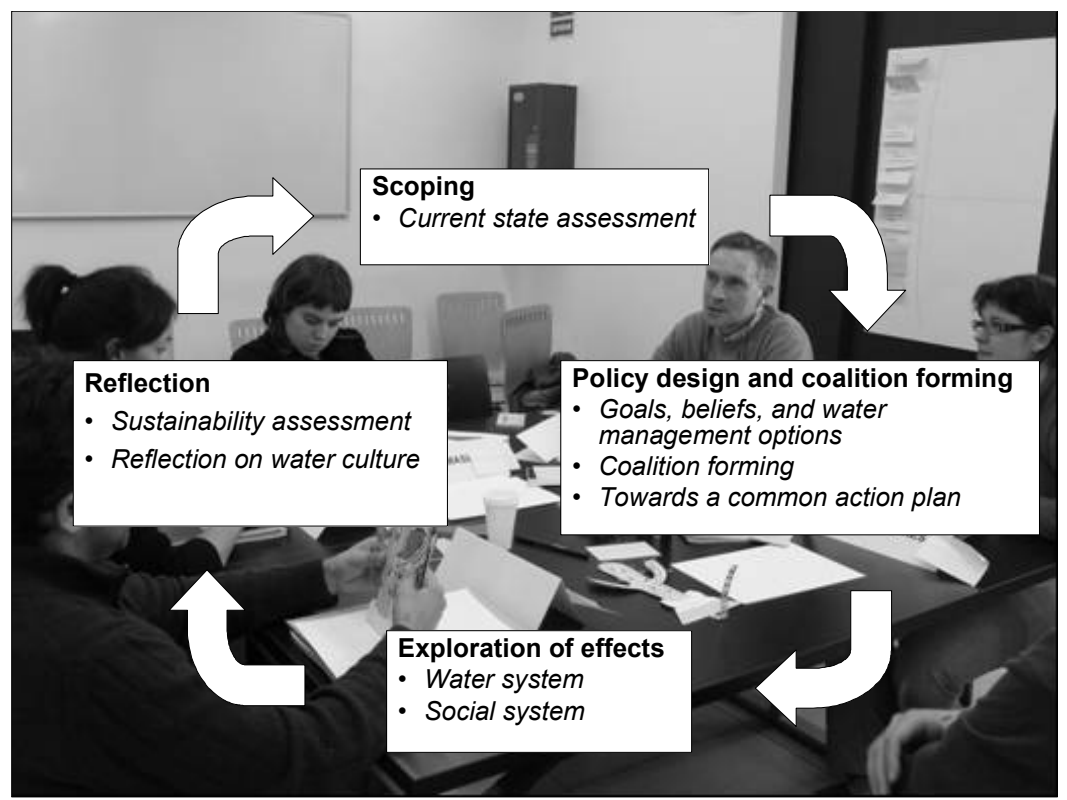

Figure 7.5: Playing the game.

The preliminary tests indicate that the game dynamics in the envisioning phase work well. Players are actively involved in coalition forming and in the formation of policy design. The overall impression was that game players are willing to cooperate, but resistant to change their views in a fundamental way ${ }^{97}$. Also, the game and the prototype computer models presented were considered useful tools by the main stakeholders involved. Thorough testing and more elaborate social experiments are still required, which will be the subject of future participatory applications.

\subsection{DISCUSSION}

\subsubsection{Limitations and potential}

Capturing complex societal processes with an analytical gaming approach obviously implies that major simplifications and crude assumptions have to be made. One limitation to the conceptual approach so far is that it is strongly focussed on the internal dynamics within and between the various sub-systems. However, a number of external drivers - such as technological changes, broader socio-cultural and economic developments, institutional changes, and individual role models - may play an important role as well. Furthermore, we implicitly assume that players exhibit real-life behaviour, a hypothesis which will require further underpinning in our future

\footnotetext{
${ }^{97}$ This observation is in line with hypotheses from Cultural Theory and the ACF and needs further attention in future work.
} 
work. Finally, since the implementation of the game is currently work in progress, thorough testing is required to refine the approach and evaluate its results.

However, with these limitations overcome, the approach might offer a great potential for better understanding the dynamics of societal change. For example, it may be used to analyse the main drivers of the societal change. In particular we may assess how environmental changes 'external' to the human system and cultural innovations 'internal' to the human system mutually interact to become a strong driver of the societal response, as an attempt to bridge the gap between the ecological realist and social constructivist views (Tàbara \& Ilhan, 2008). Also, one may further assess the response characteristics. Under which conditions are responses non-linear in time, as the transition model suggests? Or are linear responses possible as well? And given a non-linear societal response, one may assess thresholds (e.g. the level of climate change) at which such fundamental shifts occur.

With the approach being developed for the field of water, its application may well be extended to other fields such as energy, mobility, tourism, or health. Any field that involves clear interactions between policy, autonomous responses, cultural change, and the development of some domain system (e.g. water, energy, tourism, or health system) may be suitable to address. It seems particularly interesting to incorporate the gaming approach into existing IA models of those domains. Especially for PSIR based models this procedure could be feasible. Simply put, this would involve decoupling the response relations from an existing model, and replacing them with agent-based and/or game-like responses.

\subsubsection{Role in the ISA cycle}

Although the four stages of the game are similar to the stages of the ISA cycle, it is not intended to cover a full ISA. The game alone can impossibly cover the extensive tasks - in terms of process and substantive assessment - required for a full ISA. The game (both its development and application) should be perceived as part of the ISA process, and should generally be complemented with other participatory tools and more detailed water models. In different stages of the ISA cycle, the game may play different roles:

- In the Matisse project, the game was applied in the ISA experimenting stage (Tàbara et al., 2008). In the experimenting stage, the focus of the game lies on a better understanding of the social dynamics underlying the implementation of sustainability visions and pathways, to assess under which conditions a successful sustainability transition can be carried through.

- It may be also be used in the scoping stage, when the game focuses on initiating a collaborative process amongst stakeholders, to acknowledge each others interests and concerns, and to make different perspectives on the problem explicit.

- Also, it may be used in the envisioning stage, when the focus lies on the development of a shared sustainability vision and a first assessment of different possible pathways onto the vision. 


\subsubsection{Points of reflection}

The discussion is concluded with some points of reflection on the gaming approach, relating to its goal, interpretation and conceptual design:

\section{A model or a learning tool?}

In general, the goal of the gaming approach can be twofold (Barreteau, 2003). On the one hand, it may be aimed at the production of knowledge for 'the researcher'. The game is then interpreted as a model representing (aspects of) the complex dynamics of real-life socialecological systems. On the other hand, it may be aimed at learning and decision support for the stakeholders involved. The game is then considered as a tool to make people aware of their social-ecological interactions, their own impacts on the whole system, their own motives and what drives their own actions, and the limitations and opportunities to adapt them to sustainability requirements. The focus in this chapter has been clearly on the first purpose, describing the game's development and application from a modelling perspective. The aspects of learning deserve special attention.

\section{An explorative or normative approach?}

In relation to the previous point, one may distinguish two modes for interpreting the game. On the one hand, it can be interpreted as a normative approach. In this interpretation, one would stress the need for a sustainability transition, and the need for fundamental cultural change. The game is then to be perceived as a tool to empower relevant (niche) agents, for example by providing them with relevant insights about how a sustainability transition can be carried through. On the other hand, it can be interpreted as an explorative approach. In that case, the need for a sustainability transition is not a priori implemented in the game. Nor does it prescribe that players will design a shared interpretation of sustainability, a common vision, and implementation pathways. It rather aims to assess the conditions under which such a collaborative process might take place. ${ }^{98}$ Each mode has different advantages and may be useful in different settings and for different purposes. The game described in this chapter follows rather an explorative approach. However, a similar game format has been developed (the 'transition play') (Tàbara \& Haxeltine, 2008) that is more in line with the normative approach.

\section{Multi-system or multi-scale?}

The conceptual model of Figure 7.2 represents the water policy, autonomous behaviours and water culture as distinguishable, strongly related, societal subsystems. These subsystems, one might argue, reflect different societal scales, from the individual, to the organisational, to the societal level. Consequently, an alternative approach could be to represent a society with a nested or 'cellular' structure of socio-ecological agents (Tàbara \& Pahl-Wostl, 2007; Tàbara et al., 2007). In such an approach, one distinguishes at multiple scale-levels individual agents (representing autonomous behaviours), collective agents (representing coordinated responses of individual agents similar to water policy), and a system agent representing the dominant water culture. The elegance of this approach, amongst others, is that it explicitly acknowledges that culture is essentially a multi-scale phenomenon pertaining not only to a societal level, but

\footnotetext{
${ }^{98}$ Of course admitting that the game does impose the (normative) structure to allow fundamental change to happen in the game
} 
also to organisations, local communities and down to the individual level (Erez \& Gati, 2004). A thorough multi-scale conceptualisation would be an interesting step to take.

\subsection{CONCLUSION}

In this chapter, an integrated, agent-based, gaming approach is proposed for modelling the development of water management policy in the broader context of cultural and behavioural change in a meaningful way for a complex water management case like the management of the Ebro River Basin. This chapter primarily describes how this could be done. The conceptual model developed constitutes a framework for understanding processes of change and mapping the interactions across dissimilar subsystems of water, culture, policy, and autonomous behaviour. It is used as a framework for designing the game and constitutes a 'lens' to analyse the interaction processes observed while playing the game. The presented overview of external drivers and internal processes is particularly and generically useful as an inventory of potential mechanisms to be included in models of societal change. Also, we showed how the different processes and interactions can be implemented in a practical game design, as a tool to study them further. Thorough testing of the concept is left for future work.

The gaming approach aims to complement and further advance the participatory IAM-ABM modelling approach developed in this thesis so far. It includes changes of goals and beliefs ('adaptive cognition'), actor interactions like coalition-forming, and consequent changes in water management policy endogenously in the model through a participatory simulation approach. It thereby explicitly represents possible changes of the starting points of river management through changes of the so-called rules of the game. Such a representation is considered essential for understanding the development of river management on the long-term.

One of the main lessons from the exercise is that the combination of modelling and participation is promising for understanding the complex nature of societal change. Playing the game with stakeholders in an open fashion allows for a broad discussion between the game players on all the potential aspects of societal change, possibly extending the variables included in the game. The strength of the gaming approach is then that it combines the structure and scientific underpinning of analytical modelling with the richness of participatory methods so as to address real complex issues of societal change in a consistent and meaningful way. 


\section{Chapter 8}

SYNTHESIS AND CONCLUSION 


\begin{abstract}
This chapter synthesises the results and presents the main conclusions. It is to a large extent possible to represent the complex dynamics of river management through an participatory IAM-ABM approach. In particular, the model application in retrospect reconstructing the Maaswerken project - shows that the main features of historical river management strategies are adequately represented with the model proposed. The model application to assess long-term development of river management is as yet lesser developed, since it does not include formal 'goal update' and 'river model update' rules by which goals and beliefs may plausibly change. Nonetheless, the model provides an adequate tool for 'what-if' analysis to assess, for example, possible future tensions between different goals under pressure of future developments like climate change. An important added value of the approach is to support social learning amongst stakeholders of river management, as reflected in the model's acronym Toddler. The Toddler model can provide a forum to share relevant knowledge about the river system, to clarify and evaluate stakeholder perspectives, to reflect on uncertainty, and to assess the trade-offs between stakeholder interests in a more transparent way. Given its pioneering character and broad scope, the study identifies various directions for future research to further develop the participatory IAM-ABM approach. In short, these include further participatory model applications, on the one hand to better assess the future development of river management, and on the other to test the value of the model as a social learning tool. Notably, the gaming concept developed in Chapter 7 shows promise for modelling long term development of water management (including the dynamics of the water management culture) in a meaningful way. Overall, the study shows that the complex and dynamic nature of river management requires a more reflexive planning approach. In such a learning-bydoing' approach, the continuous reflection on goals and beliefs is equally (or even more) important as the detailed assessment of river management strategies, to fulfil given goals under given beliefs. To support such a reflexive planning process, the Toddler model can help as a Tool to Open-up Dialogue and Debate for Long-term Effective River management.
\end{abstract}




\section{Synthesis and Conclusion}

\subsection{WHAT HAVE WE LEARNED?}

The general aims of this research are best reflected in the main research question stated before:

- To what extent is it possible to represent the complex dynamics of river management through an Integrated Assessment modelling (IAM) - Agent-Based modelling (ABM) approach, and what can be learned from that?

Regarding the first part of this question ('to what extent is it possible ..?'), our study indicates that it is possible to a large extent. Experience was gained with developing an integrated River Model - Agent-Based Model (iRM-ABM), also referred to as the 'Toddler' model, to represent the complex dynamics surrounding the Maaswerken project in the Dutch province of Limburg. A further case study, surrounding the management of the Ebro River basin in Spain, extended the approach with an interactive gaming concept to gain insight notably in long-term cultural changes in river management. The experience shows that it is well possible to derive adequate representations of the river system on the one hand, of the various actors involved on the other, and of the interactions between the river and actor systems. Albeit the many simplifications and limitations of the approach (discussed later on), the developed IRM-ABM was shown to be suitable to reconstruct the dynamics of the Maaswerken project in retrospect, and to explore and reflect upon possible future developments surrounding the management of the River Meuse. Moreover, the gaming concept has shown promise for understanding and reflecting upon the dynamics of cultural change surrounding management of the Ebro River basin.

Concerning the second part of the research question ('and what can be learned ..?'), the study shows that a lot can be learned. Scientists, like the author, could benefit from the approach for better understanding the dynamics of river management and to explore possible developments of river management on the long term. They could learn about the value of the Toddler model as a social learning tool, and benefit from the model as a communication tool for bridging scientific disciplines. Stakeholders (including policymakers) could use this type of model to learn about the possible effects of river management options, but also about the role and implication of key uncertainties, about the interests, values and beliefs of the other stakeholders involved, and about ways to cooperate to achieve a broadly supported river management solution. Policymakers specifically could benefit from this type of model to understand why there is - or is not - stakeholder support for their policies, and get guidance on how to avoid conflict with the various stakeholders involved. Overall, this type of model could contribute to social learning amongst scientists, stakeholders and policymakers, to facilitate action towards sustainable development.

The specific modelling aims are further addressed following the four sub-questions that have been defined:

- How to integrate the IAM and ABM approaches for developing a coupled integrated River Model - Agent-Based Model for the case study under concern?

Before answering this question, note that different types of case studies require different types of $A B M$ approaches. Chapter 2 illustrates the diversity of $A B M$ approaches, ranging from the simple agent approach, to the cognitive agent approach, to participatory ABM. The simple agent 
approach is typically useful for understanding emergent phenomena in systems of many agents (e.g. $>10$ ) in which agent interaction, rather than agent reasoning, is the dominant factor for system behaviour. The more cognitive and participatory approaches are typically valuable for representing complex decision-making processes among a limited number of agents (e.g. <10), where agent reasoning tends to be equally important as - or even dominate - agent interaction for understanding system behaviour. For the case study of the Maaswerken project characterized as a 'complex sustainability planning problem' involving high uncertainty and a low consensus on interests and values - a cognitive and participatory ABM approach was followed within the context of IAM. This allowed for representing both agent reasoning and agent interactions, which can be considered a prerequisite for cases in the sustainable development domain.

The conceptual framework for integrating the IAM and ABM approaches - developed in Chapter 2 - was based on the well-known IAM concept of pressure-state-impact-response (PSIR). This concept was further developed by framing the response as the outcome of a multi-stakeholder agent planning process. Key characteristics of the response conceptualisation were a) an explicit representation of stakeholder agents perspectives in terms of their goals and beliefs about the river system, b) accounting for adaptive cognition, or 'social learning', as a change in goals and beliefs in response to perceived changes in the river system (e.g. due to model study, observations, and sudden events) and/or the interaction with other stakeholder agents (e.g. due to cooperation and coalition-forming), and c) (in the gaming concept developed in Chapter 7) accounting for a dominant water culture that constrains agent behaviour and co-evolves with the stakeholder agents' perspectives.

The conceptual framework provided an adequate means for representing and interlinking the various salient issues of river management. The framework tends to neglect a number of external drivers - such as technological changes, broader socio-cultural and economic developments, institutional changes, and individual role models - and represents actor responses only at a single scale level. Nonetheless, it proved particularly suitable to interlink on the one hand the development of the PSI part of the system (e.g. climate change, spatial pressure, water flow, and impacts on river functions), referred to as the 'river system', and on other hand the development of the actor response (including river management policy, autonomous behaviours, and cultural change). Given the various successful applications of the PSIR concept, also this elaborated framework can be considered generically useful for sustainability issues outside the water domain.

Concerning the interaction between the river system and actor response system, the conceptual framework distinguishes two relevant time scales. River management planning process (like the one of the Maaswerken project) among stakeholder agents were said to play out over the medium term: 5 - 10 years. On this time scale, the actor response system can be assumed to be highly dynamic (driven by events, new insights about the river system and agent-agent interactions), while the actual river system changes only little. Only on the long term (50 - 100 years) - possibly involving consecutive river management planning processes - dynamics is also driven by actual river system change. On this time scale, the interaction between the river and actor response systems plays out as the iterative process of the stakeholder agents deciding on the implementation of a river management plan, which changes the river system, triggering and/or influencing further stakeholder action in the future.

To account for these different time scales, the river management planning process should be represented at a relatively small (e.g. yearly) time scale. During the planning process, the river 
system model is used by the agents to make projections about the future of the river, and to assess their preferred river management strategy on the basis of their goals and beliefs. Events and new insights could be introduced in some external (and possibly probabilistic) way, to drive agent interactions and goal and belief changes. After a river management outcome has been agreed, a larger time step is taken (e.g. 10 years) for the stakeholder agents to re-evaluate the modified river system (using the river system model) on the longer term. Over this period, new knowledge can be assumed to become available (e.g. on climate change, land use development, and river engineering effects), as reflected in an updated set of beliefs, and also the goals may have been subject to change. The re-evaluation may hence reveal different outcomes then previously anticipated, triggering a further river management response, after which a new planning process is initiated.

This way of model coupling implies a number of criteria for the iRM and ABM. For the iRM, it implies first that it is compatible with the perspectives of the stakeholders involved. To this end, the iRM includes the salient decision-making criteria ('goals'), river management options ('actions'), and uncertainties (legitimizing different 'beliefs') as expressed by the various stakeholders involved. Moreover, like most IA models, the iRM was designed to be interactive (i.e. rapid, transparent, and easy to operate) and practically and conceptually valid to be useful in a participatory $A B M$ approach. For the $A B M$ (especially running in the non-participatory mode) it poses the requirement that stakeholder agents are able to find their preferred river management strategy on the basis of their goals and beliefs, which - in our model - agents are able to do on the basis of an optimization routine.

A key feature of both the iRM and $A B M$ is their simplicity. The simple cross-section implementation of the iRM lacks spatial detail and poses some fundamental limitation compared to a 2D spatial model. The advantages of the cross-section approach, however, are its transparency, intuitive visual appeal, and a reduction of the spatial complexity when discussing (or modelling) a river management strategy. The simple (yet cognitive) architecture of the stakeholder agents might seem simplistic from the point of view of the cognitive sciences (Sun, 2006). However, again its transparency and intuitive appeal make it probably more useful in a participatory $A B M$ approach then a detailed cognitive representation of the stakeholder's 'mind'. In summary, the complexity of the river management process, which finds expression notably in the high uncertainty and a diversity of interests and values, is particularly well expressed following this rather simple approach.

- To what extent can this model adequately represent the course of the Maaswerken planning process over the medium term (roughly from 1990 to 2005)? To what extent does the model provide policy relevant reflection in retrospect?

The conceptual modelling framework was applied first for analysing the course of the Maaswerken project (Chapter 4). The framework helped to interpret the development of the Maaswerken project as a dynamic process in which stakeholder perspectives, stakeholder involvement, stakeholder relations, and the river management outcomes were constantly changing. The analysis revealed several interesting insights regarding the implications of events and new insights in the river system, and the role of cooperation, conflict and coalition forming. A surprising insight, for example, was that the flood events of 1993 and 1995 seem to have put pressure on citizen support for the Grensmaas strategy, since flood prevention was added as a project goal without the allocation of more budget. Another interesting insight was that conflict can lead to coalition-forming, which can eventually support cooperation as the final stage of the 
Grensmaas planning process has shown. Overall, the analysis highlighted that conflicts were often related to lacking mutual acceptance of stakeholder perspectives, which - in turn - was often fuelled by the changing river management plans. The conceptual modelling framework thus provided a useful framework of analysis.

Following, the coupled iRM-ABM was applied to reconstruct the course of the Grensmaas project in a quantitative way (Chapter 6). The reconstruction specifically aimed to reproduce the river management outcomes of the consecutive stages of the planning process, for given groups of involved stakeholders, with given goals and beliefs. The exercise revealed significant errors between the historical and calculated river management strategies, which can be related to inaccuracy of the iRM (e.g. regarding the calculations of profitability), inaccuracy in the various goal standards (e.g. regarding the optimisation criterion for ecosystem diversity), and probably the basic structure of the $A B M$ (e.g. the assumption that the policy outcome is the river management strategy with maximum stakeholder support). Nonetheless, the general characteristics of the observed river management strategies were adequately reproduced. It is therefore concluded that the model can adequately represent the course of the Maaswerken project, however, when input is provided on historical changes of stakeholder perspectives and stakeholder involvement. In its current form, the model is thus suitable to explore the implications of changing goals and beliefs on the policy process - and hence the river system - in an integrated and quantitative way. It also forms a proper basis for implementing adaptive cognition endogenously in the model as a next step in future research.

Concrete policy relevant insights in retrospect were obtained from the sensitivity analysis of the river management outcome to changing goal standards. This analysis showed (amongst others) how 'loosening' goal standards may reveal new river management outcomes with significantly higher agent support. This analysis indicates which goal standards are most constraining on the policy process overall. Loosening the standards for profitability and nature development area, for example, could allow for new solutions with significantly higher support, whereas loosening the standard for gravel extraction had no effect. These insights might be taken into account by (cooperative) stakeholders for (re)defining their goal standards ${ }^{99}$. It would be interesting to present these results to the stakeholders involved to assess whether these types of model results are accepted and would indeed stimulate stakeholders to reflect upon, and reconsider, their perspectives.

- To what extent can this model be used to explore plausible future developments of the management of the River Meuse on the long term (e.g. 50 to 100 years)? To what extent does it provide new and policy relevant insight?

Regarding future developments, the model was used to explore the impacts of climate change. The assessment of the Preferred Alternative of 2003 (Grensmaas) under changing climate conditions (see Chapter 5) shows that the strategy would actually be rather 'climate proof'. The assessment of stakeholder support under changing climate conditions, however, does show that under an extreme climate scenario both stakeholder support and the policy outcome might significantly change. The experiment in Chapter 6 indicated that a new flood prevention strategy

\footnotetext{
${ }^{99}$ Of course, whether these criteria should be reconsidered remains a normative and political choice.
} 
based on river broadening might come to the fore, but without the support of the citizens involved, thus highlighting the dilemma of maintaining the safety norm, while not exceeding an acceptable level of hindrance. At this stage, the model results thus offer some reflection on the implications of long term developments, but the model potential in this respect remains largely to be explored (see 'Reflection and outlook' later on).

On a more fundamental level, we have argued in Chapter 7 that an exploration of the long term development of river management requires a modelling approach in which the dynamics of river management policy is embedded within the broader context of societal change. It requires a view in which changes in goals and beliefs are related to the emergence of fundamentally new perspectives as a result of which fundamentally new river management styles may come to the fore. The analysis of the project Integral Exploration of the Meuse (IEM) (Chapter 4), for example, illustrates such a possible perspective change: from the current perspective of flood prevention (based on flood norms) to a new perspective of flood adaptation (based on damage potential reduction), implying different types of river management options to take. The gaming concept of Chapter 7 is an attempt to model such perspective shifts (or changing 'water cultures') in long term river management. To this end, the gaming concept integrates the perspective based modelling approach, the concept of transitions, and participatory $A B M$, as described in Chapter 7. Amongst others, it shows that an understanding of the long-term development of river management requires insight not only in the development of water policy, but also in its interaction with autonomous responses and cultural change. By combining the analytical rigour of modelling with the richness of participatory processes, the gaming concept shows promise for better understanding such complex interactions in a consistent and meaningful way.

- To what extent is the model suitable to support stakeholder dialogue to facilitate sustainable river management?

Recall that - according to Robinson (2004) - sustainable development requires "a process by which these [irreconcilable] views [on sustainable development] can be expressed and evaluated". Following this interpretation of sustainable development, the iRM-ABM, or 'Toddler' model can certainly help.

To be able to express and evaluate different views, the Toddler model can be used as a tool to support communication between planners, policymakers and the broader stakeholder community. First, the tool can be used to illustrate the effects of river management strategies, to make trade-offs more explicit, and to assess the risks associated with the various river management strategies by reflecting on the uncertainties involved (see Chapter 5). Moreover, the tool can be used to make stakeholder viewpoints explicit, by representing their goals, beliefs, and support for various possible river management strategies (Chapter 6). This transparency might contribute to insight in the extent to which stakeholders perceive each others standpoints as being legitimate. And a more explicit consideration of this perceived legitimacy, in turn, might contribute to an increase of mutual acceptance of the various standpoints, and might support cooperation by stimulating the reconsideration of goals and beliefs for the 'common good'.

Working with the Toddler model, various conflicts regarding the Maaswerken project could have been avoided or solved at an earlier stage. In the Grensmaas project, for example, the Toddler model would have indicated that the gravel extractors were unsupportive of the Preferred 
Alternative of 1998, providing an early warning of the unsuccessful negotiation ahead. In the Zandmaas/Maasroute project, the new insights that led to a revision of the Combination Alternative of 1999 could have been anticipated on if the Combination Alternative would have been assessed from multiple interpretations of uncertainty. Thus, using the Toddler model to evaluate river management strategies more explicitly from different stakeholder perspectives allows for better anticipation on the unexpected events, new insights, and changing stakeholder involvement inherent in the river management process.

\subsection{REFLECTION AND OUTLOOK}

With substantial results obtained, there are also various limitations to the modelling approach as it has been developed so far. Here, we reflect upon those limitations and - in relation to that sketch possible avenues for further research.

\subsubsection{Concerning the iRM}

Regarding the iRM as a stand-alone application, Chapter 5 points to various limitations inherent to the cross-section approach. Regarding the design criterion validity, for example, limitations are typically related to the $1 \mathrm{D}$ or even $\mathrm{OD}$ representation of essentially $2 \mathrm{D}$ dynamics, for example in the calculations of river water and groundwater level change. These limitations were overcome, amongst others, through calibration on the basis of the Maaswerken expert model results. But this dependency on expert model results, as a Maaswerken expert pointed out, is considered a weak point, since it limits model applicability of the model to rivers that are already subject to model study. It does not do justice to the model's potential as a tool for 'quick and dirty' assessment of river engineering effects in unknown areas. Moreover, the cross-section model was only tested for a single cross-section alone. The 'proof of concept' would be much stronger if it would be performed for multiple cross-sections, preferably for different types of rivers. Finally, it is clear that the single cross-section model forms only a limited representation of a river stretch as a whole. To be able to cover the issues of the Maaswerken in a more comprehensive way, it would be advisable to design and test a multiple cross-section model covering the river stretches of the Grensmaas and Zandmaas as a whole.

Regarding the design criterion compatibility with stakeholder perspectives, it was already argued in Chapter 5 that - in relation to the Grensmaas project - this criterion was at least partly fulfilled: the model covers the main issues of the Grensmaas project as perceived by the main stakeholders involved. However, considering the broader range of perspectives that may come to the fore in future river management (e.g. the flood adaptation perspective, see Chapter 4), one might argue this criterion is not fulfilled for exploring the development of long term river management. To this end, the model would need to be extended with more policy options (e.g. in relation to flood adaptation), other relevant impacts (e.g. 'spatial quality'), and possibly focus more on socio-economic and the associated spatial developments as important drivers of change. Following the principles of participatory modelling, extending the model is done best in close collaboration with a diverse group of river management stakeholders, adhering to a variety of (fundamentally) different perspectives.

Summarizing, the following recommendations apply: 
- Apply the iRM to multiple river cross-sections, preferably for different types of river stretches, to further test the validity of the approach. Test to what extent consecutive iRM cross-sections can be combined to better map an entire river stretch.

- Assess to what extent adequate applications can be set up without calibrating on the basis of expert model results.

- Extend the coverage of the iRM - in terms of river management options, impacts, and drivers - in close collaboration with stakeholders of river management.

\subsubsection{Concerning the iRM-ABM}

It is clear that the potential of $A B M$ for representing stakeholder dynamics in the planning process of the Maaswerken project has not yet been fully explored. While the analysis of the Maaswerken project of Chapter 4 focussed in considerable detail on the dynamics of changes in stakeholder perspectives over the course of the planning process, and on the role of stakeholder interactions like cooperation, conflict, and coalition-forming, the reconstruction of the Grensmaas project in Chapter 6 did not yet implement those dynamics in an endogenous way.

For taking the next step towards a more comprehensive and dynamic reconstruction of the Maaswerken project, three directions can be given. The first is to adopt a participatory approach. The reconstruction could be redone together with the stakeholders of the Grensmaas project, to further elicit the motivations behind the changing goals and beliefs over the course of the project, to further assess the role of stakeholder interactions, and - thereby - to improve model validation. A second direction is to extend the stakeholder agent architecture of Chapter 2 with the notion of social goals and beliefs (Conte \& Castelfranchi, 1995a). Social goals and beliefs imply that stakeholder agents hold not only goals and beliefs about the river system (as they do in the current model), but also about the other stakeholder agents. Implementing social goals and beliefs will allow for representing a main factor in the occurrence of conflicts, namely the perceived legitimacy of the other stakeholders' goals and beliefs. Finally, note that the iRMABM has only been applied to reconstruct the case of the Grensmaas project, whereas also the Zandmaas/Maasroute project shows an interesting dynamics which remains to be explored.

Also considering the exploration of long term developments, much ground remains to be explored. As a general observation, the current model is too static to represent long term developments in a satisfactory way. In the climate change experiment of Chapter 6 - for example - we assumed that the goals and standards derived for the current situation would remain the same; an assumption not likely to hold. Two avenues are considered for increasing model dynamics. A first avenue would be to introduce some proper set of heuristics for goal and belief changes (i.e. the 'water model update' and 'goal update' rules) in response to perceived changes in the river system and stakeholder-stakeholder interaction. Following this avenue, it would be methodologically interesting to assess to what extent complex emergent outcomes can be simulated, and to interpret these complex model outcomes vis-à-vis the real-life case. A second avenue would be to follow a participatory ABM approach. In such an approach, stakeholder representatives would be invited to participate in the modelling exercise. They would themselves be in charge of their 'goal update' and 'water model update' rules as the river system and the other stakeholders' perspectives develop. Following this avenue, a main challenge would be to assess to what extent the participatory modelling exercise contributes to social learning amongst the stakeholder representatives involved. Reversely, a main challenge would be to assess how this social learning process contributes to model development by formalizing the observed goal and belief updates in an automated ABM. 
On a more technical note, finally, note that in the current model, stakeholder agents find their optimal river management strategy through a straightforward optimization over all possible river management strategies. Depending on the range of strategies considered, this optimization procedure can be quite time intensive, thereby reducing the model's suitability as a research and participatory tool. A major improvement would be to adopt a more efficient optimisation routine.

Summarizing, the following recommendations apply:

- A more elaborate participatory reconstruction of the Maaswerken project (both the Grensmaas and Zandmaas/Maasroute) focussing on a better representation of the stakeholder dynamics observed.

- Extension of the stakeholder agent architecture, including amongst others beliefs about the other stakeholder agents, for example regarding the legitimacy of the other's goals and beliefs.

- Development of long term experiments on the basis of a proper set of heuristics for goal and belief change; assess to what extent complex emergent outcomes can be simulated.

- Set up a participatory ABM experiment regarding the long term development of the management of the river Meuse; assess to what extent the observed goal and belief updates can be formalized, and implemented into an automated ABM.

- Assess to what extent the participatory experiment can contribute to social learning amongst the stakeholders involved.

- Adopt a more efficient optimization routine for finding preferred river management strategies.

\subsubsection{Towards an understanding of long term river management}

As described before, we argued that an exploration of long term river management requires a modelling approach in which the dynamics of river management policy is embedded within the broader context of societal change. One might wonder, what can really be learned about long term river management from analyzing the Maaswerken project? The Maaswerken project is an operational project based on clear starting points: the flood norm, the nature development criteria, the shipping route, the budget constraints, and the intention for a river widening and participatory approach. These starting points were not explicitly subject to debate. Yet an exploration of long term river management requires exactly an understanding of how these starting points might change.

The Maaswerken project does show, however, how certain starting points can come under pressure. The principle of river widening, for example, has come under pressure in the Zandmaas/Maasroute project as a result of the desire to maintain a flood norm under the budget, time and environmental constraints. This points to a possible future where - particularly under pressure of climate change and spatial scarcity - water management returns to the traditional 'fighting the water' approach: providing safety norms through dike-building. On the contrary, the analysis of the Integral Exploration of the Meuse has shown that also the flood norm can come under pressure, as a result of the desire for spatial quality, and to avoid hindrance and damage to the landscape. This points to a possible future where - for example in areas of relatively low population density and limited potential inundation depth - occasional floods along the River Meuse are accepted and dealt with through flood adaptation measures. In 
other words, the current transition of Dutch water management towards 'accommodating water', as described by Van der Brugge et al. (2005), does not seem irreversible yet. The experience with river management rather shows that Dutch water management is at a 'crossroads', where different types of water management styles (or combinations of them) may still become dominant over the decades ahead.

The change of water management styles on a more fundamental level can only be understood within the broader context of societal change. It is very much related to the development of the broader societal perspective on water management, including, for example, the view on government responsibility. With a strong national government, holding the key responsibility for flood prevention, a return to the 'fighting the water' approach may be a logical path when ongoing flood events will force the national government to urgently live up to its flood prevention responsibilities. A shift of flood prevention responsibility, however, to local governments and individual inhabitants seems more in line with the 'flood adaptation' path, as flood adaptation measures (e.g. flood resistant building) are much more appropriate at the local scale than flood prevention initiatives are. This illustrates the importance of moving beyond water and spatial planning in the formulation of strategic water management plans. One should be aware, for example, that the current focus on national government responsibility for maintaining a safe Netherlands, expressed in the recent policy advice of the 'Delta commission' (Deltacommissie, 2008), can be factor which slows the current water transition down. For the modeller, in any case, it implies that a model exploration of future water management should relate the development of water management per se to the development of the broader perspective on water.

Previous research (Hoekstra, 1998, 2000; Van Asselt et al., 2001; Middelkoop et al., 2004) has shown how Cultural Theory provides a useful theoretical framework for mapping fundamentally different perspectives water management on the basis of distinct cultural stereotypes, as a basis for integrated water modelling and for developing scenarios for Dutch water management. Their research, however, lacks the insight in the dynamical change of cultural perspectives over time. Therefore, a combination of the perspective based modelling approach and participatory ABM within the context of participatory scenario development - such as outlined in Chapter 7 and already explored in (Valkering et al., 2008) - is a promising way ahead to be able to explore long term change in water management in a meaningful way.

Summarizing, the following recommendation applies:

- Further developing the combination of participatory $A B M$ with the perspective based modelling approach in the context of participatory scenario development for modelling long term development of water management in a meaningful way.

\subsection{CONCLUSION}

In this thesis, we have explored the combination of IAM and participatory ABM to model and support stakeholder decision-making in river management. This combination has turned out to be fruitful to support the further integration of knowledge within IA. Where traditional IAMs have been strong in integrating the environmental and socio-economic dimensions of societal change, participatory $A B M$ can blend-in state-of the art social scientific knowledge and stakeholder knowledge. In doing so, the approach allows for better insight in complex societal systems. Notably, the interaction between stakeholder decision-making and the development of 
a river system (or other domain system) can be assessed. The approach combines the best of two worlds - the structure and scientific underpinning of analytical modelling and the richness and creativity of participatory methods - to address complex issues of societal change in a consistent and meaningful way. The application of the modelling approach in participatory processes is particularly suited to support social learning amongst scientists of different disciplines, and stakeholders. Stakeholders are involved in the IA modelling process, in a concrete and engaging way, through the explicit representation of the stakeholder in the model. It allows scientists to better understand the motivations behind stakeholder behaviour, and stakeholders to reflect upon the implications of their behaviours in a societal context.

The approach can support better ways of river management. Large-scale, coordinating river management projects like Maaswerken run the risk that the planning process is constantly overtaken by events, developments and new insights. Reality has changed before the new plan is prepared, fuelling conflict with the various stakeholders involved. Also, it runs the risk of creating false expectation with stakeholders involved. Stakeholders can express their opinion, but often feel that their opinion is not sufficiently taken into account. To better anticipate on such changing realities, and deal with various stakeholder concerns, river management along the Meuse could benefit from a more reflexive planning approach (Kemp \& Martens, 2007). Amongst others, such an approach could imply a stronger focus on experimentation, monitoring and learning, rather then aiming to cover all possible effects a priori in a detailed river engineering plan. It could imply a lesser focus on norms, and a stronger focus on needs, opportunities and risks. Also, it could imply a partial shift of responsibilities: Within a coordinating Maaswerken framework, local initiatives could be supported with more responsibilities, and hence awareness, for the local stakeholders involved.

In support of such a reflexive approach, the Toddler can help. In short, it can provide a forum to share relevant knowledge about the river system, to clarify and evaluate stakeholder perspectives, to reflect on uncertainty and possible future developments, to assess the tradeoffs between stakeholder interests, to stimulate stakeholders to reflect upon their goals and beliefs, and to stimulate creative thinking to explore different options than previously considered. From the perspective of sustainable development, the challenge of river management is to collectively decide what we aim to achieve, and how to achieve that, in a highly dynamic and uncertain context. The Toddler model developed in this thesis can help to address this challenge as a Tool to Open-up Dialogue and Debate for Long-term Effective River management. 


\section{References}

Adams, P. (2001a). Hoe slimme grindboeren wonnen van poenerige ambtenaren. Dagblad de Limburger. Issue 10-02-2001. Maastricht, The Netherlands.

Adams, P. (2001b). Limburg trekt zich terug uit Zandmaas. Dagblad de Limburger. Issue 05-10-2000. Maastricht, The Netherlands.

Ajzen, I. (1988). Attitudes, Personality and Behavior. Open University Press. Berkshire, UK.

Alcamo, J., Shaw, R., and Hordijk, L. (Eds.) (1990). The RAINS Model of Acidification: Science and Strategies in Europe. Kluwer Academic Publishers. Dordrecht, The Netherlands.

Alterra (1999). LGN3 - Land Use in the Netherlands. The LGN3-database is based on satellite imagery from 1995 -1997, the TOP10-vector database and agricultural statistics of the Netherlands Bureau for Economic Policy Analysis (CPB). <http://www.lgn.nl/>

Amelung, B. (2006). Global (Environmental) Change and Tourism: Issues of scale and distribution. PhD thesis. Maastricht University, The Netherlands.

Anonymous (2001). Natuur Limburg beter af zonder Zandmaasproject. Limburgers Dagblad. Issue 31-012001. Maastricht, The Netherlands.

Axelrod, R. (1984). The Evolution of Cooperation. Basic Books. New York, USA.

Axelrod, R. (1986). An Evolutionary Approach to Norms. The American Political Science Review, 80 (4), 1095 1111.

Barreteau, O., and Bousquet, F. (2000). SHADOC: a multi-agent model to tackle viability of irrigated systems. Annals of Operations Research, 94, 139-162.

Barreteau, O., Bousquet, F., and Attonaty, J.-M. (2001). Role-playing games for opening the black box of multi-agent systems: method and lessons of its application to Senegal River Valley irrigated systems. Journal of Artificial Societies and Social Simulation, 4 (2) 5.

<http://jasss.soc.surrey.ac.uk/4/2/5.html>

Barreteau, O. (2003). Our Companion Modelling Approach. Journal of Artificial Societies and Social Simulation, 6 (2) 1. <http://jasss.soc.surrey.ac.uk/6/2/1.html>

Berger, H. E. J. (1992). Flow Forecasting for the River Meuse. PhD thesis. Delft University of Technology, The Netherlands.

Bergman, N., Haxeltine, A., Whitmarsh, L., Kohler, J., Schilperoord, M., and Rotmans, J. (2008). Modelling Socio-Technical Transition Patterns and Pathways. Journal of Artificial Societies and Social Simulation, 11 (3) 7. <http://jasss.soc.surrey.ac.uk/11/3/7.html>

Booij, M. J. (2002). Appropriate modelling of climate change impacts on river flooding. PhD thesis. University of Twente, Enschede, The Netherlands.

Bossel, H. (2000). Policy assessment and simulation of actor orientation for sustainable development. Ecological Economics, 34, 337-355.

Bousquet, F., Cambier, C., and Morand, P. (1994). Distributed artificial intelligence and object-oriented modelling of a fishery. Mathematical and Computer Modelling, 20 (8), 97-107.

Bousquet, F., and Page, C. L. (2004). Multi-agent simulations and ecosystem management: a review. Ecological Modelling, 176 (3/4), 313-332.

Bouwman, A. F., Kram, T., and Goldewijk, K. K. (2006). Integrated modelling of global environmental change. An overview of IMAGE 2.4. Netherlands Environmental Assessment Agency (MNP). Publication number 500110002/2006. Bilthoven, The Netherlands.

Bratman, M. E. (1987). Intention, Plans and Practical Reason. Harvard University Press. Cambridge, Massachusetts, USA.

Briot, J.-P., Guyot, P., and Irving, M. (2007). Participatory simulation for collective management of protected areas for biodiversity conservation and social inclusion. Paper presented at the AIS-CMS '07 International Modeling and Simulation Multiconference (IMSM'07).

Brouwer, F., and Huinink, J. T. M. (2002). Opbrengstdervingspercentages voor combinaties van bodemtypen en grondwatertrappen: Geactualiseerde help-tabellen en opbrengstdepressiekaarten. Alterra report 429. Wageningen, The Netherlands.

Carmichael, J., Tansey, J., and Robinson, J. (2004). An integrated assessment modeling tool. Global Environmental change, 14, 171-183.

Castelfranchi, C. (1998). Modelling Social Action for Al Agents. Artificial Intelligence, 103 (1-2), 157-182. 
References

Castella, J.-C., Trung, T. N., and Boissau, S. (2005). Participatory simulation of land-use changes in the northern mountains of Vietnam: the combined use of an agent-based model, a role-playing game, and a geographic information system. Ecology and Society, 10 (1) 27.

$<$ http://www.ecologyandsociety.org/vol10/iss1/art27/>

Conte, R., and Castelfranchi, C. (1995a). Cognitive and Social Action. UCL Press Itd. London, UK.

Conte, R., and Castelfranchi, C. (1995b). Understanding the functions of norms in social groups. In: N. Gilbert \& R. Conte (Eds.), Artificial Societies. UCL Press. London, UK.

Craps, M. (2003). Social Learning in River Basin Management. HarmoniCOP WP2 reference document. Catholic University of Leuven, Centre for Organizational and Personnel Psychology. Leuven, Belgium. <http://www.harmonicop.info>

CWB21 (2000). Waterbeheer 21ste eeuw. Commissie Waterbeheer 21ste eeuw. The Hague, The Netherlands.

De Blois, C. J. (2000). Uncertainty in large-scale models for decision support in water management. PhD thesis. University of Twente, Enschede, The Netherlands.

De Lange, W. J. (1996). Groundwater modelling of large domains with analytic elements. PhD thesis. Delft University of Technology, The Netherlands.

De Vries, B. J. M. (2001). Perceptions and risks in the search for a sustainable world: a model-based approach. The International Journal of Sustainable Development, 4 (4), 434-453.

De Waal-Malefijt, J. J. (2002). Limburg trekt zijn eigen plan. Paper presented at the symposium 'Ander zicht op de Maaswerken?' Delft University of Technology, The Netherlands.

De Wit, M. (2001). Effect of Climate Change on the Hydrology of the River Meuse. Wageningen University, Environmental sciences, sub-department Water Resources. Report 104. Wageningen, The Netherlands.

De Wit, M. (2008). Van regen tot Maas. Grensoverschrijdend waterbeheer in droge en natte tijden. Veen Magazines. Diemen, The Netherlands.

Deltacommissie (2008). Samen werken met water. Bevindingen van de Deltacommissie 2008. Staatscommissie voor Duurzame Kustontwikkeling. The Hague, The Netherlands. $<$ http://www.deltacommissie.com>

Doran, J., Palmer, M., Gilbert, N., and Mellars, P. (1994). The EOS project: modelling Upper Palaeolithic social change. In: N. Gilbert \& J. Doran (Eds.), Simulating Societies. UCL Press. London.

Downing, T., Moss, S., and Pahl-Wostl, C. (2001). Understanding Climate Policy Using Participatory AgentBased Simulation. In: S. Moss \& P. Davidsson (Eds.), Multi-Agent-Based Simulation. Springer. Berlin, Germany.

Dray, A., Perez, P., Page, C. L., D'Aquino, P., and White, I. (2005). Companion modelling approach: the AtollGame experience in Tarawa atoll (Republic of Kiribati). Paper presented at the MODSIM 2005 International Congress on Modelling and Simulation. Melbourne, Australia.

Edmonds, B., and Möhring, M. (2005). Agent-Based Simulation Modeling in Social and Organizational Domains. SIMULATION, 81 (3), 173-174.

EEA (2003). Europe's water: An indicator-based assessment. European Environment Agency (EEA). Topic report $1 / 2003$. Copenhagen, Denmark.

Eijgenraam, C. J. J., Koopmans, C. C., Tang, P. J. G., and Verster, A. C. P. (2000). Evaluatie van Infrastructuurprojecten. Netherlands Bureau for Economic Policy Analysis (CPB) / Netherlands Economic Institute (NEI). The Hague, The Netherlands.

Epstein, J. M., and Axtell, R. (1996). Growing Artificial Societies: Social Science from the Bottom Up. The MIT Press. Cambridge, Massachusetts, USA.

Erez, M., and Gati, E. (2004). A Dynamic, Multi-Level Model of Culture: From the Micro Level of the Individual to the Macro Level of a Global Culture. Applied Psychology: An International Review, 53 (4), 583 598.

Forrester, J. W. (1971). World Dynamics. Wright-Allen Press. Cambridge, Massachusetts, USA.

Forrester, J. W. (1975). Collected papers of Jay W. Forrester. Wright-Allen. Cambridge, Massachusetts, USA.

Funtowicz, S. O., and Ravetz, J. R. (1993). Science For The Post-Normal Age. Futures, 25 (7), 739-755.

Geels, F. W., and Schot, J. (2007). Typology of sociotechnical transition pathways. Research Policy, 36 (3), 399-417.

Gibbons, M., Limoges, C., Nowotny, H., Schwartzman, S., Scott, P., and Trow, M. (1994). The New Production of Knowledge: The Dynamics of Science and Research in Contemporary Societies. SAGE Publications Ltd. London, UK. 
Giddens, A. (1984). The constitution of society: outline of the theory of structuration. University of California Press. Berkeley, USA.

Gilbert, N., and Troitzsch, K. G. (2005). Simulation for the Social Scientist (2nd edition). Open University Press. Berkshire, UK.

Gilbert, N., Besten, M. d., Bontovics, A., Craenen, B. G. W., Divina, F., Eiben, A. E., et al. (2006). Emerging Artificial Societies Through Learning. Journal of Artificial Societies and Social Simulation, 9 (2) 9. $<$ http://jasss.soc.surrey.ac.uk/9/2/9.html>

Gilbert, N. (2006). When does social simulation need cognitive models? In: R. Sun (Ed.), Cognition and multiagent interaction: from cognitive modelling to social simulation. Cambridge University Press. Cambridge, UK.

Gilbert, N. (2008). Agent-Based Models. SAGE Publications Ltd. London, UK.

Grimm, V. (1999). Ten years of individual-based modelling in ecology: what have we learned and what could we learn in the future? Ecological Modelling, 115, 129-148.

Grosskurth, J. (2008). Regional sustainability: Tools for integrated governance. PhD thesis. Maastricht University, The Netherlands.

Gurung, T. R., Bousquet, F., and Trebuil, G. (2006). Companion Modeling, Conflict Resolution, and Institution Building: Sharing Irrigation water in the Lingmuteychu Watershed, Bhutan Ecology and Society, 11 (2) 36. <http://www.ecologyandsociety.org/vol11/iss2/art36/>

Guyot, P., and Honiden, S. (2006). Agent based participatory simulations: Merging multi-agent systems and role-playing games. Journal of Artificial Societies and Social Simulation, 9 (4) 8. <http://jasss.soc.surrey.ac.uk/9/4/8.html>

Hare, M., and Deadman, P. (2004). Further towards a taxonomy of agent-based simulation models in environmental management. Mathematics and computers in simulation, 64, 25-40.

Haxeltine, A., Whitmarsh, L., Bergman, N., Rotmans, J., Schilperoord, M., and Kohler, J. (2008). A Conceptual Framework for transition modelling. International Journal of of Innovation and Sustainable Development, 3 (1/2), 93-114.

Hertogh, M., Baker, S., Staal-Ong, P. L., and Westerveld, E. (2008). Managing Large Infrastructure Projects: Research on Best Practices and Lessons Learnt in Large Infrastructure Projects in Europe. AT Osborne BV. Baarn, The Netherlands.

Hisschemöller, M., and Hoppe, R. (1995). Coping with intractable controversies: The case for problem structuring in policy design and analysis. Knowledge, Technology, and Policy, 8 (4), 40-60.

Hoekstra, A. Y. (1998). Perspectives on Water: An integrated model-based exploration of the future. International Books. Utrecht, The Netherlands.

Hoekstra, A. Y. (2000). Appreciation of water: four perspectives. Water Policy, 1 (6), 605-622.

Hogeweg, P., and Hesper, B. (1983). The ontogeny of the interaction structure in bumble bee colonies: a mirror model. Behavioral Ecology and Sociobiology, 12, 271-283.

Huynen, M. (2008). Future Health in a Globalising World. PhD thesis. Maastricht University, The Netherlands.

IMC (2003). Rapport over de kwaliteit van de Maas. International Meuse Commission (CIM-IMC-IMK). Liège, Belgium.

IPCC (2001). Climate change 2001: The Scientific Basis. Contribution of Working Group I to the Third Assessment Report of the Intergovernmental Panel on Climate Change (IPCC). Cambridge University Press. Cambridge, UK.

IPCC (2007). Climate Change 2007: Synthesis Report. Contribution of Working Groups I, II and III to the Fourth Assessment Report of the Intergovernmental Panel on Climate Change. IPCC. Geneva, Switzerland.

Jackson, T. (2005). Motivating Sustainable Consumption. Centre for Environmental Strategy (CES), University of Surrey. Surrey, UK.

Jager, W. (2000). Modelling consumer behaviour. PhD thesis. University of Groningen, The Netherlands.

Janssen, M. A. (1996). Meeting Targets: Tools to Support Integrated Assessment Modelling of Global Change. PhD thesis. University of Maastricht, The Netherlands.

Janssen, M. A., and de Vries, B. (1998). The Battle of Perspectives: a multi-agent model with adaptive responses to climate change. Ecological Economics, 26, 43-65.

Janssen, M. A., and Jager, W. (2000). The human actor in Ecological-Economic models Ecological Economics, 35 (3), 307-310.

Janssen, M. A., and Ostrom, E. (2006a). Empirically Based, Agent-based models. Ecology and Society, 11 (2) 37. <http://www.ecologyandsociety.org/vol11/iss2/art37/> 
References

Janssen, M. A., and Ostrom, E. (2006b). Governing Social-Ecological Systems. In: L. Tesfatsion \& K. L. Judd (Eds.), Handbook of Computational Economics, Volume 2: Agent-Based Computational Economics. Elsevier. Amsterdam, The Netherlands.

Janssen, M. A., and Ostrom, E. (2007). Adoption of a New Regulation for the Governance of Common-Pool Resources by a Heterogeneous Population. In: J.-M. Baland, P. K. Bardhan \& S. Bowles (Eds.), Inequality, cooperation, and environmental sustainability. Princeton University Press. New Jersey, USA.

Janssen, P. H. M., Slob, W., and Rotmans, J. (1990). Gevoeligheidsanalyse en Onzekerheidsanalyse: een Inventarisatie van Ideeën, Methoden en Technieken. National Institute for Public Health and the Environment (RIVM). Report 958805001 . Bilthoven, The Netherlands.

Jonkman, S. N., Bockarjova, M., Kok, M., and Bernardini, P. (2008). Integrated hydrodynamic and economic modelling of flood damage in the Netherlands. Ecological Economics, 66, 77-90.

Kemp, R., and Martens, P. (2007). Sustainable development: how to manage something that is subjective and never can be achieved? Sustainability: Science, Practice, \& Policy, 3 (2), 5-14. <http://ejournal.nbii.org/archives/vol3iss2/0703-007.kemp.html>

Klaassen, G., Amann, M., Berglund, C., Cofala, J., Höglund-Isaksson, L., Heyes, C., et al. (2004). The Extension of the RAINS Model to Greenhouse Gases. An interim report describing the state of work as of April 2004. International Institute for Applied Systems Analysis (IIASA). Report IR-04-015. Laxenburg, Austria.

Klusch, M., Bergamaschi, S., Edwards, P., and Petta, P. (Eds.) (2003). Intelligent Information Agents: The AgentLink Perspective. Springer. Berlin, Germany.

KNMI (2006). KNMI Climate Change Scenarios 2006 for the Netherlands. Royal Netherlands Meteorological Institute (KNMI). KNMI Scientific Report WR 2006-01. De Bilt, The Netherlands.

Kok, M., Huizinga, H. J., Vrouwenvelder, A. C. W. M., and Barendrecht, A. (2005). Standaardmethode 2004. Schade en Slachtoffers als gevolg van overstromingen. Rijkswaterstaat, Dienst Weg- en Waterbouwkunde. Delft, The Netherlands.

Kwadijk, J. C. J. (1993). The impact of climate change on the discharge of the River Rhine. PhD thesis. Utrecht University, The Netherlands.

Langton, R. (Ed.). (1995). Artificial Life: An Overview. The MIT Press. Cambridge, Massachusetts, USA.

Lansing, S. J., and Kremer, J. N. (1993). Emergent properties of Balinese water temple networks: coadaptation on a rugged fitness landscape. American Anthopologist, 95, 97-114.

Liberatore, A. (1999). The Management of Uncertainty. Learning from Chernobyl. Gordon and Breach Publishers. Amsterdam, The Netherlands.

Limburg (2001). Liefde voor Limburg, Provinciaal Omgevingsplan Limburg (POL). Province of Limburg. Maastricht, The Netherlands.

Limburg (2003). Bedenkingennota ontwerp-POL Grensmaas en MER Grensmaas 2003. Province of Limburg. Maastricht, The Netherlands.

Loorbach, D. (2007). Transition Management: New mode of governance for sustainable development. PhD thesis. Erasmus University Rotterdam, The Netherlands.

Lotze-Campen, H. (2006). Integrated Assessment Models. In: Advanced Tools for Sustainability Assessment: webbook of the Sustainability A-Test project. <http://ivm5.ivm.vu.nl/sat/>

Lotze-Campen, H. (2008). The role of modelling tools in Integrated Sustainability Assessment (ISA). International Journal of of Innovation and Sustainable Development, 3 (1/2), 70-92.

Maaswerken (1997a). Maasvarianten. Maaswerken. Maastricht, The Netherlands.

Maaswerken (1997b). Maasvarianten: De Reacties. Maaswerken. Maastricht, The Netherlands.

Maaswerken (1998a). MER Grensmaas. Hoofdrapport A: Hoofdlijnen. Maaswerken. Maastricht, The Netherlands.

Maaswerken (1998b). MER Grensmaas. Deelrapport 8: Landschap, cultuurhistorie en archeologie. Maaswerken. Maastricht, The Netherlands.

Maaswerken (1998c). Visie Maasdal. Zandmaas/Maasroute. Maaswerken. Maastricht, The Netherlands.

Maaswerken (1998d). MER Grensmaas. Deelrapport 2: Rivierkunde. Maaswerken. Maastricht, The Netherlands.

Maaswerken (1998e). MER Grensmaas. Deelrapport 7: Delfstoffenwinning en hinder. Maaswerken. Maastricht, The Netherlands.

Maaswerken (1999a). Trajectnota/MER Zandmaas/Maasroute. Hoofdnota. Maaswerken. Maastricht, The Netherlands. 
Maaswerken (1999b). Trajectnota/MER Zandmaas/Maasroute. Huidige situatie en autonome ontwikkeling. Maaswerken. Maastricht, The Netherlands.

Maaswerken (1999c). Trajectnota/MER Zandmaas/Maasroute. Achtergronddocument Methodiek. Maaswerken. Maastricht, The Netherlands.

Maaswerken (1999d). Streekplan Grensmaas. Concept Bestuurlijke Reactie op de Bedenkingen. Maaswerken. Maastricht, The Netherlands.

Maaswerken (2001a). Plan Maasdal. Zandmaas/Maasroute. Maaswerken. Maastricht, The Netherlands.

Maaswerken (2001b). Zandmaas/Maasroute. Ontwerp-Tracebesluit en Ontwerp-POL Zandmaas. De reacties. Samenvatting van de inspraakreacties en antwoorden. Maaswerken. Maastricht, The Netherlands.

Maaswerken (2002a). Zandmaas/Maasroute. POL Zandmaas. Provinciaal Omgevingsplan Limburg. Aanvulling Zandmaas. Maaswerken. Maastricht, The Netherlands.

Maaswerken (2002b). Zandmaas/Maasroute. Tracebesluit. Maaswerken. Maastricht, The Netherlands.

Maaswerken (2003a). MER Grensmaas 2003. Hoofdrapport. Maaswerken. Maastricht, The Netherlands.

Maaswerken (2003b). MER Grensmaas 2003. Achtergronddocument 2.1: Morfologie - bureaustudie. Maaswerken. Maastricht, The Netherlands.

Maaswerken (2003c). MER Grensmaas 2003. Achtergronddocument 3: Grondwater. Maaswerken. Maastricht, The Netherlands.

Maaswerken (2004). Water level changes for the Preferred Alternative 2003. Calculated with WAQUA. Obtained from: Maaswerken, Maastricht, The Netherlands.

Martens, P. (1998). Health and climate change: modelling the impact of global warming and ozone depletion. Earthscan Publications. London, UK.

Martens, P. (2006a). Sustainability: science or fiction? Sustainability: Science, Practice, \& Policy, 2 (1), 36-41. $<$ http://ejournal.nbii.org/archives/vol2iss1/communityessay.martens.html>

Martens, P. (2006b). Integrated assessment models. In: P. Valkering, B. Amelung, R. Van der Brugge \& J. Rotmans (Eds.), More puzzle-solving for policy. International Centre for Integrated assessment and Sustainable development (ICIS), Maastricht University. Maastricht, The Netherlands.

Matthews, R., Gilbert, N., Roach, A., Polhill, G., and Gotts, N. (2007). Agent-based land-use models: a review of applications. Landscape Ecology, 22 (10), 1447-1459.

Mayer, I., and Veeneman, W. (Eds.) (2002). Games in a world of Infrastructures: Simulation-Games for research, learning and intervention. Eburon Academic Publishers. Delft, The Netherlands.

Meadows, D. H., Meadows, D. L., Randers, J., and Behrens, W. W. (1972). The limits to growth. Universe Books. New York, USA.

Middelkoop, H., and Van Haselen, C. O. G. (1999). Twice a River. Rhine and Meuse in The Netherlands. RIZA report 99.003. Arnhem, The Netherlands.

Middelkoop, H., Asselt, M. B. A. V., Klooster, S. A. V. t., Deursen, W. P. A. V., Kwadijk, J. C. J., and Buiteveld, H. (2004). Perspectives on flood management in the Rhine and Meuse Rivers. River research and applications, 20, 327-342.

MNP (2008). The Netherlands in a Sustainable World. Netherlands Environmental Assessment Agency (MNP). Report 500084003. Bilthoven, The Netherlands.

Moss, S., Pahl-Wostl, C., and Downing, T. (2001). Agent-based integrated assessment modelling: the example of climate change. The Integrated Assessment Journal, 2 (1), 17-30.

Mysiak, J., Giupponi, C., and Rosato, P. (2005). Towards the development of a decision support system for water resource management. Environmental Modelling \& Software, 20, 203-214.

Nierop, T. M. (1997). Schade in kaart. Schadeanalyse van de Maasoverstromingen 1993 en 1995 in Limburg. Masters thesis. University of Twente, Enschede, The Netherlands.

Nieuwkamer, R. L. J. (1995). Decision support for river management. PhD thesis. University of Twente, Enschede, The Netherlands.

Nordhaus, W. D. (1979). The Efficient Use of Energy Resources. Yale University Press. New Haven, Connecticut, USA.

OECD (1993). OECD Core Set of Indicators for Environmental Performance Reviews: A Synthesis Report by the Group on the State of the Environment. Organisation for Economic Co-operation and Development (OECD). Paris, France.

Otter, H., Valkering, P., and Wolters, H. (2004). Participation and Social Learning in the Meuse River: Case study report produced under Work Package 5. The HarmoniCOP project. <http://www.harmonicop.info> 
References

Pahl-Wostl, C. (2002). Participative and Stakeholder-Based Policy Design, Evaluation and Modeling Processes. The Integrated Assessment Journal, 3 (1), 3-14.

Pahl-Wostl, C., and Hare, M. (2004). Processes of Social Learning in Integrated Resource Management. Journal of Community and Apllied Social Psychology, 14, 193-206.

Pahl-Wostl, C., Craps, M., Dewulf, A., Mostert, E., Tabara, D., and Taillieu, T. (2007). Social Learning and Water Resources Management. Ecology and Society, 12 (2) 5. <http://www.ecologyandsociety.org/vol12/iss2/art5/>

Parker, P., Letcher, R., Jakeman, A., Beck, M. B., Harris, G., Argent, R. M., et al. (2002). Progress in integrated assessment and modelling. Environmental Modelling \& Software, 17 (3), 209-217.

Pereira, A. G., and Quintana, S. C. (2002). From Technocratic to Participatory Decision Support Systems: responding to the new governance initiatives. Journal of Geographic Information and Decision Analysis, 6 (2), 95-107.

Pereira, A. G., Quintana, S. C., and Funtowicz, S. (2004). GOUVERNe: new trends in decision support for groundwater governance issues. Environmental Modelling \& Software, 20, 111-118.

Ramanath, A. M., and Gilbert, N. (2004). The Design of Participatory Agent-Based Social Simulations. Journal of Artificial Societies and Social Simulation, 7 (4) 1. <http://jasss.soc.surrey.ac.uk/7/4/1.html>

Reynolds, C. W. (1987). Flocks, Herds, and Schools: A Distributed Behavioral Model. Computer Graphics, 21 (4), 25-34.

Ribberink, J. S., Hulscher, S. J. H. M., and Buijsrogge, R. H. (1999). Ondiepwaterstromingen. University of Twente. College dictaat, vakcode 221011. Enschede, The Netherlands.

Ridder, D., Mostert, E., and Wolters, H. A. (Eds.) (2005). Learning together to manage together: Improving participation in water management. University of Osnabrueck, Institute of Environmental Systems research. Osnabrück, Germany.

Rittel, H. W. J., and Webber, M. M. (1973). Dilemmas in a General Theory of Planning. Policy Sciences, 4, 155169.

RIZA (2001). Hydraulische randvoorwaarden 2001: maatgevende afvoeren Rijn en Maas. RIZA report 2002.014. Arnhem, The Netherlands.

RIZA (2005). Watertekortopgave. Eindrapportage Droogtestudie Nederland. RIZA / HKV / Arcadis / KIWA / Koerbee and Hovelynck. RIZA report 2005.015. Lelystad, The Netherlands. $<$ http://www.droogtestudie.nl>

Robinson, J. (2004). Squaring the circle? Some thoughts on the idea of sustainable development. Ecological Economics, 48, 369-384.

Rotmans, J. (1990). IMAGE: An Integrated Model to Assess the Greenhouse Effect. Kluwer Academic Publishers. Dordrecht, The Netherlands.

Rotmans, J. (1998). Methods for IA: The challenges and opportunities ahead. Environmental Modelling \& Assessment, 3 (3), 155-179.

Rotmans, J., Kemp, R., and Van Asselt, M. B. A. (2001). More evolution than revolution: transition management in public policy. Foresight, 3 (1), 15-31.

Rotmans, J., and Van Asselt, M. B. A. (2001). Uncertainty management in integrated assessment modeling: towards a pluralistic approach. Environmental Monitoring and Assessment, 69, 101-130.

Rotmans, J. (2003). Transitiemanagement: sleutel voor een duurzame samenleving. Koninklijke Van Gorcum. Assen, The Netherlands.

Rotmans, J. (2005). Societal innovation: Between dream and reality lies complexity. Inaugural speech. Erasmus University Rotterdam, The Netherlands.

Rotmans, J. (2006). Tools for Integrated Sustainability Assessment: A two-track approach. The Integrated Assessment Journal, 6 (4), 35-57.

Rotmans, J., and de Vries, H. J. M. (Eds.) (1997). Perspectives on Global Change: The TARGETS approach. Cambridge University Press. Cambridge, UK.

RWS (1994). De Maas slaat toe.... verslag hoogwater Maas december 1993. Rijkswaterstaat, Directie Limburg. Maastricht, The Netherlands.

RWS (1995). De Maas slaat weer toe.... verslag hoogwater Maas januari/februari 1995. Rijkswaterstaat, Directie Limburg. Maastricht, The Netherlands.

RWS (1999a). Digital Elevation Model of The Netherlands (AHN). State April 1st 1999. Rijkswaterstaat Meetkundige Dienst. Delft, The Netherlands. <http://www.ahn.nl>

RWS (1999b). Laagwaterbeleid. Rijkswaterstaat, Directie Limburg. Maastricht, The Netherlands. 
RWS (2000a). Sobekschematisatie Maas: Versie 2000.33. Rijkswaterstaat, Directie Limburg. Maastricht, The Netherlands.

RWS (2000b). Stage-dicharge relation at Borgharen. State 2000. Rijkswaterstaat, Directie Limburg. Maastricht, The Netherlands.

RWS (2003). Daily discharge and water level data for various stations along the Meuse (including Monsin, Borgharen, Grevenbicht) for the period 1911 - 2003. Rijkswaterstaat, Directie Limburg. Maastricht, The Netherlands.

Sabatier, P. A., and Jenkins-Smith, H. C. (1993). Policy change and learning: an advocacy coalition approach. Westview Press. Boulder, Colorado, USA.

Schilperoord, M., Rotmans, J., and Bergman, N. (2008). Modelling societal transitions with agent transformation. Computational \& Mathematical Organization Theory, 14, 283-301.

Schneider, S., and Lane, J. (2005). Integrated Assessment Modeling of Global Climate Change: Much Has Been Learned - Still a Long and Bumpy Road Ahead. The Integrated Assessment Journal, 5 (1), 41 75.

Shaw, E. M. (1994). Hydrology in practice (3rd edition). Stanly Thornes. Cheltenham, UK.

Strack, O. D. L. (1989). Groundwater Mechanics. Prentice Hall. London, UK.

Stroming (1991). Toekomst voor een grindrivier: Hoofdrapport. Bureau Stroming. Nijmegen, The Netherlands.

Stroming (1995). De Grensmaas. Ecologisch toetsingskader. Studie voor de MER Grensmaas. Bureau Stroming. Nijmegen, The Netherlands.

Stroming (2004). Bergen bij de bron. Bureau Stroming. Nijmegen, The Netherlands.

Sun, R. (Ed.). (2006). Cognition and Multi-Agent Interaction. From Cognitive Modelling to Social Simulation. Cambridge University Press. Cambridge, UK.

Tàbara, J. D., Wallman, P., Elmqvist, B., Ilhan, A., Madrid, C., Olson, L., et al. (2007). Participatory modelling for the integrated sustainability assessment of water: the world cellular model framework. The Matisse project. Working paper 9. <http://www.matisse-project.net/>

Tàbara, J. D., and Pahl-Wostl, C. (2007). Sustainability Learning in Natural Resource Use and Management. Ecology and Society, 12 (2) 3. <http://www.ecologyandsociety.org/vol12/iss2/art3/>

Tàbara, J. D., and Ilhan, A. (2008). Culture as trigger for sustainability transition in the water domain: the case of the Spanish water policy and the Ebro river basin. Regional Environmental Change, 8 (2), 59-71.

Tàbara, J. D., Roca, E., Madrid, C., Valkering, P., Wallman, P., and Weaver, P. M. (2008). Integrated sustainability assessment of water systems: lessons from the Ebro River Basin. International Journal of Innovation and Sustainable Development, 3 (1/2), 48-69.

Tàbara, J. D., and Haxeltine, A. (2008). The Transition Play. A participatory tool for exploring opportunities and contraints of sustainability transitions.

Tesfatsion, L., and Judd, K. L. (Eds.) (2006). Handbook of Computational Economics, Volume 2: Agent-Based Computational Economics. Elsevier. Amsterdam, The Netherlands.

Thompson, M., Ellis, R., and Wildavsky, A. B. (1990). Cultural Theory. Westview Press. Boulder, Colorado, USA.

Torrecilla, N. J., and Martinez-Gil, J. (2005). The new culture of water in Spain: A philosophy towards a sustainable development. E-WAter, 7/2005. <http://www.ewaonline.de/journal/2005_07.pdf>

Trompetter, P., and Kuijper, E. (1995). Watersnood in Limburg van 1900 tot nu. Van Geyt d.o.o. Ljubljana.

Tu, M., Hal, M. J., de Laat, P. J. M., and de Wit, M. J. M. (2004). Extreme floods in the Meuse river over the past century: aggravated by land-use changes? Physics and Chemistry of the Earth, 30, 267-276.

UNEP (2007). Global Environment Outlook 4. Environment for development. United Nations Environment Programme (UNEP). Nairobi, Kenya.

V\&W (1995). Deltaplan Grote Rivieren. Ministry of Transport, Public Works and Water Management. The Hague, The Netherlands.

V\&W (1997). Bestuursovereenkomst Maasproject. Ministry of Transport, Public Works and Water Management / Ministry of Agriculture, Nature and Food Quality / Province of Limburg. The Hague, The Netherlands.

V\&W (1998). Vierde Nota waterhuishouding. Ministry of Transport, Public Works and Water Management. The Hague, The Netherlands.

V\&W (2008). Nationaal Waterplan. Ministry of Transport, Public Works and Water Management. The Hague, The Netherlands. 
References

Valkering, P. (2005a). De Maaswerken in perspectief. International Centre for Integrated assessment and Sustainable development (ICIS), Maastricht University. Report 2005-2. Maastricht, The Netherlands.

Valkering, P. (2005b). IVM in perspectief. International Centre for Integrated assessment and Sustainable development (ICIS), Maastricht University. Report 2005-3. Maastricht, The Netherlands.

Valkering, P., Offermans, A., Lieshout, M. v., Rijkens, N., Brugge, R. v. d., Haasnoot, M., et al. (2008). Inspelen op verandering: Naar een robuuste en flexibele strategie voor waterbeheer. Eindrapportage Perspectieven in Integraal Waterbeheer. International Centre for Integrated assessment and Sustainable development (ICIS), Maastricht University. Maastricht, The Netherlands.

Valkering, P., Amelung, B., Brugge, R. V. d., and Rotmans, J. (Eds.) (2006). More puzzle-solving for policy. International Centre for Integrated assessment and Sustainable development (ICIS), Maastricht University. Maastricht, The Netherlands.

Van Asselt, M. B. A. (2000). Perspectives on Uncertainty and Risk : The PRIMA approach to decision support. Kluwer Academic Publishers. Dordrecht, The Netherlands.

Van Asselt, M. B. A., Middelkoop, H., Van 't Klooster, S. A., Van Deursen, W. P. A., Haasnoot, M., Kwadijk, J. C. J., et al. (2001). Development of flood management strategies for the Rhine and Meuse basins in the context of integrated river management. Report of the IRMA-SPONGE project 3/NL/1/164/991518301. International Centre for Integrated assessment and Sustainable development (ICIS), Maastricht University. Maastricht/Utrecht, The Netherlands.

Van Asselt, M. B. A., and Rijkens-Klomp, N. (2002). A Look in the Mirror: Reflection on participation in Integrated Assessment from a methodological perspective. Global Environmental Change, 12, 167-184.

Van Asselt, M. B. A., and Rotmans, J. (2002). Uncertainty in integrated assessment modelling, from positivism to pluralism. Climatic Change, 54, 75-105.

Van de Kerkhof, M., and Wieczorek, A. (2005). Learning and stakeholder participation in transition processes towards sustainability: Methodological considerations. Technological Forecasting and Social Change, 72 (6), 733-747.

Van de Ven, G. (1996). The Netherlands and its rivers. Tijdschrift voor Economische en Sociale Geografie, 87 (4), 364-370.

Van Delden, H., Luja, P., and Engelen, G. (2005). Integration of multi-scale dynamic spatial models of socioeconomic and physical processes for river basin management. Environmental Modelling \& Software, 22 (2), 223-238.

Van den Bergh, J. C. J. M., Ferrer-i-Carbonell, A., and Munda, G. (2000). Alternative models of individual behavior and implications for environmental policy. Ecological Economics, 32, 43-61.

Van der Brugge, R., Rotmans, J., and Loorbach, D. (2005). The transition in Dutch water management. Regional Environmental Change, Volume 5, 164-176.

Van der Sluijs, J. P. (1997). Anchoring amid uncertainty: On the management of uncertainties in risk assessment of anthropogenic climate change. PhD thesis. Utrecht University, The Netherlands.

Van der Sluijs, J. P. (2002). A way out of the credibility crisis of models used in integrated environmental assessment. Futures, 34, 133-146.

Van der Veen, A., and Rotmans, J. (2001). Dutch perspectives on "Agents, Regions and Land Use Change". Environmental Modeling \& Assessment, 6 (2), 83-86.

Van Deursen, W. (1999). Rapportage MEUSEFLOW 2.0. Carthago Consultancy. Rotterdam, The Netherlands.

Van Deursen, W. (2000). MEUSEFLOW 2.1: Laagwaterstudies Maasstroomgebied. Carthago Consultancy. Rotterdam, The Netherlands.

Van Deursen, W., Middelkoop, H., and Kwadijk, J. (2002). Grenzen aan de werking van bovenstroomse berging. $\mathrm{H}_{2} \mathrm{O}$ Tijdschrift voor watervoorziening en waterbeheer, nummer 5, 2002.

Van Deursen, W. (2006). Rapportage Rhineflow/Meuseflow Nieuwe KNMIscenarios 2050. Carthago Consultancy. Rotterdam, The Netherlands.

Van Deursen, W. (2007). Rapportage Rhineflow/Meuseflow Klimaatscenarios 2100. G, Gplus, W, Wplus. Carthago Consultancy. Rotterdam, The Netherlands.

Van Echoud, J. J. M. (2002). Hoogwaterbeveiliging in het Limburgse Maasdal: het middel is erger dan de kwaal. Paper presented at the symposium 'Ander zicht op de Maaswerken?' Delft University of Technology, The Netherlands.

Van Leussen, W. (2000). Maaswerken: van sectoraal plan naar adaptief proces. In: A. Driesprong, M. V. Van Ginkel, H. G. Heegstra \& W. H. M. A. Pluimakers (Eds.), Lex aquarum, liber amicorum. Opstellen 
over waterstaat, waterstaatswetgeving en wetgeving, opgedragen aan mr. J.H.A. Teulings (pp. 30-52). Ministry of Transport, Public Works and Water Management. The Hague, The Netherlands.

Van Notten, P. (2005). Writing on the Wall: Scenario development in times of discontinuity. PhD thesis. Maastricht University, The Netherlands.

Vennix, J. (1996). Group Model Building: Facilitating team learning using system dynamics. John Wiley \& Sons Ltd. Chichester, UK.

Volkskrant (1995). In de ban van het water. De Volkskrant en Kosmos-Z\&K Uitgevers. Amsterdam, The Netherlands.

VROM and V\&W (1997). Beleidslijn 'Ruimte voor de Rivier'. Ministry of Housing, Spatial Planning and the Environment / Ministry of Transport, Public Works and Water Management. The Hague, The Netherlands.

VROM (2001). Vijfde Nota over de Ruimtelijke Ordening, PKB deel 1: Ruimte maken, ruimte delen. Ministry of Housing, Spatial Planning and the Environment. The Hague, The Netherlands.

Wallman, P. (2008). The LASY model. The Matisse project. Deliverable 6.9. <http://www.matisse-project.net>

Warwick, C., and Gilbert, N. (2003). Integration report of the FIRMA project. The FIRMA project. $<$ http://cfpm.org/firma/>

WCED (1987). Our common future. Oxford University Press. New York, USA.

Weaver, P. M., and Rotmans, J. (2006). Integrated Sustainability Assessment: what it is, why do it and how? International Journal of Innovation and Sustainable Development, 1 (4), 284-303.

Weiss, G. (Ed.). (1999). Multiagent Systems: A Modern Approach to Distributed Artificial Intelligence. MIT Press. Cambridge, Massachusetts, USA

Weyden, S. (1997). Wateroverlast in het Limburgse Maasdal: Historisch onderzoek naar de relatie tussen ruimtegebruik en Maasoverstromingen. Deel 6 in de reeks Achtergrondstudies Interfacultair Onderzoeksproject Grensmaas. Wetenschapswinkel Universiteit Maastricht. Maastricht, The Netherlands.

WHM (2002). Actieplan Hoogwater Maas. Werkgroep Hoogwater Maas. Namur, Belgium.

WL (1994a). Onderzoek Watersnood Maas. Hoofdrapport: De Maas meester. WL I Delft Hydraulics for the Ministry of Transport, Public Works and Water Management. The Hague, The Netherlands.

WL (1994b). Onderzoek Watersnood Maas. Deelrapport 4: Hydrologische aspecten. WL | Delft Hydraulics for the Ministry of Transport, Public Works and Water Management. The Hague, The Netherlands.

WL (1994c). Onderzoek Watersnood Maas. Deelrapport 9: Schademodellering. WL | Delft Hydraulics for the Ministry of Transport, Public Works and Water Management. The Hague, The Netherlands.

WL (1995). AGRICOM gebruikershandleiding. WL | Delft Hydraulics. Report T1605. Delft, The Netherlands. Wooldridge, M. (1999). Intelligent Agents. In: G. Weiss (Ed.), Multiagent Systems: A Modern Approach to Distributed Artificial Intelligence. MIT Press. Cambridge, Massachusetts, USA. 


\section{Appendix A: The conditional peak method}

The conditional peak method has been developed to assess the impacts of climate change on the discharge of the River Rhine (Kwadijk, 1993). It can be used to assess potential changes in the recurrence times of peak discharges and in flow durations. The method is based on the assumption that the statistical relationships between the recurrence times and flow durations on the one hand, and average monthly discharges on the other, remain invariant under climate change. Consequently, changes are estimated on the basis of scenario time series of average monthly discharges obtained from hydrological models, such as Rhineflow (Kwadijk, 1993) and Meuseflow (Van Deursen, 1999, 2000).

\section{Theory}

\section{Recurrence times of peak discharges}

In accordance with the conditional peak method the monthly probability $p_{m}\left(Q_{p}>Q_{c}\right)$ that the peak discharge $Q_{p}$ exceeds a critical value $Q_{c}$ is written as:

$$
p_{m}\left(Q_{p}>Q_{c}\right)=\int_{0}^{\infty} p d f_{m}\left(Q_{m}\right) d Q_{m}{ }^{*} p_{Q m}\left(Q_{p}>Q_{c}\right)
$$

Here, $p d f_{m}\left(Q_{m}\right)$ is the probability that the average discharge in month $m$ lies between $Q_{m}$ and $Q_{m}$ $+d Q_{m}$, while $p_{Q m}\left(Q_{p}>Q_{c}\right)$ denotes the probability that $Q_{p}$ exceeds $Q_{c}$ given the average discharge $Q_{m}{ }^{100}$. Given a discrete time series of average monthly discharges, Equation A1 can be rewritten as:

$$
p_{m}\left(Q_{p}>Q_{c}\right)=\frac{1}{N_{m}} \sum_{Q m \rightarrow m} p_{Q m}\left(Q_{p}>Q_{C}\right)
$$

where the summation extends over all $N_{m}$ entries $Q_{m}$ in the data set corresponding to the month $m$.

Equation A2 allows a simple numerical calculation of the monthly probabilities $p_{m}$ for any given time series of average monthly discharges (whether they be a historical or scenario time series) once the probabilities $p_{Q m}$ are known. These probabilities can per definition be expressed in terms of a probability density function $p d f_{Q m}\left(Q_{p}\right)$ as:

$$
p_{Q m}\left(Q_{p}>Q_{c}\right) \equiv \int_{Q c}^{\infty} p d f_{Q m}\left(Q_{p}\right) d Q_{p}
$$

\footnotetext{
${ }^{100}$ Note that we assume the probability $p_{Q m}(Q p>Q c)$ to be equal for all months $m$, i.e. to be independent of the season of the year.
} 
Assuming that the relative peak discharges $Q_{p} / Q_{m}$ are log normal distributed, and substituting for $Q_{p} \rightarrow Y \equiv \ln \left(Q_{p} / Q_{m}\right)$, the probabilities $p_{Q m}$ can be written as:

$$
p_{Q m}\left(Q_{p}>Q_{c}\right) \equiv \frac{1}{\sigma_{Q m} * \sqrt{2^{*} \pi}} \int_{Y_{c}}^{\infty} \exp \left[-\frac{1}{2} *\left(\frac{Y-\mu_{Q m}}{\sigma_{Q m}}\right)^{2}\right] d Y,
$$

with

$Y_{c}=\ln \left(Q_{d} / Q_{m}\right)$,

$\mu_{Q m}=$ the average of $Y$ for an average discharge $Q_{m}$,

$\sigma_{Q m}=$ the standard deviation of $Y$ for an average discharge $Q_{m}$.

Substituting $Y \rightarrow X \equiv\left(Y-\mu_{Q m}\right) / \sigma_{Q m}$ one finds:

$$
p_{Q m}\left(Q_{p}>Q_{c}\right)=\frac{1}{\sqrt{2^{*} \pi}} \int_{X_{c}}^{\infty} \exp \left[-\frac{1}{2} * X^{2}\right] d X \equiv F\left(X_{c}\right)
$$

with $X_{c} \equiv \frac{Y_{c}-\mu_{Q m}}{\sigma_{Q m}}$.

The probability $p_{Q m}$ that $Q_{p}$ exceeds $Q_{c}$ for as given discharge $Q_{m}$ is thus expressed in terms of the dimensionless variable $X_{c}$. The corresponding function $F\left(X_{c}\right)$ is displayed in Figure A1. This function fully specifies the probabilities $p_{Q m}$, and hence the monthly probabilities $p_{m}$ (see Equation A2), once the parameters $\mu_{Q m}$ and $\sigma_{Q m}$ are known (i.e. derived from historical data).

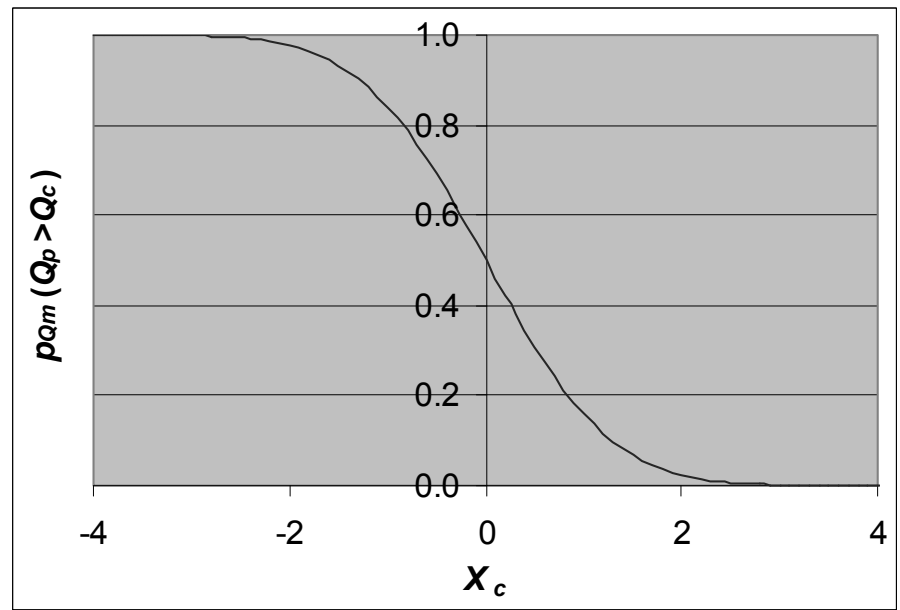

Figure A1: The probability $p_{Q m}$ that $Q_{p}$ exceeds $Q_{c}$ for as given discharge $Q_{m}$ as a function of the dimensionless variable $X_{c}$. 
We are left with deriving the yearly peak discharge probability, and consequently the recurrence times of peak discharges, from the monthly probabilities $p_{m}$. The yearly probability $P_{y}$ of a peak flood $Q_{p}$ exceeding a given discharge $Q_{c}$ equals unity minus the probability that $Q_{p}$ does not exceed $Q_{c}$ for all months $m$. When all $p_{m}$ 's are much smaller than unity (which is generally the case for high peak discharges) its value is well approximated by the summation of all monthly probabilities $p_{m}$. In formulae we write:

$$
P_{y}\left(Q_{p}>Q_{c}\right)=1-\prod_{m=1}^{12}\left(1-p_{m}\left(Q_{p}>Q_{c}\right)\right) \approx \sum_{m=1}^{12} p_{m}\left(Q_{p}>Q_{c}\right)
$$

The recurrence times of peak discharges is then simply given by:

$$
T_{\text {rec }} \equiv \frac{1}{P_{y}}
$$

\section{Flow duration curves}

Flow duration is defined as the percentage of time during which any selected discharge is being equalled or exceeded. Here we define the yearly flow duration curve $F D_{y}\left(Q>Q_{c}\right)$ as the number of days a critical discharge $Q_{c}$ is exceeded per year. It is calculated on the basis of a discrete time series of average monthly discharges $Q_{m}$ and on the monthly flow duration curves $f d_{Q m}$ that specify the average fraction of time a critical discharge $Q_{c}$ is exceeded for a month with a given average discharge $Q_{m}$. In correspondence with Equation A2 we write:

$$
F D_{y}\left(Q>Q_{c}\right)=365.25 \frac{1}{N} \sum_{Q m} f d_{Q m}\left(Q>Q_{c}\right),
$$

where the summation extends over all $N$ entries $Q_{m}$ in the data set. The number 365.25 corresponds to the average number of days per year. Again, once the monthly flow duration curves $f d_{Q m}$ are known (i.e. derived from historical data), the yearly flow duration curves are fully specified for any given time series (historical or scenario) of average monthly discharges.

\section{Application for the Meuse}

\section{Discharge data}

The conditional peak method was applied using the daily records of discharge measured at 'Borgharen dorp' for the period 1911 - 2000 (RWS, 2003). The time series is composed of the discharge measured at 8:00 AM for $1911-1974$, and of daily averaged discharges for the years $1975-2000$. For each month, the average discharge $Q_{m}$ and peak discharge $Q_{p}$ were readily obtained. Figure A2 shows the observed $Q_{p}$ for all $Q_{m}$, which gives a first indication that the two parameters correlate well. 


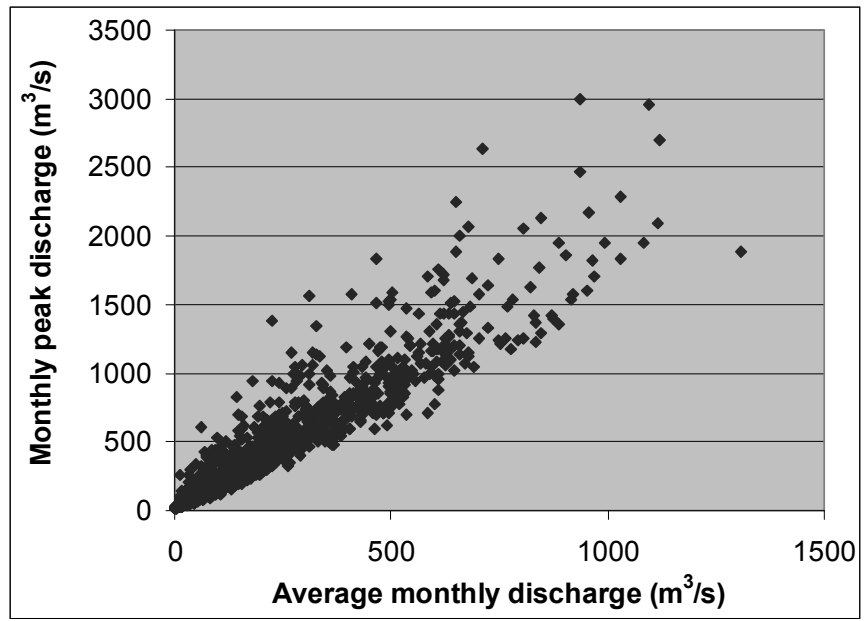

Figure A2: Monthly average discharge versus monthly peak discharge for the period 1911-2000.

\section{Estimating $\mu_{\mathrm{Qm}}$ and $\sigma_{\mathrm{Qm}}$}

The discharge data of Figure A2 was used to derive the values of the parameters $\mu_{Q m}$ and $\sigma_{Q m}$ appearing in the expression for $X_{c}$ in Equation A5. Following Kwadijk (1993), $\mu_{Q m}$ and $\sigma_{Q m}$ were determined for a number of discharge classes $k:\left\{100-300 \mathrm{~m}^{3} / \mathrm{s}\right\},\left\{300-500 \mathrm{~m}^{3} / \mathrm{s}\right\},\{500-700$ $\left.\mathrm{m}^{3} / \mathrm{s}\right\},\left\{700-900 \mathrm{~m}^{3} / \mathrm{s}\right\}$, and $\left\{>900 \mathrm{~m}^{3} / \mathrm{s}\right\}$. Within these classes, the values of $\mu_{Q m}$ and $\sigma_{Q m}$ were assumed to be constant. The $95 \%$ confidence interval for the mean $E_{\mu}$ is calculated as:

$$
E_{\mu}=1.96 * \frac{\sigma}{\sqrt{N}}
$$

with $\sigma$ the estimated standard deviation. The $95 \%$ confidence interval for $\sigma$ is estimated from the appropriate upper and lower critical values from the chi-squared distribution. The results of the analysis are displayed in Figures $\mathrm{A} 3$ and $\mathrm{A} 4$.

\section{Verification}

As a verification of the method used, the recurrence times calculated with the conditional peak method are compared in Figure $\mathrm{A} 5$ with the recurrence times obtained through a direct statistical analysis of the peak discharge data set (Gumble statistics) as described in (RIZA, 2001). The two curves form a close match. Also, the 95\% confidence intervals created by the uncertainty in $\mu$ and $\sigma$ are comparable to the $95 \%$ uncertainty intervals of RIZA, the latter adopting a somewhat broader uncertainty range on the upper side. 

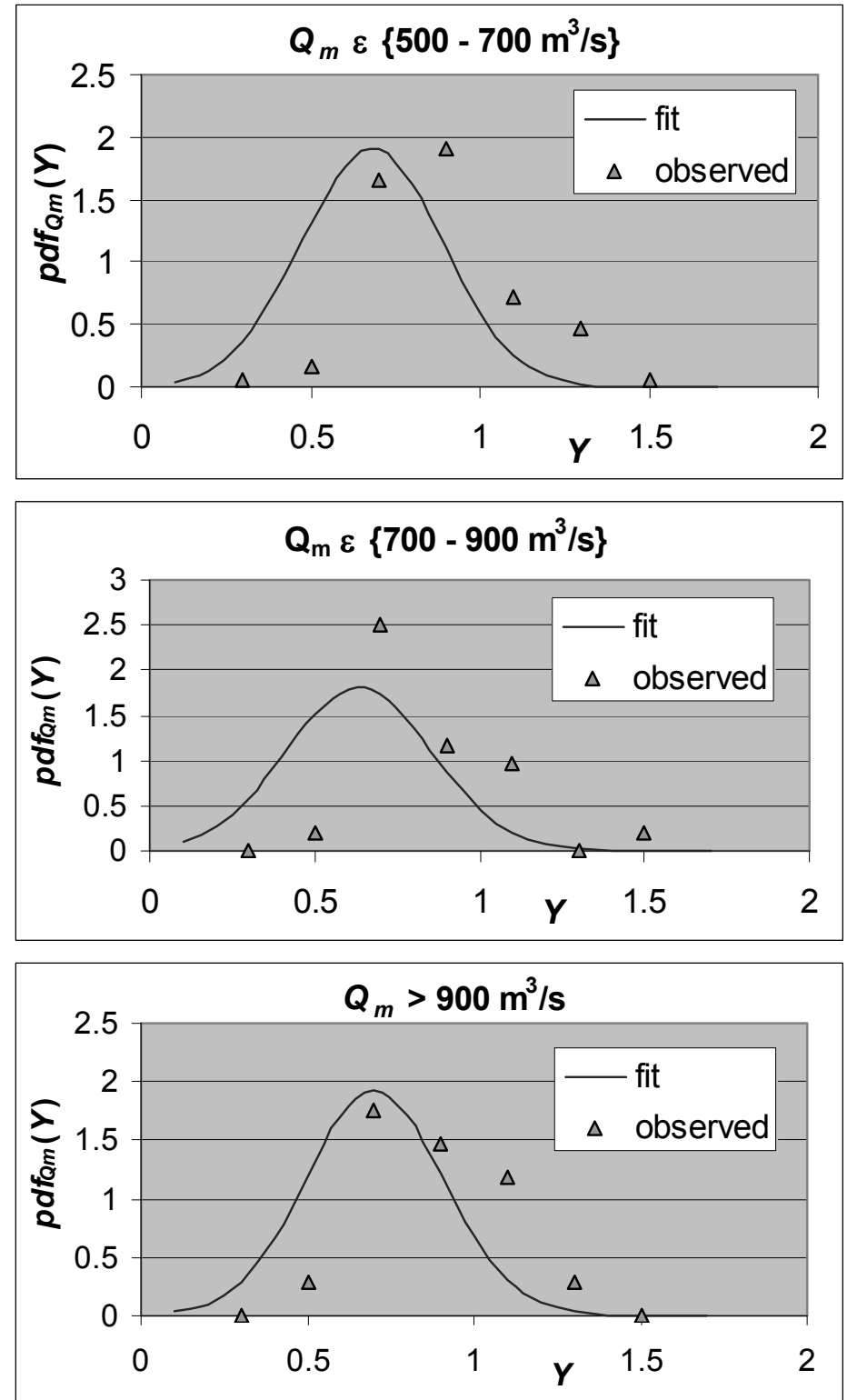

Figure A3: Observed and parametric probability density function $\left.p d f_{Q m}(Y)\right)$ of Equation A3 for the three highest discharge classes considered. 


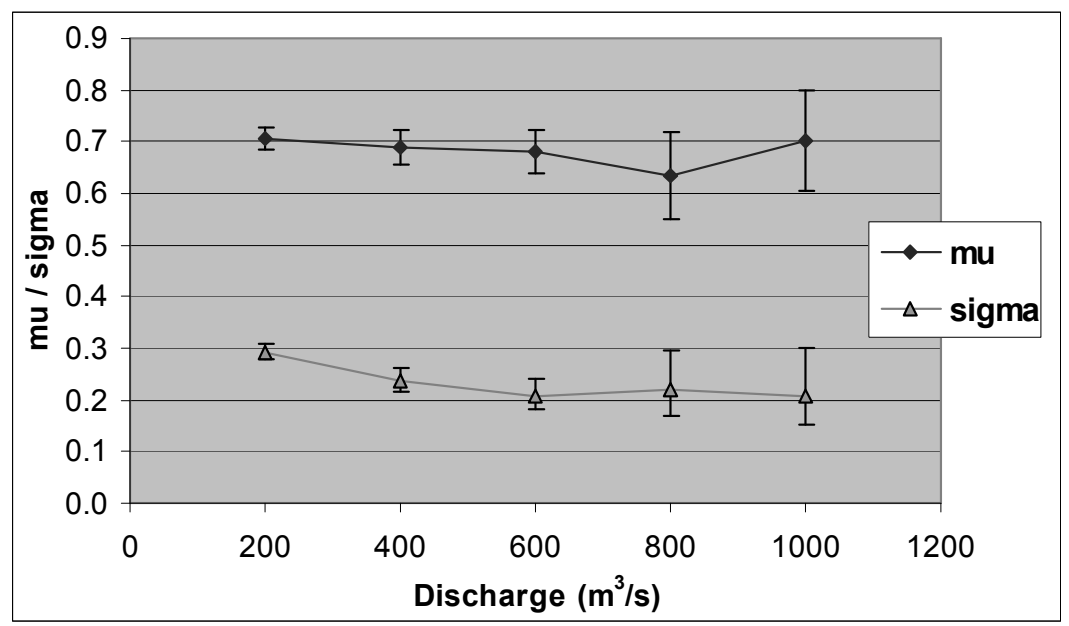

Figure A4: The values of $\mu_{\mathrm{Qm}}$ and $\sigma_{\mathrm{Q} m}$ for the different discharge classes $k$. At the discharge-scale, values denote the middle of the corresponding discharge class. The error bars correspond to the $95 \%$ confidence intervals.

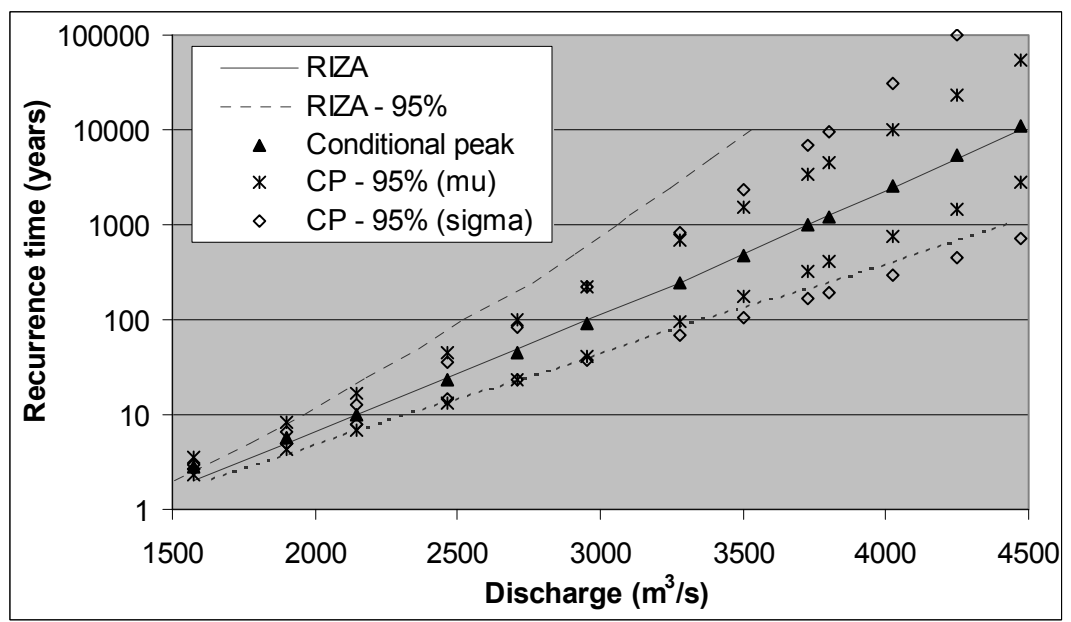

Figure A5: Recurrence times of peak discharges for the present situation calculated with the conditional peak (CP) method compared to the estimated recurrence times from (RIZA, 2001). Both the estimated recurrence times and the $95 \%$ confidence intervals form a reasonable match. 


\section{Estimating the monthly flow duration curves}

The monthly flow duration curves $f d_{Q m}\left(Q>Q_{c}\right)$ of Equation $A 8$ were determined from the daily discharge data as follows. First, the daily discharges $Q_{d}$ were divided by their corresponding average monthly discharge, to obtain a dataset of average monthly discharges $Q_{m}$ and relative daily discharges $Q_{r} \equiv Q_{d} / Q_{m}$. Then, data was subdivided along the same discharge classes as previously considered, with the discharge range $\left\{0-100 \mathrm{~m}^{3} / \mathrm{s}\right\}$ as an additional class. The corresponding flow duration curves were derived, as a function of $Q_{r}$, as the cumulative probability density functions specifying the probability of $Q_{r}$ exceeding a relative critical discharge $Q_{c}^{\prime}$. As the flow duration curves were found to be strongly homogeneous for all discharge classes above $100 \mathrm{~m}^{3} / \mathrm{s}$, eventually only two main discharge classes were distinguished: $Q_{m} \varepsilon\left\{0-100 \mathrm{~m}^{3} / \mathrm{s}\right\}$ and $Q_{m}>100 \mathrm{~m}^{3} / \mathrm{s}$. The corresponding flow duration curves are displayed in Figure A6. In contrast to the conditional peak method, these functions were not parameterized, but adopted directly in the flow duration calculations.

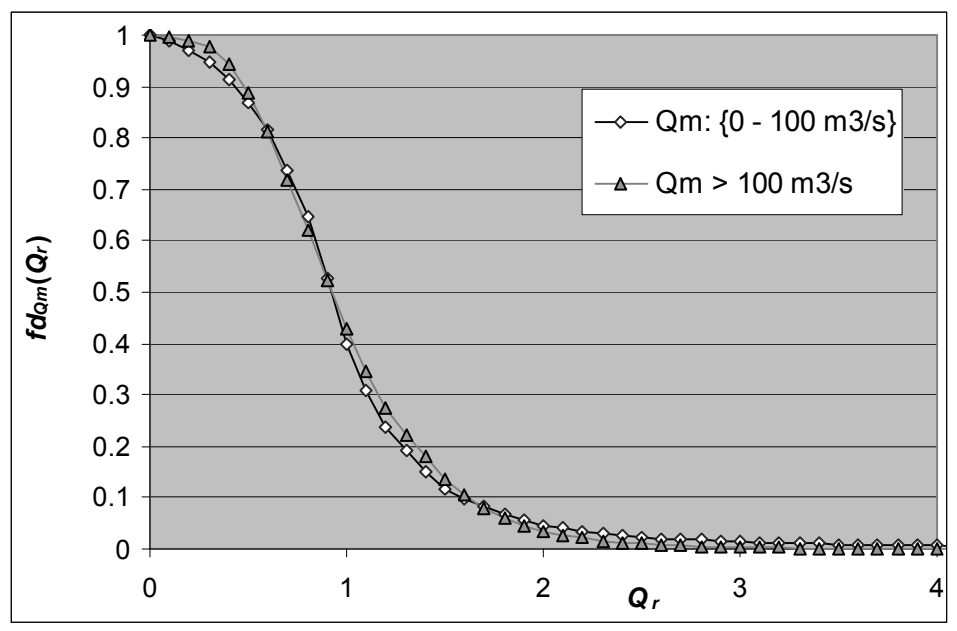

Figure A6: Flow duration curves $f d_{Q m}$ of Equation A8 as a function of the relative discharge $Q_{r} \equiv Q / Q_{m}$. The curves are derived from historical daily discharge data, considering two discharge classes $Q_{m} \varepsilon\{0-100$ $\left.\mathrm{m}^{3} / \mathrm{s}\right\}$ and $Q_{m}>100 \mathrm{~m}^{3} / \mathrm{s}$.

\section{Verification}

As verification, the yearly flow duration curves for the present situation calculated from the historical set of monthly average discharges and the derived monthly flow duration curves were compared with the flow durations obtained directly from the historical daily discharge data (see Figure A7). The two curves coincide well, illustrating the validity of the approach. 


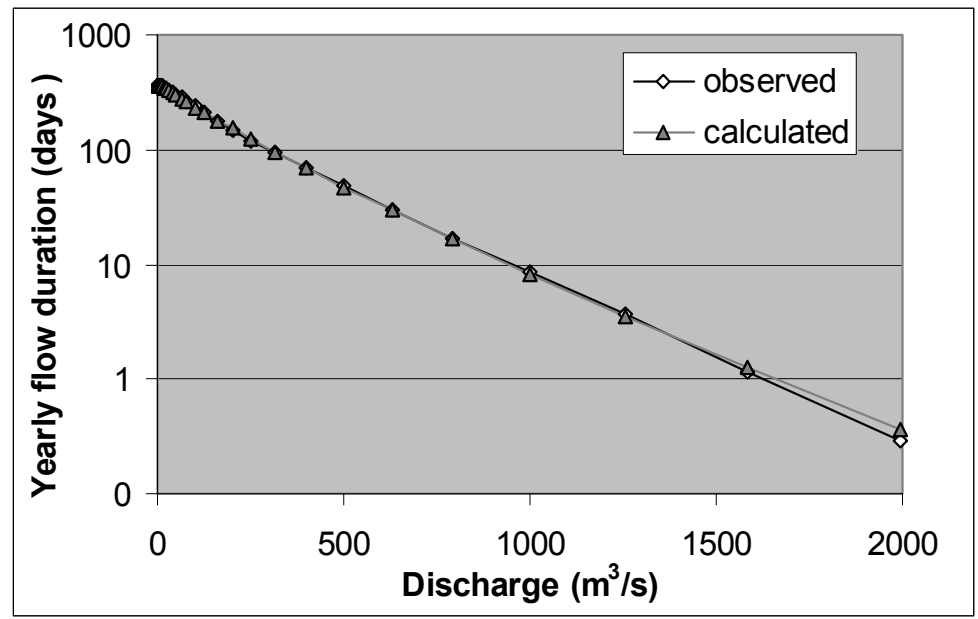

Figure A7: The yearly flow duration curve for the present situation calculated from the historical set of monthly average discharges and derived monthly flow duration curves ('calculated'), and obtained directly from the historical daily discharge data set ('observed').

\section{Discharge scenarios}

The Dutch government has adopted four climate scenarios as a standard for climate impact studies: the so-called G, G+, W, and W+ scenarios (KNMI, 2006). The effects of these climate change scenarios for the discharge of the River Meuse have been estimated by (Van Deursen, 2006, 2007), using the Meuseflow model. His estimates for monthly average discharge change (Table A1) are superposed on the historical monthly average discharge time series to obtain a new $Q_{m}$ data set representative for scenario conditions. Using the methods described above, estimates for changes in peak flow recurrence and flow duration are obtained. In addition, changes in seasonal average discharges ${ }^{101}$ are discussed.

The results are displayed in Table A2 and Figures A8 and A9. Some main observations are:

- Under all scenarios, peak flow recurrence increases. Estimates for the increase of the design discharge $Q_{1: 250}{ }^{102}$ range from 2 to $9 \%$ in 2050 , and 4 to $17 \%$ in 2100 , with the G+ and $\mathrm{W}$ scenarios providing the lower and upper limit respectively.

- Regarding flow durations, the $\mathrm{G}$ and $\mathrm{W}$ scenarios foresee a slightly higher river flow. The G+ and $\mathrm{W}+$ scenarios, however, foresee a signification increase of drought. In the $\mathrm{W}+$ scenario, in particular, the number of days the discharge falls below the critical level of $50 \mathrm{~m}^{3} / \mathrm{s}$

\footnotetext{
101 Three seasons are defined: winter (October - March), spring (April - June), and summer (July September).

${ }^{102}$ The discharge corresponding to a recurrence time of 250 years
} 
increases with some 30\% in 2050 (from 50 to 80 days/year) and with $40 \%$ in 2100 (to $\sim 90$ days/year).

- The same trends are reflected in the seasonal average discharges. Under the $G$ and $W$ scenarios, minor increases of average discharges are foreseen, notably in winter. In the G+ and $\mathrm{W}+$ scenarios, the spring and winter discharges hardly change, but the summer discharge decreases sharply, down to $32 \%$ in the $W+$ scenario (2100).

\begin{tabular}{|l|l|l|l|l|l|l|l|l|}
\hline Month & \multicolumn{7}{|l}{ KNMI 2050} & KNMI 2100 \\
\hline & G & G+ & W & W+ & G & G+ & W & W+ \\
\hline jan & 4.8 & 4.2 & 9.5 & 8.6 & 9.5 & 8.7 & 18.4 & 17.5 \\
\hline feb & 4.1 & 4.7 & 8.0 & 9.5 & 8.0 & 9.6 & 16.1 & 20.4 \\
\hline mar & 2.9 & 4.8 & 6.4 & 10.3 & 6.4 & 10.3 & 13.8 & 23.0 \\
\hline apr & 2.4 & 2.6 & 5.6 & 6.2 & 5.6 & 6.3 & 12.4 & 14.8 \\
\hline may & 2.0 & -2.3 & 5.1 & -2.9 & 5.1 & -2.8 & 11.7 & -1.9 \\
\hline jun & 2.0 & -8.5 & 5.2 & -13.5 & 5.2 & -13.6 & 12.0 & -18.4 \\
\hline jul & 1.5 & -13.7 & 4.5 & -22.4 & 4.6 & -22.3 & 11.0 & -30.9 \\
\hline aug & 0.8 & -16.1 & 3.7 & -24.8 & 3.7 & -24.8 & 9.8 & -30.7 \\
\hline sep & 1.5 & -16.9 & 5.0 & -25.5 & 5.1 & -25.6 & 12.5 & -35.7 \\
\hline oct & 2.7 & -20.8 & 5.8 & -35.7 & 5.8 & -35.6 & 12.1 & -50.7 \\
\hline nov & 4.4 & -13.4 & 8.3 & -25.9 & 8.6 & -24.4 & 16.4 & -39.8 \\
\hline dec & 5.1 & -0.4 & 9.5 & -2.2 & 9.5 & -1.6 & 18.0 & -4.0 \\
\hline
\end{tabular}

Table A1: Changes in average monthly discharges (\%) for the G, G+, W, and W+ scenarios of (KNMI, 2006) calculated with the Meuseflow model (Van Deursen, 2006, 2007).

\begin{tabular}{|l|l|l|l|l|l|l|l|l|}
\hline & \multicolumn{6}{|l}{ KNMI 2050 } & \multicolumn{2}{l|}{ KNMI 2100 } \\
\hline & G & G+ & W & W+ & G & G+ & W & W+ \\
\hline $\mathbf{Q}_{\text {spring }}$ & 2.2 & -1.2 & 5.4 & -0.6 & 5.4 & -0.5 & 12.1 & 2.9 \\
\hline $\mathbf{Q}_{\text {winter }}$ & 4.2 & -0.2 & 8.3 & 0.0 & 8.3 & 0.3 & 16.4 & 3.6 \\
\hline $\mathbf{Q}_{\text {summer }}$ & 1.3 & -15.5 & 4.4 & -24.1 & 4.5 & -24.1 & 11.1 & -32.4 \\
\hline
\end{tabular}

Table A2: Estimated seasonal discharge change (\%) for the G, G+, W, W+ scenarios in 2050 and 2100. 

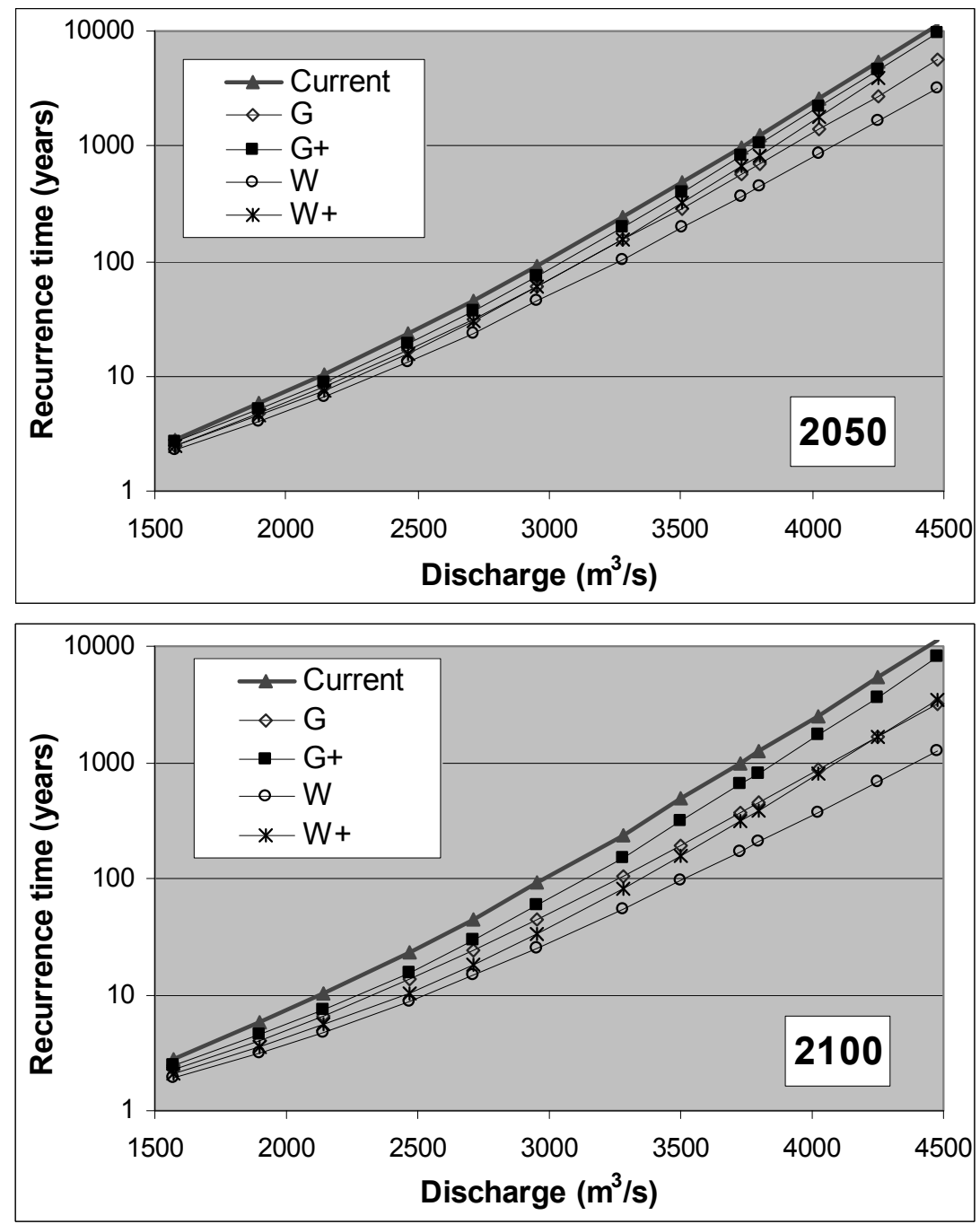

Figure A8: Estimated peak discharge recurrence times for the G, G+, W, W+ scenarios in 2050 and 2100. 

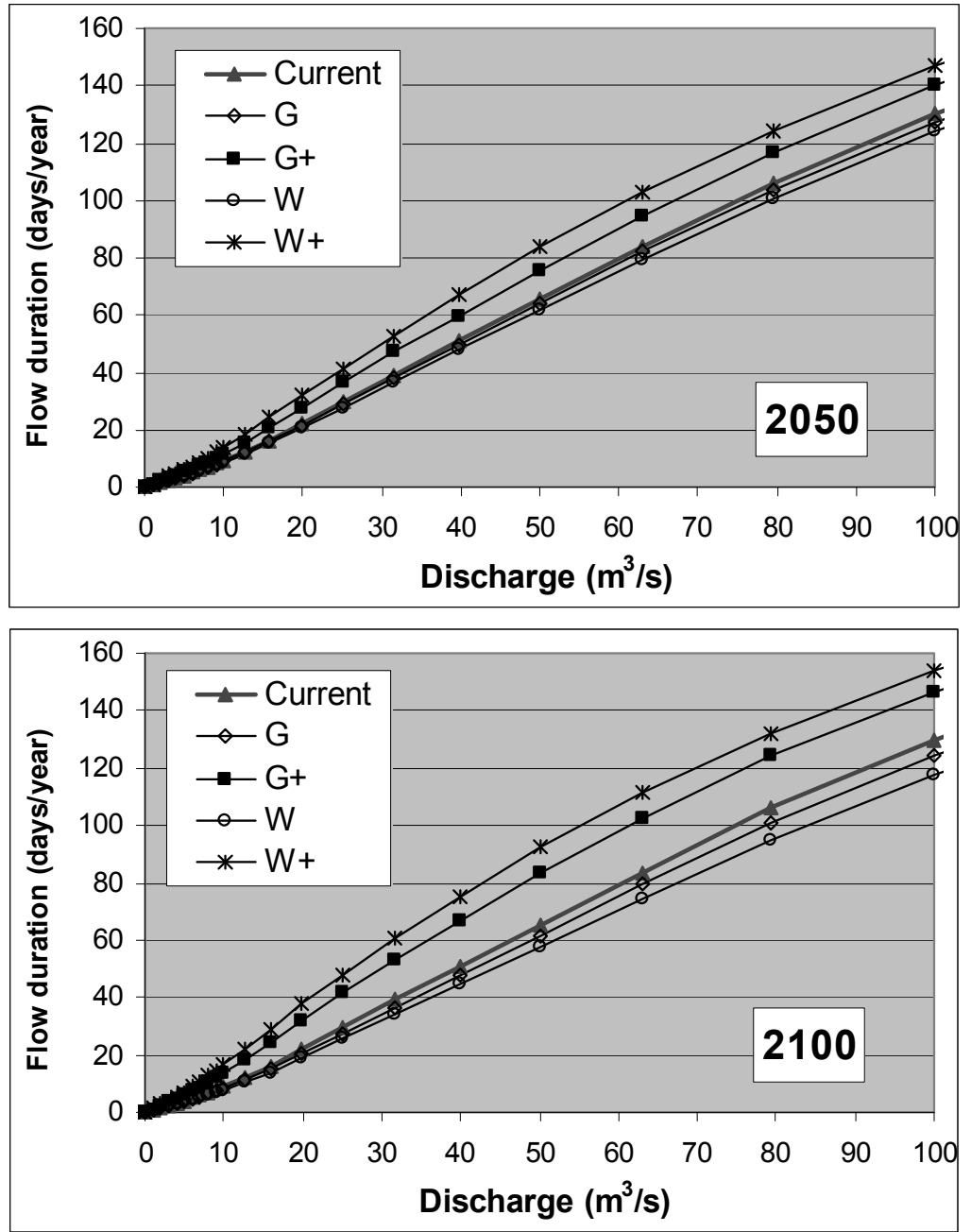

Figure A9: Estimated flow durations (days/year discharge falls below given levels) for the G, G+, W, W+ scenarios in $\mathbf{2 0 5 0}$ and $\mathbf{2 1 0 0 .}$ 


\section{Appendix B: Schematisation of the location Borgharen}

The river engineering alternatives proposed by the project organisation Maaswerken are designed for a sequential set of distinct locations along the river Meuse. The integrated River Model of Chapter 5 was applied for one of those locations, namely the location Borgharen. In this appendix we show how this location was schematised.

Borgharen is a village with approximately 2000 inhabitants that lies just North of the city of Maastricht. The location surrounding Borgharen is bounded by the Grensmaas in the West, the Juliana Canal in the East, and ends just below the village of Itteren, see Figure B1. This area is used primarily for agricultural purpose and its current natural value is considered to be low. The Maaswerken organisation currently proposes a number of river engineering measures, such as main channel broadening, floodplain excavation, clay storage and additional nature area.

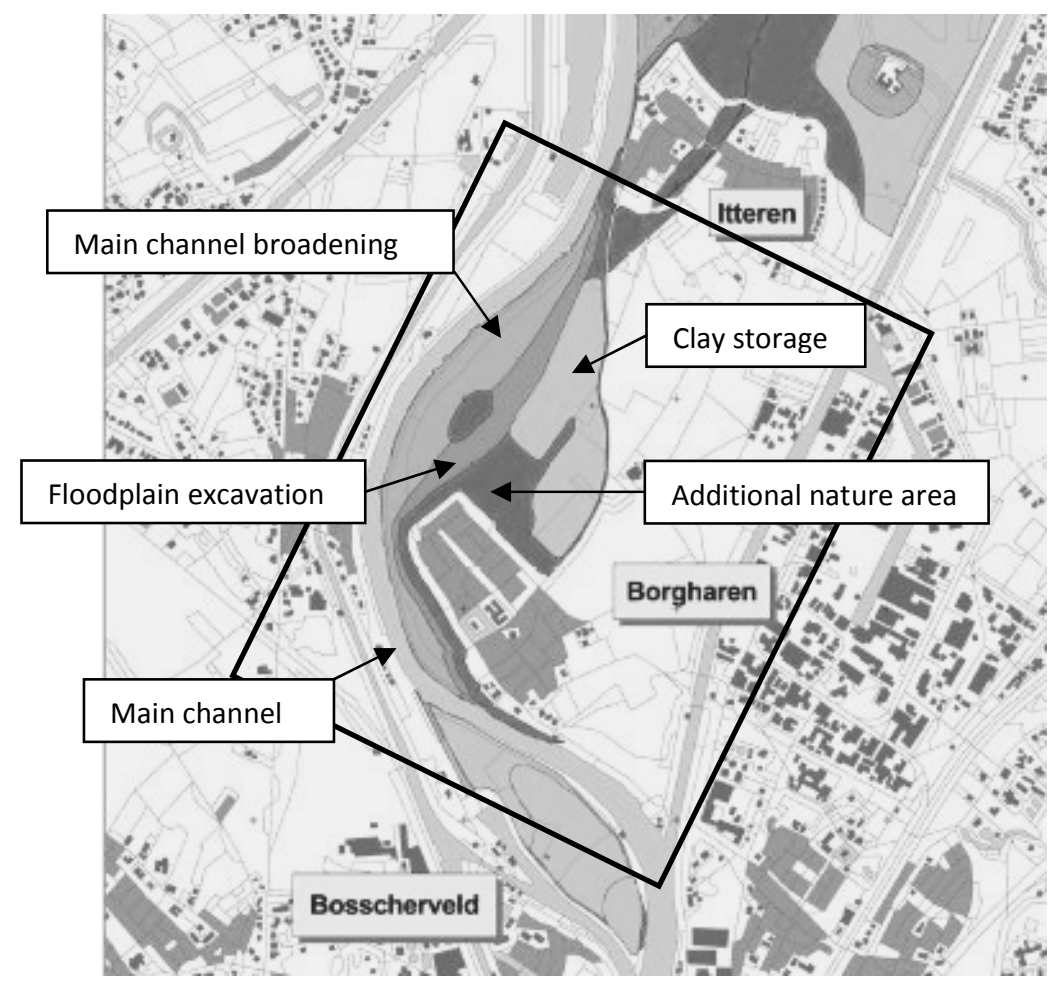

Figure B1: The location Borgharen is bounded by the Grensmaas in the West, the Juliana Canal in the East, and the village of Itteren in the North. The picture shows the Preferred Alternative of 2003 (Maaswerken, 2003a). 


\section{Cross-section dimensions}

The cross-section dimensions are represented with the curved geometry shown in Figure B2. This geometry was chosen to represent the dimensions of a river management location in the most realistic way, with a realistic representation of both river length and surface area.

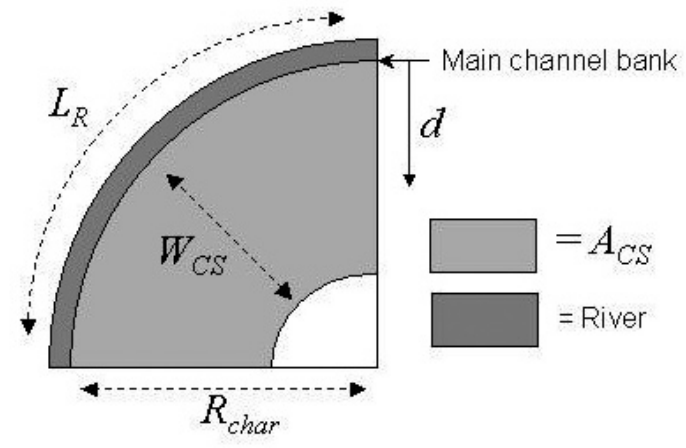

Figure B2: The schematisation of the cross-section geometry. $L_{R}$ indicates the river length, $W_{c S}$ the typical cross-section width, $\boldsymbol{R}_{\text {char }}$ the characteristic radius, $\boldsymbol{A}_{c S}$ the cross-section area, and $\boldsymbol{d}$ the distance from the original main channel bank.

The curved geometry is characterized by the cross-section area $A_{C S}$, the river length $L_{R}$, and a typical cross-section width $W_{C S}$. These parameters determine the characteristic cross-section radius $R_{\text {char }}$. A simple geometric calculation shows that:

$$
R_{\text {char }}=\frac{1}{2} W_{C S} * \frac{1}{1-f}, \text { with } f \equiv \frac{A_{C S}}{L_{R}{ }^{*} W_{C S}}
$$

In the curved geometry, the cross-section length $L$ decreases when moving away from the river. At a distance $d$ from the original main channel bank the cross-section length $L$ is then given by:

$$
L(d)=L_{R} *\left(1-\frac{d}{R_{\text {char }}}\right)
$$

The cross-section area $A$ as a function of the distance $d$ is obtained through integration over Equation B2:

$$
A(d)=L_{R} * \int_{0}^{d}\left(1-\frac{D}{R_{c h a r}}\right) d D=L_{R} * d^{*}\left(1-\frac{d}{2 R_{c h a r}}\right)
$$

\section{Geographic data}

\section{Cross-section dimensions}

The cross-section dimensions for the location of Borgharen listed in Table B1 were derived as follows: 
- $\quad$ The total cross-section area was derived from a digital land use map (Alterra, 1999).

- The river length (2800 $\mathrm{m}$ ) was obtained from river maps, for example (Maaswerken, 2003a).

- The cross-section width was chosen as the actual location width at river kilometre 18.4.

- The characteristic radius follows from Equation B1.

\begin{tabular}{|l|l|}
\hline Parameter & Value \\
\hline Cross-section area $\left(A_{C S}\right)$ & 358 ha \\
\hline River length $\left(L_{R}\right)$ & $2800 \mathrm{~m}$ \\
\hline Cross-section width $\left(W_{C S}\right)$ & $1700 \mathrm{~m}$ \\
\hline Characteristic Radius $\left(R_{\text {char }}\right)$ & $3426 \mathrm{~m}$ \\
\hline
\end{tabular}

Table B1: Cross-section dimensions

\section{Land use}

The land use map of the location Borgharen was derived from (Alterra, 1999) and is shown in Figure B3. The surface areas of the different land use types considered are displayed in Table B2. The corresponding widths follow from Equation B3, assuming a specific sequence of land use types. In our case we assume grassland to be located closest to the river, followed by arable land, natural land, infrastructure and inhabited area, see Figure B3.

\begin{tabular}{|l|l|l|}
\hline Land use & Area (ha) & Corresponding width (m) \\
\hline Grassland & 128 & 608 \\
\hline Arable land & 154 & 731 \\
\hline Natural land & 21 & 100 \\
\hline Infrastructure & 15 & 71 \\
\hline Housing area & 40 & 190 \\
\hline Total & $\mathbf{3 5 8}$ & $\mathbf{1 7 0 0}$ \\
\hline
\end{tabular}

Table B2: Land use areas and the corresponding widths.
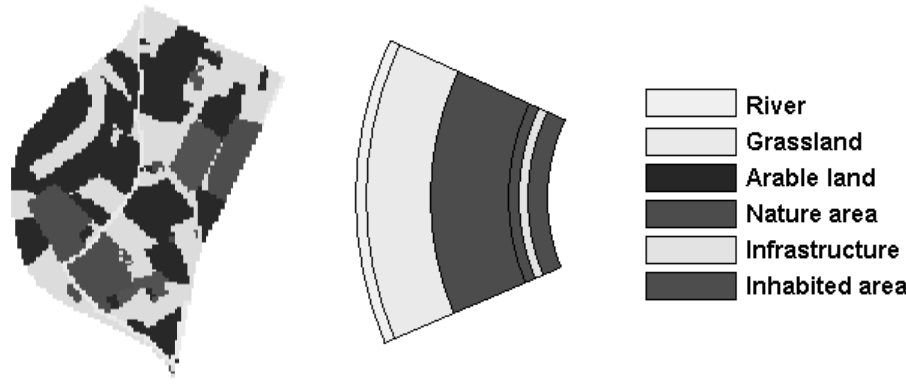

Figure B3 The original land use map of the location Borgharen (left) and the adopted schematisation (right) 


\section{Elevation}

The floodway elevation was initially schematised in accordance with the floodplain elevation in the hydraulic schematisation at $\mathbf{4 4 . 4}$ meter. This elevation is in reasonable correspondence with the floodplain elevation found from the digital elevation model (RWS, 1999a), see Figure B4. The elevations of the flood fringe and housing area are schematised at 44.6 and 45 meter respectively on the basis of a rough visual inspection of the elevation model.

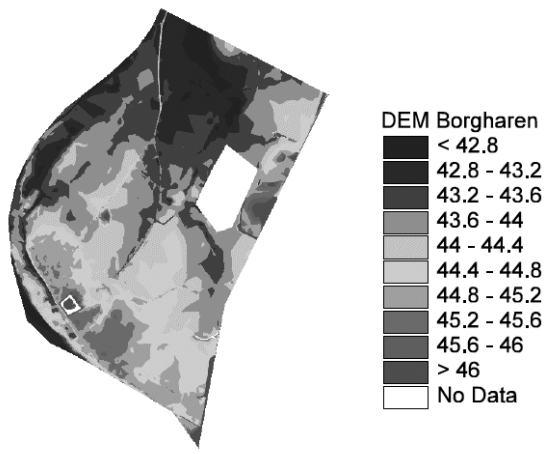

Figure B4: The digital elevation model for the location Borgharen

\section{Soil}

We assume constant thickness of the clay and toutvenant layers throughout the cross-section area. Their values are displayed in Table 5.7. These values were derived from a combination of Maaswerken expert judgement in combination with estimations of total clay/toutvenant production for a given surface areas (Maaswerken, 2003a).

\section{Hydraulic schematisation}

The hydraulic schematisation was derived from 8 SOBEK profiles (RWS, 2000a) pertaining to the location of Borgharen (river kilometre $16-19.8$ ). An example of such a profile is displayed in Table B3. The SOBEK profiles are translated to the composite rectangular cross-section representation of the iRM. We thereby consider the three sections relevant in the current situation: 'main channel', 'floodway' and 'housing area'.

The following procedure was used:

- $\quad$ First, all 8 SOBEK profiles were aggregated into an average SOBEK profile for the location of Borgharen. To this end, the profiles were homogenized to a common reference height of the lowest mark $h 1$. Then, the heights and floodway widths for the consecutive marks were averaged, arriving at the average SOBEK profile displayed in Figure B5.

- The sections 'main channel' and 'riverbank' of the average profile were considered representative for the main channel parameters of the iRM cross-section, and the section 'floodplain' was considered representative for the floodway parameters.

- The main channel width $(89 \mathrm{~m})$ was taken as the average floodway width of the SOBEK profile. 


\begin{tabular}{|c|c|c|c|}
\hline & Mark & Height (m NAP) & Floodway width (m) \\
\hline \multirow{5}{*}{ 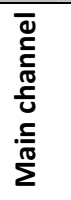 } & $\mathrm{h}_{1}$ & 36.82 & 14 \\
\hline & $\mathrm{h}_{2}$ & 38.21 & 85 \\
\hline & $h_{3}$ & 39.59 & 102 \\
\hline & $\mathrm{h}_{4}$ & 40.98 & 105 \\
\hline & $h_{5}$ & 42.36 & 106 \\
\hline \multirow{3}{*}{$\frac{\pi}{\frac{0}{2}}$} & $\mathrm{~h}_{6}$ & 42.78 & 120 \\
\hline & $\mathrm{h}_{7}$ & 43.19 & 121 \\
\hline & $h_{8}$ & 43.61 & 122 \\
\hline \multirow{7}{*}{$\begin{array}{l}\frac{5}{\pi} \\
\frac{\pi}{2} \\
\frac{0}{0} \\
\frac{0}{4}\end{array}$} & $\mathrm{~h}_{9}$ & 43.71 & 133 \\
\hline & $\mathrm{h}_{10}$ & 43.81 & 134 \\
\hline & $\mathrm{h}_{11}$ & 43.82 & 163 \\
\hline & $\mathrm{h}_{12}$ & 44.18 & 174 \\
\hline & $h_{13}$ & 44.54 & 284 \\
\hline & $\mathrm{h}_{14}$ & 44.9 & 376 \\
\hline & $\mathrm{h}_{15}$ & 45.26 & 528 \\
\hline
\end{tabular}

Table B3: The SOBEK hydraulic profile at Borgharen (river kilometre 16.0). After (RWS, 2000a).

- The main channel depth $(7.2 \mathrm{~m})$ was deduced from a assumed constant main channel volume.

- Schematising the main channel elevation at $37.2 \mathrm{~m}$ (in correspondence with the zero point value of the stage-discharge relation) implies a floodway elevation of $44.4 \mathrm{~m}$.

- The floodway width (550 m), finally, was deduced from an assumed constant flow volume over the floodway area, and adopting a maximum flow height in correspondence with the maximum height $h_{15}$ of the average profile.

- $\quad$ The profile parameters were fine-tuned through calibration, see Section 5.4.3.

- The main channel roughness is obtained from the WAQUA schematisation (Ron Agtersloot, pers. comm.).

- The floodway roughness is obtained from the SOBEK schematisation (RWS, 2000a).

- The height of the current embankment around Borgharen was initially set at $0.7 \mathrm{~m}$ (according to expert judgement) and later fine tuned $(0.6 \mathrm{~m})$ to achieve a flood recurrence of 1:50 years for the current situation.

The results are summarized in Table B4 and Figure B5.

\begin{tabular}{|l|l|l|l|l|}
\hline Section & $\begin{array}{l}\text { Elevation }(\mathrm{m} \\
\text { NAP) }\end{array}$ & Width $(\mathrm{m})$ & $\begin{array}{l}\text { Hydraulic } \\
\text { roughness }(\mathrm{m})\end{array}$ & $\begin{array}{l}\text { Embankment } \\
(\mathrm{m})\end{array}$ \\
\hline Main channel & 37.2 & $89(81)$ & 0.12 & 0 \\
\hline Floodway & $44.4(44.1)$ & $550(575)$ & 0.2 & 0 \\
\hline Flood fringe & 44.6 & $850(825)$ & - & 0 \\
\hline Housing area & 45 & 300 & - & $0.7(0.6)$ \\
\hline
\end{tabular}

Table B4: The hydraulic schematisation for the current situation. Values in parentheses are the finally adopted values obtained through calibration. 


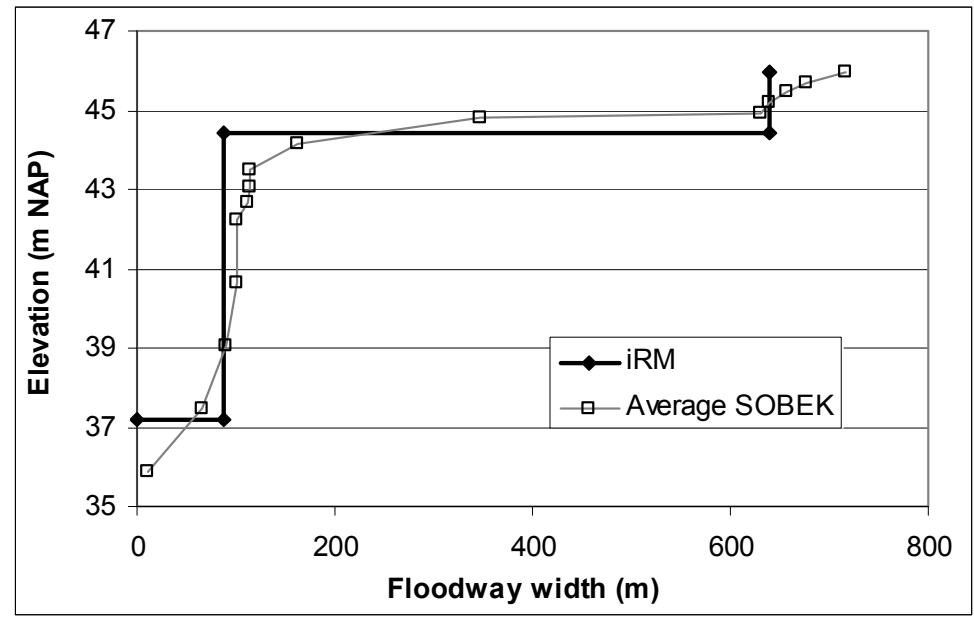

Figure B5: SOBEK profiles near the location of Borgharen and the composite rectangular cross-section applied in the iRM. Some SOBEK profiles used are omitted from the graph for clarity.

\section{Schematisation of river management strategies}

The historical river management strategies 'Green for Gravel' of 1991 (GFG1991), 'Preferred alternative' of 1998 (PA1998) and 'Preferred alternative' of 2003 (PA2003) are documented in (Stroming, 1991), (Maaswerken, 1998a), and (Maaswerken, 2003a) respectively. This data was used to derive iRM river management strategies with the following procedure:

- Main channel elevation was proposed only for the Green for Gravel strategy (roughly $1 \mathrm{~m}$ elevation).

- The data for main channel broadening, floodplain lowering, and additional nature area were specified in terms of surface areas. The surface areas are translated to corresponding widths by means of Equation B3. The reported areas for clay storage are included as natural area.

- No strategy incorporated dike-building.

- The estimated elevation of the broadened main channel $E_{M C B}$ roughly equals $1-1.2 \mathrm{~m}$ above main channel height. We adopt $E_{M C B}=38.3 \mathrm{~m}$ NAP.

- Brink elevation is chosen as the thickness of the clay layer $(1.9 \mathrm{~m})$

- The clay storage position is schematised at the end of additional nature area for PA1998 and PA2003 and at the end of the area of flood plain lowering for GVG1991.

- $\quad$ The clay storage surface depths are listed in Table B5. 


\begin{tabular}{|l|l|l|l|l|}
\hline & & GFG1991 & PA1998 & PA2003 \\
\hline \multirow{4}{*}{$\begin{array}{l}\text { Strategy } \\
\text { variables }\end{array}$} & $M C D$ & -1 & 0 & 0 \\
\cline { 2 - 5 } & $M C B$ & $127(35 \mathrm{ha})$ & $150(41 \mathrm{ha})$ & $136(37 \mathrm{ha})$ \\
\cline { 2 - 5 } & $\boldsymbol{F P E}$ & $295(76 \mathrm{ha})$ & $130(34 \mathrm{ha})$ & $77(20 \mathrm{ha})$ \\
\cline { 2 - 5 } & $A N A$ & 0 & $160(40 \mathrm{ha})$ & $259(65 \mathrm{ha})$ \\
\cline { 2 - 5 } & $D B$ & 0 & 0 & 0 \\
\hline \multirow{4}{*}{$\begin{array}{l}\text { Strategy } \\
\text { constants }\end{array}$} & $E_{M C B}$ & 38.3 & 38.3 & 38.3 \\
\cline { 2 - 5 } & $E_{b}$ & 1.9 & 1.9 & 1.9 \\
\cline { 2 - 5 } & $C S_{p}$ & 422 & 440 & 472 \\
\cline { 2 - 5 } & $C S_{d}$ & 0 & 0 & 2.4 \\
\hline
\end{tabular}

Table B5: Schematisation of the historically proposed river management strategies 'Green for Gravel' (1991), 'Preferred Alternative 1998' and 'Preferred Alternative 2003'. All values in meters. 


\section{Appendix C: The hydraulic effectiveness parameter}

Introducing the dimensionless lengths

$$
\begin{gathered}
x_{1} \equiv-I_{w} / L_{a}, \\
x_{2} \equiv-\left(I-I_{w}\right) / L_{a}, \\
x \equiv x_{1}+x_{2}
\end{gathered}
$$

and the maximum water level change

$$
\Delta h \equiv h_{n}-h_{w}
$$

we write for the water levels at the successive nodes:

$$
\begin{aligned}
& h_{0}=h_{n} \\
& h_{1}=h_{w}+\left(h_{0}-h_{w}\right)^{*} e^{x 1}=h_{w}+\Delta h^{*} e^{x 1} \\
& h_{2}=h_{n}+\left(h_{1}-h_{n}\right)^{*} e^{x 2}=h_{n}+\left(h_{w}+\Delta h^{*} e^{x 1}-h_{n}\right)^{*} e^{x 2}=h_{n}+\Delta h^{*}\left(e^{x 1}-1\right)^{*} e^{x 2} \\
& =h_{n}+\Delta h^{*}\left(e^{x}-e^{x 2}\right) \\
& h_{3}=h_{w}+\left(h_{2}-h_{w}\right)^{*} e^{x 1}=h_{w}+\left(h_{n}+\Delta h\left(e^{x}-e^{x 2}\right)-h_{w}\right)^{*} e^{x 1}=h_{w}+\Delta h\left(e^{x}-e^{x 2}+1\right)^{*} e^{x 1}= \\
& h_{w}+\Delta h\left(e^{x+x 1}-e^{x}+e^{x 1}\right) \\
& h_{4}=h_{n}+\left(h_{3}-h_{n}\right)^{*} e^{x 2}=h_{n}+\Delta h\left(e^{x+x 1}-e^{x}+e^{x 1}-1\right)^{*} e^{x 2}= \\
& h_{n}+\Delta h\left(e^{2 x}-e^{x+x 2}+e^{x}-e^{x 2}\right) \\
& h_{5}=h_{w}+\left(h_{4}-h_{w}\right)^{*} e^{x 1}=h_{w}+\left(h_{n}+\Delta h\left(e^{2 x}-e^{x+x 2}+e^{x}-e^{x 2}+1\right)^{*} e^{x 1}=\right. \\
& =h_{w}+\Delta h\left(e^{2 x+x 1}-e^{2 x}+e^{x+x 1}-e^{x}+e^{x 1}\right) \\
& h_{6}=h_{n}+\left(h_{5}-h_{n}\right)^{*} e^{x 2}=h_{n}+\Delta h\left(e^{2 x+x 1}-e^{2 x}+e^{x+x 1}-e^{x}-1\right)^{*} e^{x 2}= \\
& h_{n}+\Delta h^{*}\left(e^{3 x}-e^{2 x+x 2}+e^{2 x}-e^{x+x 2}+e^{x}-e^{x 2}\right) \\
& \text { and so on } \ldots
\end{aligned}
$$

For arbitrary nodes $2 \mathrm{~N}$ and $2 \mathrm{~N}+1$ one thus finds:

$$
h_{2 N}=h_{n}+\Delta h^{*}\left[\sum_{i=1}^{N} e^{i x}-e^{x 2} * \sum_{i=0}^{N} e^{i x}\right]=h_{n}-\Delta h^{*}\left[1-\sum_{i=0}^{N} e^{i x}\left(1-e^{x 2}\right)\right],
$$




$$
h_{2 N+1}=h_{w}+\Delta h^{*}\left[e^{x 1} \sum_{i=0}^{N} e^{i x}-\sum_{i=1}^{N} e^{i x}\right]=h_{n}-\Delta h^{*} \sum_{i=0}^{N} e^{i x}\left(1-e^{x 1}\right) .
$$

Using the summation rule:

$$
\sum_{i=0}^{\infty} x^{i}=\frac{1}{1-x} \quad(0 \leq x<1)
$$

one finds for the limits $i \rightarrow \infty$ :

$$
\begin{gathered}
\lim _{i \rightarrow \infty} h_{2 i}=h_{n}-\Delta h^{*}\left[1-\frac{\left(1-e^{x 2}\right)}{\left(1-e^{x}\right)}\right]=h_{n}-\Delta h^{*} \frac{\left(e^{x 2}-e^{x}\right)}{\left(1-e^{x}\right)} \\
\lim _{i \rightarrow \infty} h_{2 i+1}=h_{n}-\Delta h * \frac{\left(1-e^{x 1}\right)}{\left(1-e^{x}\right)} .
\end{gathered}
$$

If we define the actual water level as:

$$
h_{\mathrm{act}} \equiv \lim _{i \rightarrow \infty} h_{2 i+1}
$$

and defining the fraction of river length where measures are carried out:

$$
f \equiv \frac{I_{w}}{l} \equiv \frac{x_{1}}{x}
$$

and the dimensionless adaptation length:

$$
L \equiv \frac{L_{a}}{l} \equiv-\frac{1}{x}
$$

one finds for the for the effectiveness parameter:

$$
E f_{\mathrm{i}=\mathrm{odd}} \equiv \frac{h_{n}-h_{\mathrm{act}}}{\Delta h}=\frac{1-e^{-f / L}}{1-e^{-1 / L}}
$$

Otherwise, defining the actual water level as:

$$
h_{\text {act }} \equiv \lim _{i \rightarrow \infty} h_{2 i},
$$

one would find:

$$
\text { Eff }_{\mathrm{i}=\text { even }}=\frac{e^{-(1-f) / L}-e^{-1 / L}}{1-e^{-1 / L}}
$$




\section{Appendix D: Stakeholder participation}

\section{Stakeholder interviews}

\begin{tabular}{|l|l|l|l|}
\hline Organization & Interviewee & $\begin{array}{l}\text { Involveme } \\
\text { nt }^{{ }^{2}}\end{array}$ & Date interview \\
\hline Municipality of Venlo & Dhr. Verbart & ZM & $21 / 9 / 2001$ \\
\hline Municipality of Roermond & Dhr. Diederen & ZM & $25 / 9 / 2001$ \\
\hline Municipality of Maastricht & Mevr. Christeo Cornelissen & GM & $4 / 10 / 2001$ \\
\hline $\begin{array}{l}\text { Limburgse Land en } \\
\text { Tuinbouw Bond (LLTB) }\end{array}$ & ir. G.Th.W. Thijssen & GM/ZM & $25 / 9 / 2001$ \\
\hline Province of Limburg & Dhr. J.Brouns & GM/ZM & $2 / 10 / 2001$ \\
\hline Staatsbosbeheer & Drs. Ph. Bossenbroek & GM/ZM & $8 / 10 / 2001$ \\
\hline $\begin{array}{l}\text { Stichting Watersnood } \\
\text { Herten }\end{array}$ & Mevr. Geelen-Hegtermans & ZM & $8 / 10 / 2001$ \\
\hline Citizen group & Dhr. N. Naus & GM & $12 / 10 / 2001$ \\
\hline
\end{tabular}

${ }^{\mathrm{a}} \mathrm{GM} \rightarrow$ Grensmaas, ZM $\rightarrow$ Zandmaas

\section{Maaswerken expert meeting 2002}

Goal: Validation of the first prototype integrated River Model; Acquiring data.

Date: December 4th 2002

\begin{tabular}{|l|l|}
\hline Expert & Expertise \\
\hline Anne Wijbenga & Hydraulics and morphology \\
\hline Johan Griffioen & Costs and benefits \\
\hline Jasper van de Hoef & Soil and excavation \\
\hline
\end{tabular}

\section{Maaswerken expert consultation 2005}

Goal: Obtain critical feedback on the adopted modelling approach.

\begin{tabular}{|l|l|l|}
\hline Expert & Expertise & Date interview \\
\hline Ron Agtersloot & Hydraulics & $8 / 3 / 2005$ \\
\hline Bart Peters & Nature development & $7 / 4 / 2005$ \\
\hline Hank Vermulst & Groundwater modelling & $12 / 4 / 2005$ \\
\hline
\end{tabular}




\section{Summary}

To obtain a better understanding of the river system as a whole, a balanced representation of river dynamics and stakeholder decision-making is required. To achieve such a representation, participatory Agent-Based modelling within the context of Integrated Assessment modelling is adopted as an innovative core approach. The approach is applied to the case study of the Maaswerken project, which is a typical example of a complex sustainability planning problem characterized by high stakes and salient uncertainties. Representing this case entailed the development of an integrated River Model (iRM) to calculate the impacts of different river management strategies, which was coupled to an Agent-Based Model (ABM) representing stakeholder decision-making. The specific modelling objectives were to assess the course of the Maaswerken planning process in retrospect over the medium term, to reflect upon plausible future developments for the management of the Meuse in Limburg on the long term, and to provide a tool to support stakeholder dialogue on sustainable river management. In light of the latter aim, the coupled iRM-ABM model was called Toddler model: Tool to Open-up Dialogue and Debate for Long-term Effective River management.

Chapter 2 describes the methodological building blocks upon which this study is based, and develops a conceptual framework underlying the modelling work. It gives a brief account of the field of Integrated Assessment modelling (IAM), emphasising the current methodological challenge to improve the representation of stakeholder behaviour in IAMs. It discusses ABM as a promising approach with which this challenge can be addressed. Building upon insights from the IAM and $A B M$ fields, a conceptual framework is developed for representing the complex sustainability planning problem of the Maaswerken project presents. The conceptual framework builds upon the well-known model of Pressure-State-Impact-Response (PSIR) by explicitly framing the response as the outcome of a planning process amongst so-called 'stakeholder agents'. The stakeholder agents represent real-life stakeholders on the basis of a simple agent architecture of goals and beliefs, where the latter are related to their interpretation of the various uncertainties surrounding river management. The river management process is interpreted as a process of social learning. In this process, stakeholder agents are assumed to adapt their goals and beliefs in response to perceived changes in the river system and/or the interaction with other stakeholder agents. Compromising, learning about the environment, and learning from agent interaction (including cooperation and the development of social norms) are introduced as key mechanism driving the social learning process.

The integrated analysis of the River Meuse in Limburg of Chapter 3 maps out the problems and possible solutions of river management. It describes its current state hydrology, its main river functions, and touches upon current problems of flooding, drought, and pollution. Focussing on the issue of flooding, three distinct problem perceptions are discussed: it is a problem of (increasing) discharge, of (decreasing) discharge capacity, or of (increasing) vulnerability for floods. These three problem perceptions are related to three corresponding river management strategies: upstream retention as a way to regulate discharge, river engineering as way to increase the discharge capacity, and river adaptation as a way to reduce vulnerability. For synthesis, the conceptual model of PSIR is applied to gain better insight in the relation between various developments over the longer term. Following this conceptual model, a first reflection is provided on the effectiveness and robustness of the various river management approaches discussed. The river widening approach of Maaswerken, for example, appears to be an effective way for increasing the discharge capacity during peak flows, but may possibly contribute to 
spatial scarcity on the longer term, especially under ongoing spatial pressure and climate change.

Chapter 4 zooms in on the planning process of the Maaswerken project. A historical analysis is presented of its two sub-projects Grensmaas and Zandmaas/Maasroute, which - as it turns out were strongly driven by unexpected events, changing insights, increasing stakeholder involvement, and financial constraints. A stakeholder analysis illustrates the 'playing field' of stakeholder perspectives in terms of goals and beliefs. A process analysis furthermore describes some examples of perspective change, and highlights stakeholder dynamics (in terms of conflict, cooperation and coalition forming) observed. Finally, a short analysis of the strategic long-term study Integral Exploration of the Meuse signals new goals (e.g. spatial quality), new perspectives (e.g. based on flood adaptation rather than flood protection) and additional stakeholder dynamics (e.g. conflict between the national government and regional parties) that may possibly play an role in the future management of the River Meuse. Overall, this chapter shows that the complex and dynamic nature of river management requires a flexible planning approach in which uncertainties and the possibility of changing boundary conditions are explicitly taken into account.

In Chapter 5, the focus shifts from qualitative analysis to quantitative modelling. The chapter describes the iRM: a simple modelling tool for the order of magnitude analysis of river management options and their impacts. In this model, a short river stretch is represented by a single river cross-section. It was applied to and tested for the Maaswerken/Grensmaas location of Borgharen. The model aims to be compatible with stakeholder perspectives, by including the most relevant impacts (flood risk, nature development, agriculture, excavation, hindrance and costs) and river engineering options (river widening, floodplain excavation, dike-building, and clay storage) as considered by the various stakeholders involved. Also, it addresses main uncertainties regarding, for example, climate change, nature development, flood damage, and project costs. Despite the inherent limitations of the cross-section approach, the model is calibrated and validated to form a realistic description of the river management issues of concern. Due to its transparent and interactive nature, the model is well-suited to reflect upon various trade-offs, uncertainties, and long term context developments in an integrated way. The model may be used on the strategic policy level to reflect on various river management approaches, in participatory settings to support communication amongst the stakeholders of river management, and as a scientific tool to advance the understanding of human-environment systems through application in combination with a participatory ABM approach.

Chapter 6 presents an Agent-Based Model representing a planning process among stakeholders of river management. The stakeholders are represented as computer agents whose support for a river management strategy is modelled on the basis of their goals and beliefs. Plausible policy outcomes are then derived as the river management strategy with maximum stakeholder support. For evaluating the different river management strategies, the ABM is coupled to the iRM that describes the impacts of river management, such as flood risk, nature development and costs. The model is applied to the case of the ongoing Dutch river management project 'Grensmaas'. In this application, stakeholder support is analysed for three main river management strategies proposed over the last fifteen years (the so-called 'Green for Gravel' alternative of 1991, and the 'Preferred Alternatives' of 1998 and 2003). Consequently, these strategies are reconstructed to provide a first validation of the model. Finally, an assessment is made of changes in stakeholder support and policy outcomes, when stakeholders would change their goals, or would take climate change into account. We conclude that the main virtue of the 
developed modelling framework lies in its application within participatory processes, to support stakeholders to reflect upon their goals and uncertainty interpretations in a social context.

Chapter 7 extends the scope of the modelling exercise towards modelling the development of water management on the long term. To this end, it presents a broader conceptualisation of the water management process, in which the dynamics of water management policy is explicitly related to the broader dynamics of water management culture and autonomous responses. Focussing on the case study of the Ebro River Basin in Spain, the approach is to develop an interactive computer game. In the game, the water system is modelled using spatially-explicit integrated assessment models, and water management is represented as the dynamic outcome of interactions between water culture, water policy and autonomous actor behaviour. The purpose of the game is to explore future pathways of water management in the Ebro River Basin in Spain, and contribute to a social learning process amongst the players involved. The chapter focuses on the concept of the game, but the conceptual approach has already been translated into a game format, which has been tested and shows promise.

Chapter 8 synthesises the results and presents the main conclusions. It is to a large extent possible to represent the complex dynamics of river management through a participatory IAMABM approach. In particular, the model application in retrospect - reconstructing the Maaswerken project - shows that the main features of historical river management strategies are adequately represented with the model proposed. The model application to assess longterm development of river management is as yet lesser developed, since it does not include formal 'goal update' and 'river model update' rules by which goals and beliefs may plausibly change. Nonetheless, the model provides an adequate tool for 'what-if' analysis to assess, for example, possible future tensions between different goals under pressure of future developments like climate change. An important added value of the approach is to support social learning amongst stakeholders of river management, as reflected in the model's acronym Toddler. The Toddler model can provide a forum to share relevant knowledge about the river system, to clarify and evaluate stakeholder perspectives, to reflect on uncertainty, and to assess the trade-offs between stakeholder interests in a more transparent way. Given its pioneering character and broad scope, the study identifies various directions for future research to further develop the participatory IAM-ABM approach. In short, these include further participatory model applications, on the one hand to better assess the future development of river management, and on the other to test the value of the model as a social learning tool. Notably, the gaming concept developed in Chapter 7 shows promise for modelling long term development of water management (including the dynamics of the water management culture) in a meaningful way.

Overall, the study shows that the complex and dynamic nature of river management requires a more reflexive planning approach. In such a 'learning-by-doing' approach, the continuous reflection on goals and beliefs is equally (or even more) important as the detailed assessment of river management strategies to fulfil given goals under given beliefs. To support such a reflexive planning process, the Toddler model can help as a Tool to Open-up Dialogue and Debate for Long-term Effective River management. 


\section{Samenvatting}

Voor een beter begrip van een riviersysteem als geheel is een evenwichtige beschrijving noodzakelijk van enerzijds de fysieke dynamiek van processen in en om de rivier, en anderzijds de sociale dynamiek van de besluitvormingsprocessen rondom rivierbeheer. Om zo'n beschrijving te geven wordt in dit proefschrift de (innovatieve) aanpak van participatieve AgentBased modellering in het kader van Integrated Assessment modellering gehanteerd. De aanpak wordt toegepast op het project 'De Maaswerken'. Dit project is een typisch voorbeeld van een complex duurzaamheidsprobleem, gekenmerkt door grote belangen en onzekerheden. Voor een beschrijving van dit project werd een geïntegreerd Rivier Model (iRM) ontwikkeld om de effecten te berekenen van verschillende strategieën voor rivierbeheer. Dit werd vervolgens gekoppeld aan een Agent-Based Model (ABM) dat het collectieve besluitvormingsproces van de belanghebbenden van de Maaswerken beschrijft. De concrete doelstellingen van deze modelstudie waren het analyseren van het historische verloop van het planproces van de Maaswerken op de middellange termijn, het verwerven van inzicht in de mogelijke toekomstige ontwikkelingen van het beheer van de Maas in Limburg op de lange termijn, en te voorzien in een instrument om de dialoog tussen belanghebbenden van rivierbeheer te ondersteunen. Het gekoppelde iRM-ABM is daarom Toddler model genoemd: Tool voor het Ondersteunen van Dialoog en Debat voor Lange-termijn Effectief Rivierbeheer.

Hoofdstuk 2 beschrijft de methodologische bouwstenen waarop dit onderzoek is gebaseerd, en ontwikkelt een conceptueel raamwerk als basis voor de verdere modellering. Het omschrijft kort het veld van Integrated Assessment modellering (IAM), en benadrukt de huidige methodologische uitdaging van een betere representatie van het gedrag van belanghebbenden in geïntegreerde modellen. Het bespreekt vervolgens Agent-Based modellering (ABM) als een veelbelovende benadering om deze uitdaging mee aan te gaan. Voortbouwend op inzichten uit IAM en ABM, wordt een conceptueel raamwerk ontwikkeld waarmee het complexe duurzaamheidsprobleem van het Maaswerkenproject wordt gepositioneerd in de context van het riviersysteem als geheel. Het conceptuele kader bouwt voort op het bekende model van Pressure-State-Impact-Response (PSIR). De Response wordt verder uitgewerkt door deze expliciet te omschrijven als de uitkomst van een collectief planproces tussen zogenaamde 'stakeholder agents'. De stakeholder agents representeren de belanghebbenden van Maaswerken (de 'actoren') door middel van een eenvoudig agentenmodel dat de doelen en overtuigingen van de belanghebbenden m.b.t. het riviersysteem (samen hun 'perspectief') omschrijft. Verschil in overtuiging wordt hierbij gezien als een verschillende interpretatie van de onzekerheden rondom rivierbeheer. Het planproces, vervolgens, wordt geïnterpreteerd als een proces van sociaal leren. Hierbij wordt aangenomen dat de stakeholder agents hun perspectieven continu aanpassen naar aanleiding van veranderde inzichten in het riviersysteem en / of hun interacties met andere stakeholder agents. Compromisvorming, coöperatie, conflict, coalitievorming en de ontwikkeling van sociale normen worden als belangrijke mechanismen van het sociaal leerproces geïdentificeerd.

De geïntegreerde analyse van de Maas in Limburg van Hoofdstuk 3 brengt de problemen en mogelijke oplossingsrichtingen van rivierbeheer in kaart. Het beschrijft de hydrologie, de belangrijkste rivierfuncties, en de huidige problematiek van overstromingen, droogte en vervuiling. Ten aanzien van de overstromingsproblematiek, worden drie verschillende probleempercepties besproken: het is een probleem van (toenemende) afvoer, van (afnemende) afvoercapaciteit, of van (toenemende) kwetsbaarheid voor overstromingen. Deze drie probleempercepties worden gerelateerd aan drie mogelijke oplossingsrichtingen: het vergroten 
van bovenstroomse retentie voor een betere regulering van afvoer, het aanpassen van de rivier voor het vergroten van de afvoercapaciteit, en het aanpassen aan de rivier om de kwetsbaarheid te verminderen. Als synthese worden de verschillende probleempercepties bezien vanuit het conceptuele model van PSIR. Aan de hand van dit model, worden vervolgens de effectiviteit en de robuustheid van de verschillende oplossingsrichtingen kwalitatief besproken. De oplossingsrichting van rivierverruiming, bijvoorbeeld, lijkt een effectieve manier voor het accommoderen van piekafvoeren door het vergroten van de afvoercapaciteit. Zij lijkt echter minder robuust, omdat ze bijdraagt aan de ruimtelijke druk, wat vooral onder een toenemende maatschappelijke ruimtebeoefte en klimaatverandering tot toekomstige problemen zou kunnen leiden.

Hoofdstuk 4 zoomt in op het planproces van het Maaswerkenproject. Een historische analyse van de twee subprojecten Grensmaas en Zandmaas/Maasroute beschrijft in grote lijnen hoe het verloop van het project is beïnvloed door onverwachte gebeurtenissen, veranderende inzichten, de toenemende betrokkenheid van belanghebbenden, en financiële beperkingen. Een stakeholderanalyse laat vervolgens in meer detail het 'speelveld' van belanghebbenden zien: hun invloed, doelen, overtuigingen, en voorkeuren voor verschillende typen maatregelen. Een procesanalyse beschrijft vervolgens de dynamiek van het planproces, en geeft voorbeelden van perspectiefverandering als gevolg van veranderende inzichten in het riviersysteem, en interacties tussen actoren zoals conflict, coöperatie en coalitievorming. Een korte analyse van de strategische langetermijnstudie Integrale Verkenningen Maas, ten slotte, signaleert nieuwe doelen (bijvoorbeeld ruimtelijke kwaliteit), nieuwe actorinteracties (bijvoorbeeld conflict tussen de nationale overheid en regionale partijen), en geheel nieuwe perspectieven (bijvoorbeeld rivieradaptatie in plaats van rivierverruiming) die mogelijk een rol gaan spelen in het toekomstige beheer van de Maas. Al met al laat dit hoofdstuk vooral zien dat het rivierbeheer inherent complex en dynamisch is, zodat een flexibele benadering is vereist.

In hoofdstuk 5 verschuift de aandacht van kwalitatieve analyse naar kwantitatieve modellering. Het hoofdstuk beschrijft het iRM: een eenvoudige 'tool' waarmee de orde van grootte van de effecten van verschillende maatregelen voor rivierbeheer geanalyseerd kan worden. In dit model wordt een korte rivierlengte gerepresenteerd door een enkele dwarsdoorsnede. Het werd toegepast en getest op de Maaswerken/Grensmaas locatie van Borgharen. Het model sluit aan bij de perspectieven van de verschillende belanghebbenden, zoals onderzocht in Hoofdstuk 4. Hiertoe zijn de meest relevante doelstellingen (overstromingsrisico, natuurontwikkeling, landbouw, grindwinning, hinder en kosten) en maatregelen (rivierverruiming, aanleg kades, kleiberging) opgenomen in het model. Ook kunnen gebruikers verschillende interpretaties van onzekerheid invoeren, bijvoorbeeld m.b.t. klimaatverandering, natuurontwikkeling, overstromingsschade en kosten. Ondanks enkele inherente beperkingen van het dwarsdoorsnedemodel, geeft het na calibratie en validatie een realistische, kwantitatieve beschrijving van de rivier. Dankzij haar transparante en interactieve karakter, is het model vooral geschikt om de 'trade-offs' tussen doelstellingen, de rol van onzekerheden, en de effecten van contextontwikkelingen in samenhang te beschrijven. Het model kan op verschillende manieren gebruikt worden: op strategisch beleidsniveau om verschillende oplossingsrichtingen te evalueren, in participatieve settings om de communicatie tussen belanghebbenden te ondersteunen, en als wetenschappelijk instrument voor het analyseren van mens-milieu systemen via de combinatie met de participatieve ABM aanpak.

Hoofdstuk 6 presenteert vervolgens het ABM dat het planproces tussen de belanghebbenden van rivierbeheer beschrijft. De belanghebbenden worden gemodelleerd als computeragenten (de 'stakeholder agents'). Hun voorkeur voor een strategie voor rivierbeheer (een set 
maatregelen) wordt berekend op basis van de hun toegekende doelen en overtuigingen. De uitkomst van het planproces wordt vervolgens bepaald als de strategie met een maximaal draagvlak onder de stakeholder agents. Voor de evaluatie van de strategieën, is het ABM gekoppeld aan het iRM omschreven in Hoofdstuk 5. Het gekoppelde iRM-ABM wordt toegepast voor het Maaswerken subproject Grensmaas. In deze toepassing wordt het draagvlak onder de belanghebbenden geanalyseerd, voor drie verschillende strategieën die gedurende de afgelopen 15 jaar zijn voorgesteld (het zogenaamde 'Groen voor Grind' alternatief van 1991, en de 'Voorkeursalternatieven' van 1998 en 2003). Vervolgens worden deze strategieën gereconstrueerd als eerste validatie van het model. Ten slotte is beoordeeld hoe het draagvlak onder belanghebbenden, en daarmee de uitkomst van het planproces, zou kunnen veranderen bij veranderende doelstellingen, of wanneer men expliciet met klimaatveranderingen rekening zou gaan houden. Het iRM-ABM lijkt vooral geschikt als instrument voor het reflecteren op (de implicaties van) aangehangen doelstellingen en overtuigingen in een participatief proces met belanghebbenden.

In Hoofdstuk 7 wordt de benadering verder uitgewerkt voor het modelleren van de ontwikkeling van het waterbeheer op de lange termijn. Om deze langetermijndynamiek te begrijpen is het noodzakelijk de dynamiek van het waterbeheer an sich in samenhang te zien met de verandering van de meer fundamentele uitgangspunten en aannamen m.b.t. het omgaan met water in de maatschappij. Aan de hand van de droogteproblematiek rondom het stroomgebied van de Ebro in Spanje wordt het conceptuele model van Hoofdstuk 2 daartoe uitgebreid. Hierbij wordt de dynamiek van het waterbeleid gepositioneerd binnen de bredere dynamische maatschappelijke context van een zogenaamde 'watercultuur' en 'autonome respons'. Het conceptuele model wordt geïmplementeerd in de vorm van een interactief computerspel. In het spel wordt het watersysteem gemodelleerd met behulp van een ruimtelijk IAM, worden computeragenten gebruikt voor het modelleren van de autonome response, en is de verandering van waterbeleid en watercultuur inzet van het spel zelf. De implementatie van het spel en de benodigde tools zijn nog volop in ontwikkeling. Niettemin is de conceptuele benadering reeds vertaald naar een concrete spelopzet, dat bij een eerste test positief werd geëvalueerd.

Hoofdstuk 8 vat de belangrijkste resultaten en conclusies samen. Het proefschrift laat zien dat het mogelijk is de complexe dynamiek van rivierbeheer te modelleren met een aanpak gebaseerd op participatieve IAM-ABM. Vooral de modeltoepassing in retrospect laat zien dat de belangrijkste kenmerken van de historische strategieën van de Maaswerken adequaat kunnen worden gereconstrueerd. Het kwantitatief modelleren van de ontwikkeling van het rivierbeheer op de lange termijn is nog onderontwikkeld; er zijn nog geen formele regels geformuleerd op basis waarvan de stakeholder agents hun doelstellingen en overtuigingen in de toekomst mogelijk aan zullen passen. Desondanks is het model geschikt voor een 'what-if' analyse, bijvoorbeeld om te beoordelen wat de consequenties zijn van veranderende doelstellingen voor de rivierbeheerstrategie, en wat de gevolgen zijn van klimaatverandering voor de mate waarin doelstellingen kunnen worden gehaald. Een belangrijke meerwaarde van de participatieve IAM$A B M$ aanpak lijkt het ondersteunen van een proces van sociaal leren onder de belanghebbenden van rivierbeheer. Dit wordt uitgedrukt in het model acroniem Toddler. Het Toddler model kan fungeren als een forum voor het delen van kennis over het riviersysteem, het communiceren en kritisch evalueren van de verschillende perspectieven, het reflecteren op onzekerheid, en het afwegen van de verschillende belangen op een transparante manier. Gezien het innovatieve karakter en brede toepassingsgebied van deze studie, worden verschillende aanbevelingen voor vervolgonderzoek gepresenteerd. Vooral verdere participatieve modeltoepassing wordt aanbevolen: enerzijds voor de inhoudelijke analyse van mogelijke toekomstige ontwikkelingen 
van het rivierbeheer (het 'modelleren'), en anderzijds voor het testen van de waarde van het model voor het ondersteunen van sociaal leren (het 'leren'). Het verder uitwerken en implementeren van het spelconcept van Hoofdstuk 7 binnen het kader van participatieve scenario-ontwikkeling wordt hierbij als een interessante onderzoeksrichting gezien.

Al met al laat dit onderzoek zien dat het complexe en dynamische karakter van rivierbeheer een reflexieve planbenadering vereist. In een dergelijke 'learning-by-doing' aanpak is de voortdurende reflectie op doelen en overtuigingen van even groot (of zelfs groter) belang als de gedetailleerde effectanalyse van rivierbeheerstrategieën, gegeven de doelstellingen en overtuigingen van dat moment. Voor het ondersteunen van een dergelijk reflexief planproces, kan het Toddler model uitkomst bieden als een Tool voor het Ondersteunen van Dialoog en Debat voor Lange-termijn Effectief Rivierbeheer. 


\section{List of abbreviations}

\begin{tabular}{|c|c|}
\hline ABLUM & Agent Based Land Use Model \\
\hline ABM & Agent-Based Model / Agent-Based Modelling \\
\hline ACF & Advocacy Coalition Framework \\
\hline AHG / ALG / ASG & Average High / Low / Spring Groundwater table \\
\hline CPM & Conditional Peak Method \\
\hline CPR & Common Pool Resource \\
\hline CS & Conditional Standard \\
\hline DICE & Dynamic Integrated Climate-Economy model \\
\hline EEA & European Environment Agency \\
\hline EIA & Environmental Impact Assessment \\
\hline EOW & Ecosystem Development Index \\
\hline EU & European Union \\
\hline FIRMA & Freshwater Integrated Resource Management with Agents (EU project) \\
\hline GFG1991 & Green For Gravel river management alternative of 1991 \\
\hline GV & Goal Value \\
\hline HarmoniCOP & Harmonizing Collaborative Planning (EU project) \\
\hline IA & Integrated Assessment \\
\hline IAM & Integrated Assessment Model / Integrated Assessment Modelling \\
\hline IEM & Integral Exploration of the Meuse (river management planning study) \\
\hline IMAGE & Integrated Model to Assess the Global Environment \\
\hline IPCC & Intergovernmental Panel on Climate Change \\
\hline iRM & integrated River Model \\
\hline ISA & Integrated Sustainability Assessment \\
\hline KNMI & Royal Netherlands Meteorological Institute \\
\hline Matisse & Methods and Tools for Integrated Sustainability Assessment (EU project) \\
\hline MIASMA & $\begin{array}{l}\text { Modelling Framework for the Health Impact Assessment of Man- } \\
\text { Induced Atmospheric Changes }\end{array}$ \\
\hline MoMaRo & Modernising Meuse Route (river management planning study) \\
\hline NAP & Amsterdam Ordnance Datum (Normaal Amsterdams Peil) \\
\hline NGO & Non-Governmental Organisation \\
\hline OECD & Organisation for Economic Co-operation and Development \\
\hline OS & Optimisation Standard \\
\hline PA1998 & Preferred river management Alternative of 1998 \\
\hline PA2003 & Preferred river management Alternative of 2003 \\
\hline PSIR & Pressure-State-Impact-Response \\
\hline QUEST & Quite Useful Ecosystem Scenario Tool \\
\hline RAINS & Regional Air Pollution INformation and Simulation model \\
\hline SD & Sustainable Development \\
\hline SES & Social-Ecological System \\
\hline SustA-Test & Sustainability A-Test (EU project) \\
\hline TARGETS & $\begin{array}{l}\text { Tool to Assess Regional and Global Environmental and Health Targets for } \\
\text { Sustainability }\end{array}$ \\
\hline TIAS & The Integrated Assessment Society \\
\hline Toddler & $\begin{array}{l}\text { Tool to Open-up Dialogue and Debate for Long-term Effective River } \\
\text { management }\end{array}$ \\
\hline TV & Toutvenant (raw excavated material of gravel, sand, and rest material) \\
\hline UNEP & United Nations Environment Programme \\
\hline
\end{tabular}




\section{About the author}

Pieter Valkering was born on May 18, 1975 in Oldenzaal, The Netherlands. In 1993 he received his VWO diploma from the Thycollege in Oldenzaal. Pieter went on to study physics at the University of Utrecht, The Netherlands. After an intermediate year abroad in 1997 - in which he completed a DEA (Master of Science equivalent) in solid state physics at the University of Grenoble - Pieter graduated at the University of Utrecht in 1999. Following a desire to work on issues of sustainable development, Pieter started his research career at the International Centre for Integrated assessment and Sustainable development (ICIS), Maastricht University, in the year 2000 to work on the European FIRMA project. This project aimed to gain insights in the social aspects of water management through the application of agent-based social simulation models. Pieter worked on model development: integrated river modelling and Agent-Based modelling for the case study of the river management project 'De Maaswerken' in Limburg. Recent work experience at ICIS includes the development of an innovative participatory Agent-Based modelling tool as part of the EU project Matisse, work on Social Learning and Information and Communication Tools as part of the EU project HarmoniCOP, and the development of a qualitative modelling tool for actor analysis and communication support in the context of city planning (COHESIE). Current work includes the development of water management scenarios as part of the Dutch project Perspectives in Integrated Water Resource Management in River Deltas, and supporting the sustainable development of deprived urban neighbourhoods in the Euregio as part of the Interreg project SUN. Besides work, Pieter is very much interested in classical and Spanish guitar, and outdoor sports. 